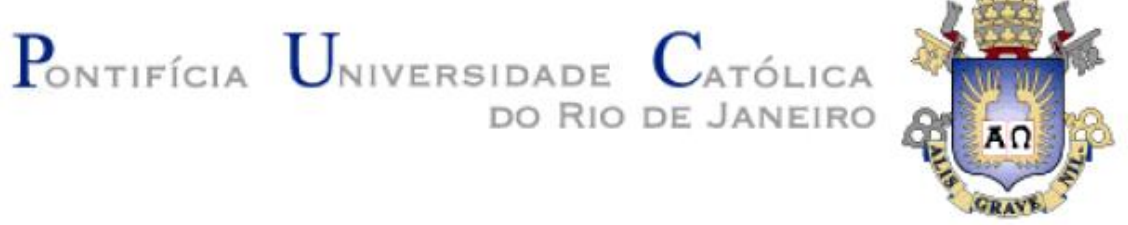

Enrique Roy Dionisio Calderon

\title{
Superfície de Mínimo Consumo de Carbono do Processo de Redução em Altos-Fornos
}

Tese de Doutorado

Tese apresentada como requisito parcial para a obtenção do título de Doutor pelo programa de Pós-graduação em Engenharia de Materiais e de Processos Químicos e Metalúrgicos do Departamento de Engenharia Química e de Materiais da PUC-Rio.

Orientador: Prof. José Carlos D’Abreu

Rio de Janeiro

Fevereiro de 2016 


\section{Pontifícia Universidade Católica $_{\text {a }}$}

\section{Enrique Roy Dionisio Calderon}

\section{Superfície de Mínimo Consumo de Carbono do Processo de Redução em Altos-Fornos}

Tese apresentada como requisito parcial para a obtenção do grau de Doutor pelo Programa de Pós-graduação em Engenharia de Materiais e de Processos Químicos e Metalúrgicos do Departamento de Engenharia Química e de Materiais do Centro Técnico Científico da PUC-Rio. Aprovada pela Comissão Examinadora abaixo assinada.

Prof. José Carlos D'Abreu

Orientador

Departamento de Engenharia Química e de Materiais - PUC-Rio

Prof. Rogerio Navarro Correia de Siqueira

Departamento de Engenharia Química e de Materiais - PUC-Rio

Profa. Marília Garcia Diniz Universidade Estadual do Rio de Janeiro - UERJ

Dra. Karla Ohler Martins

Thyssenkrupp Steel Europa - TKSE

Dr. Maurício Marcos Otaviano

Samarco Mineração S.A

Prof. Marcio da Silveira Carvalho Coordenador Setorial de Pós-Graduação do Centro Técnico Cientifico da PUC-Rio

Rio de Janeiro, 19 de Fevereiro de 2016 
Todos os direitos reservados. É proibida a reprodução total ou parcial do trabalho sem autorização da universidade, do autor e do orientador.

\section{Enrique Roy Dionisio Calderon}

Graduou-se em Engenharia Química (Universidad Nacional del Centro del Perú-UNCP - Perú, 2002), trabalhou na companhia Cemento Andino S.A. até Agosto do 2010, no Departamento de Produção no controle e operação dos Fornos de Cimento.

Ficha Catalográfica

Calderon, Enrique Roy Dionisio.

Superfície de Mínimo Consumo de Carbono do Processo de Redução em Altos-Fornos / Enrique Roy Dionisio Calderón; orientador: José Carlos D'Abreu. - 2016.

166 f. : il. (color.) ; $30 \mathrm{~cm}$

Tese (doutorado)-Pontifícia Universidade Católica do Rio de Janeiro, Departamento de Engenharia Química e de Materiais, 2016.

Inclui bibliografia

1. Engenharia Química e de materiais Teses. 2. Alto-Forno. 3. Coque "Rate". 4. Reduções Direta e Indireta. 5. Balanços de Massa e Energia. 6. Modelo de Mínimo Consumo de Carbono. I. D’Abreu, José Carlos. II. Pontifícia Universidade Católica do Rio de Janeiro. Departamento de Engenharia Química e de Materiais. III. Título.

CDD: 620.11 
À minha família, ao meu Pai Julio, in memoriam, e a minha querida Mãe

Basilia por terem sido os meus grandes inspiradores e motivadores.

Aos meus irmãos, em especial a Oswaldo, Samuel e Alfredo por sinalizarem o caminho da Engenharia. Ao Professor Helio M. Kolher, in memoriam. 


\section{Agradecimentos}

Ao meu orientador, Professor José Carlos D’Abreu, pelo estímulo, pela amizade e pelos ensinamentos valiosos da ciência da Metalurgia, que foram essenciais para o desenvolvimento deste trabalho, e pelos conselhos durante minha estância e formação Humana e Professional.

Ao Professor Helio Kohler pela amizade incondicional e pelo apoio e inspiração no desenvolvimento na modelagem correspondente.

Aos professores do DEQM da PUC-Rio pelos ensinamentos fornecidos durante o período de minha formação.

A todos os amigos do grupo de Siderurgia da PUC-Rio, em especial a Raimundo Nonato Filho pela amizade durante os vários anos de trabalho da tese e convivência do dia a dia.

Aos meus companheiros de turma pelo ambiente fraterno que mantivemos durante os anos de estudo conjuntos e que depois desta jornada ora concluímos.

À minha família por me fornecer os ensinamentos morais e, sobretudo por serem a fonte onde começaram meus primeiros desafios na fundição e aprendizado dos primeiros conceitos de Metalurgia.

À Companhia Cemento Andino, em especial aos colegas do departamento de Produção, por terem sido a fonte que motivou minhas inquietudes pela procura de soluções na área de processos, pela colaboração na administração de meu turno de trabalho, mediante o qual consegui minha formação de mestrado e me encaminhei para o desafio do Doutorado. 
À Coordenação de Aperfeiçoamento de Pessoal de Nível Superior (CAPES) e à PUC-Rio pelos auxílios concedidos, sem os quais este trabalho não poderia ter sido realizado.

Aos professores da FIQ-UNCP pelos ensinamentos teóricos e práticos fornecidos durante a minha graduação.

Agradeço aos meus irmãos Cesar, Ronald, Romulo, Oswaldo, Samuel, Edith, Victoria, Lidya e Alfredo que em todo momento estiveram presente com os conselhos e pelo investimento na minha educação.

Agradeço à Cleide Trapp pelo apoio na revisão e organização da parte escrita deste trabalho e pela compreensão nos momentos de estudo com paciência e carinho.

Ao Engenheiro José Hurtado pelo apoio e suporte nas respectivas viagens ao Peru.

Ao Engenheiro Eduardo Lazo pelos conselhos e recomendações durante a organização desta tese, a quem desejo sucesso no seu doutoramento.

Agradeço a toda a turma GE-122 da FGV pela amizade e por transmitir positividade, motivação e alegria durante os momentos que foram de intenso estudo.

Agradeço a todos os demais amigos e pessoas que sem se encontrarem aqui mencionados, de algum modo, colaboraram na minha formação.

Por fim, agradeço a Deus pelo suporte em todos os momentos e por ser a fonte de energia que dia a dia me acompanha. 


\section{Resumo}

Dionisio Calderon, Enrique Roy; D'Abreu, José Carlos. Superfície de Mínimo Consumo de Carbono do Processo de Redução em AltosFornos. Rio de Janeiro, 2016. 166p. Tese de Doutorado - Departamento de Engenharia Química e de Materiais, Pontifícia Universidade Católica do Rio de Janeiro.

O cenário siderúrgico brasileiro passa, atualmente, por uma forte depressão, com uma capacidade instalada de 48,9 milhões de toneladas de aço bruto (que alcançará 51,9 milhões no primeiro trimestre de 2016) e uma queda na produção de 1,9 \% em relação a 2014 (33,2 milhões de toneladas em 2015). Em 2015 tevese um nível de utilização de $67,89 \%$ das indústrias frente aos $85 \%$ considerados como bom desempenho pelo Banco Nacional de Desenvolvimento Econômico e Social (BNDES), porcentagem que diminuiu em consequência da queda do consumo interno $21 \%$ (24 milhões de toneladas). A indústria siderúrgica brasileira utiliza o Alto-Forno como uma tecnologia para obtenção de ferro gusa. O AltoForno, nos dias de hoje, continua sendo o reator que apresenta a melhor opção entre as diversas tecnologias de obtenção de ferro-gusa devido a sua alta taxa de produção, alto desempenho térmico, estabilidade e segurança operacional e longevidade dos equipamentos. Contudo, diversas melhoras no processo são pesquisadas, sendo uma delas o controle operacional do reator que visa manter sua estabilidade prevendo possíveis falhas e reduzindo os consumos energéticos para mantê-los com produtividade competitiva frente ao mercado internacional. $\mathrm{O}$ presente trabalho apresenta a concepção de um modelo com objetivo de gerar a superfície de mínimo consumo de redutor (carbono) para a produção de ferro primário em Altos-Fornos. No seu desenvolvimento foram consideradas as condições de equilíbrio das reações de redução, os balanços de massa e de energia do processo e o equacionamento de parâmetros operacionais. Sua aplicação à redução em Altos-Fornos é exemplificada para situações reais, baseada no banco de dados operacionais de uma usina siderúrgica. Foi possível, a partir de planos de corte nestas superfícies, gerar diagramas binários do tipo CR-RD (Consumo de Redutor-Redução Direta), passíveis de serem obtidos “on-line” com o processo. 
Dentre os resultados obtidos, foi possível identificar, confirmar e prever, através da análise dos casos estudados que o fenômeno que se costuma chamar de "gelada" do forno, são essencialmente inviabilidades termodinâmicas importantes, geradas por procedimentos inadequados na sua operação. Como na prática tais fenômenos só são detectados após já terem afetado em definitivo a marcha normal do forno, o resultado é uma significativa perda de produtividade do equipamento devido à necessidade de algumas horas para a retomada da normalidade da operação. Assim, o presente modelo, permitindo através de seus "outputs" gráficos acompanhar a dinâmica de tais fenômenos, ou seja, a detecção do movimento da operação do forno na direção daquelas inviabilidades termodinâmicas, conferirá ao processo, quando implementado “on line” , não só a garantia de correções operacionais antecipadamente à ocorrência do problema, mas, principalmente, maior segurança operacional ao processo. $\mathrm{O}$ sucesso da aplicação do presente modelo tanto em condições operacionais normais como anormais do Alto-Forno, concluíram por sua plena adequação aos objetivos propostos.

\section{Palavras-chave}

Alto-Forno; Coque "Rate"; Reduções Direta e Indireta; Balanços de massa e energia; Modelo de Mínimo Consumo de Carbono. 


\section{Abstract}

Enrique Roy, Dionisio Calderon; D’Abreu, José Carlos (Advisor). Diagram for Minimum Carbon Consumption. Application in the Blast Furnace Ironmaking Process. . Rio de Janeiro, 2016. 166p, Doctorate Thesis Departamento de Engenharia Química e de Materiais, Pontifícia Universidade Católica do Rio de Janeiro.

The Brazilian steel sector currently faces a severe depression, with an installed capacity of 48.9 million tons of crude steel (which will reach 51.9 million in the first quarter of 2016) and there was a decrease in production of $1.9 \%$ in relation to production in 2014 (33.2 million tons in 2015). In 2015, it was registered a level of use of $67.89 \%$ from industries compared to $85 \%$ considered as an indicator of good performance by the National Bank of Economic and Social Development (BNDES), percentage which decreased as consequence of the fall in internal consumption equivalent to $21 \%$ (24 million). The brazilian steel industry uses blast furnace as a technology for obtaining pig iron. Currently, the blast furnace continues being the reactor which is considered the best option among the several technologies for obtaining pig iron due to the high production rate, high thermal performance, stability and operational safety as well as longevity of equipments. However, various improvements are being researched, being one of them the operational control of the reactor which aims to maintain its stability in order to prevent possible failures and reduce the energy consumptions to keep them competitive productivity on the international market. This work presents a model is unwrapped with the objective to generate the surface of minimum consumption of reductant (carbon) for the blast furnace ironmaking process. In developing the model the equilibrium conditions of the reduction, the mass and energy balances and the equations of major operational parameters, were considered. Its application to the blast furnaces is exemplified for real operational conditions, which were databases duly extracted from an integrated steelworks. It was also possible, from cutting plans on these surfaces, to obtain binary diagrams of RC-DR type (Reductant Consumption-Direct Reduction), able to be generated on-line with the process. Among the results, one could identify, confirm and predict through analysis of those real case studies, important thermodynamic 
unfeasibility of the furnace, which allowed to provide greater operational safety to the process. The excellent results obtained applying this model to regular and abnormal blast furnace operational conditions, led to conclude that their objectives were fully succeeded.

\section{Keywords}

Blast furnace; Coke rate; Direct and Indirect Reductions; Mass and Energy balances; Model for Minimum Carbon Consumption. 


\section{Sumário}

1. Considerações 22

2. Objetivos 24

2.1. Objetivo Geral 24

2.2. Objetivos Específicos $\quad 24$

3. Introdução 25

3.1. Processo de Obtenção de Ferro e Aço 25

3.1.1. Evolução do Processo de Redução 25

3.1.2. História do Alto-Forno no Brasil 30

3.1.3. Rotas Tecnológicas para Produção de Ferro Primário 33

3.1.3.1. Rotas Tecnológicas para Produção de Ferro-Gusa 33

3.1.3.2. Rotas Tecnológicas para Produção de Ferro Esponja 39

3.1.4. Matérias-Primas Usadas para Obtenção de Ferro-Gusa no Alto- Forno 42

3.1.4.1. Carga Metálica 42

3.1.4.1.1. Sínter 43

3.1.4.1.2. Pelotas 43

3.1.4.1.3. Minério Granulado 44

3.1.4.2. Combustíveis e Redutores Sólidos 44

3.1.4.2.1. Coque 45

3.1.4.2.2. Carvão Vegetal 46

3.1.4.3. Fundentes 47

3.1.4.4. Injeções Auxiliares 48

3.2. Alto-Forno 49

3.2.1. Descrição do Equipamento 50

3.2.1.1. Goela $\quad 50$

3.2.1.2. Cuba 51

3.2.1.3. Ventre 51

3.2.1.4. Rampa 52 
3.2.1.5. Cadinho 52

3.2.2. Modelo Operacional do Alto-Forno 52

3.2.2.1. Estudo de Michard 53

3.2.2.1.1. Regiões de Trocas Térmicas 53

3.2.2.1.2. Regiões de Trocas de Oxigênio 54

3.2.2.2. Reta Operacional de Rist 57

3.2.2.3. Congelamento e Dissecação do Alto-Forno 59

3.2.2.4. Zonas Internas do Alto-Forno 60

3.2.2.4.1. Zona Granular 60

3.2.2.4.2. Zona Coesiva ou de Amolecimento 60

3.2.2.4.3. Zona de Gotejamento 61

3.2.2.4.4. Zona de Combustão 61

3.2.2.4.5. Zona de Cadinho 61

3.3. Termoquímica do Alto-Forno 62

3.3.1. Reações Químicas do Processo de Redução dos Óxidos de Ferro 62

3.3.2. Diagramas de Predominância 64

3.3.3. Balanço de Massa 66

3.3.4. Balanço de Energia 68

3.4. Operação do Alto-Forno 71

3.4.1. Considerações Gerais 71

3.4.2. Variáveis de Operação do Alto-Forno 72

3.4.2. Geladas do Alto-Forno 72

3.4.4. Cenário atual e visão da siderurgia $\quad 74$

4. Desenvolvimento 76

4.1. Considerações 76

4.2. Equacionamento do Balanço de Massa 77

4.2.1. Balanço Geral de Massa 77

4.2.2. Balanço de Carbono 78

4.2.3. Balanço de Oxigênio $\quad 79$

4.2.4. Balanço de Hidrogênio 79

4.2.5. Análise da Fração de Carbono usado na Redução Direta 80 
4.3.1. Estudo das Reduções Diretas dos Óxidos não ferrosos na Zona de Elaboração $\quad 85$

4.3.1.1. Análise do Oxigênio Contido nos Óxidos não Ferrosos 85

4.3.1.1.1. Redução do $\mathrm{SiO}_{2}$

4.3.1.1.2. Redução do $\mathrm{P}_{2} \mathrm{O}_{5}$

4.3.1.1.3. Redução do $\mathrm{MnO}$

4.3.1.1.4. Dessulfuração do Enxofre 88

4.3.2. Estudo da Redução Direta dos Óxidos Ferrosos na Zona de Elaboração 89

4.3.3. Estudo da Redução por $\mathrm{H}_{2}$ dos Óxidos Ferrosos na Zona de Elaboração 92

4.3.4. Estudo da Redução por CO na Zona de Preparação 94

4.3.5. Análise da Geração de $\mathrm{CO} 96$

4.3.5.1. Reação de $\mathrm{SiO}_{2}$ com Carbono para Gerar $\mathrm{SiO} 96$

4.3.5.2. Reação da Água com Carbono 96

4.3.5.3. Queima de Carbono com Oxigênio 97

4.3.6. Análise da Necessidade de Carbono para Queima 97

4.4. Equacionamento do Balanço de Energia 97

4.4.1. Equacionamento do Balanço de Energia da Zona de Elaboração 98

4.4.1.1. Calor por Perdas Térmicas na Zona de Elaboração 99

4.4.1.2. Calor Contido no Gusa que Sai da Zona de Elaboração 100

4.4.1.2.1. Entalpia da Liga 100

4.4.1.2.2. Cálculo do Calor de Dissolução dos Elementos Si, S, Mn, P e C no Ferro 104

4.4.1.3. Calor Contido na Escória que Sai da Zona de Elaboração 105 4.4.1.3.1. Entalpia da Escória 105

4.4.1.3.2. Entalpia da formação da Escória 111

4.4.1.4. Calor Produzido pelas Reações Químicas na Zona de Elaboração

4.4.1.4.1. Fração-Porcentagem de Redução das Reações que Ocorrem na Zona de Elaboração 
4.4.1.4.2. Entalpia das Reações de Redução dos Óxidos não

Ferrosos na Zona de Elaboração 114

4.4.1.4.3. Entalpia das Reações de Redução dos Óxidos Ferrosos na Zona de Elaboração 116

4.4.2. Balanço Térmico da Zona de Combustão 118

4.4.2.1. Calor Contido no ar de Sopro que Ingressa na Zona de Combustão

4.4.2.1.1. Fração Molar dos Compostos do ar que Ingressa na Zona de Combustão

4.4.2.1.2. Cálculo do Poder Calorífico dos Compostos que Constituem o ar de Sopro que Ingressa na Zona de Combustão

4.4.2.2. Calor Gerado pelas Reações Químicas na Zona de Combustão

4.4.2.2.1. Fração de Contribuição das Reações na Zona de Combustão

4.4.2.2.2. Calor das Reações Químicas que Ocorrem na Zona de Combustão 124

4.4.3. Fechamento do Balanço Térmico da Zona de Elaboração. 126

4.5. Equacionamento do Modelo de Geração da SMCC

4.5.1. Estudo do Valor Mínimo do Rendimento do Gás de topo (Minimização do Valor da Relação R de Gases de topo)

4.5.2. Determinação do Consumo Mínimo de Carbono que Satisfaz o Equilíbrio das Reações

4.5.3. Determinação do Consumo Mínimo de Carbono que Satisfaz o Balanço Térmico 134

4.6. Diagrama do Consumo Mínimo de Coke por Fração de Redução Direta 136

4.7. Determinação gráfica do Ponto Operacional do Alto-Forno 136

4.7.1. Coque Rate da Operação: CRoP 137

4.7.2. Fração de Redução Direta da Operação: RD OP 138

5. Resultados e Discussões 
5.1. Traçado da SMCC Usando as Equações do Equilíbrio, Balanço Térmico e suas Inter-Relações

5.1.1. Traçado da Superfície que Satisfaz o Equilíbrio das Reações 144

5.1.2. Traçado da Superfície que Satisfaz o BalançoTérmico

5.1.3. Traçado da Superfície de Mínimo Consumo de CarbonoSMCC

5.1.4. Traçado das Curvas tipo CR-RD

5.2. Validação do modelo: Diagramas tipo CR-RD para Condições

Reais dos Processos em Altos-Fornos com marchas industrias tipicas

5.2.1. CASO A: Traçado de Diagramas tipo CR-RD para

Condições Operacionais Reais de um Alto-Forno exibindo marcha industrial normal

5.2.2. CASO B: Traçado de Diagramas tipo CR-RD para Condições Operacionais Reais de um Alto-Forno exibindo marcha industrial anormal ("gelada")

6. Conclusões

7. Referências Bibliográficas

Anexo A - Função Cp e valores para as constantes - Kubaschevski

Apêndice I - Equação para o traçado do diagrama de predominância 164 Apêndice II - Fechamento do Balanço de Energia 


\section{Lista de figuras}

Figura 1 - Fornos de lupa ${ }^{(6)} \quad 26$

Figura 2 - Forja Catalã ${ }^{(9)} \quad 27$

Figura 3 - Forno Stuckofen ${ }^{(9)} \quad 27$

Figura 4 - Alto-Forno americano movido a rodas de água(11) 28

Figura 5 - Fornos de São João de Ipanema (Associação de Engenheiros Brasil-Alemanha) ${ }^{(12)} \quad 31$

Figura 6 - Tecnologias para Produção de Ferro Primário 34

Figura 7 - Processo de Redução no Alto-Forno 34

Figura 8 - Processo Corex ${ }^{(5,14)} 35$

Figura 9 - Processo HISmelt ${ }^{(5)} \quad 35$

Figura 10 - Processo Finex ${ }^{(5,46)} 36$

Figura 11 - Processo ITmk3 ${ }^{(5)} 37$

Figura 12 - Processo DIOS ${ }^{(7)} \quad 38$

Figura 13 - Processo TECNO RED ${ }^{(5,6)} \quad 39$

Figura 14 - Processo MIDREX ${ }^{(5)} \quad 40$

Figura 15 - Processo Rotary kiln ${ }^{(5)} 41$

Figura 16 - Injeção de PCI no Alto-Forno ${ }^{(6)} 49$

Figura 17 - Alto-Forno e Equipamentos Auxiliares ${ }^{(5)} 50$

Figura 18 - Divisão do Alto-Forno pela Geometria ${ }^{(6)} 51$

Figura 19 - Esquema de Michard ${ }^{(18)} 56$

Figura 20 - Diagrama de Reichardt e Perfil de Temperaturas do Alto- Forno ${ }^{(19)} \quad 57$

Figura 21 - Diagrama Operacional de Rist 58

Figura 22 - Zonas Internas do Alto-Forno ${ }^{(7)} 62$

Figura 23 - Diagrama de Predominância-Operacional para a redução $\begin{array}{ll}\text { com CO } & 65\end{array}$

Figura 24 - Diagrama de Predominância-Operacional para a redução com $\mathrm{H}_{2} \quad 65$

Figura 25 - Diagrama do Alto Forno para Balanço de Massa 67

Figura 26 - Variação da Entalpia com Fenômeno de Transformação 
Figura 27 - Variação da Entalpia com Fenômeno de Transformação Alotrópica e Mudança de Fase 70

Figura 28 - Divisão do Alto Forno: Z. Preparação e Z. Elaboração 76

Figura 29 - Esquema para o Balanço Geral de Massa 77

Figura 30 - Diagrama Utilizado para o Estudo da Zona de Elaboração 84

Figura 31 - Diagrama Utilizado para o Estudo da Zona de Combustão 85

Figura 32 - Diagrama para o Estudo do Balanço Térmico da Zona de

Elaboração

Figura 33 - Diagrama da Zona de Combustão 119

Figura 34 - Balanço de Carbono 130

Figura 35 - Gráfico da Superfície de Mínimo Consumo de Carbono (at-C/at-Fe)

Figura 36 - gráfico CR vs RD 136

Figura 37 - Ponto Operacional do Alto-Forno (em vermelho) 137

Figura 38 - Reta Operacional de Rist 138

Figura 39 - Ponto Operacional (o) Junto à Curva que Satisfaz o

Equilíbrio e Balanço Térmico (para $R=1,012$ )

Figura 40 - Visão gráfica da metodologia do trabalho para Obtenção das Equações que Serviram para Traçar a SMCC

Figura 41 - Diagrama que Mostra a Superfície que Satisfaz o

Equilíbrio

Figura 42 - Diagrama que Mostra a Superfície que Satisfaz o

Balanço Térmico

Figura 43 - Diagrama que Mostra a Superfície que Satisfaz o

Equilíbrio (em azul) e o Balanço Térmico (em laranja)

Figura 44 - Diagrama que Mostra a Curva de Demanda de Carbono Cumprindo as Restrições do Equilíbrio e Balance Térmico (para um valor de $\mathrm{R}=1,012$ ).

Figura 45 - Diagrama que Mostra a Variação na Curva de Demanda de Carbono para Diferentes Valores da Relação de Gases do Topo do Alto-Forno

Figura 46 - Diagrama que Mostra o Gráfico do Ponto da Operação

Normal 1 
Figura 47 - Diagrama que Mostra o Gráfico do Ponto da Operação Normal 2

Figura 48 - Diagrama que Mostra o Gráfico do Ponto da Operação Anormal 3

Figura 49 - Diagrama que Mostra o Gráfico do Ponto da Operação Anormal 4 


\section{Lista de tabelas}

Tabela 1 - Resumo da Análise da Redução Direta dos Óxidos de Ferro e não Ferrosos $\quad 91$

Tabela 2 - Resumo das Reduções Diretas e pelo $\mathrm{H}_{2}$ na ZE 95

Tabela 3 - Resumo das Reduções Indiretas na ZP 96

Tabela 4 - Dados Operacionais Normais (Operação 1) 148

Tabela 5 - Dados Operacionais Normais (Operação 2) 149

Tabela 6 - Dados Calculados pelo Modelo de SMCC para

Operações Normais de um Alto-Forno. 150

Tabela 7 - Dados Operacionais Anormais (Operação 3) 151

Tabela 8 - Dados Operacionais Anormais (Operação 4) 151

Tabela 9 - Dados Calculados pelo Modelo de SMCC para 


\section{Lista de símbolos}

X: $\quad$ Consumo de carbono por redução direta

V: $\quad$ Taxa de injeção de vapor da água por átomo de $\mathrm{Fe}$

Z: Total de hidrogênio por átomo de Fe.

a: Átomos de Carbono presentes no gás $\mathrm{CO}$ do gás de topo

b: Átomos de Carbono presentes no gás $\mathrm{CO}_{2}$ do gás de topo

w: Nitrogênio presente no ar de sopro

G: Total de oxigênio nos óxidos não ferrosos

RD: Fração de Redução Direta

$\mathrm{G}_{\mathrm{Si}}$ : Total de oxigênio reduzido do SiO2 carregado

\%Si: Porcentagem de silício no gusa

Gp: Total de oxigênio reduzido do P2O5 carregado

\%P: Porcentagem de fósforo no gusa

$\mathrm{G}_{\mathrm{Mn}}$ : Total de oxigênio reduzido do $\mathrm{MnO}$ carregado

$\% \mathrm{Mn}$ : Porcentagem de manganês no gusa

Gs: Total de oxigênio pela transferência do enxôfre para a escória

$\mathrm{V}_{\mathrm{E}}$ : Volume de escória

\% $\mathrm{S}_{\mathrm{E}}$ : Porcentagem de enxôfre na escória

$\% F e$ : Porcentagem de ferro no gusa

FC: Fator de conversão entre a redução direta global e a redução direta na zona de elaboração

$\mathrm{K}_{\mathrm{H}}$ : $\quad$ Constante de equilíbrio para a reação de redução do $\mathrm{FeO}$ pelo $\mathrm{H}_{2}$

$\mathrm{K}_{\mathrm{C}}$ : $\quad$ Constante de equilíbrio para a reação de redução de $\mathrm{FeO}$ pelo $\mathrm{CO}$

$\omega$ : $\quad$ Fator omega (Rist)

$\mathrm{C}_{\text {gusa }}$ : Átomos de Carbono presentes no gusa

CEQ: Carbono necessário para satisfazer o equilíbrio

PMGUSA: Massa molecular do gusa

$\mathrm{C}_{\mathrm{GU}}$ : Calor contido no gusa

$\mathrm{C}_{\text {IM: }}$ Calor que ingressa com os materiais na Zona de Elaboração

$\mathrm{C}_{\text {SG: }}$ Calor que sai com os gases da Zona de Elaboração

$\mathrm{C}_{\mathrm{NZC}}$ : Calor necessário proveniente da Zona de Combustão

$\mathrm{C}_{\mathrm{PT}}$ : Calor perdido nas paredes da zona de elaboração 
$\mathrm{C}_{\mathrm{RQ}}$ : Calor gerado pelas reações químicas na Zona de Elaboração PMESCORIA: Massa molecular da escória

$\mathrm{C}_{\mathrm{ESC}}$ : Calor contido na escória

$\Delta \mathrm{H}_{\mathrm{RD}}$ :Entalpia para a Redução Direta

$\Delta \mathrm{H}_{\mathrm{RI}}$ : Entalpia para a Redução Indireta

$\mathrm{C}_{\mathrm{RQ}}$ : Calor das reações químicas que ocorrem na zona de elaboração

$\mathrm{C}_{\mathrm{AR}}$ : Calor contido no ar de sopro que ingressa na Zona de Combustão

$\mathrm{C}_{\mathrm{RQZC}}$ : Calor produzido pelas reações químicas na Zona de Combustão

$C_{\text {IMZE: }}$ Calor contido nos materiais que ingressam da Zona de Elaboração

$\mathrm{C}_{\mathrm{GzC}}$ : Calor gerado na zona de combustão

$\Delta H_{(C-A R)_{Z C}}$ : Calor produzido pela reação do carbono com o ar

$\Delta H_{\left(H_{2} O\right)_{Z C}}$ : Calor produzido pela reação de redução da água com o carbono

$\Delta H_{\left(\mathrm{SiO}_{2}\right)_{\mathrm{ZC}}}$ : Calor produzido pela reação do $\mathrm{SiO}_{2}$ com o carbono

$X_{(A R)_{Z C}}$ : Fração molar do ar que reage com um átomo de carbono

$X_{\left(\mathrm{H}_{2} \mathrm{O}\right)_{Z C}}$ : Fração molar da água que reage com um átomo de carbono

$X_{\left(\mathrm{SiO}_{2}\right)_{Z C}}$ : Fração molar da $\mathrm{SiO}_{2}$ que reage com um átomo de carbono

CBT: Carbono necessário para satisfazer o balanço térmico

CCM: Carbono mínimo necessário para o processo

R: Relação entre os gases $\mathrm{CO}, \mathrm{CO} 2, \mathrm{H}_{2}, \mathrm{H}_{2} \mathrm{O}$

$\mathrm{CC}_{\text {eff: }}$ Carbono efetivo necessário para o processo

Cfix: Conteúdo de carbono fixo no coque

LAPO:Lama do Venturi e pó do coletor perdidos pelo processo

$\mathrm{CR}_{\mathrm{op}}$ : Coque rate da operação 


\section{1. \\ Considerações}

No mundo a indústria produtora de aço vem crescendo numa escala que exige destas a otimização dos seus processos para se manterem competitivos no mercado, além da diminuição da qualidade das matérias-primas e as exigências para a redução dos impactos ambientais de seus processos. A indústria de transformação do aço tem o Alto-Forno como uma tecnologia para obtenção de ferro gusa (ferro primário) que hoje em dia continua sendo a melhor opção devido a sua alta taxa de produção, alto desempenho térmico, estabilidade e segurança operacional e longevidade dos equipamentos ${ }^{(1)}$.

No ano de 2015, 1662 milhões t/ano de aço foram produzidas no mundo (65,5 milhões correspondem a produção da América latina, e 33,2 deles foram produzidos no Brasil) ${ }^{(2)}$. Da produção de aço no mundo $65 \%$ passam pelo AltoForno. Sendo que no Brasil a produção de aço que passa pelo o Alto-Forno é de 85\%. (para uma capacidade instalada: 48,9 milhões t/ano)

A indústria do aço no Brasil vem enfrentando grandes dificuldades como mostram os dados de 2015, dificuldades decorrentes da crise econômica global e local. O excedente da capacidade de produção mundial, superior a 717 milhões de toneladas trouxe reflexos negativos ao desempenho econômico do setor. Foram produzidos no Brasil em 2015, 33,2 milhões o que representam uma queda de $1,9 \%$ em relação ao ano anterior (grau de utilização da capacidade de produção das usinas muito baixo, igual a $67,89 \%$, frente a mais de $85 \%$ recomendado pelo BNDES) ${ }^{(2)}$

As circunstâncias operantes nos dias de hoje em relação ao excesso de capacidade, custos mais altos, matérias-primas de qualidades inferiores, pressão sobre os preços do produto acabado e atual crise econômica, requerem revisão nas operações de produção de gusa do alto forno.

Entretanto as operações deveriam ser, otimizadas para atender as demandas em termos de volume assim como em relação à qualidade. Nas circunstâncias atuais cada tonelada produzida além da demanda e das especificações torna-se uma penalidade financeira. 
O aumento do grau de utilização poderá levar os produtores a reduzirem preços e margem de custos, criando um ambiente mais competitivo. A disciplina, em relação a novos desenvolvimentos, ditará a duração deste período de competitividade aumentada ${ }^{(3)}$.

Neste possível cenário de maior competitividade, é essencial, para qualquer empresa, manter-se como um produtor de baixo custo, de modo a poder continuar competindo eficazmente com seus concorrentes ${ }^{(3,29)}$. Isto será possível com o desenvolvimento de técnicas que permitam melhorar o controle e operação dos Altos-Fornos.

O presente trabalho tem por motivação a busca de melhores técnicas de monitoramento e operação do processo de redução dos óxidos de ferro nos AltosFornos. Para tanto gerou-se uma superfície resposta de mínimo consumo de carbono que baseada em balanços mássicos e térmicos, no equilíbrio das reações e no equacionamento dos principais parâmetros "chave" da operação, permitiu prever um bom desempenho do reator em relação a possibilidade dele sofrer o fenômeno de resfriamento, conhecido por "gelada" do forno. 
2.

\section{Objetivos}

\section{1.}

Objetivo Geral

Desenvolver um modelo matemático para geração da superfície de mínimo consumo de carbono no Alto-Forno, visando evitar o fenômeno de resfriamento.

\section{2.}

\section{Objetivos Específicos}

- Definir a equação global de consumo de Carbono $C C=f(R, R D)$.

- Estabelecer o procedimento sequencial para definição do ponto operacional no diagrama CC-R-RD.

- Validação do modelo utilizando um banco de dados real, obtido dos relatórios de produção cedidos por uma usina siderúrgica integrada nacional. 


\section{3. Introdução}

\section{1.} Processo de Obtenção de Ferro e Aço

A extração de metais surgiu há mais de 6 mil anos no Oriente, sendo o bronze o material dominante no início. $\mathrm{O}$ ferro foi usado em ferramentas e armas pelos Chalibas, uma tribo hitita da região que hoje é a Armênia ${ }^{(4)}$. A idade do ferro é fixada no ano 1000 a.C. Originariamente surgiu no Oriente e disseminouse pela Europa. É provável que a metalurgia do ferro surgisse independentemente na China, Índia e na África, ao passo que na Oceania e nas Américas só chegou com o invasor europeu ${ }^{(4)}$.

A essência do processo siderúrgico de redução do minério de ferro em aço continua sendo a mesma desde o princípio. Usa-se uma fonte de carbono (carvão vegetal ou coque) reagindo com sopro de ar para extrair o ferro do minério e para fornecer energia necessária para o processo, logo o ferro obtido e trabalhado térmica e mecanicamente para a obtenção do produto final ${ }^{(4,5,6)}$.

\subsection{1. \\ Evolução do Processo de Redução}

Os primeiros processos de redução correspondem aos observados quando as pedras utilizadas para contornar as fogueiras mudavam de propriedades com o tempo. O que estava acontecendo é que os óxidos de ferro das pedras do contorno da fogueira se reduziam com o carbono da madeira num ambiente aquecido pela queima de madeira. Aquele ferro tinha baixo teor de carbono, pois a temperatura do processamento era baixa, o que dificultava a incorporação do carbono no ferro, este baixo conteúdo de carbono faz que seja considerado como as primeiras amostras de aço obtidas ${ }^{(4,6,41)}$.

Por volta do ano 100 a.C. a produção de aço utilizava minério e carvão vegetal como carga redutora e para queima do carvão era utilizado ar, que era 
soprado por uma ventaneira. Como produtos resultantes se tinham uma massa de aço e escória que eram separados a marteladas depois de sua solidificação ${ }^{(1,6,7)}$.

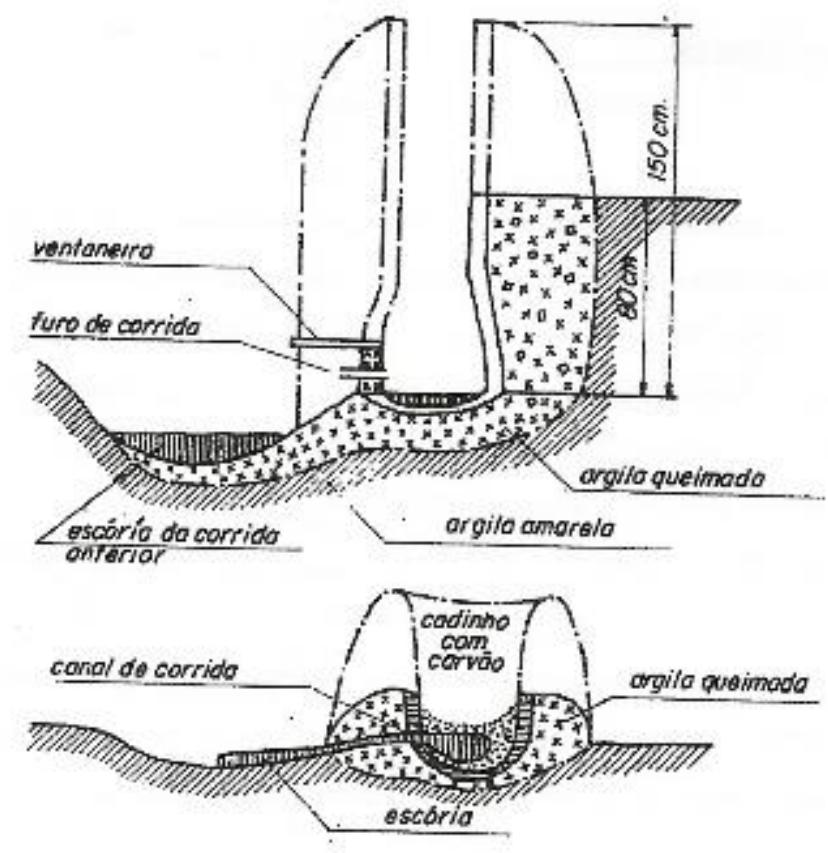

Figura 1 - Fornos de lupa ${ }^{(6)}$.

Os fornos de lupa trazem uma inovação devido ao controle do fluxo de ar foi visto a partir do ano 800 d.C., quando foram construídos fornos com pedras e entradas de ar acionadas por foles de pisotear ou manuais. O produto era conformado a marteladas depois da solidificação da massa (aço e escória).

No mesmo século, em Catalunha foi desenvolvida a forja Catalã (fig. 2) que predominou a produção de aço nos séculos XI e XV na Europa. A primeira forja Catalã feitas de pedras, de seção circular, tinha aproximadamente $1 \mathrm{~m}$ de altura por $0,76 \mathrm{~m}$ de diâmetro conhecida como cuba, com um bocal inferior conectado a um fole para o suprimento de ar. A soleira era coberta com uma camada de carvão vegetal e por cima era carregado o minério de ferro. Entre duas a quatro horas levava a formação da massa pastosa, a produção da forja Catalã era cerca de 160 $\mathrm{kg}$ de ferro, as técnicas anteriores produziam no mesmo intervalo de tempo, no máximo $23 \mathrm{~kg}$. As temperaturas do forno eram baixas o carbono incorporado ao ferro era baixo pelo qual o metal obtido era o aço ${ }^{(4,6,8)}$. 

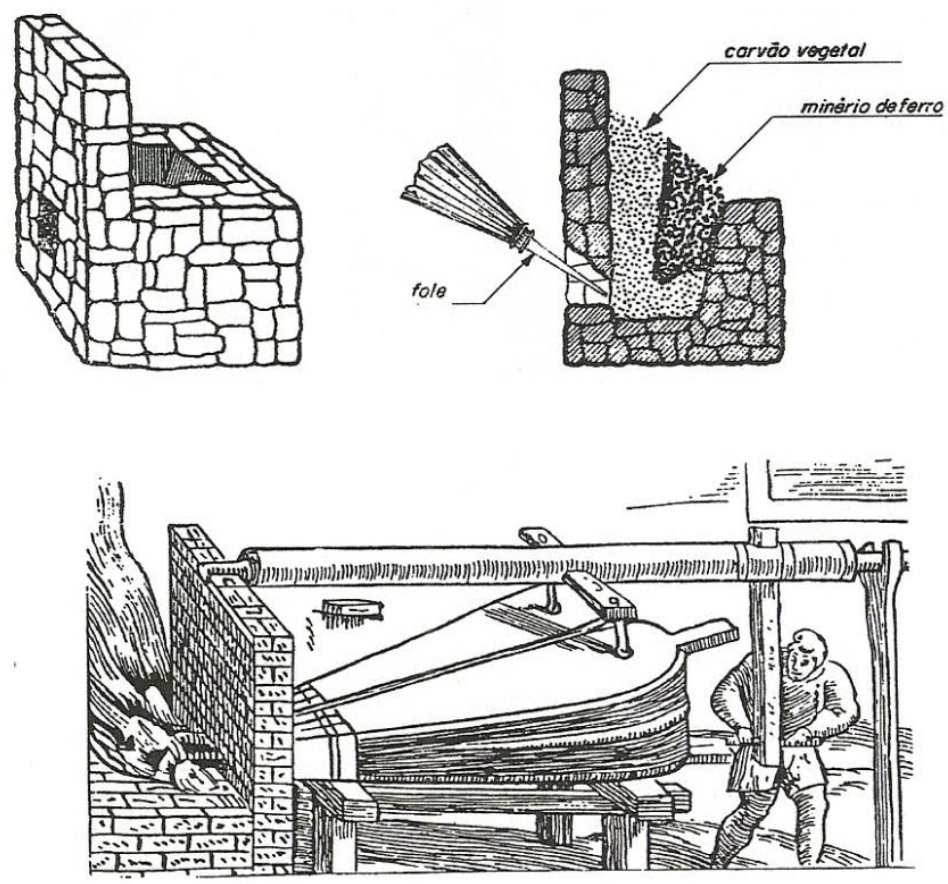

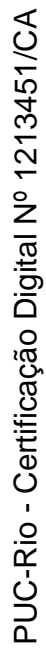

Figura 2 - Forja Catalã ${ }^{(9)}$

Melhoramentos em alturas de chaminé, colunas de carga, aumentos de pressão de sopro deram origem aos precursores dos Altos-Fornos modernos. O forno Stuckofen (fig. 3) que tinha de 3 a 4,8 metros de altura e produzia de 100 a 150 toneladas por ano começou a funcionar a partir do ano 1300, produziam uma liga metálica com maior teor de carbono que era o ferro gusa.

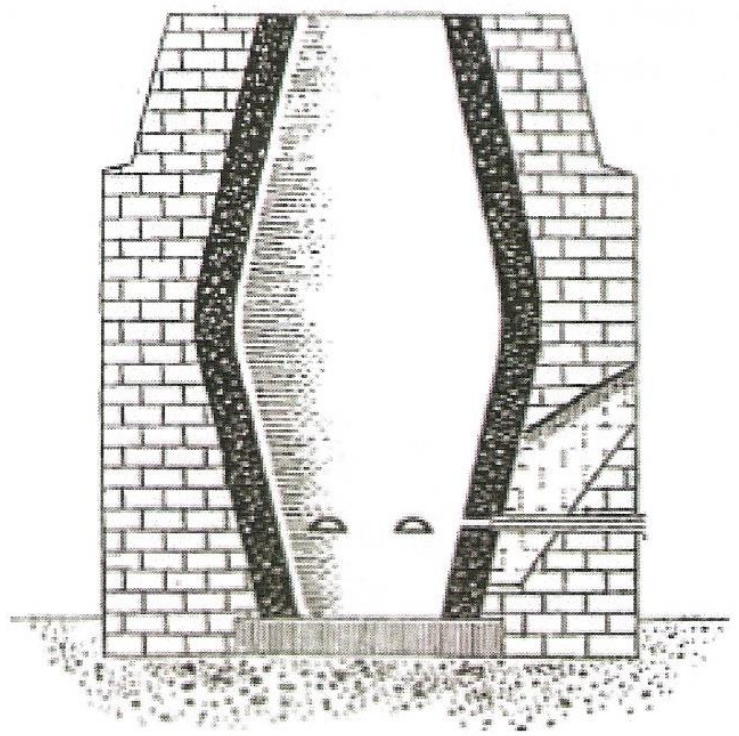

Figura 3 - Forno Stuckofen ${ }^{(9)}$. 
O primeiro Alto-Forno foi o Flussöfen, desenvolvido na região que hoje ocupa a Franca, Bélgica e Alemanha em torno do ano 1340, a diferença com o Stuckofen é o perfil interno, que passou a ter um cadinho para acúmulo de ferro gusa líquido.

Nos anos 1600 no Reino Unido foram fechados diversos Altos-Fornos pela devastação florestal, com isto a produção de ferro nas colônias norte-americanas se viu motivada, isso levou a um avanço significativo, os foles passaram a ser acionados através de rodas de água (fig. 4) aumentando a capacidade de sopro e a produtividade, logrou-se a produção de uma tonelada de ferro gusa por dia ${ }^{(9,10,11)}$.

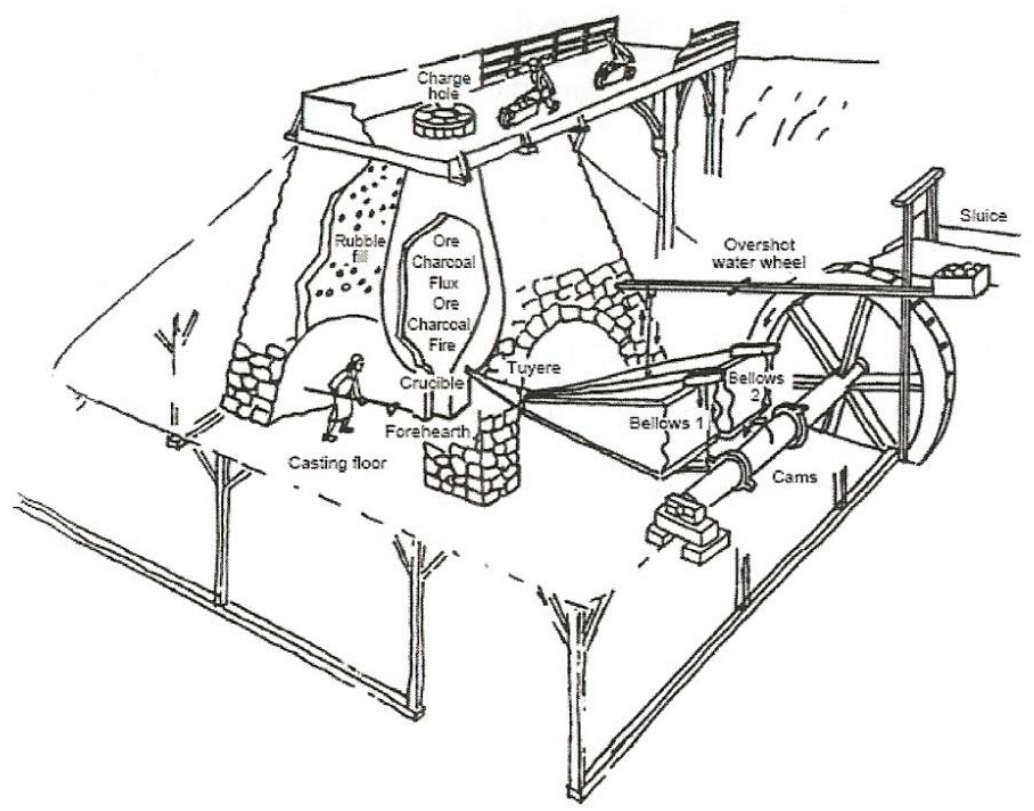

Figura 4 - Alto-Forno Americano Movido a Rodas de Água ${ }^{(11)}$.

A partir de 1700 iniciou-se no Reino Unido o uso de carvão mineral, a produção de coque se desenvolveu no ano 1709, para 1735 foi produzido o primeiro ferro gusa com $100 \%$ de coque, isto gerou um aumento significativo de produção pois permitia carregar maior quantidade de minério, o coque melhorou a permeabilidade do leito para os gases, permitindo-se soprar mais e aumentando os índices de produção ${ }^{(8-11)}$.

Com o uso do coque os avanços tecnológicos foram muitos, dos quais podese destacar ${ }^{(8-11)}$ :

- 1780 Uso de engrenagens movidas a vapor para acionamento dos foles 
- 1828 Uso de ar pré-aquecido nas ventaneiras

- 1832 Uso dos gases de topo para preaquecimento do ar

- 1857 Desenvolvimento dos trocadores de calor tipo Cowpers

- 1870 Otimização dos sistemas de carregamento através do uso de elevadores a água , skips, etc

- 1880 Sistemas de limpeza de gases com a utilização de um dustcatcher e difusão de técnicas para proteção do revestimento interno dos fornos (refratários, tubos de refrigeração, painéis refrigerados, etc.)

-1910 Utilização de sopradores tipo turbo, ao invés de foles e construção das primeiras máquinas de sinterização

-1917 Construção da primeira máquina para fabricação de tijolos refratários de qualidade -1944 Primeira patente para a injeção de finos pelas ventaneiras -1950 Otimização do sistema de controle dos fornos

仓 $\quad-1951$ Enriquecimento de ar com oxigênio puro

- Entre 1950 e 1975 o coque-rate desceu de 925 para $550 \mathrm{~kg} / \mathrm{t}$, a partir dos anos 80 , o coque-rate caiu abaixo de $450 \mathrm{~kg} / \mathrm{t}$ pelos seguintes motivos ${ }^{(9,40)}$ :

- Melhorias na composição do coque

- Tamanho calibrado do coque, retirando os finos abaixo de $25 \mathrm{~mm}$, aumento da permeabilidade e ritmo de aquecimento

- Emprego de sínter e pelotas, e mais recentemente de sínter auto-fundente.

- Elevadas temperaturas de sopro, em torno de 1200 C e $1400 \mathrm{C}$

- Injeção de oxigênio para aumentar a temperatura de chama

- Injeção de hidrocarbonetos nas ventaneiras aumentando o poder redutor do gás da rampa e substituindo parcialmente o consumo de coque por um combustível mais barato

- Operação em alta pressão aumentando o volume de ar injetado no interior do forno

- Melhor distribuição da carga com palhetas móveis 


\subsection{2.}

\section{História do Alto-Forno no Brasil}

A história da fabricação do ferro no Brasil remonta-se ao século XVI, na época da colonização. O Padre jesuíta José de Anchieta é o primeiro a reportar a existência de depósitos de ferro no interior da capitania de São Vicente (São Paulo) ${ }^{(6,12)}$. A primeira tentativa de redução do ferro no Brasil e também em solo americano corresponde à data de 1557 com a instalação de dois fornos rústicos catalães por Alfonso Sardinha e seu filho, em Iperó, Morro Araçoiaba. Com a morte de Alfonso Sardinha, pai, em 1616, e a proibição da produção de artigos manufaturados na colônia, a fabricação de ferro que atendia a produção de ferramentas agrícolas e utensílios domésticos ficou estagnada. Em 1682, foi criada a Fundição de Ferro de Araçoiaba. Em 1785 se proibia, mediante uma publicação de um alvará real, de manter fábricas no Brasil, a fim de que cuidassem apenas da agricultura e do ouro. Outro tipo de restrição no início do século XVIII limitava a fundição de metais, estritamente, na fundição real por motivos de arrecadação de impostos ${ }^{(12)}$. Até aqui foram intentos e restrições no desenvolvimento do processo para obtenção do ferro. O ano de 1808 deu início a uma nova fase na siderurgia no Brasil, João VI e a família real chegam ao Brasil fugindo do avanço das tropas de Napoleão na Europa ${ }^{(6,12)}$. Criaram-se a partir desse ano diversas indústrias siderúrgicas: fundição de Sorocaba-São João de Ipanema (figura 5), e o primeiro Alto-Forno e forjas de refino no Morro do Pilar, em Minas Gerais, em 1815, e cuja melhor produção, em 1820, foi de 38 toneladas (tinha 8,5 metros de altura) ${ }^{(12)}$, esta mesma foi fechada em 1831, devido à competição com os produtos importados e escassez de mão de obra.

Segundo Marcos de Mendonça, em sua obra, O intendente Câmara, que foi o Barão de Eschwege, o primeiro a fabricar ferro líquido, em 17 de dezembro de 1812, em fornos tipo sueco, na fábrica Patriota, nas proximidades de Congonhas do Campo. Por outro lado, diz que Manuel Ferreira da Câmara de Bittencourt e Sá, foi o primeiro a produzir ferro gusa em Alto-Forno, em agosto de $1814^{(12)}$. 


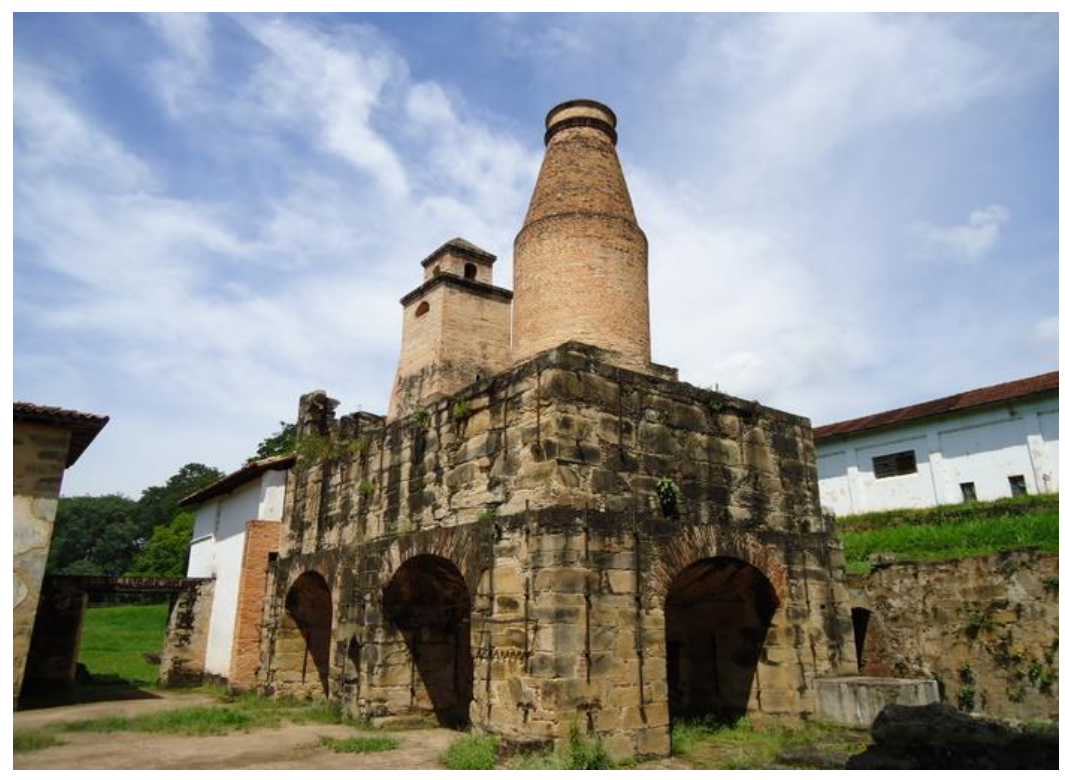

Figura 5 - Fornos de São João de Ipanema (Associação de Engenheiros BrasilAlemanha) ${ }^{(12)}$.

Um marco importante para o setor foi a fundação da Escola de Minas de ouro Preto, em 1876, pelo engenheiro francês Henrique Gorceix, antes disso muitos professionais estrangeiros como o sueco C. A. Hedberg, os alemães Schoenewolf (técnico), e o barão de Eschewege ( engenheiro) levaram com relativo êxito ao desenvolvimento da siderurgia ${ }^{(13)}$. Foi então, a partir da criação da Escola de Minas que se superou a falta de técnicos preparados para o ofício.

No século XX a criação da Companhia Siderúrgica Belgo-Mineira; com operação de sua primeira usina de Sabará em Minas Gerias, em 1925, e a inauguração, em 1939, de sua segunda usina em Monlevade, MG, marca o início de criação de companhias com altos volumes de produção. Logo, em 1942, é fundada a Companhia Ferro Aço de Vitoria (Cofavi). Em 1946, a Companhia Siderúrgica Nacional entra em operação como a maior usina integrada a coque produtora de aço da América Latina. Em 1951, inicia sua produção a companhia Aços Especiais Itabira (Acesita) ${ }^{(13)}$.

Um resumo, segundo o Instituto Aço Brasil, dos empreendimentos sucedidos a partir de 1952 é listado a seguir:

Em 1952é criado o Banco Nacional de Desenvolvimento Econômico (BNDES) que foi um importante agente financeiro da estratégia do governo que impulsionou o desenvolvimento do setor. 
Em 1954 é inaugurada a Companhia Siderúrgica Mannesmann, Belo Horizonte, MG, com o primer forno elétrico.

Em 1961 entra em operação a Siderúrgica Riograndense, em Porto Alegre, com a primeira máquina de lingotamento continuo de aço.

Em 1966 é inaugurada a primeira usina de pelotização da companhia Vale do Rio Doce, em Vitoria Espírito Santo (ES).

Em 1973 é inaugurada a primeira usina integrada de redução direta, Usina Siderúrgica da Bahia (Usiba). É criada a Companhia Siderúrgica Brasileira (SIDERBRAS).

Em 1983 entra em operação a Companhia Siderúrgica de Tubarão (CST), em Vitoria, Espírito Santo.

Em 1986 entra em operação a Companhia Aço Minas (Açominas), em Ouro Branco, Minas Gerais.

Em 1990 no governo Fernando Collor de Mello é extinta a SIDERBRAS.

Entre 1991 e 1993 acontece a privatização das Siderúrgicas: Cosinor, Usiminas, Aços Finos Piratini, CST, Acesita, CSN, Cosipa e Açominas.

Em 2010 é fundada a Thyssenkrupp CSA, Companhia Siderúrgica do Atlântico, no Rio de Janeiro.

Em 2011 é fundada a Vallourec\&Sumitomo Tubos do Brasil(VSB), em Jeceaba, Minas Gerais. É criada a Aperam, com a união da ex-Arcelor Mittal Inox Brasil e outras sete plantas industriais localizadas na França e Bélgica.

O atual parque Siderúrgico Brasileiro é representado por 14 empresas privadas, controladas por onze grupos empresariais que operam 29 usinas distribuídas em 10 estados:

- Siderúrgica Norte Brasil-SINOBRAS

- Vallourec

- Thyssenkrupp CSA Siderúrgica do Atlântico

- Villares Metals

- Arcelor Mittal Brasil- inclui Arcelor Mittal Aços longos e Arcelor Mittal Tubarão

- Aperam

-Companhia Siderúrgica Nacional CSN 
- Usiminas

- Votorantim Siderurgia

- Gerdau

- Vallourec \& Sumitomo Tubos do Brasil

\subsection{3.}

Rotas Tecnológicas para Produção de Ferro Primário

Segundo E.M.S Rizzo ${ }^{(6)}$, ferro primário são os produtos obtidos a partir do processamento por redução do minério de ferro nas usinas siderúrgicas.

Existem diversas tecnologias para produção de ferro primário, que podem ser divididas pelo tipo de estado do produto final: quando o produto final é líquido chama-se ferro gusa, e se o produto final é sólido denomina-se ferro esponja, como mostrado na figura 6 .

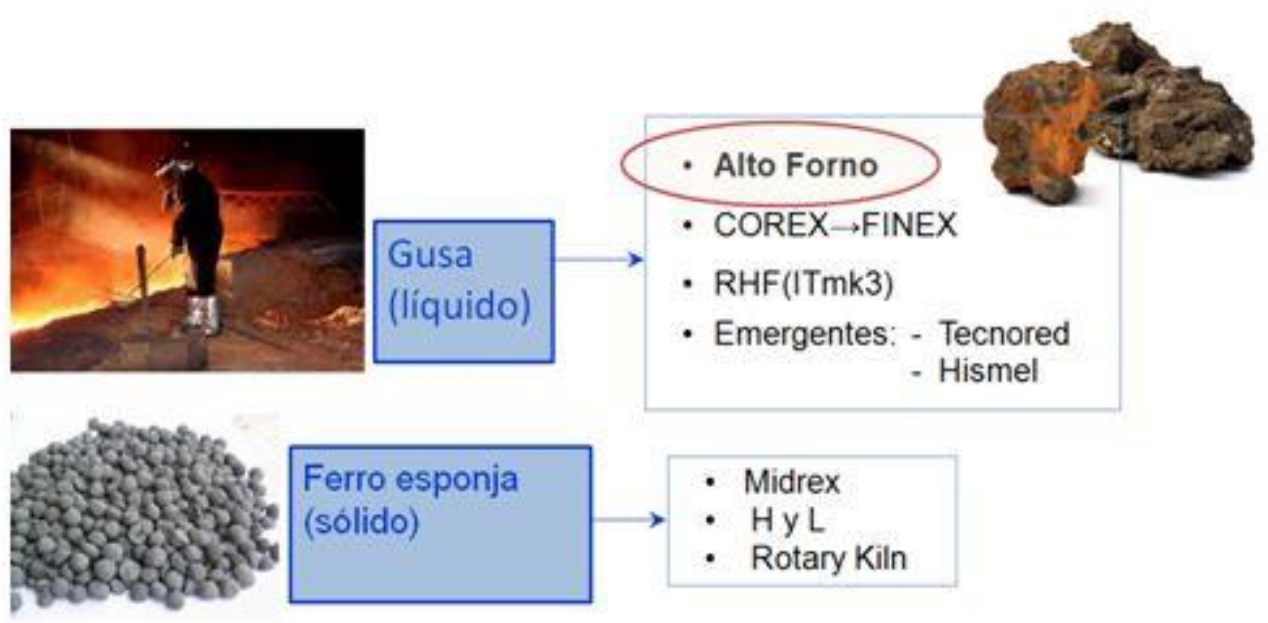

Figura 6 - Tecnologias para Produção de Ferro Primário.

\subsubsection{1.}

Rotas Tecnológicas para Produção de Ferro-Gusa

Ferro-gusa é uma liga de ferro-carbono no estado líquido produto da redução dos minérios de ferro que pode ser obtida através dos seguintes processos: 


\section{- Altos Fornos:}

Processo fortemente estabelecido mediante o qual ferro-gusa é produzido através da redução e fusão dos minérios de ferro, caraterizado por ser um processo em contracorrente que ocorre num reator denominado Alto-Forno, onde os óxidos contendo ferro são carregados pela parte superior e que na sua descida são reduzidos pela ação redutora dos gases ascendentes $\left(\mathrm{CO}\right.$ e $\left.\mathrm{H}_{2}\right)$ provenientes da combustão do carbono (do coque ou carvão vegetal) com o oxigênio soprado pelas ventaneiras, e da reação da agua com o carbono, reações que ocorrem em temperaturas elevadas.

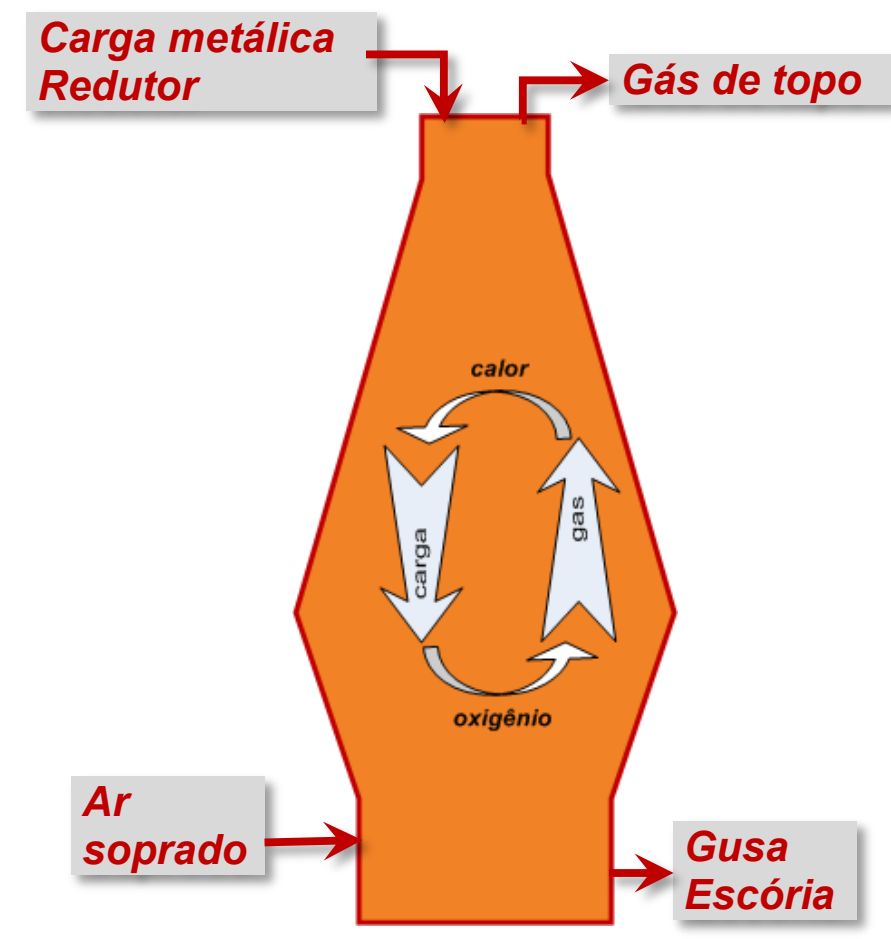

Figura 7 - Processo de redução no Alto-Forno.

\section{- Corex:}

É um processo que realiza a redução do minério de ferro em estado sólido, numa primeira etapa, e logo a fusão numa segunda etapa, isto quer dizer que se aproxima a um alto forno divido em duas partes. O Corex utiliza oxigênio puro nas ventaneiras para produzir gás redutor $\mathrm{CO}$ e $\mathrm{H}_{2}$ ( numa temperatura de $1050{ }^{\circ} \mathrm{C}$ aprox.) que será utilizado na primeira etapa (reator de redução) Após de ser despoeirado e resfriado a $850{ }^{\circ} \mathrm{C}$ aprox. O gás que sai do reator de redução tem alto poder calorífico, aproximadamente o dobro do gás do alto forno ${ }^{(5,14)}$. 


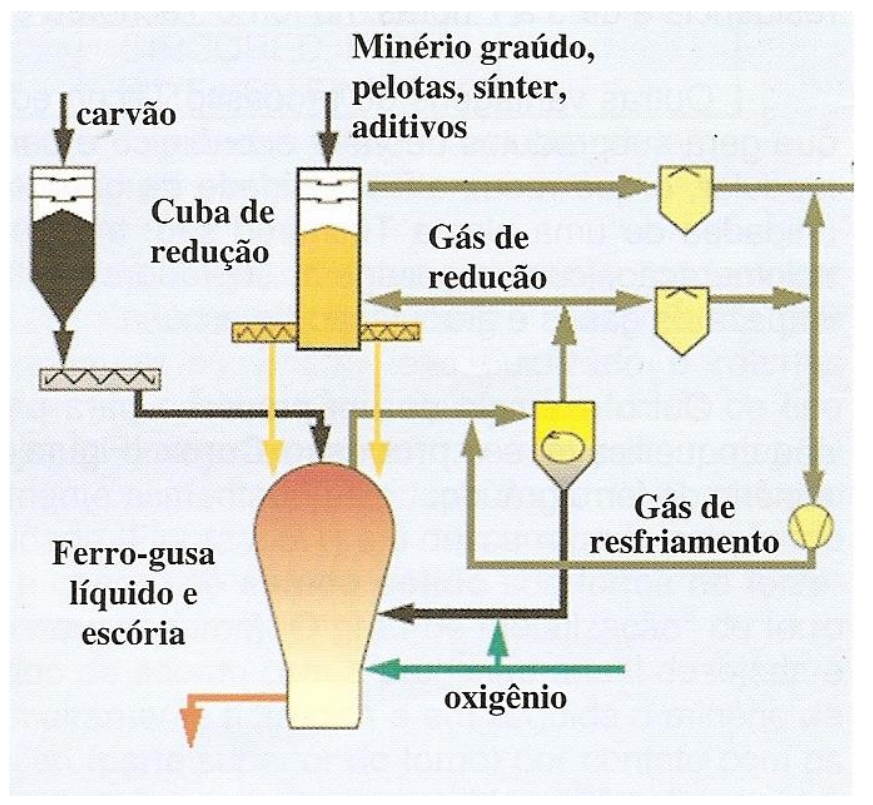

Figura 8 - Processo Corex ${ }^{(5,14)}$.

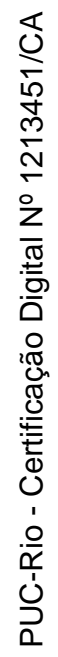

\section{- HISmelt:}

O High Intensity Smeltin (HISmelt) é um processo de redução em fase líquida no qual os minérios de ferro e carvão pulverizados são injetados diretamente no interior do banho de ferro líquido. O carvão dissolve-se no ferro, e o carbono dissolvido reduz os óxidos de ferro, (figura 9) ${ }^{(4)}$.

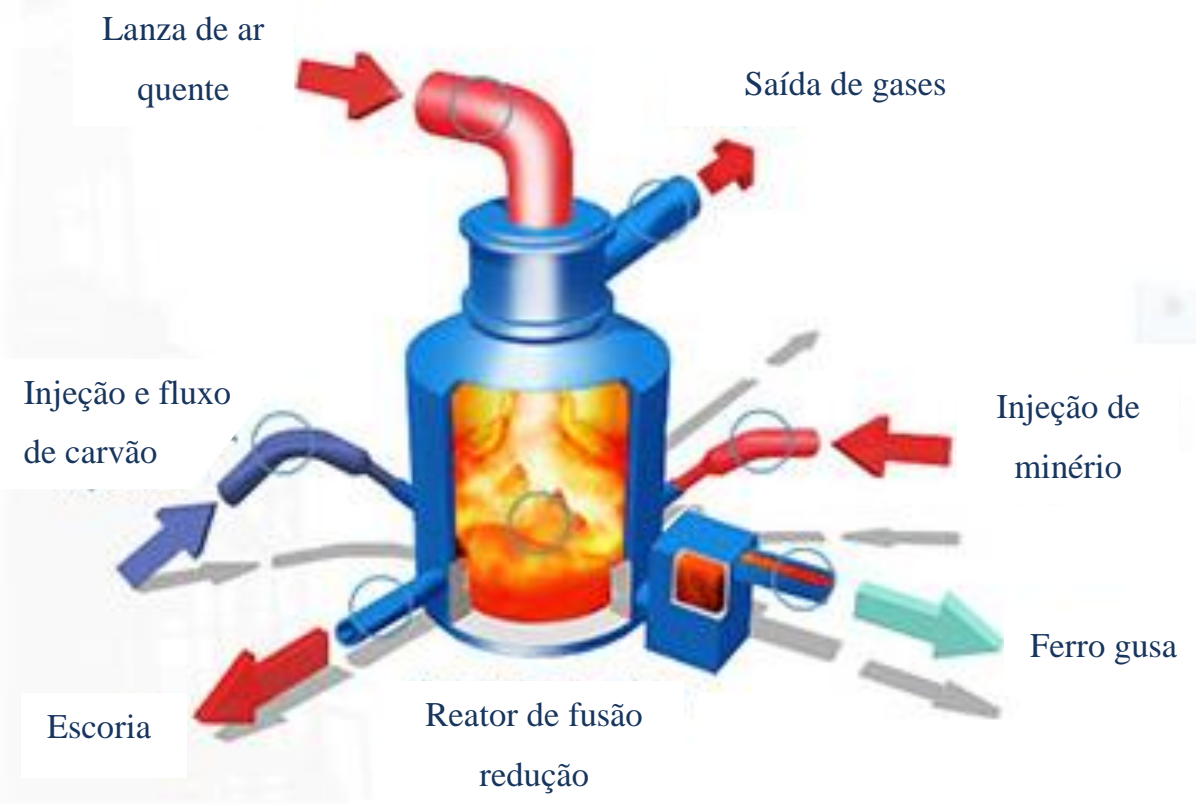

Figura 9 - Processo HISmelt ${ }^{(5)}$. 


\section{- Finex:}

O reator da parte superior é de leito fluidizado (entre 3 a 4 fluidizadores) onde o minério de ferro é agregado fino e pré-reduzido, depois passa a ser briquetado em quente para logo ser alimentado junto com briquetes de carvão e completar a redução (direta) na unidade inferior de fusão-redução ${ }^{(4,46)}$.

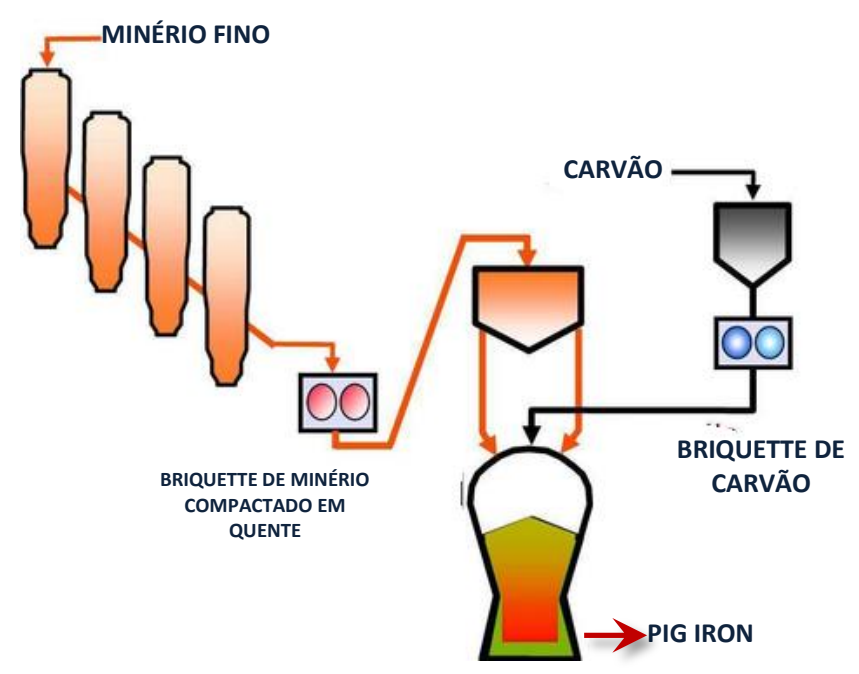

Figura 10 - Processo Finex ${ }^{(5,46)}$.

\section{- $\operatorname{RHF(ITmk3)}$}

Os processos Rotary Hearth Furnace (Forno de Soleira rotativa) são tecnologias que tratam pelotas auto-redutoras em temperaturas entre 1250 a $1450{ }^{\circ} \mathrm{C}$ aprox., o aquecimento é produto da queima de gás ou carvão pulverizado, os tempos de residência das pelotas no forno variam de 9 a 12 minutos e na sua descargas as pelotas já metalizadas alcançam entre 900 e $1000^{\circ} \mathrm{C}$, exemplos de esse tipo de processo são Inmetco e o Fasmet.

O processo ITmk3(Ironmaking Technology Mark 3, tecnologia de fabricação de ferro de terceira geração, é a terceira etapa no desenvolvimento dos processos RHF, o produto formado no forno são nódulos de ferro-carbono separados da escória. O diâmetro aproximado do forno de uma planta industrial instalada nos EUA (2007) pela Steel Dinamics e financiada pela Kobe Steel, é de 
50 metros e largura de $7 \mathrm{~m}$, a capacidade da produção é de 500 mil toneladas por ano de ferro granulado. A planta comercial começou a operar em $2010^{(4)}$.

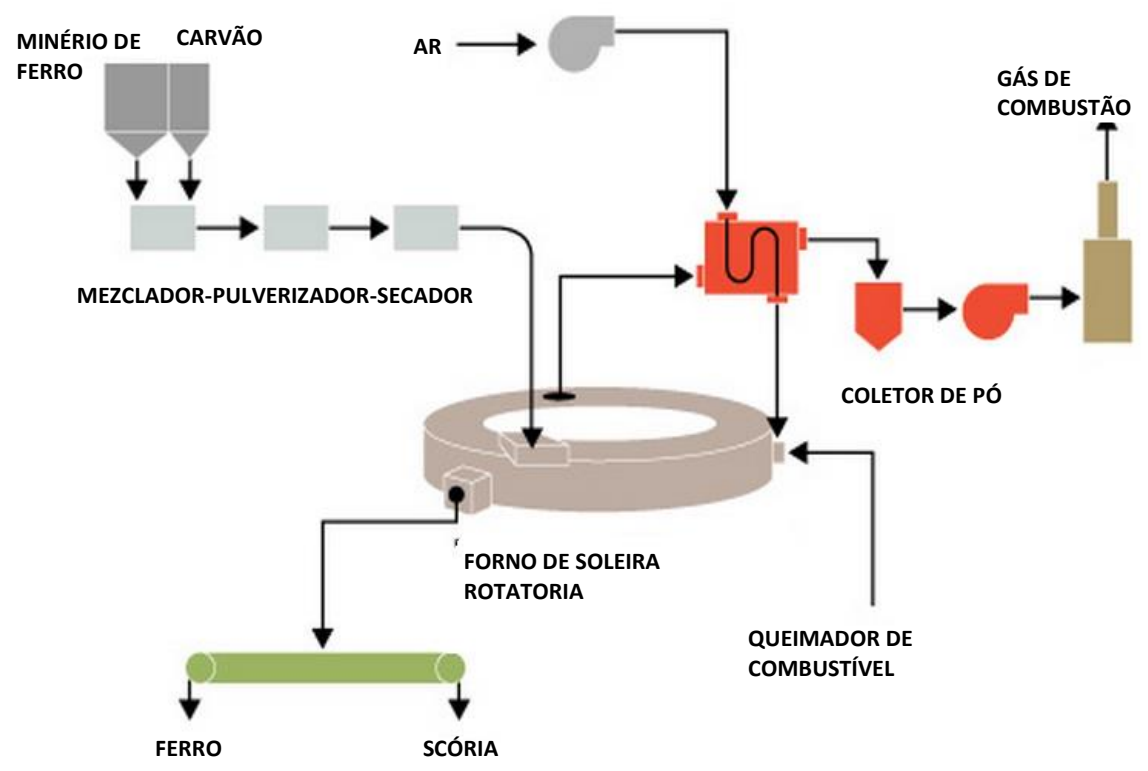

Figura 11 - Processo ITmk3 ${ }^{(5)}$.

- DIOS: The Direct Iron Ore Smelting Reduction Process

Este tipo de tecnologia utiliza carbono e minério de ferro granulado. Corresponde aos processos de fusão-redução em banho líquido onde o minério de ferro é preaquecido e logo pré-reduzido para depois ser adicionado junto com o carvão, pela parte de cima em um reator de fusão com injeção de oxigênio ${ }^{(7)}$ como mostrado na figura 12. 


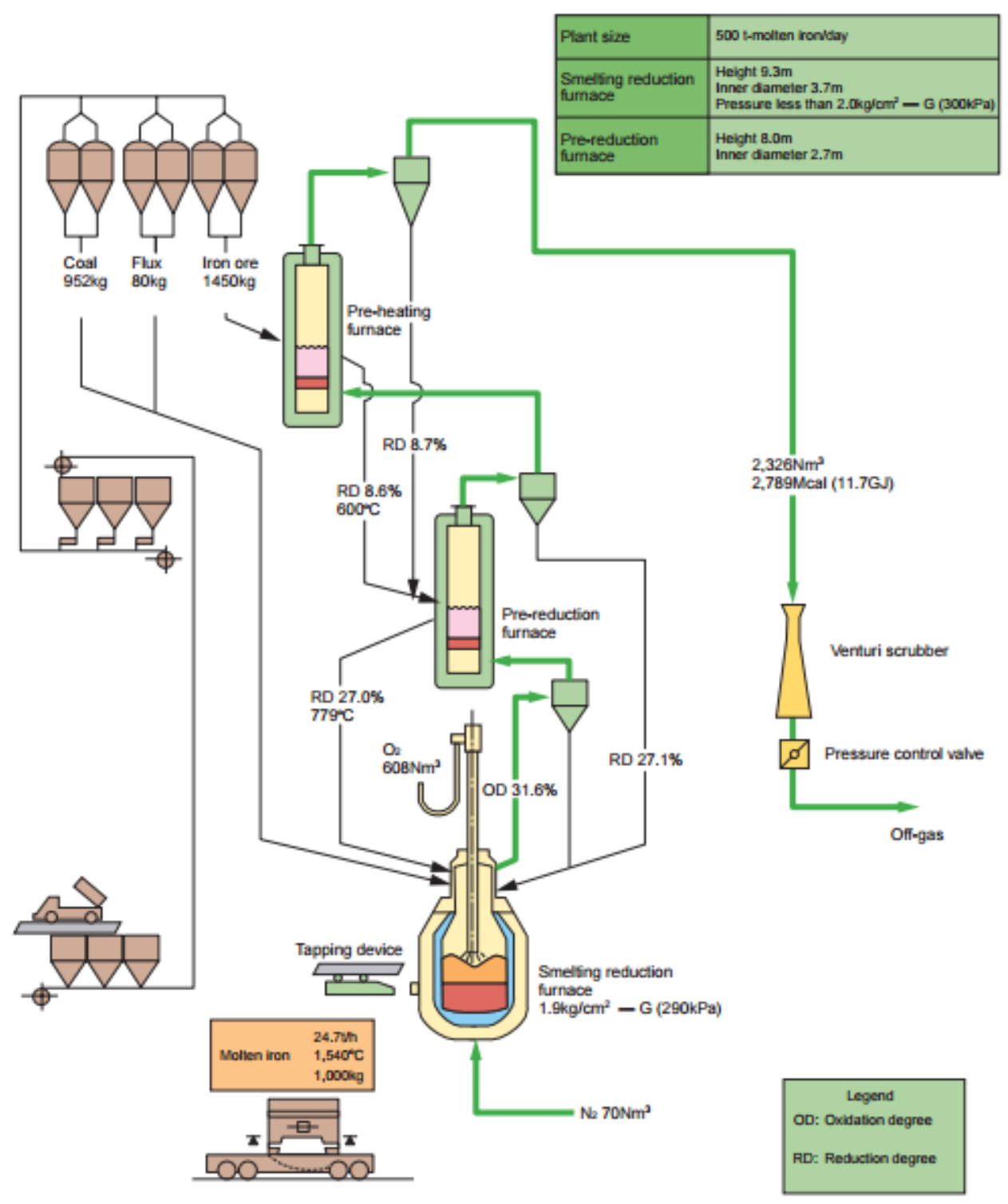

Figura 12 - Processo DIOS ${ }^{(7)}$.

\section{- Tecnored:}

O Processo de redução-fusão se realiza num forno que contém: uma cuba superior, zona de fusão, e uma cuba inferior como pode-se observar na figura(13). Este processo utiliza aglomerados autorredutores compostos de finos de minério e carvão (vegetal, mineral ou coque), resíduos, lamas e pós-metálicos. É introduzido ar quente nas ventaneiras primárias (parte inferior) para combustão do combustível (carvão ou coque) e geração dos gases redutores que ascendem pela cuba central propiciando a redução e fusão. Na parte superior é injetado ar frio 
pelas ventaneiras secundárias com o objetivo de queimar completamente os gases ascendentes gerando assim uma região de temperaturas altas onde se produz a fusão dos aglomerados (pelotas). O tempo de residência do material redutível é de cerca de 30 a 40 minutos ${ }^{(4,6)}$.

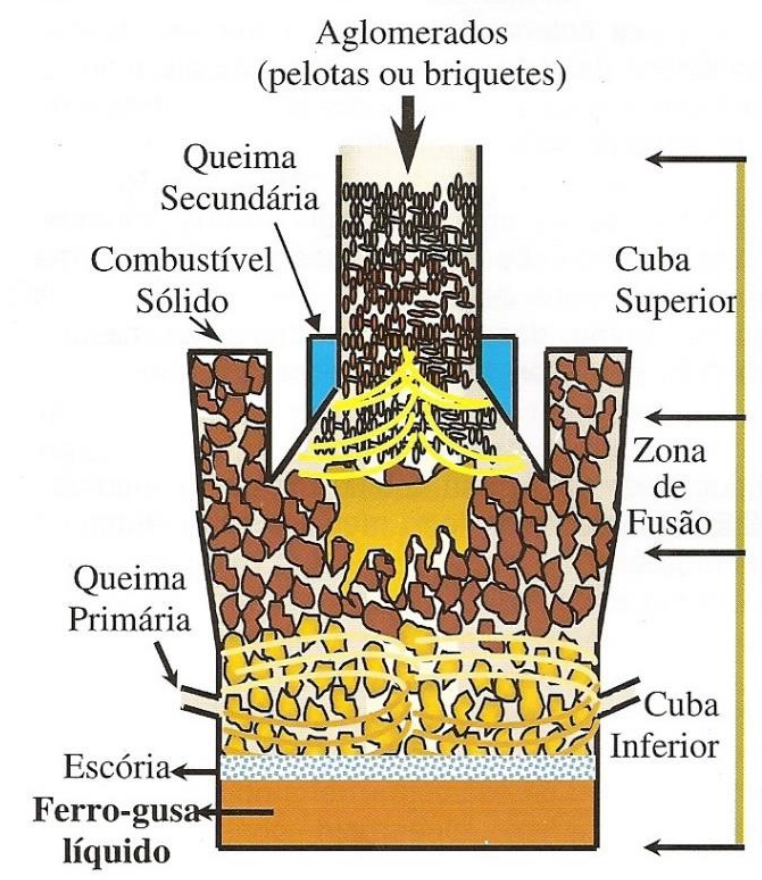

Figura 13 - Processo TECNORED ${ }^{(5,6)}$.

\subsubsection{2.}

\section{Rotas Tecnológicas para Produção de Ferro Esponja}

O ferro esponja é uma liga ferrosa obtida sem fusão dos minérios de ferro, e é produzido nos processos de redução direta utilizando gás natural ou carvão mineral não coqueificável ou finos de carvão mineral. Estes processos incluem:

\section{- Midrex:}

O processo Midrex usa gás natural, o qual deve ser transformado em gases redutores $\mathrm{CO}$ e $\mathrm{H}_{2}$ (no reformador). Estes gases com conteúdo aprox. de $95 \%$ ( $\mathrm{CO}, \mathrm{H}_{2}$ ), uma relação entre $\mathrm{H}_{2} / \mathrm{C}$ de 1,5 a 1,6 são introduzidos no reator (cuba) a 
temperaturas entre 760 e $930{ }^{\circ} \mathrm{C}$. A cuba compreende três zonas: zona de Redução, zona de Transição e zona de resfriamento.

O processo de redução em contracorrente acontece na cuba, pela parte superior é carregada a carga metálica (minério bitolado ou pelotas) que na sua descida é aquecida e reduzida pelos gases ascendentes, o gás que sai no topo da cuba contém em torno de $70 \%$ de $\mathrm{CO}_{2}$ e $\mathrm{H}_{2}$ além de $\mathrm{CO}_{2}$ e $\mathrm{H}_{2} \mathrm{O}$, este gás de topo retorna ao reformador como gás reagente e/ou combustível. O produto ferro esponja é resfriado na parte inferior com uma mistura gasosa (gás de saída de lavado e gás natural), produzindo a carburização com teores de 1,4 a 1,7 \% de carbono $^{(4)}$.

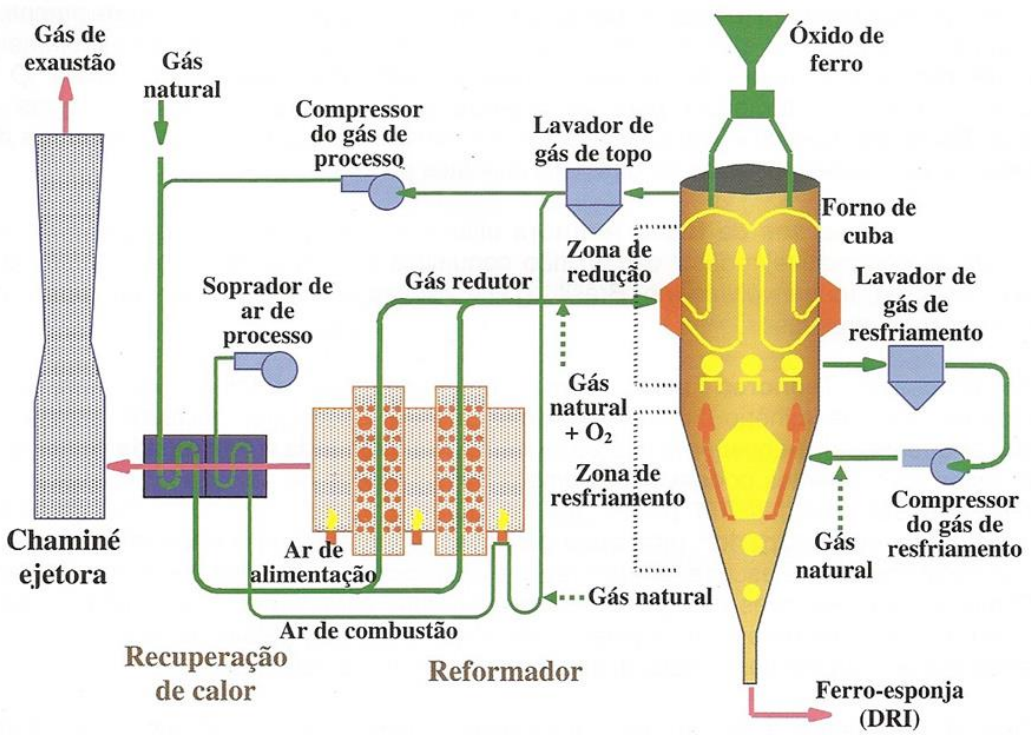

Figura 14 - Processo MIDREX ${ }^{(5)}$.

\section{- Rotary kiln}

O Rotary Kiln emprega fornos rotativos com diâmetro entre 4 a 6 m e de 60 a $125 \mathrm{~m}$ de comprimento, com rotação de 0,4 a 1,25 rpm. No processo, a carga composta por minério de ferro bitolado ou na forma de pelotas, o redutor sólido e os fluxantes como cal e/ou dolomita são carregados na extremidade com maior elevação. No lado oposto ao carregamento é injetada por um queimador gás ou óleo que por sua combustão aportarão a energia necessária para o processo. Ao longo do forno entradas de ar promovem a queima do CO gerado na redução e assim complementam as necessidades térmicas. 
O forno divide-se em duas regiões: a primeira correspondente à zona de preaquecimento, e a segunda à zona de redução (perto do queimador) que caracteriza-se por alcançar temperaturas entre 850 a $900{ }^{\circ} \mathrm{C}$ onde se inicia a reação de Boudouard.

Este tipo de processo apresenta como problema tendência à formação de anéis nos fornos por processar em temperaturas altas materiais suscetíveis à abrasão, a formação de anéis traz dificuldade em passagem da carga chegando até obstruir o forno ${ }^{(4)}$.

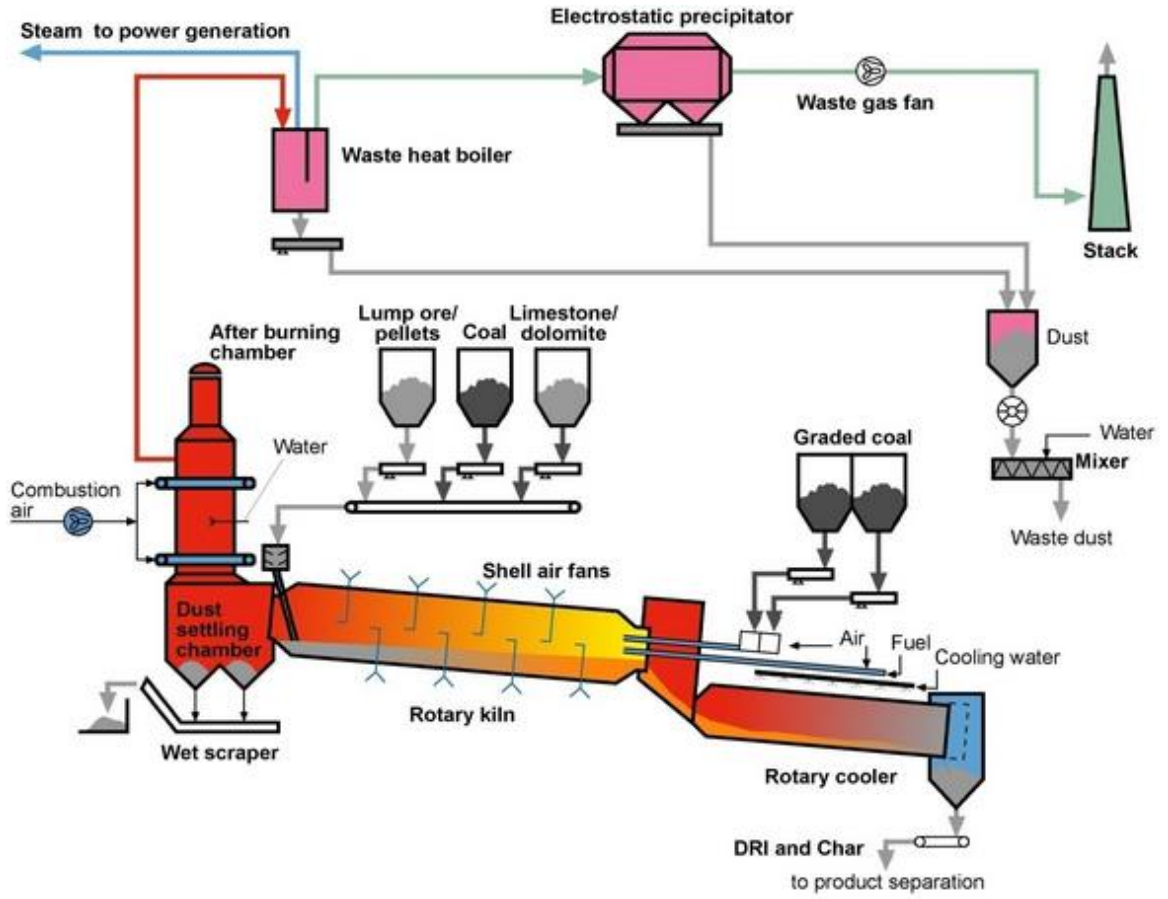

Figura 15 - Processo Rotary kiln ${ }^{(5)}$.

Como mostrado existem diversas tecnologias em andamento para produzir ferro primário, estas iniciativas de desenvolver novos processos tem as seguintes razões:

- redução da energia consumida.

- redução das emissões de $\mathrm{CO}_{2}$, o Alto-Forno responde por $70 \%$.

- a operação do Alto-Forno é fonte de PM10, NOx, SOx.

- Diminuir o tempo de residência, aumentando a produtividade.

- Flexibilizar o uso das matérias-primas (não precisar de matérias-primas 
muito elaboradas).

- Reduzir o custo de capital inicial.

- Redução da área necessária para implantação.

Porém o processo do Alto-Forno domina o cenário mundial de produção de ferro-gusa líquido para a produção de aço. Predomínio que é mantido pela tecnologia operacional e de manutenção, desenvolvimentos que a partir da década de 1970 levaram a aumentos significativos de produtividade, operação contínua por longo tempo, acentuada redução do fuel rate e ao uso de outros redutores tais como o gás natural e o carvão pulverizado. Sua elevada eficiência energética, capacidade de produção, evolução tecnológica e flexibilidade operacional fazem que o Alto-Forno seja, hoje em dia, mais competitivo, e que novas unidades estejam sendo construídas no Brasil e no mundo.

\subsection{4. Matérias-Primas Usadas para Obtenção de Ferro-Gusa no Alto- Forno}

\subsubsection{1. Carga Metálica}

A característica do processo de redução do Alto-Forno, envolvendo o fluxo gasoso em contracorrente, torna necessária a existência de uma boa permeabilidade da carga sólida que permita garantir o escoamento suave e uniforme dos gases. O maior contato dos gases redutores com a carga sólida facilita a redução do minério de ferro, reduzindo o consumo de combustível, essa é a importância junto com o grande número de operações de manuseio e o submetimento no interior do Alto-Forno a uma grande pressão (suporte da carga), determina a necessidade que estes materiais carregados no alto forno sejam mais granulados ${ }^{(4,6)}$. 


\subsubsection{1. \\ Sínter}

Produzido a partir de minérios de ferro com uma granulometria entre 6,35 mm e $0,15 \mathrm{~mm}$ (sínter feed). O processo de produção do sínter é realizado dentro da própria usina integrada. Convenientemente misturados (minérios de ferro, fundentes, materiais reciclados como pó de Alto-forno, lixo industrial, carepa, sínter de retorno, e combustível sólido; coque, carvão vegetal ou antracito) e dosados são carregados nas esteiras contínuas e submetidos a temperaturas de 1250 a $1350{ }^{\circ} \mathrm{C}$. O processo de sinterização queima o combustível presente na mistura, vaporizando a água, gera a decomposição dos carbonatos e reduz parcialmente o minério. O produto obtido após resfriamento final é classificado $(4,6)$.

As características exigidas para o sínter são:

- composição química estável.

- elevado teor de ferro.

- não conter elementos químicos indesejáveis para o Alto-Forno (S, P).

- baixo volume de escória.

- elevada resistência mecânica.

- granulometria estável.

- baixa porcentagem de finos.

- baixa degradação sob redução.

- possuir alta redutibilidade.

\subsubsection{2.}

\section{Pelotas}

São aglomerados de finos em forma de esferas com diâmetro aproximado de $10 \mathrm{~mm}$ a15 mm, obtidas mediante rolamento em discos ou tambores rotativos aproveitando a força capilar entre a água e o material a pelotizar, a água é o componente de ligação e quanto maior a superfície específica do material melhor a aglomeração, isso determina que as partículas sejam menores a $0,15 \mathrm{~mm}$ no possível ${ }^{(4,6)}$. 
As pelotas formadas (pelotas verdes ou cruas) precisam de maior resistência para seu manuseio e transporte, porém é submetido a tratamento térmico em temperaturas de $1300{ }^{\circ} \mathrm{C}$ aproximadamente, onde alcançam uma resistência à compressão de $3000 \mathrm{~N} /$ pelota. Depois deste processo de queima, as pelotas alcançam uma porosidade típica de 22 a $30 \%$.

\subsubsection{3. Minério Granulado}

Os minérios granulados são utilizados diretamente nas usinas siderúrgicas. O minério extraído na mineração é fragmentado, britado e depois classificado considerando um tamanho máximo em termos de redutibilidade de 25 a $30 \mathrm{~mm}$ e mínimo de 5 a $10 \mathrm{~mm}$ em termos de permeabilidade.

A Permeabilidade ao fluxo de gás depende da fração de vazios, que por sua vez depende da relação entre as partículas menores e maiores.

Segundo sua importância, os minérios de ferro são os hematíticos e magnetíticos, no Brasil na sua maioria são hematíticos com teores de ferro até de $70 \%{ }^{(4,6)}$.

\subsubsection{2.}

\section{Combustíveis e Redutores Sólidos}

São usados normalmente dois tipos de redutor/combustível: o coque de carvão mineral e o carvão vegetal ${ }^{(43)}$. As usinas integradas na sua grande maioria utilizam o coque como redutor. O Brasil é líder no uso de carvão vegetal e ele apresenta vantagens que vão desde menores conteúdos de enxofre até menores emissões de $\mathrm{CO}_{2}$ (no balanço geral; $\mathrm{CO}_{2}$ que serão absorvidos pelas florestas e se converterão em carvão vegetal no futuro, e maior emissão de oxigênio pelas florestas). 


\section{- Combustível}

As reações de oxidação dos carbonos presentes no coque com o oxigênio do ar são reações exotérmicas e geram a quantidade de calor necessária para aquecer e fundir a carga. As reações do $\mathrm{CO}$ com óxidos de ferro e com outros elementos são exotérmicas gerando também calor no processo.

\section{- Redutor}

O CO gerado na combustão e em outras reações é utilizado para remover o oxigênio da carga metálica.

\section{- Permeabilizador e Agente Estrutural}

O coque sólido forma uma estrutura que permite o suporte do peso da carga assim como permite o fluxo de gases ascendentes e o fluxo do ferro-gusa líquido descendente. Por sua menor densidade ocupa o maior volume no Alto-Forno.

\section{- Fornecedor de Carbono}

Transferem carbono para o ferro líquido, formando o ferro-gusa com temperatura mais baixa de fusão do que ferro puro.

\subsection{Coque}

Produto do processo de coqueificação (desenvolvido na Inglaterra no século XVI), o coque é um produto da destilação do carvão mineral feita aproximadamente a $1000^{\circ} \mathrm{C}$ em fornos sem a presença de ar.

$\mathrm{Na}$ atualidade o coque é produzido em unidades denominadas coquerias. $\mathrm{O}$ coque metalúrgico obtido atua nos Altos-Fornos como combustível, redutor, permeabilizador, agente estrutural e fornecedor de carbono. 


\subsubsection{2. Carvão Vegetal}

O carvão vegetal é produto da pirólise da madeira, processo que consiste no aquecimento na ausência do ar em temperaturas acima de $280^{\circ} \mathrm{C}$. A madeira que é composta por carbono, oxigênio e hidrogênio, na forma de celulosa, hemicelulose e lignina, é degradada pelo aquecimento dentro dos fornos para preparação de carvão vegetal.

O processo de conversão da madeira em carvão vegetal compreende três etapas:

\section{- Secagem}

Etapa onde é retirada a umidade da madeira sendo este um processo endotérmico.

\section{- Pirólise}

Nessa etapa sucede a destruição da estrutura química da madeira que acontece em temperaturas elevadas e na ausência de ar. Há liberação de $\mathrm{CO}, \mathrm{CO}_{2}$, $\mathrm{H}_{2}, \mathrm{CH}_{4}$, vapor de agua, hidrocarbonetos gasosos, vapores de alcatrão, de metanol ácido acético e licor pirolenhoso.

\section{- Resfriamento}

O resfriamento do carvão vegetal produzido deve ser realizado para evitar a queima pelo ar.

O uso do carvão vegetal como combustível-redutor no Alto-Forno, trás vantagens como:

- utilização de temperaturas menores de sopro devido à maior reatividade do carvão vegetal.

- A operação do Alto-Forno em temperaturas inferiores $\left(100\right.$ a $\left.150{ }^{\circ} \mathrm{C}\right)$ resulta em menor perda térmica por tonelada de ferro produzido e um menor desgaste de refratário ou uso de revestimentos com menores custos.

- O Alto-Forno opera com baixo volume de escória por tonelada de ferro- gusa, que se traduz em menor consumo de energia para fusão de escoria. 
- Elimina a necessidade de dessulfuração devido a seu baixo conteúdo de enxofre ( $0,5 \mathrm{~kg} / \mathrm{t}$ comparados com $3 \mathrm{~kg} / \mathrm{t}$ quando é usado o coque).

- Geração de gás de Alto-Forno com até $30 \%$ a mais de poder calorífico e com baixa contaminação com $\mathrm{SO}_{2}$.

Como desvantagem no uso do carvão vegetal em Altos-Fornos pode-se citar: ${ }^{(6)}$

- Menor produtividade com maior consumo específico de carbono, devido às caraterísticas do próprio carvão vegetal, como menor densidade, menor resistência mecânica, e maior higroscopicidade.

- A cinética das reações é desfavorecida devido às temperaturas menores.

- A heterogeneidade do carvão vegetal originado pelos diversos tipos de madeiras utilizados, tipos de fornos, carvoarias, fazendo a operação do Alto- Forno ter uma maior flutuação.

\subsubsection{3.} Fundentes

$\mathrm{O}$ minério de ferro contém impurezas como sílica $\left(\mathrm{SiO}_{2}\right)$ e alumina $\left(\mathrm{Al}_{2} \mathrm{O}_{3}\right)$ que elevam o ponto de fusão da carga metálica e dificultam sua remoção. Os fundentes ou também denominados fluxantes por sua facilidade de se associar quimicamente com as impurezas diminuem o ponto de fusão e facilitam sua remoção.

Um dos fundentes mais utilizado é a cal, que adicionada diretamente pelo topo do Alto-Forno a carvão vegetal permite remover o enxofre. Nos AltosFornos a coque o fundente é utilizado como componente do sínter ou das pelotas de minério de ferro ${ }^{(4,6)}$. 


\subsubsection{4. Injeções Auxiliares}

Com o objetivo de reduzir o consumo de combustível/redutor carregado via topo do Alto-Forno são empregadas técnicas de injeção pelas ventaneiras de materiais que possam atuar como combustíveis. Materiais como plásticos picotados, óleo combustível, álcool, alcatrão, gás natural, coque de petróleo, pneus, carvão vegetal e carvão mineral pulverizado, entre outros, foram testados. No Alto-Forno na zona de combustão as temperaturas de chama são elevadas permitindo a degradação dos materiais injetados em moléculas simples de $\mathrm{H}_{2} \mathrm{e}$ CO que servirão como combustíveis e redutores no processo ${ }^{(4-6,15,33,39,44)}$.

A prática mais usada no Brasil é a injeção de carvão pulverizado conhecido como PCI (Pulverized Carbon Injection), os benefícios desta técnica são ${ }^{(5,6,44)}$ :

- Redução de custos, devido ao uso de finos de carvão ou carvões nãocoqueificáveis.

- Aumento da produtividade do Alto-Forno devido à possibilidade de incremento da taxa de enriquecimento com oxigênio no ar soprado e uma elevação da temperatura.

- Permite um ajuste da temperatura da chama na zona de combustão através da alteração da taxa de injeção, que por sua vez permite maior estabilidade operacional do forno já que o tempo de resposta por alterações na taxa de injeção é menor ( 2 horas comparadas com 6 quando se altera no carregamento do coque).

- Diminuição nos impactos ambientais, por serem as coquerias equipamentos altamente polidores do ambiente.

O carvão a ser injetado no Alto-Forno é adequado antes de sua injeção. Primeiro ele é moído de modo a atingir a granulometria ideal, normalmente $60 \%$ do carvão com menos de 75 mícron. Numa segunda etapa o carvão é secado para conter uma umidade de 8 a $10 \%$. O transporte do carvão pulverizado é feito por meio pneumático podendo utilizar ar ou uma mistura ar-nitrogênio. 
$\mathrm{Na}$ atualidade a utilização de PCI média das usinas brasileiras alcança uma taxa de injeção entorno de $140 \mathrm{~kg}$ de carvão por tonelada de ferro-gusa em usinas a carvão vegetal é de $170 \mathrm{~kg}$ de carvão por tonelada de ferro-gusa em usinas a coque ${ }^{(16)}$.

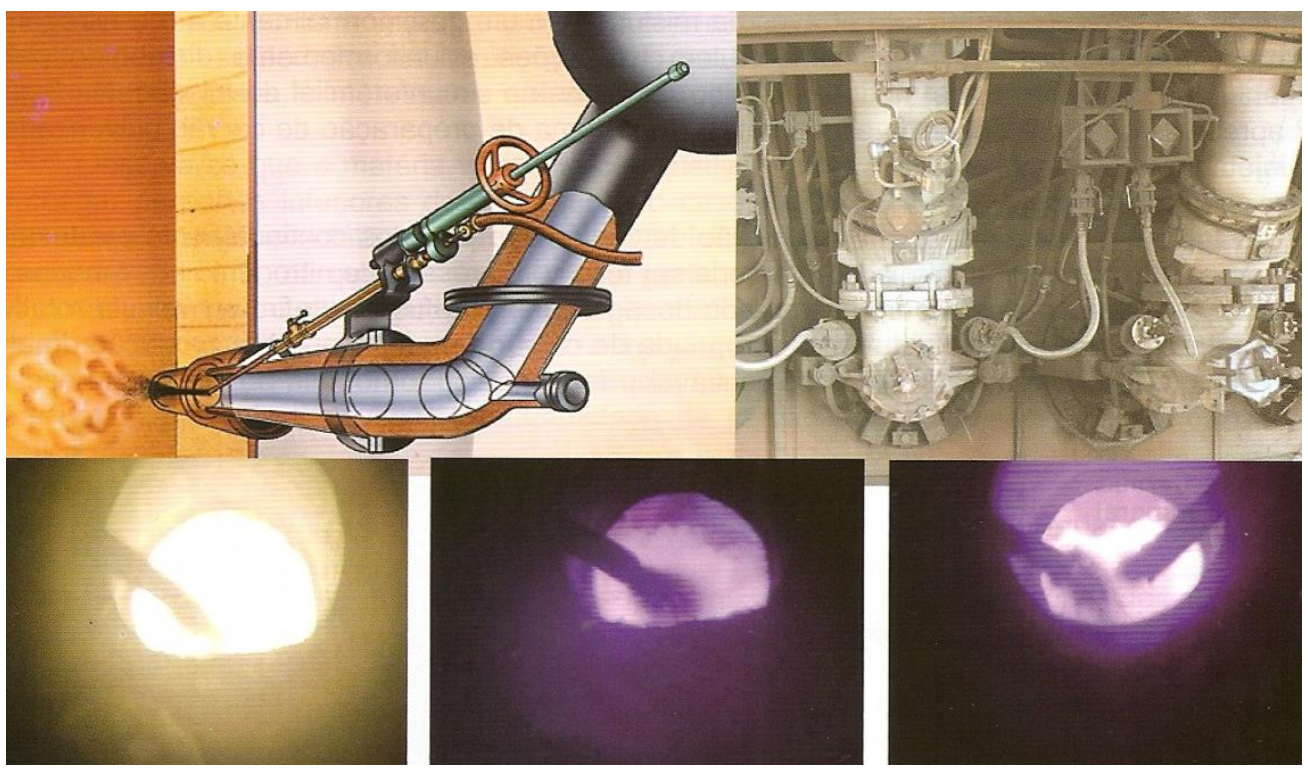

Figura 16 - Injeção de PCI no Alto Forno ${ }^{(6)}$.

\section{2.}

Alto-Forno

O Alto-Forno moderno (fig. 17) é um reator de contracorrente destinado à redução de minérios de ferro, é formado por uma carcaça metálica externa com revestimento refratário, stave coolers e seus equipamentos auxiliares. O proposito do Alto-Forno como reator em contracorrente é a redução química e a fusão dos óxidos de ferro em ferro-gusa ${ }^{(37,40)}$. 


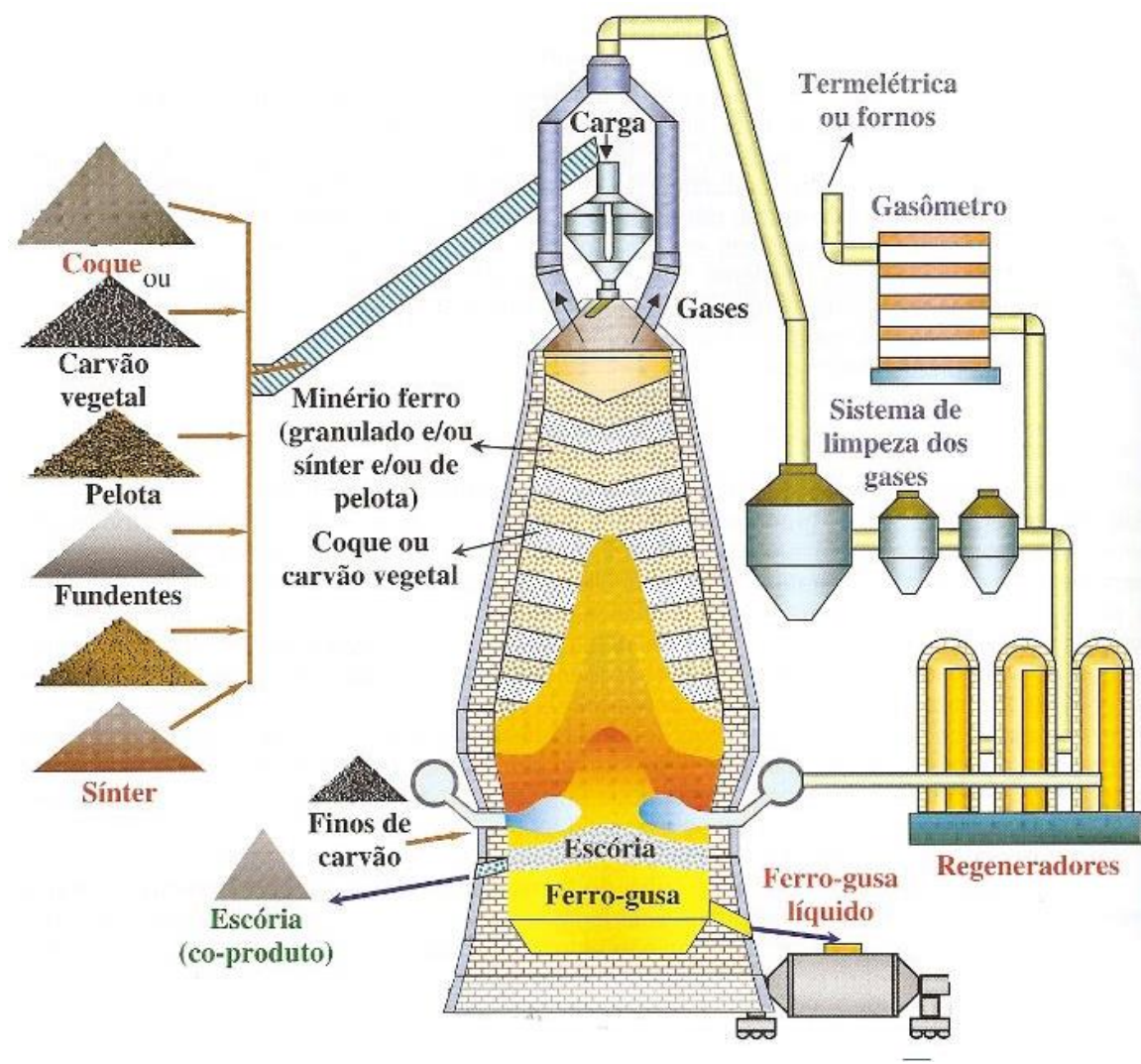

Figura 17 - Alto-Forno e Equipamentos Auxiliares ${ }^{(5)}$.

\subsection{1. \\ Descrição do Equipamento}

Em função da geometria e da função de cada região, o Alto-Forno (figura 18) divide-se em: goela, cuba, ventre, rampa e cadinho.

\subsubsection{1.}

Goela

Parte superior do forno de forma cilíndrica, por onde é feito o carregamento das matérias-primas, nesta região ficam os equipamentos de distribuição da carga, sensores que ajudam na medição do nível da carga, perfil da carga, temperatura e composição dos gases produzidos ${ }^{(6)}$. 


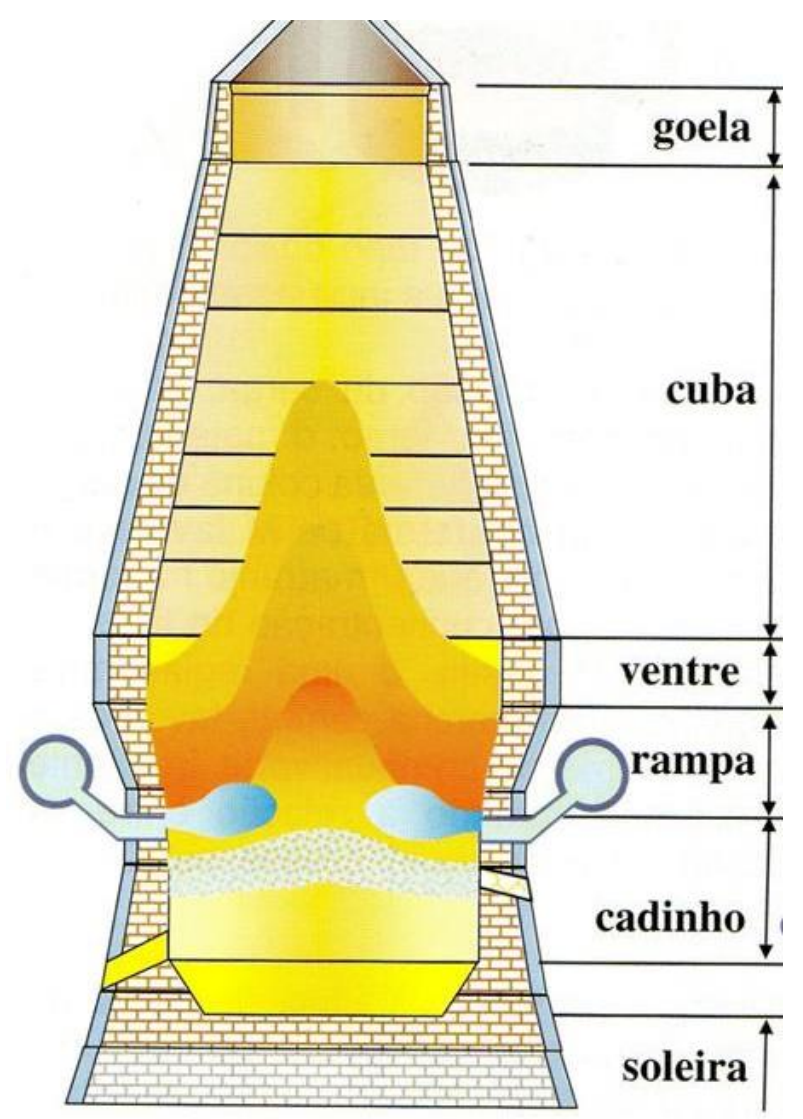

Figura 18 - Divisão do Alto-Forno pela geometria ${ }^{(6)}$.

\subsubsection{2.}

Cuba

Representa a maior parte volumétrica do Alto-Forno, é de formato tronco cônico com o maior diâmetro na sua parte inferior, formato que compensa o aumento do volume da carga, devido à elevação da temperatura, além de permitir a descida da carga.

\subsubsection{3.}

Ventre

Situada entre a cuba e a rampa, apresenta intensa oscilação de temperatura em função da variação da posição da zona compreendida entre os pontos de amolecimento e fusão da carga metálica, denominada de zona coesiva. 


\subsubsection{4.}

Rampa

De formato tronco cônico com diâmetro maior na parte superior, ajuda na sustentação da carga. É nesta região que ocorre o gotejamento do gusa e a escória para o cadinho, através dos interstícios das partículas do coque.

\subsubsection{5.}

\section{Cadinho}

Região inferior do Alto-Forno de formato cilíndrico onde é armazenada temporariamente o gusa e a escória produzidos. Na parte inferior do cadinho, se encontram os furos de corrida onde são feitas as perfurações periódicas para a drenagem do gusa e da escoria produzidos. Na parte superior do cadinho se encontram as ventaneiras, por onde é introduzido o ar quente para a combustão do coque, também são feitas as injeções de carvão pulverizado.

\subsection{2.}

\section{Modelo Operacional do Alto-Forno}

O modelo Operacional atual do Alto-Forno é o resultado de vários séculos de desenvolvimento. Entre 1940 e 1980 a capacidade de produção do Alto-Forno se duplicou e o consumo de coque foi reduzido de 1000 para menos de $500 \mathrm{~kg}$ de coque por tonelada de ferro-gusa produzido. Estas melhoras foram possíveis somente através da melhor compreensão das reações que acontecem dentro do forno.

As origens dos estudos do esquema ideal do Alto-Forno e modelos matemáticos para o mesmo encontram-se nas sondagens de cuba e dados de operação de usinas. Estas sondagens foram feitas inicialmente na Rússia e posteriormente, pela equipe do IRSID (Instituto de pesquisa da Siderurgia,) na França $^{(4,6,17)}$. 


\subsubsection{1.}

\section{Estudo de Michard}

Os trabalhos de Michard, Rist e seus colaboradores do IRSID estabeleceram por primeira vez um esquema de funcionamento ideal do Alto-Forno e um modelo matemático, na qual se integraram conhecimentos teóricos.

A base do modelo é a divisão do Alto-Forno em zonas de trocas térmicas e trocas químicas (fig. 19). Este esquema foi proposto em 1959 e divide o funcionamento do Alto-Forno em duas regiões, sua validade foi amplamente confirmada tanto por meio de aparatos experimentais como por investigações e sondagens em aparelhos industriais ${ }^{(1,18)}$.

\subsubsection{1.}

Regiões de Trocas Térmicas

\section{- Região Superior de Trocas Térmicas}

Situada imediatamente abaixo do nível de carregamento, região onde os sólidos enfornados são rapidamente aquecidos até $950^{\circ} \mathrm{C}$ pelos gases provenientes das diversas reações que ocorrem nas regiões inferiores do forno.

\section{- Região Intermediária}

Os sólidos e gases conservam, em uma altura apreciável da cuba, temperaturas bem próximas.

É uma região que pode ser considerada inoperante termicamente, $\mathrm{T}_{\text {carga }} \cong$ $\mathrm{T}_{\text {gases }}=950^{\circ} \mathrm{C}$, também chamada de "zona de reserva térmica".

\section{Região Inferior de Trocas Térmicas}

Abaixo da Região intermediaria a uma zona de troca térmica elevada e intensa (Região inferior de trocas térmicas), onde a diferença de temperatura entre 
a fase sólida (semifundida) e a gasosa aumenta rapidamente até o nível das ventaneiras. A temperatura é importante nesta região para o desenvolvimento da reação de Boudouard, (abaixo de $950^{\circ} \mathrm{C}$ se processa a taxas desprezíveis).

\subsubsection{2.}

\section{Regiões de Trocas de Oxigênio}

\section{- Região Superior de Trocas de Oxigênio}

No interior da região superior de trocas de oxigênio os óxidos superiores de ferro (Hematita e Magnetita) são reduzidos pelo $\mathrm{CO}$ a wustita, esta zona tem início na zona superior de trocas térmicas e se desenvolve até a zona de reserva térmica, as reações que acontecem são as de Redução Indireta (RI).

\section{- Região Intermediária de Trocas de Oxigênio}

Existe a presença única de wustita. Relações impostas pelo equilíbrio Fe-Wgás, é uma região considerada quimicamente inerte "zona de reserva química" (que fica abaixo da zona de reserva térmica).

\section{- Região Inferior de Trocas de Oxigênio}

Nesta região a wustita é reduzida a Ferro, esta redução se efetua em grande parte antes da fusão e com participação da reação de "solution loss" que regenera o CO, (ocorrência da RD).

Os ensaios e sondagens realizados nos Alto-Fornos permitiram a Michard definir um novo esquema de funcionamento para o Alto-Forno (figura 19) dividido em duas zonas, zona de preparação e zona de elaboração. O novo modelo se baseia na separação do Alto-Forno em dois trocadores divididos por uma isoterma de $950{ }^{\circ} \mathrm{C}$. 


\section{- Zona de Preparação}

A zona de preparação servirá para secagem da carga e efetuar as Reduções Indiretas, sua característica principal é que o coque não reage. Estende-se da goela até o nível da zona de reserva química. Ela utiliza os potenciais térmico e redutor dos gases que a atravessam provenientes da zona de elaboração,

\section{- Zona de Elaboração}

$\mathrm{Na}$ zona de elaboração serão efetuadas as outras reduções (Redução Direta dos óxidos ferrosos e não ferrosos) bem como a fusão do gusa e a escória. Compreende a partir da zona de reserva química.

A temperatura da zona de reserva térmica é fixada pela reatividade do coque. É a temperatura na qual não se passa mais a reação $\mathrm{CO}_{2(\mathrm{~g})}+\mathrm{C}=2 \mathrm{CO}_{(\mathrm{g})} \mathrm{e}$ tanto maior a reatividade do coque, menor a temperatura da zona de reserva térmica.

A temperatura da zona de reserva térmica foi determinada em média, $950{ }^{\circ} \mathrm{C}$ para reatividade normal do coque. Já em 1967 sondagens feitas por pesquisadores do IRSID em Altos-Fornos a carvão vegetal da companhia Belgo-Mineira determinaram um valor de $800{ }^{\circ} \mathrm{C}$ para a zona de reserva térmica em fornos a carvão vegetal. 


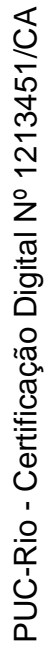

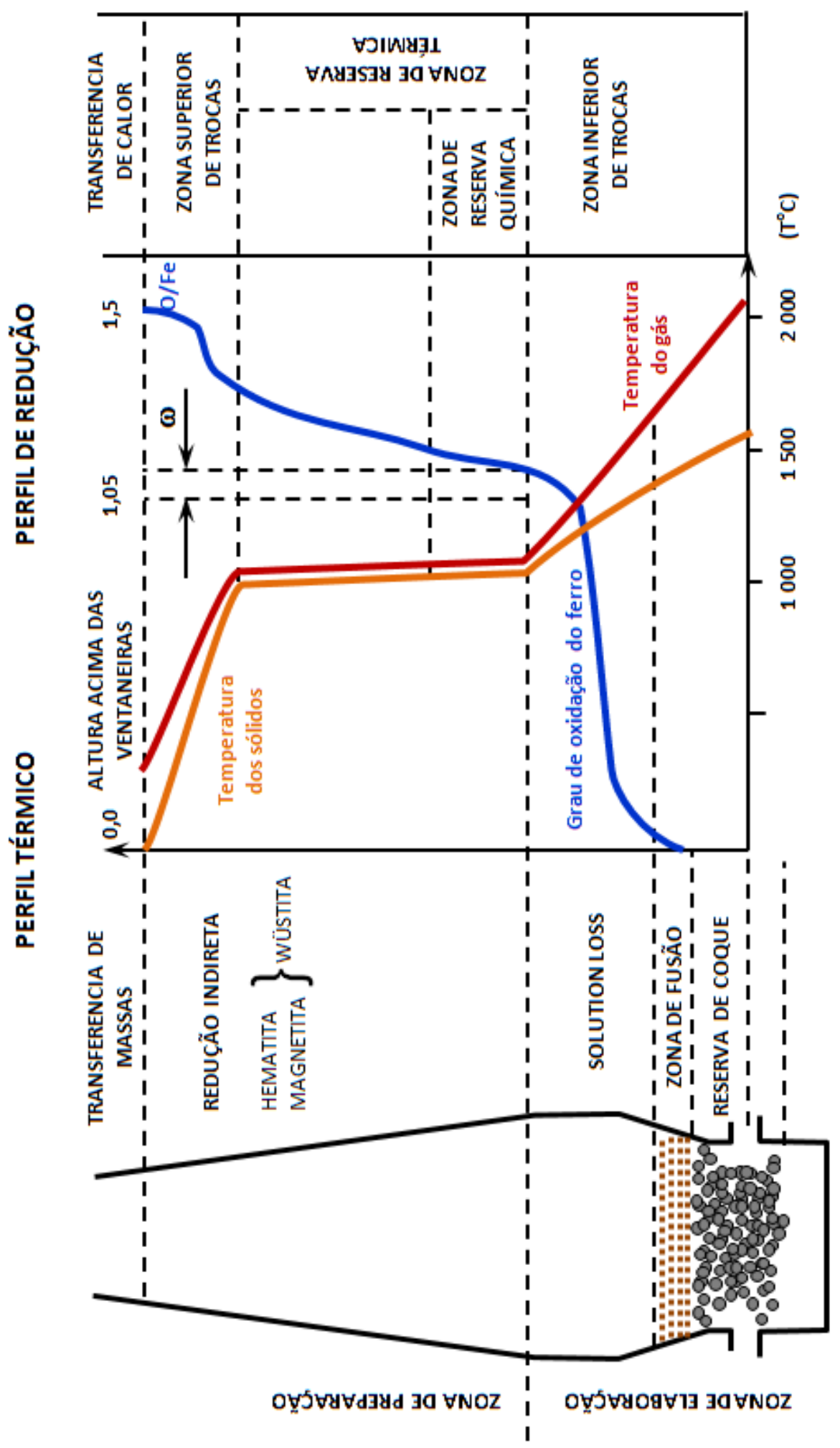

Figura 19 - Esquema de Michard ${ }^{(18)}$. 


\subsubsection{2.}

\section{Reta Operacional de Rist}

Um caminho alternativo para a apresentação dos balanços de massa e de energia de um Alto-Forno foi apresentado por A. Rist mediante um modelo gráfico operacional. Para a representação do balanço de energia foi adotado o diagrama de Reichardt que é adequado para representar as condições de transferência de calor para a carga. Para a representação gráfica do balanço de massa (carbono, oxigênio e hidrogênio) foi utilizado o diagrama operacional, este diagrama é adequado para indicar o ponto químico de quebra e as condições de transferência de oxigênio da carga para o gás ${ }^{(19-21,35)}$ (figura 20).

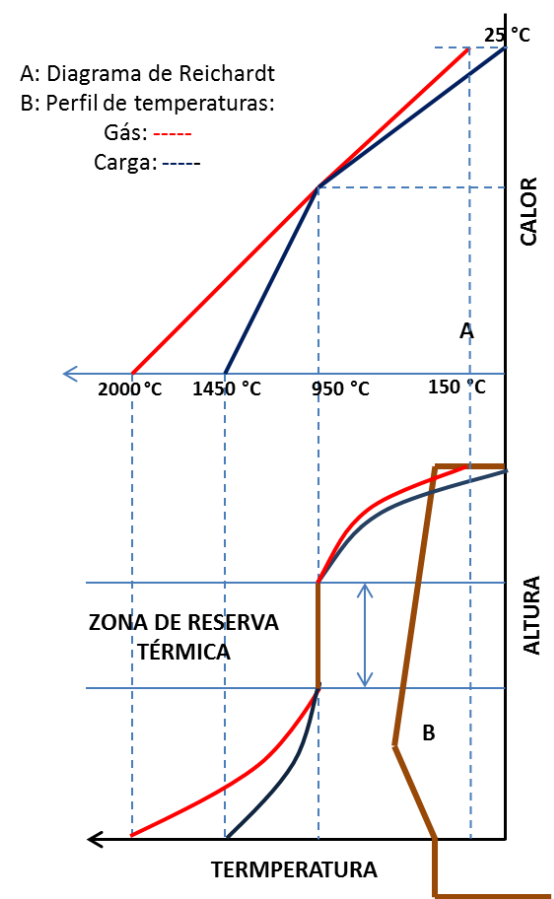

Figura 20 - Diagrama de Reichardt e Perfil de Temperaturas do Alto- Forno ${ }^{(19)}$.

Rist e Bonnivard propuseram um diagrama em eixos cartesianos de trocas de oxigênio, onde no eixo $\mathrm{Y}$ temos o número de átomos de oxigênio por átomo de ferro da carga metálica, e no eixo X o número de átomos de oxigênio por átomo de carbono do gás do Alto-Forno como apresenta-se na figura $(21)^{(1,19,20,22)}$. 


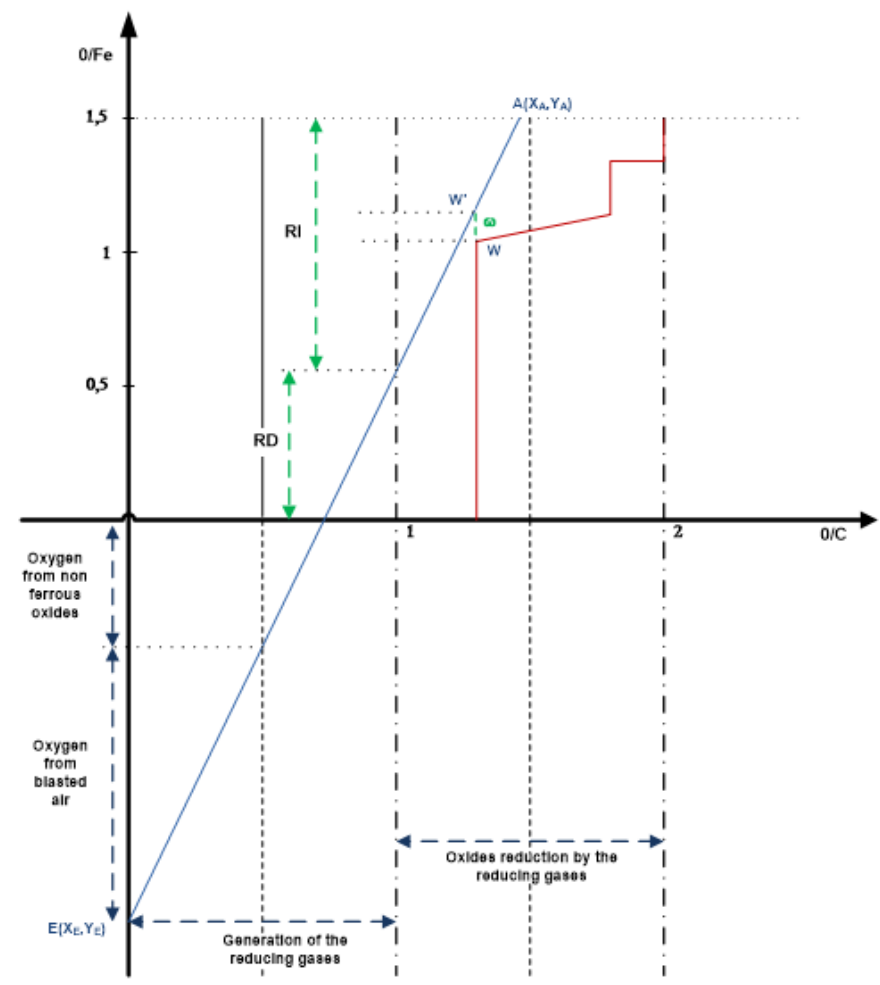

Figura 21 - Diagrama Operacional de Rist.

No gráfico operacional podemos verificar o seguinte:

- As condições de operação do forno são de regime permanente, ou seja, não existe acúmulo de massa no forno. Desta forma são balanceados o carbono, o ferro e o oxigênio.

- Os três elementos anteriores entram e saem da seguinte forma: ${ }^{(20)}$

$\begin{array}{cll}\text { Elemento } & \text { Forma de entrada } & \text { Forma de saída } \\ \mathrm{Fe} & \text { Óxidos de ferro } & \text { Ferro-Gusa } \\ \mathrm{C} & \text { Coque } & \mathrm{CO}, \mathrm{CO}_{2}, \mathrm{Cgusa} \\ \mathrm{O} & \text { Óxidos ferrosos e não ferrosos } & \mathrm{CO}, \mathrm{CO}_{2}\end{array}$

De tal forma: é mínimo o ferro perdido na escória $(0,5 \%)$, o teor de Oxigênio é desprezível no gusa. 
- Na figura 21 a linha $\overline{A E}$ representa o processo de redução e é deduzida do balanço de oxigênio.

- A gradiente da linha $\overline{A E}$ é igual à razão entre o número de moles do gás redutor e o número de átomos de ferro.

- O ponto $\mathrm{W}$ é importante, ele possui abscissa definida pela razão $\mathrm{CO}_{2} /\left(\mathrm{CO}+\mathrm{CO}_{2}\right)$.

- No ponto E a concentração de $\mathrm{CO}_{2}$ é zero.

- O ponto A representa os átomos de oxigênio por átomo de ferro na carga na entrada do Alto-Forno.

- A fração de Redução Direta pode ser encontrada a partir da interseção da linha $\overline{A E}$ com um eixo vertical projetado num valor de 1 para o eixo das abscissas.

- Valores para o eixo $\mathrm{X}$ entre: $0<\mathrm{X} \leq 1$ representam a região de formação dos gases $\mathrm{CO}$ e $\mathrm{H}_{2}$.

- Valores para o eixo $\mathrm{X}$ entre: $1<\mathrm{X} \leq 2$ representam a região onde tem conversão dos gases $\mathrm{CO}$ em $\mathrm{CO}_{2}$ e $\mathrm{H}_{2}$ a $\mathrm{H}_{2} \mathrm{O}$.

\subsubsection{3. \\ Congelamento e Dissecação do Alto-Forno}

Estudos de dissecação de Altos-Fornos foram realizados na década de 1970 no Japão, onde Altos-Fornos em operação foram congelados. Nestes estudos muito aprofundados e com muito rigor científico foram dissecados três fornos japoneses da Nippon Steel Corporation (NSC): Forno No 5 de Higashida em 1968; Forno $\mathrm{N}^{\mathrm{o}} 1$ de Hirohata em 1970 e Forno $\mathrm{N}^{\circ} 4$ de Kukioka em 1971. Os três Altos-Fornos foram resfriados em estágio de operação normal utilizando água para resfriamento. Foi feita uma amostragem da carga, analisada e avaliada desde o topo do forno até o cadinho ${ }^{(6,42)}$.

Este estudo permitiu verificar a existência de camadas de minério de ferro e de coque com apenas diminuição em sua espessura até regiões onde a alta temperatura amolece e funde o ferro.

Sondagens com fornos em operação e diversos outros estudos em vários países permitiram aperfeiçoar as conclusões a partir das técnicas de dissecação. 
Como resultado destas dissecações pode-se definir cinco zonas internas no Alto-Forno (figura 22).

\subsubsection{4.}

\section{Zonas Internas do Alto-Forno}

\subsubsection{1. Zona Granular}

Onde os materiais se encontram como sólidos (minérios e coque) e gases (redutores: $\mathrm{CO}, \mathrm{H}_{2}$ e oxidados; $\mathrm{CO}_{2}, \mathrm{H}_{2} \mathrm{O}$ ). $\mathrm{O}$ minério e o coque mantêm a sua configuração em camadas.

O combustível sólido (Carvão vegetal ou coque) ocupa a maior parte do volume devido a sua menor densidade, a permeabilidade das camadas da carga são um fator importante que devem ser mantidas considerando as caraterísticas dos materiais para assegurar o fluxo gasoso ascendente.

\subsubsection{2.}

\section{Zona Coesiva ou de Amolecimento}

Esta região está formada por camadas de massas semifundidas de partículas de minério de ferro (impermeáveis ao fluxo gasoso), e camadas de coque sólido por onde passa preferencialmente o fluxo gasoso. Esta região responde pela maior perda da pressão.

A maior parte de redução dos óxidos e da reação de gaseificação do carbono ocorre nesta zona. Existe uma região dentro da zona coesiva onde a temperatura do gás e da carga é constante e quase a mesma $\left(950{ }^{\circ} \mathrm{C}\right.$ aprox. para processos com coque e de $800{ }^{\circ} \mathrm{C}$ aprox. em processos com carvão vegetal), região denominada zona de reserva térmica. 


\subsubsection{3.}

\section{Zona de Gotejamento}

Contém coque na forma sólida por cujos interstícios escoam o gusa e a escória. Na decida do gusa ao cadinho acontecem as reações que incorporam os elementos de liga. Esta zona tem temperatura entre $1400{ }^{\circ} \mathrm{C}$ e $1800{ }^{\circ} \mathrm{C}$.

Divide-se em:

Região de coque ativo: que contém o coque para ser queimado nas ventaneiras.

Região do homem morto: que basicamente contém o carbono que será incorporado ao gusa.

\subsubsection{4. \\ Zona de Combustão}

É uma região parcialmente vazia frente às ventaneiras devido à elevada energia cinética do sopro do ar quente, aqui as partículas de coque são queimadas gerando o gás redutor $\left(\mathrm{CO}, \mathrm{H}_{2}\right)$ e energia térmica. A temperatura nesta zona alcança de $2000^{\circ} \mathrm{C}$ a $2400{ }^{\circ} \mathrm{C}$.

\subsubsection{5.} Zona de Cadinho

Zona preenchida com coque granulado, por cujos interstícios se depositam o gusa e a escória que se separam em duas camadas por diferença de densidade. 


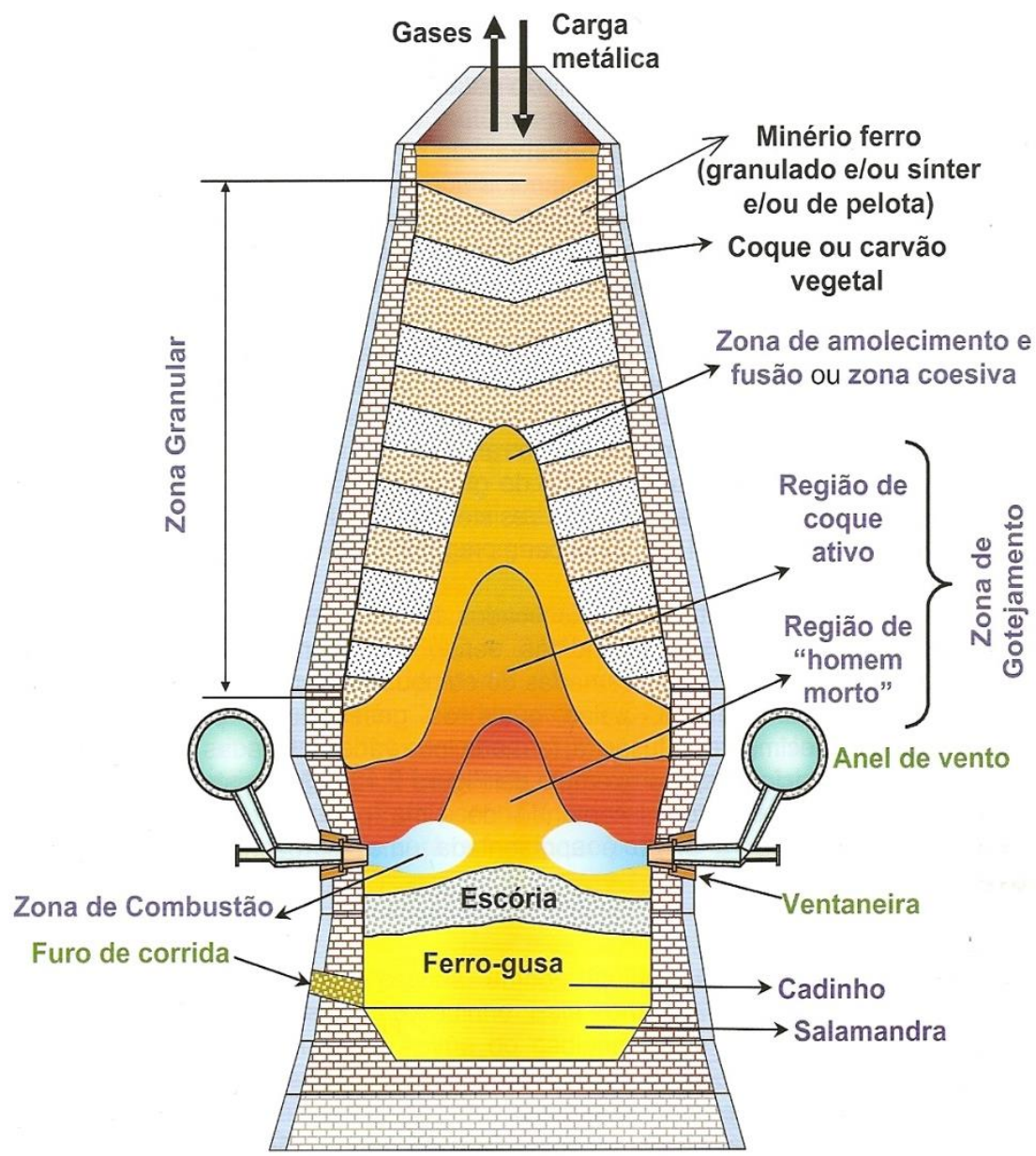

Figura 22- Zonas Internas do Alto-Forno ${ }^{(6)}$.

\section{3.}

Termoquímica do Alto-Forno

\subsection{1.}

Reações Químicas do Processo de Redução dos Óxidos de Ferro

Numerosos são as reações químicas que acontecem no Alto-Forno, a continuação se apresenta as principais reações de redução o óxido de ferro pelos redutores $\mathrm{CO}$ e $\mathrm{H}_{2}{ }^{(32,41)}$ :

- Reações dos Óxidos de Ferro com o Redutor CO e C

$$
\begin{aligned}
& 3 \mathrm{Fe}_{2} \mathrm{O}_{3(\mathrm{~s})}+\mathrm{CO}_{(\mathrm{g})}=2 \mathrm{Fe}_{3} \mathrm{O}_{4(\mathrm{~s})}+\mathrm{CO}_{2(\mathrm{~g})} \quad 25-1457^{\circ} \mathrm{C} \quad \Delta \mathrm{H}=(-10,747 \\
& -10,064) \mathrm{kcal} / \mathrm{mol} \\
& \mathrm{Fe}_{3} \mathrm{O}_{4(\mathrm{~s})}+\mathrm{CO}_{(\mathrm{g})}=3 \mathrm{FeO}_{(\mathrm{s})}+\mathrm{CO}_{2(\mathrm{~g})} \quad 25-560^{\circ} \mathrm{C} \quad \Delta \mathrm{H}=(7,344 ;
\end{aligned}
$$


$3,545) \mathrm{kcal} / \mathrm{mol}$

$\mathrm{Fe}_{3} \mathrm{O}_{4(\mathrm{~s})}+\mathrm{CO}_{(\mathrm{g})}=3 \mathrm{FeO}_{(\mathrm{L})}+\mathrm{CO}_{2(\mathrm{~g})}$

1424- $1597^{\circ} \mathrm{C} \Delta \mathrm{H}=(21,634$;

$-10,449) \mathrm{kcal} / \mathrm{mol}$

$\mathrm{Fe}_{3} \mathrm{O}_{4(\mathrm{~s})}+4 \mathrm{CO}_{(\mathrm{g})}=3 \mathrm{Fe}_{(\mathrm{s})}+4 \mathrm{CO}_{2(\mathrm{~g})}$

$25-560{ }^{\circ} \mathrm{C} \quad \Delta \mathrm{H}=(-3,909 ;$

-10,427) kcal/mol

$\mathrm{FeO}_{(\mathrm{s})}+\mathrm{CO}_{(\mathrm{g})}=\mathrm{Fe}_{(\mathrm{s})}+\mathrm{CO}_{2(\mathrm{~g})}$

$25-1371{ }^{\circ} \mathrm{C} \quad \Delta \mathrm{H}=(-3,451 ;$

-4,074) kcal/mol

$\mathrm{FeO}_{(\mathrm{L})}+\mathrm{CO}_{(\mathrm{g})}=\mathrm{Fe}_{(\mathrm{s})}+\mathrm{CO}_{2(\mathrm{~g})}$

$1371-1537^{\circ} \mathrm{C} \Delta \mathrm{H}=(-4,074$;

$-9,780) \mathrm{kcal} / \mathrm{mol}$

$\mathrm{FeO}_{(\mathrm{L})}+\mathrm{CO}_{(\mathrm{g})}=\mathrm{Fe}_{(\mathrm{L})}+\mathrm{CO}_{2(\mathrm{~g})}$

$>1537{ }^{\circ} \mathrm{C} \quad \Delta \mathrm{H}>-9,780 \mathrm{kcal} / \mathrm{mol}$

$3 \mathrm{Fe}_{2} \mathrm{O}_{3(\mathrm{~s})}+\mathrm{C}_{(\mathrm{s})}=2 \mathrm{Fe}_{3} \mathrm{O}_{4(\mathrm{~s})}+\mathrm{CO}_{(\mathrm{g})}$

$25-1457^{\circ} \mathrm{C} \quad \Delta \mathrm{H}=(30,463 ;$

28,736) $\mathrm{kcal} / \mathrm{mol}$

$\mathrm{Fe}_{3} \mathrm{O}_{4(\mathrm{~s})}+\mathrm{C}_{(\mathrm{s})}=3 \mathrm{FeO}_{(\mathrm{s})}+\mathrm{CO}_{(\mathrm{g})}$

$25-560{ }^{\circ} \mathrm{C} \quad \Delta \mathrm{H}=(48,554 ;$

$44,669) \mathrm{kcal} / \mathrm{mol}$

$\mathrm{FeO}_{(\mathrm{s})}+\mathrm{C}_{(\mathrm{s})}=\mathrm{Fe}_{(\mathrm{s})}+\mathrm{CO}_{(\mathrm{g})}$

$25-1371^{\circ} \mathrm{C} \quad \Delta \mathrm{H}=(37,459$;

$34,978) \mathrm{kcal} / \mathrm{mol}$

- Reações dos Óxidos de Ferro com o Redutor $\mathrm{H}_{2}$

$3 \mathrm{Fe}_{2} \mathrm{O}_{3(\mathrm{~s})}+\mathrm{H}_{2(\mathrm{~g})}=2 \mathrm{Fe}_{3} \mathrm{O}_{4(\mathrm{~s})}+\mathrm{H}_{2} \mathrm{O}_{(\mathrm{g})} \quad 25-1457^{\circ} \mathrm{C} \quad \Delta \mathrm{H}=(-0,914$

$-3,259) \mathrm{kcal} / \mathrm{mol}$

$\mathrm{Fe}_{3} \mathrm{O}_{4(\mathrm{~s})}+\mathrm{H}_{2(\mathrm{~g})}=3 \mathrm{FeO}_{(\mathrm{s})}+\mathrm{H}_{2} \mathrm{O}_{(\mathrm{g})}$

$25-560{ }^{\circ} \mathrm{C} \quad \Delta \mathrm{H}=(17,176$;

$12,291) \mathrm{kcal} / \mathrm{mol}$

$\mathrm{Fe}_{3} \mathrm{O}_{4(\mathrm{~s})}+\mathrm{H}_{2(\mathrm{~g})}=3 \mathrm{FeO}_{(\mathrm{L})}+\mathrm{H}_{2} \mathrm{O}_{(\mathrm{g})}$

$1424-1597^{\circ} \mathrm{C} \Delta \mathrm{H}=(28,496$;

$-3,881) \mathrm{kcal} / \mathrm{mol}$

$\mathrm{Fe}_{3} \mathrm{O}_{4(\mathrm{~s})}+4 \mathrm{H}_{2(\mathrm{~g})}=3 \mathrm{Fe}_{(\mathrm{s})}+4 \mathrm{H}_{2} \mathrm{O}_{(\mathrm{g})}$

$25-560{ }^{\circ} \mathrm{C} \quad \Delta \mathrm{H}=(35,420 ;$

$24,558) \mathrm{kcal} / \mathrm{mol}$

$\mathrm{FeO}_{(\mathrm{s})}+\mathrm{H}_{2(\mathrm{~g})}=\mathrm{Fe}_{(\mathrm{s})}+\mathrm{H}_{2} \mathrm{O}_{(\mathrm{g})}$

$25-1371{ }^{\circ} \mathrm{C} \quad \Delta \mathrm{H}=(6,081$;

$2,882) \mathrm{kcal} / \mathrm{mol}$

$\mathrm{FeO}_{(\mathrm{L})}+\mathrm{H}_{2(\mathrm{~g})}=\mathrm{Fe}_{(\mathrm{s})}+\mathrm{H}_{2} \mathrm{O}_{(\mathrm{g})}$

$1371-1537^{\circ} \mathrm{C} \Delta \mathrm{H}=(2,882$;

$-3,112) \mathrm{kcal} / \mathrm{mol}$ 


$$
\mathrm{FeO}_{(\mathrm{L})}+\mathrm{H}_{2(\mathrm{~g})}=\mathrm{Fe}_{(\mathrm{L})}+\mathrm{H}_{2} \mathrm{O}_{(\mathrm{g})} \quad>1537^{\circ} \mathrm{C} \quad \Delta \mathrm{H}>-0,306 \mathrm{kcal} / \mathrm{mol}
$$

- Reações do Carbono com o $\mathrm{CO}_{2}$ e com a $\mathrm{H}_{2} \mathrm{O}$

$$
\begin{array}{lrr}
\mathrm{CO}_{2(\mathrm{~g})}+\mathrm{C}_{(\mathrm{s})}=2 \mathrm{CO}_{(\mathrm{g})} & >950{ }^{\circ} \mathrm{C} & \Delta \mathrm{H}<40,224 \mathrm{kcal} / \mathrm{mol} \\
\mathrm{C}_{(\mathrm{s})}+\mathrm{H}_{2} \mathrm{O}_{(\mathrm{v})}=\mathrm{CO}_{(\mathrm{g})}+\mathrm{H}_{2(\mathrm{~g})} & 1000^{\circ} \mathrm{C} & \Delta \mathrm{H}=32,397 \mathrm{kcal} / \mathrm{mol}
\end{array}
$$

\section{- Reações Indiretas.}

São denominadas assim as reações dos óxidos ferrosos com o CO e que tem como produto $\mathrm{CO}_{2}$. Estas reações são as que foram mostradas nas equações (1) a (7).

\section{- Reações Diretas}

As Reações Diretas são reações dos óxidos ferrosos com o carbono, estas reações ocorrem com intermediação da reação de Boudouard e tem como produto o CO. Pode-se exemplificar uma reação direta utilizando a reação da equação (5) com a equação (18) ${ }^{(23)}$.

$$
\begin{array}{ll}
\mathrm{FeO}_{(\mathrm{s})}+\mathrm{CO}_{(\mathrm{g})}=\mathrm{Fe}_{(\mathrm{s})}+\mathrm{CO}_{2(\mathrm{~g})} & \text { Reação Indireta } \\
\mathrm{CO}_{2(\mathrm{~g})}+\mathrm{C}_{(\mathrm{s})}=2 \mathrm{CO}_{(\mathrm{g})} & \text { Reação de Boudouard }
\end{array}
$$

$$
\mathrm{FeO}_{(\mathrm{s})}+\mathrm{C}_{(\mathrm{s})}=\mathrm{Fe}_{(\mathrm{s})}+\mathrm{CO}_{(\mathrm{g})} \quad \text { Reação Direta }
$$

\subsubsection{Diagramas de Predominância}

Considerando as equações das reações dos óxidos de ferro com o CO (equações 1 ao 7) e com $\mathrm{H}_{2}$, (equações 11 ao 17) podem ser traçadas as curvas da figura 19.1 de acordo com a equação 19.1(Apêndice I). 
A função que determina as diferentes curvas de equilíbrio dos diversos óxidos é dependente das atividades dos óxidos e da temperatura, as curvas também estão limitadas nos intervalos de temperatura das referidas equações.

$$
N_{R}=\left[1+\frac{a_{M O_{2}}}{a_{M O}} \times e^{\frac{-\Delta G^{\circ}}{R T}}\right]^{-1}
$$

Onde:

MO: são os óxidos de ferro nos produtos das reações 1 ao 7 ou 11 ao 17, para o caso da redução por $\mathrm{CO}$ ou por $\mathrm{H}_{2}$ respectivamente.

$\mathrm{MO}_{2}$ : são os óxidos de ferro nos reagentes das reações 1 ao 7 ou 11 ao 17, para o caso da redução por $\mathrm{CO}$ ou por $\mathrm{H}_{2}$, respectivamente.

$a_{\mathrm{MO}_{2}}$ : é a atividade do óxido no reagente.

$a_{M O}$ : é a atividade do óxido no produto.

$-\Delta G^{\circ}$ : é a energia livre da reação.

$R$ : é constante dos gases ideais.

$T$ : é a temperatura na que acontece a reação.

A figura 23 mostra o diagrama de Predominância-Operacional para a redução com o gás $\mathrm{CO}$, onde se podem apreciar as regiões de predominância dos diferentes compostos do Ferro.

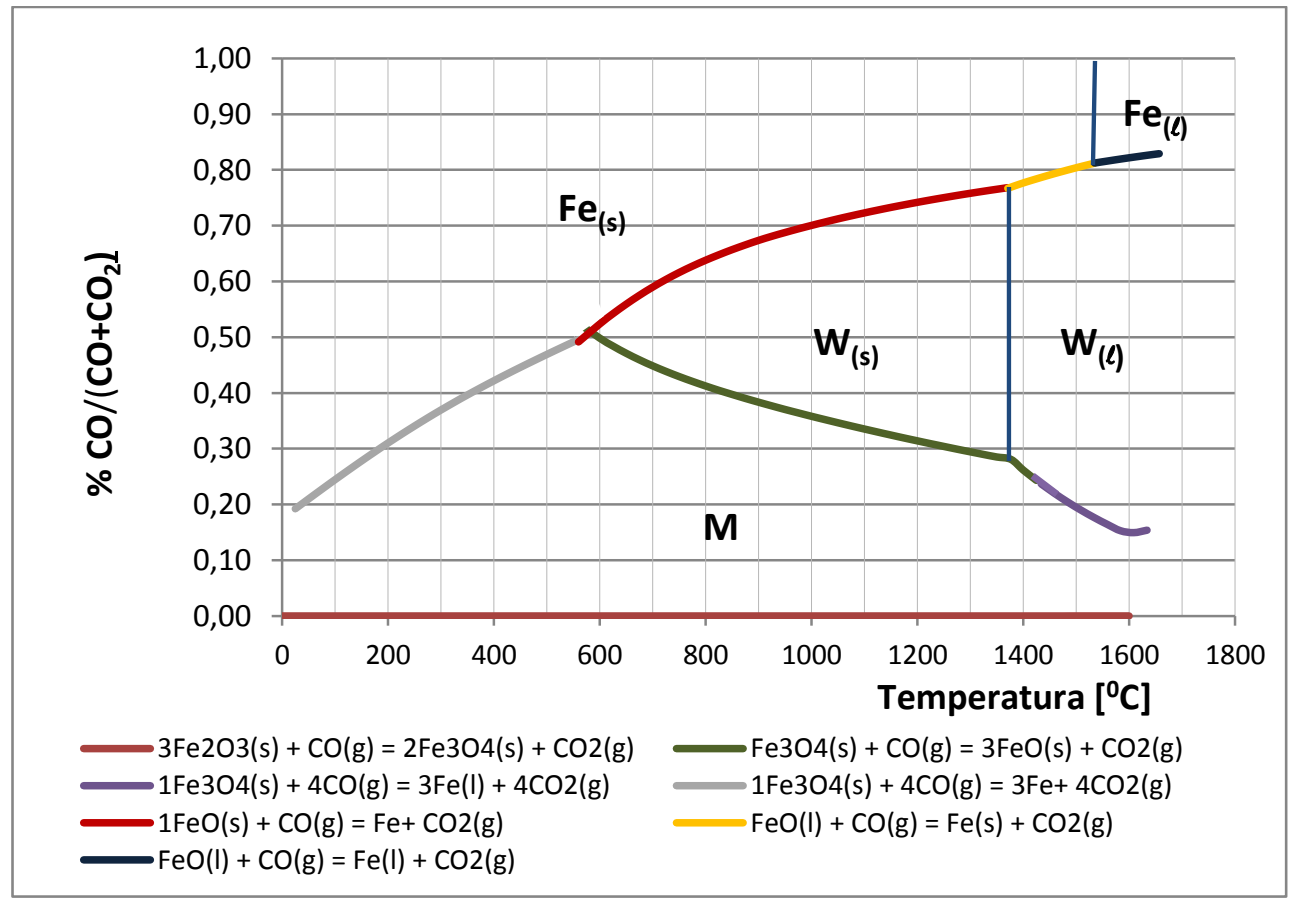

Figura 23 - Diagrama de Predominância-Operacional para a redução com CO. 
A figura 24 mostra o diagrama de Predominância-Operacional para a redução com o gás $\mathrm{H}_{2}$, onde se podem apreciar as regiões de predominância dos diferentes compostos do Ferro.

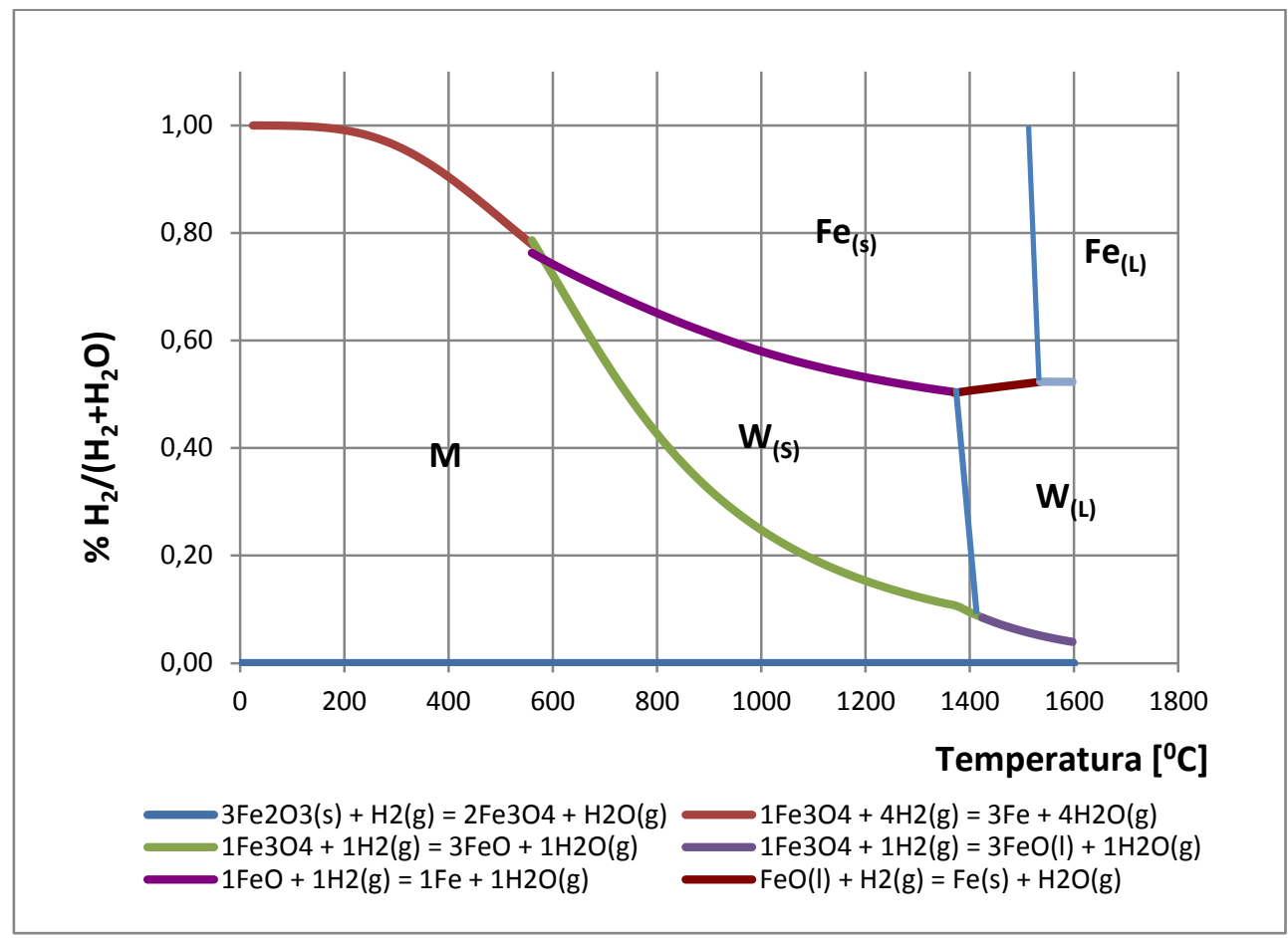

Figura 24 - Diagrama de Predominância-Operacional para a redução com $\mathrm{H}_{2}$.

\subsection{3.}

\section{Balanço de Massa}

Os balanços de massa são uma forma de manter a contabilidade de um processo que se encontra já em operação. A equação básica para os balanços de massa é a lei da conservação da massa mostrada na equação 21 , foi enunciada pelo químico Antoine Lavoisier que na letra diz: "Na natureza nada se cria, nada se perde, tudo se transforma" (22).

Para a análise e equacionamento do balanço de massa recomenda-se ${ }^{\text {(24): }}$

- Formar um diagrama detalhado do processo (por exemplo, figura 25).

- Delimitar, com uma linha tracejada, a parte do processo que será estudada.

- Reunir todas as equações possíveis, relacionando os diversos constituintes de todas as correntes. 
- Quantificar todas as correntes conhecidas.

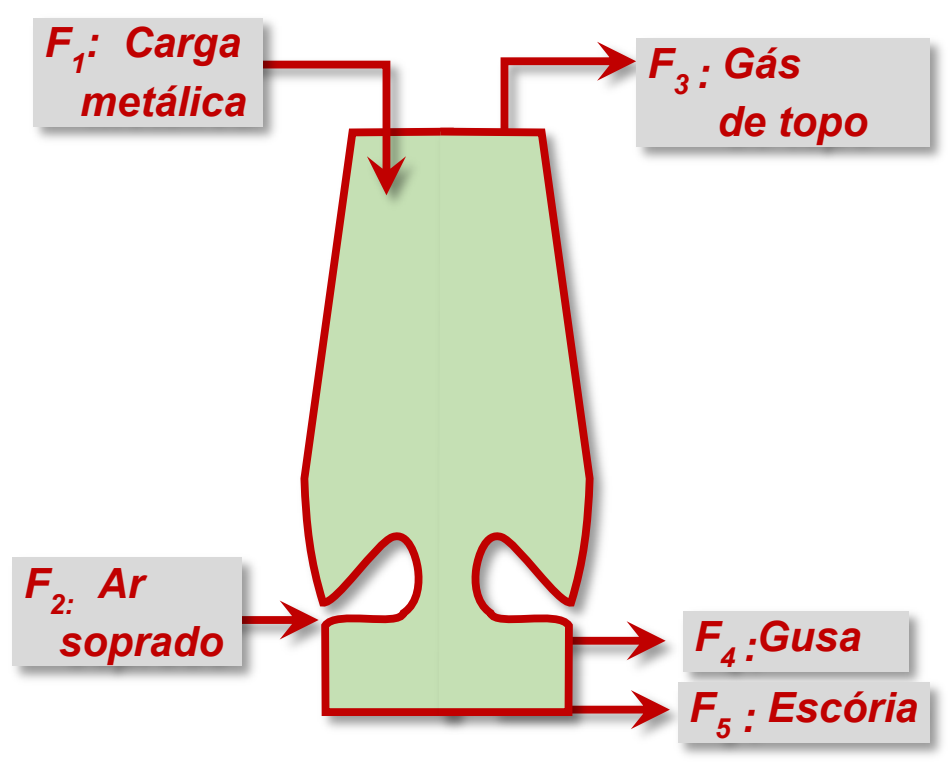

Figura 25 - Diagrama do Alto Forno para Balanço de Massa.

$$
\begin{gathered}
\text { Entrada de massa }=\text { Saída de massa }+ \text { Acumulação de massa }{ }^{(32)} \\
\sum_{i=1}^{i=n} m_{i}(\% X)=\sum_{j=1}^{j=m} m_{j}(\% X)+\Delta m_{x}
\end{gathered}
$$

Onde :

$\mathrm{m}_{\mathrm{i}}$ : $\quad$ é a massa de cada tipo de matéria-prima que ingressa no sistema.

$\mathrm{m}_{\mathrm{j}}$ : $\quad$ é a massa de cada produto que sai do sistema depois de um intervalo de tempo.

\%X: $\quad$ é a fração em peso do elemento $\mathrm{X}$ na matéria-prima ou no produto.

$\Delta \mathrm{m}_{\mathrm{x}}$ : é a massa que se acumula no processo.

No sistema definido podem ser realizados: um balanço global e os balanços individuais para cada uma das espécies químicas. Assim sendo, será obtido um sistema de equações. 
A soma dos balanços individuais constitui o balanço global que sempre deve ser satisfeito. Os balanços devem ser feitos considerando uma base de cálculo.

\subsection{4.}

\section{Balanço de Energia}

O balanço energético é imprescindível nos estudos de viabilidade econômica de um processo. Porém não apenas por questões econômicas, mas também como requisito para o projeto de equipamento, estudos de impacto ambiental e desenvolvimento de novos processos.

O fundamento principal do balanço de energia está na primeira lei da termodinâmica, que afirma que a variação do conteúdo energético de um sistema fechado é a diferença entre o calor fornecido a este e o trabalho realizado pelo mesmo (equação 22) ${ }^{(17,22,36,38)}$.

$$
\Delta U=q-w
$$

Nos balanços de energia precisamos considerar os seguintes fenômenos que podem levar a variações da entalpia:

- Variações de temperaturas

- Transformações alotrópicas

- Transformações de fases

- Reações químicas

- Solubilidades

Logo para cada um destes fenômenos serão realizados os estudos de variação da entalpia $(\Delta \mathrm{H})$. no Sistema.

- Variação de Temperatura de Qualquer Substância que Esteja

$\mathrm{Na}$ análise do Alto-Forno não consideramos o uso da capacidade calorífica a volume constante $(\mathrm{Cv})$. 
Logo a partir da definição da capacidade calorífica a pressão constante (equação 23):

$$
C p=\left(\frac{\partial H}{\partial T}\right)_{P, n}
$$

Pode ser feita a integração considerando os limites dos estados inicias (1) e finais (2) que podem corresponder ao aquecimento de um material (temperatura inicial e final respectivamente). Assim teremos:

$$
\Delta H=\int_{1}^{2} C p^{\propto} d T
$$

Onde a equação 24 é válida desde que não exista mudança de fase ou transformações na estrutura do material.

\section{- Transformações Alotrópicas.}

Um fenômeno de variação alotrópica (transformação da estrutura) pode ser observado na figura 26. Um exemplo de este tipo de variação alotrópica é o passo de $\mathrm{Fe}^{\alpha}$ (ferro alfa) com estrutura cúbica de corpo centrado para $\mathrm{Fe}^{\gamma}$ (ferro gama ou austenita) com estrutura cúbica de faces centradas que acontece no mesmo estado físico sólido ( $912^{\circ} \mathrm{C}$ aprox.).

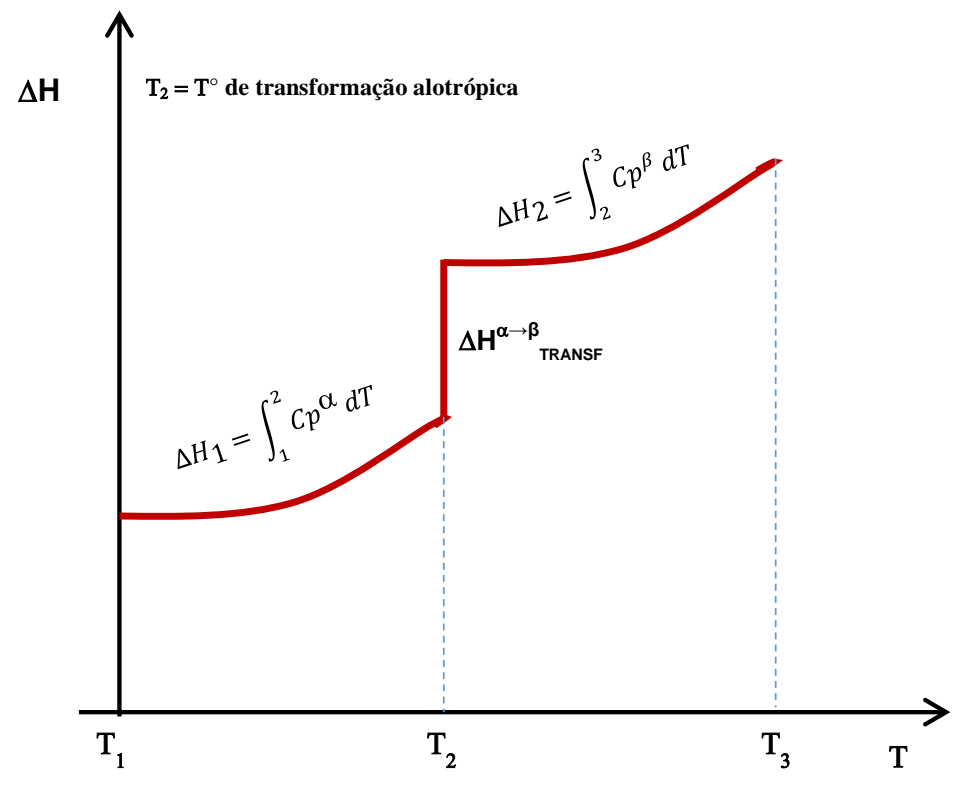

Figura 26 - Variação da Entalpia com Fenômeno de Transformação Alotrópica. 
Considerando o fenômeno de transformação alotrópica que acontece na $\mathrm{T}_{2}$, teremos a seguinte expressão para a variação da entalpia:

$$
\Delta H=\int_{1}^{2} C p^{\alpha} d T+\Delta H_{\text {transf }}^{\alpha \rightarrow \beta}+\int_{2}^{3} C p^{\beta} d T
$$

\section{- Transformações de Fase.}

Um fenômeno de mudança de fase, incluindo a variação alotrópica pode ser exemplificado na figura 27. A mudança de estado físico para o $\mathrm{Fe}$ puro, por exemplo, acontece a $1538{ }^{\circ} \mathrm{C}$ aprox. quando o ferro delta de estrutura cúbica de corpo centrado torna-se amorfa, sem ordenação cristalina, caracterizando o estado líquido.

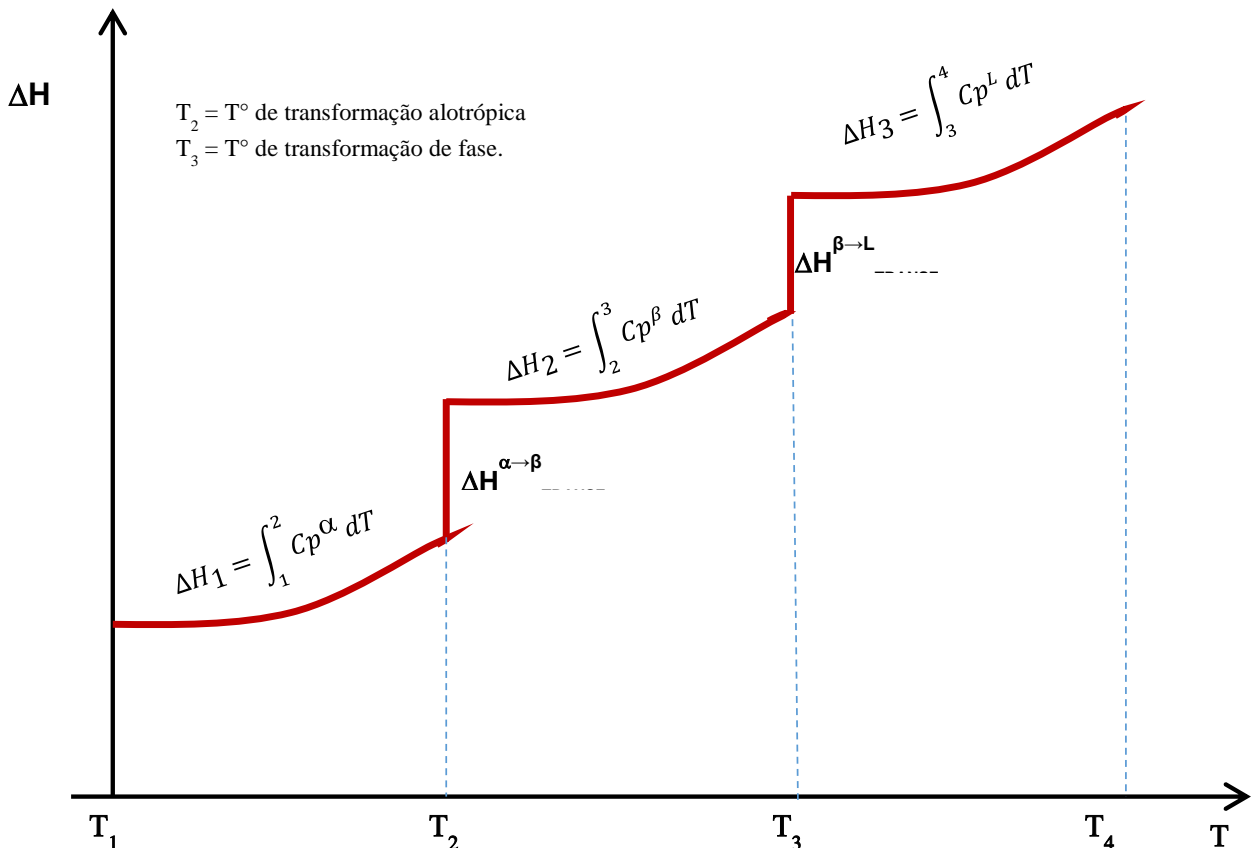

Figura 27 - Variação da Entalpia com Fenômeno de Transformação Alotrópica e Mudança de Fase. 
Considerando o fenômeno de transformação alotrópica que acontece na $T_{2}$, e a mudança de fase na temperatura $T_{3}$ teremos a seguinte expressão para a variação de entalpia:

$\Delta H=\int_{1}^{2} C p^{\alpha} d T+\Delta H_{\text {transf }}^{\alpha \rightarrow \beta}+\int_{2}^{3} C p^{\beta} d T+\Delta H_{\text {transf }}^{\beta \rightarrow \mathrm{L}}+\int_{3}^{4} C p^{L} d T$

- Reações Químicas.

Considerando uma reação do tipo:

$$
\mathrm{mA}+\mathrm{nB} \leftrightarrow \mathrm{rD}+\mathrm{sE}
$$

A variação da entalpia para a reação (27) para uma temperatura de $298 \mathrm{~K}$ será expresso como:

$$
\left.\Delta H_{298}\right|_{R x}=\left.\sum \Delta H_{298}\right|_{\text {prod }}-\left.\sum \Delta H_{298}\right|_{\text {reagentes }}
$$

Avaliando para temperaturas diferentes a $298 \mathrm{~K}$, por exemplo, na temperatura Ti onde ocorre a reação teremos:

$$
\left.\Delta H_{T i}\right|_{R x}=\left.\Delta H_{298}\right|_{R x}+\left.\sum \Delta H_{298}\right|_{\text {prod }} ^{T i}-\left.\sum \Delta H_{298}\right|_{\text {reagentes }} ^{T i}
$$

\section{- Solubilidades.}

As variações da entalpia de solubilização tanto do metal dissolvido [M] como do óxido metálico dissolvido (MO) são tabelados e conhecidos experimentalmente, e são simbolizados como na equação (30).

$$
\Delta \mathrm{H}_{\mathrm{i}}^{\text {solub }}
$$

\section{4 .}

\section{Operação do Alto-Forno}

\subsection{1.}

\section{Considerações Gerais}

Desde o pátio de estocagem ou dos processos anteriores (coqueria e sinterização), são transportadas as matérias-primas (Sínter, pelotas, minério 
granulado, coque, fundentes, etc.) para a casa de silos e armazenados em silos separados. As matérias-primas são pesadas e logo carregadas no topo do AltoForno (mediante um carro skip ou uma correia transportadora) baseados em regras predeterminadas de modo a obter a composição química desejada do ferro-gusa e da escória a partir das análises químicas de cada material.

No topo do Alto-Forno o material é recebido na tremonha, em seguida são carregados no interior do forno por meio de um sistema de dois estágios de cones que permitem a selagem dos gases e a distribuição circunferencial dos materiais (outro tipo de descarregamento inclui uma calha rotativa). $\mathrm{O}$ carregamento dos materiais assegura a distribuição em camadas separadas de coque ${ }^{(4,6)}$.

\subsection{2.}

\section{Variáveis de Operação do Alto-Forno}

A operação normal de um Alto-Forno procura obter e, sobretudo manter uma boa estabilidade da marcha do Alto-Forno. Para conseguir este objetivo é preciso manter condições térmicas, e de permeabilidade, condições que serão atingidas mediante monitoramento e controle de diversas variáveis que auxiliarão no processo decisório automatizado desde a sala de controle ${ }^{(34,45)}$.

Algumas destas variáveis na operação do Alto-Forno podem ser descritas como: $(16,18)$

Vazão de ar soprado: Quantidade de ar aquecido soprado para o interior do Alto-Forno através das ventaneiras $\left(\mathrm{Nm}^{3} / \mathrm{h}\right)$. Um aumento na vazão do ar soprado gera um aumento na produção, porém otimiza o coke-rate.

Temperatura do ar de soprado: É a temperatura do ar de sopro ao ingressar pelas ventaneiras do Alto-Forno. $\mathrm{O}$ aumento em $100^{\circ} \mathrm{C}$ da temperatura do ar de sopro equivale a retirar de 15 a $20 \mathrm{~kg}$ de carvão vegetal ou coque por tonelada de ferro, e tem como efeito um incremento na temperatura do gusa. 
Ritmo de carregamento: Frequência de carregamento dos materiais pelo topo do forno. Afeta a distribuição gasosa no interior do forno podendo melhorar a utilização de gás redutor.

Ritmo de vazamento de gusa e escória: Frequência de retirada do ferro gusa do Alto-Forno. Afeta a reserva térmica, por consequência pode produzir engaiolamento quando o vazamento e lento e queima de ventaneiras, caso seja rápido demais.

Taxa de injeção de vapor: É a quantidade de agua em forma de vapor que ingressa ao Alto-Forno pelas ventaneiras. A diminuição de $1 \mathrm{~g}$ de vapor injetado, ocasiona aproximadamente $1 \mathrm{~kg}$ a menos de consumo de coque, melhora o coquerate e aumenta a temperatura da gusa (a resposta é mais rápida que a do aumento da temperatura do ar soprado).

Pressão de topo: É a pressão exercida pelos gases no interior do AltoForno, medido no topo do forno. $\mathrm{O}$ aumento da densidade do gás no interior do alto forno diminui a velocidade ascendente dos gases, melhora as trocas de calor e massa e o coque-rate.

\subsection{3. Geladas Do Alto-Forno}

A operação normal de um Alto-Forno é em forma continua, a não ser para realizar manutenções programadas em equipamentos considerados críticos. Para uma boa estabilidade da marcha do Alto-Forno é necessário que a operação seja efetuada com boa produtividade, segurança para os funcionários, estabilidade operacional, menor consumo de combustível, e sem danos ao meio-ambiente. ${ }^{(1,7)}$

A estabilidade da marcha do Alto-Forno é conseguida com o controle adequado do nível térmico, permeabilidade do forno e do esgotamento do cadinho. Assim o controle operacional do processo no Alto-Forno é principalmente feito através do controle de nível térmico. O resfriamento do cadinho do Alto-Forno (gelada) é indesejável e, caso ocorra sua recuperação é difícil e pode gerar prejuízos para a usina siderúrgica. O nível térmico do forno é 
monitorado constantemente e dentre as causas que podem afetar o nível térmico, temos: ${ }^{(6)}$

- Vazamento de água

- Descida irregular da carga

- Erro no cálculo do leito de fusão

- Erro na aferição e/ou calibração de balanças

- Variações nas características dos materiais

O nível térmico é monitorado principalmente pela temperatura do ferro-gusa além de observações na composição do ferro-gusa como teores de: silício, carbono, enxofre, manganês. Estes parâmetros mostram a variação do nível térmico após a ocorrência, o que significa que não é uma boa ajuda no controle efetivo para a conservação do nível térmico do Alto-Forno.

Outros parâmetros como a pressão e temperatura do gás de topo, comportamento da sonda que acompanha a descida da carga, permitem um melhor controle preventivo, mas é de fato uma necessidade a falta de estudos e modelos preditivos destes comportamentos de nível térmico que levaram a elaboração do presente trabalho ${ }^{(4,6)}$.

Na prática os fenômenos de resfriamento do forno só são detectados após já terem afetado em definitivo a marcha normal do forno o que resulta numa significativa perda de produtividade do equipamento, devido à necessidade de algumas horas para a retomada da normalidade da operação. Assim, o modelo a desenvolver permitirá através de seus "outputs" gráficos acompanharem a dinâmica de tais fenômenos, ou seja, a detecção do movimento da operação do forno na direção daquelas inviabilidades termodinâmicas, conferindo ao processo maior segurança operacional.

\subsection{4.}

\section{Cenário atual e visão da siderurgia}

O setor siderúrgico brasileiro vive, hoje, uma dramática crise por uma conjugação de fatores conjunturais e estruturais, dos fatores conjunturais podemos mencionar as quedas significativas das vendas para os setores de construção e a indústria automotiva, assim como o aumento da participação do aço chinês e o 
excedente de capacidade de produção de aço no mundo. Por outro lado, os fatores estruturais como elevação do custo de energia elétrica, juros altos, cumulativa de impostos e carga tributária extremamente elevada, acentuam a crise do setor ${ }^{(25,26)}$. A saída momentânea encontrada está sendo por meio das exportações que representam mais de $40 \%$ em volume das vendas totais do setor ${ }^{(25,26)}$.

O cenário siderúrgico atual apresenta as seguintes variáveis relevantes ${ }^{(27)}$ :

- Abertura crescente da economia;

- Acirramento da competição e persistência do protecionismo no mercado internacional;

- Aumento da concentração e poder de mercado dos segmentos fornecedores da siderurgia e consumidores de aço;

- Novos acordos de comércio e maior integração das economias;

- Avanços tecnológicos contínuos com fortes impactos na qualidade, produtividade e competição entre materiais;

- Exigências sociais e ambientais crescentes;

- Disponibilidade de serviços de logística adequados;

Neste cenário os principais desafios são ${ }^{(27,28)}$ :

- Adequação as novas exigências ambientais;

- Crescente competição com materiais sucedâneos e substitutos do aço;

- Superação de barreiras de acesso a mercados externos;

- Atualização tecnológica permanente;

- Desenvolvimento de métodos gerenciais e de relações do trabalho ajustados a novas demandas da sociedade e do mercado;

- Aprimoramento de mecanismos de defesa contra práticas de comércio desleal;

- Maior disseminação de informações quanto à importância do aço e da siderurgia brasileira. 
4.

Desenvolvimento

\section{1.}

\section{Considerações}

O desenvolvimento do modelo que gera a Superfície de Mínimo Consumo de Carbono (SMCC) estará baseado no cumprimento dos balanços de massa e energia assim como no estudo do equilíbrio das reações.

Por outro lado, é considerada a divisão do Alto-Forno em duas zonas (figura 28): Zona de Preparação (onde ocorrem as Reações Indiretas da hematita, magnetita até a wustita) e Zona de Elaboração (onde ocorrem as Reduções Diretas dos óxidos ferrosos e não ferrosos).

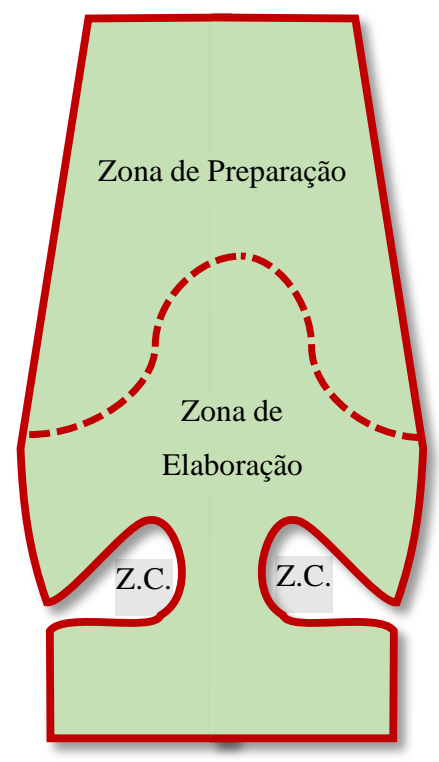

Figura 28 - Divisão do Alto Forno: Z. Preparação e Z. Elaboração. 


\section{2.}

\section{Equacionamento do Balanço de Massa}

\subsection{1.}

\section{Balanço Geral de Massa}

O Balanço geral de massa foi realizado considerando os gases que saem da zona de combustão (como mostrado na figura 29)

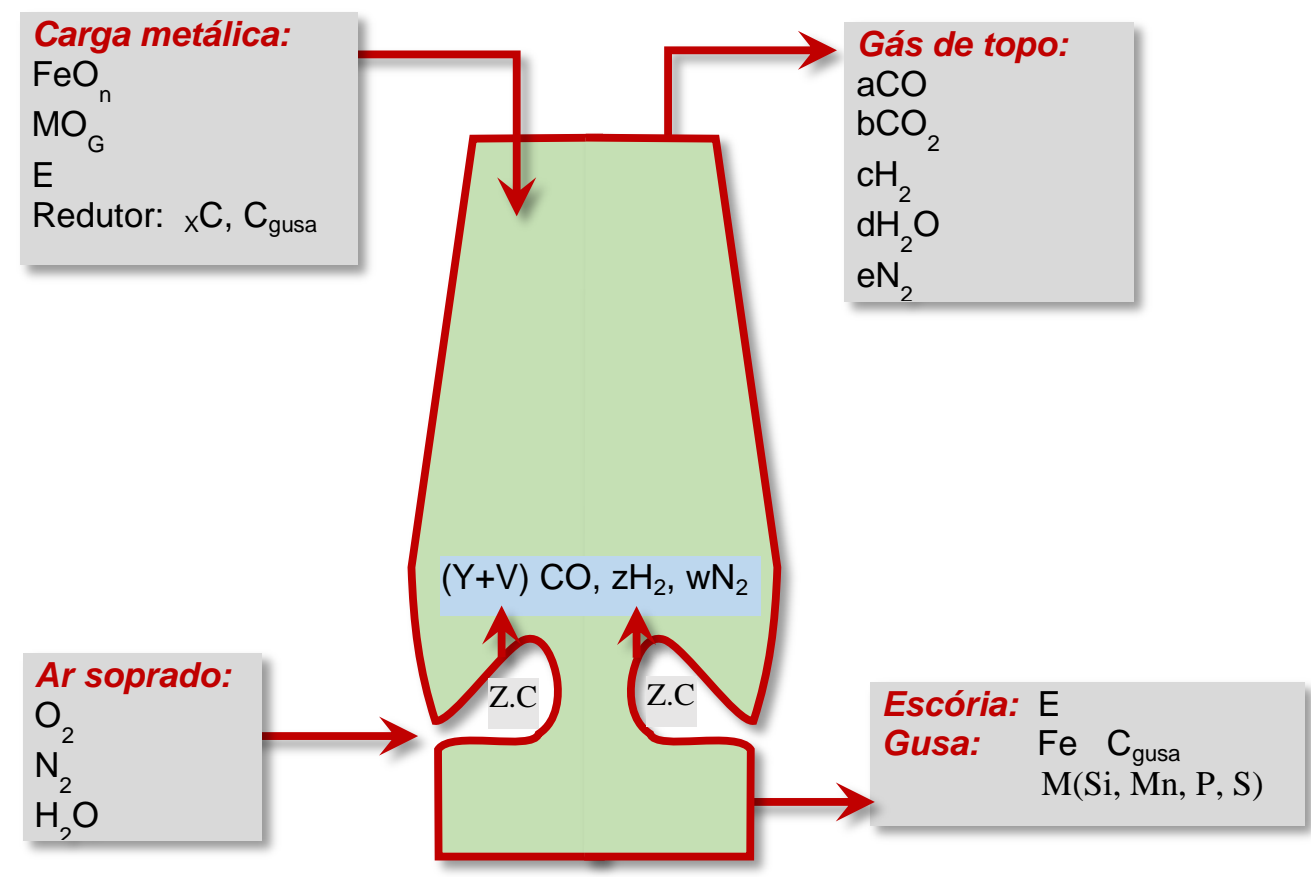

Figura 29 - Esquema para o Balanço Geral de Massa.

A equação (31) mostra o balanço geral de massa e é proposta com os gases que saem da zona de combustão.

$$
\begin{aligned}
& \mathrm{FeO}_{\mathrm{n}}+\mathrm{MO}_{\mathrm{G}}+{ }_{\mathrm{x}} \mathrm{C}+{ }_{(\mathrm{Y}+\mathrm{V})} \mathrm{CO}+\mathrm{zH}_{2}+\mathrm{wN}_{2}+\mathrm{E}+\mathrm{C}_{\text {gusa }}= \\
& =\mathrm{Fe}+\mathrm{M}+\mathrm{aCO}+\mathrm{bCO}_{2}+\mathrm{cH}_{2}+\mathrm{dH}_{2} \mathrm{O}+\mathrm{eN}_{2}+\mathrm{E}+\mathrm{C}_{\text {gusa }}
\end{aligned}
$$

Onde:

$\mathrm{FeO}_{\mathrm{n}}$ : $\quad$ Óxidos de ferro da carga metálica que serão reduzidos e formarão o gusa. 
$\mathrm{MO}_{\mathrm{G}}$ : Óxidos não ferrosos que serão reduzidos, e os metais incorporados no gusa.

$\mathrm{x}_{\mathrm{C}}$ : Carbono para Redução Direta.

yCO: $\quad$ Gás redutor $\mathrm{CO}$, produto da redução de $\mathrm{CO}_{2}-$ Boudouard.

vCO: $\quad$ Gás redutor $\mathrm{CO}$, produto da redução da água.

${ }_{\mathrm{Z}} \mathrm{H}_{2}$ : Gás redutor $\mathrm{H}_{2}$ produto da redução da água.

${ }_{\mathrm{w}} \mathrm{N}_{2}$ : Nitrogênio do ar soprado.

E: $\quad$ Óxidos não ferrosos que vão para a escória.

$\mathrm{C}_{\text {gusa }}$ : $\quad$ Carbono que vai para o gusa.

a, b, c, d, e: $\quad \mathrm{CO}, \mathrm{CO}_{2}, \mathrm{H}_{2}, \mathrm{H}_{2} \mathrm{O}$ e $\mathrm{N}_{2}$ no gás de topo.

\subsection{2.}

\section{Balanço de Carbono}

Partindo da equação (31)

$$
X+Y+V+C_{\text {gusa }}=\mathrm{a}+b+C_{\text {gusa }}
$$

$$
X=\mathrm{a}+b-(Y+V)
$$

Onde:

Y: Átomos de Carbono presentes no gás redutor $\mathrm{CO}$ produto da redução de $\mathrm{CO}_{2}$ (Boudouard) ou átomos de Carbono que se transformaram em $\mathrm{CO}$ via Boudouard, disponíveis para realizar RI.

V: Átomos de Carbono presentes no gás redutor $\mathrm{CO}$, produto da redução da água $\left(\mathrm{H}_{2} \mathrm{O}+\mathrm{C}=\mathrm{CO}+\mathrm{H}_{2}\right)$, também disponíveis para realizar $\mathrm{RI}$.

X: Átomos de Carbono usados para redução direta, RD.

a: Átomos de Carbono presentes no gás $\mathrm{CO}$ do gás de topo.

b: Átomos de Carbono presentes no gás $\mathrm{CO}_{2}$ do gás de topo.

$\mathrm{C}_{\text {gusa }}$ : Átomos de Carbono presentes no gusa. 


\subsection{3.}

\section{Balanço de Oxigênio}

A partir da equação (31)

$$
n+G+Y+V=\mathrm{a}+2 b+d
$$

$$
n+G=\mathrm{a}+2 b+d-(Y+V)
$$

Onde:

n: Átomos de oxigênio presentes nos óxidos de ferro que ingressam com a carga metálica.

G: Átomos de oxigênio presentes nos óxidos não ferrosos que ingressam com a carga metálica.

Y: Átomos de oxigênio presentes no gás redutor $\mathrm{CO}$, produto da redução de Boudouard.

V: Átomos de oxigênio presentes no gás redutor $\mathrm{CO}$, produto da redução da água $\left(\mathrm{H}_{2} \mathrm{O}+\mathrm{C}=\mathrm{CO}+\mathrm{H}_{2}\right)$.

a: $\quad$ Átomos de oxigênio presentes no CO do gás de topo.

2b: Átomos de oxigênio presentes no gás $\mathrm{CO}_{2}$ do gás de topo.

d: Átomos de oxigênio presentes no $\mathrm{H}_{2} \mathrm{O}$ do gás de topo.

Observação: $\mathrm{n}+\mathrm{G}$ significa total de átomos de oxigênio da carga metálica (óxidos ferrosos e não ferrosos) que foram reduzidos.

\subsection{4.}

\section{Balanço de Hidrogênio}

A partir da equação (31)

$$
2 z=2 c+2 d
$$

$$
z=\mathrm{c}+d
$$

Onde:

2z: Átomos de hidrogênio que ingressam com a água $\mathrm{H}_{2} \mathrm{O}$ pelo ar injetado.

2c: Átomos de hidrogênio presentes no gás de topo.

2d: Átomos de hidrogênio presentes na $\mathrm{H}_{2} \mathrm{O}$ do gás de topo. 


\subsection{5.}

Análise da Fração de Carbono usado na Redução Direta

O consumo de redutor é uma função da fração de RD ${ }^{\text {(apud 11,30,35) }}$. Logo a fração de Redução Direta "RD” é definida como a relação entre o número de átomos de oxigênio retirados pelo carbono que faz a Redução Direta com o número de átomos de oxigênio que ingressam com a carga metálica (óxidos ferrosos e não ferrosos).

Assim:

$R D=\frac{X}{n+G}$

Isolando $\mathrm{X}$

$$
X=R D(n+G)
$$

Definindo $\alpha$ como:

$$
\alpha=\frac{Y+V}{n+G}
$$

$$
Y+V=\alpha(n+G)
$$

Onde:

$\mathrm{Y}+\mathrm{V}$ : Átomos de Carbono presentes no gás redutor $\mathrm{CO}$, produto da reação de Boudouard e do carbono com a água, disponíveis para RI.

$\mathrm{n}+\mathrm{G}$ : Átomos de oxigênio presentes nos óxidos ferrosos e não ferrosos que ingressam com a carga metálica e que sofreram redução.

X: Átomos de Carbono usados para RD.

$\alpha: \quad$ Fração de Carbono disponibilizado para RI.

Como: $\mathrm{RD}=\mathrm{X} /(\mathrm{n}+\mathrm{G})$ e fazendo uso dos balanços de carbono e oxigênio equações (32) e (33) respectivamente, teremos: 


$$
R D=\frac{X}{n+G}=\frac{\mathrm{a}+b-(Y+V)}{\mathrm{a}+2 b+d-(Y+V)}
$$

Substituindo (36) em (37)

$$
R D=\frac{\mathrm{a}+b-\alpha(n+G)}{\mathrm{a}+2 b+d-\alpha(n+G)}
$$

Substituindo (36) em (33)

$$
\begin{aligned}
& n+G=\mathrm{a}+2 b+d-\alpha(n+G) \\
& n+G=\frac{\mathrm{a}+2 b+d}{1+\alpha}
\end{aligned}
$$

Substituindo (39) em (38)

$$
\begin{aligned}
& R D=\frac{\mathrm{a}+b-\alpha\left(\frac{\mathrm{a}+2 b+d}{\alpha+1}\right)}{\mathrm{a}+2 b+d-\alpha\left(\frac{\mathrm{a}+2 b+d}{\alpha+1}\right)} \\
& R D=\frac{(\mathrm{a}+b)-\alpha(b+d)}{(\mathrm{a}+b)+(b+d)}
\end{aligned}
$$

Definindo R como um parâmetro que relaciona os gases $\mathrm{CO}, \mathrm{CO}_{2}, \mathrm{H}_{2}, \mathrm{H}_{2} \mathrm{O}$, que saem na fronteira definida pela isoterma de $950{ }^{\circ} \mathrm{C}$.

$$
\begin{aligned}
& R=\frac{b+d}{a+b} \\
& b+d=R(a+b)
\end{aligned}
$$

Substituindo (41) em (40) 


$$
R D=\frac{(\mathrm{a}+b)-\alpha R(\mathrm{a}+b)}{(\mathrm{a}+b)+R(\mathrm{a}+b)}
$$

Fatorando $(a+b)$

$$
\begin{aligned}
& R D=\frac{(\mathrm{a}+b)(1-\alpha R)}{(\mathrm{a}+b)(1+R)} \\
& R D=\frac{(1-\alpha R)}{(1+R)}
\end{aligned}
$$

Colocando em evidência $\alpha$

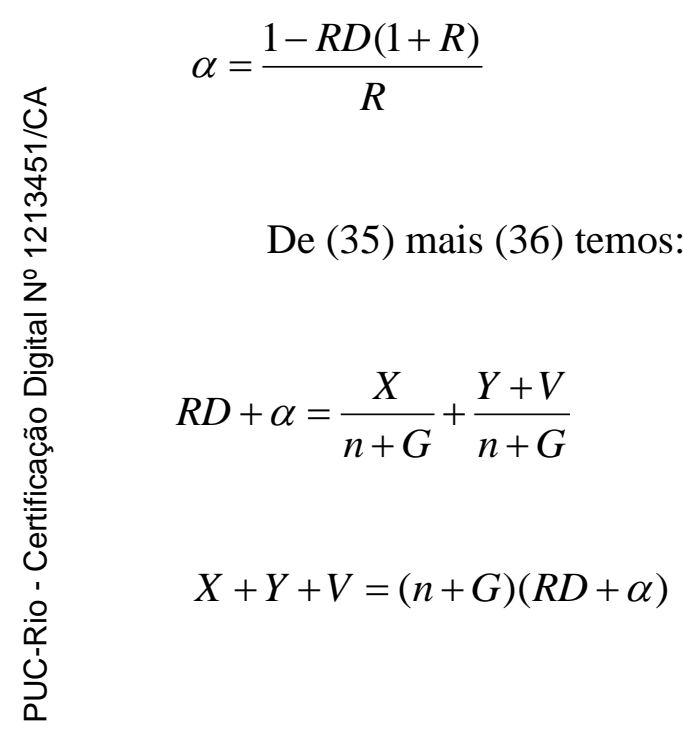

(43) em (44)

$$
\begin{aligned}
& X+Y+V=(n+G)\left[R D+\frac{1-R D(1+R)}{R}\right] \\
& X+Y+V=(n+G)\left(\frac{1-R D}{R}\right)
\end{aligned}
$$

Definindo uma variável $\boldsymbol{\gamma}$ como: 


$$
\gamma=\frac{\mathrm{a}-d}{b+d}
$$

Acrescentando aos dois membros da equação (46) o termo: $\quad \frac{b+d}{b+d}$

$$
\begin{gathered}
\gamma+\frac{b+d}{b+d}=\frac{a-d}{b+d}+\frac{b+d}{b+d} \\
\gamma+1=\frac{a+b}{b+d}
\end{gathered}
$$

Lembrando que:

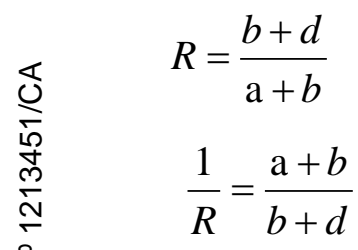

Substituindo (48) em (47)

$$
\gamma+1=\frac{1}{R}
$$

Substituindo (49) em (45)

$$
\begin{aligned}
& X+Y+V=(1-R D)(n+G)(1+\gamma) \\
& X+Y+V=(1-R D)(n+G)\left(\frac{1}{R}\right)
\end{aligned}
$$

Voltando para as variáveis originais. 


$$
X+Y+V=(1-R D)(n+G)\left(\frac{a+b}{b+d}\right) \rightarrow \frac{\text { at } C}{\text { at } F e}
$$

Onde:

$\mathrm{X}+\mathrm{Y}+\mathrm{V}: \quad$ Carbono que ingressa para fazer as reduções (RD e RI),

equivalente aos átomos de Oxigênio retirados pelas reduções Direta e Indireta.

n+G: $\quad$ Átomos de oxigênio que ingressam pela carga metálica (ferrosos e não ferrosos).

$\mathrm{a}+\mathrm{b}$ : Átomos de oxigênio contidos no gás $\mathrm{CO}$ e $\mathrm{CO}_{2}$ que sai pelo gás de topo.

b+d: Átomos de oxigênio contidos no gás $\mathrm{CO}_{2}$ e $\mathrm{H}_{2} \mathrm{O}$ que sai pelo gás de topo.

\section{3.}

\section{Estudo do Equilíbrio das Reações}

As figuras 30 e 31 auxiliarão na compreensão do desenvolvimento das equações que regem o equilíbrio das reações. No estudo da Zona de Elaboração foi considerado que todas as reações ocorrem em fase sólida (carbono).

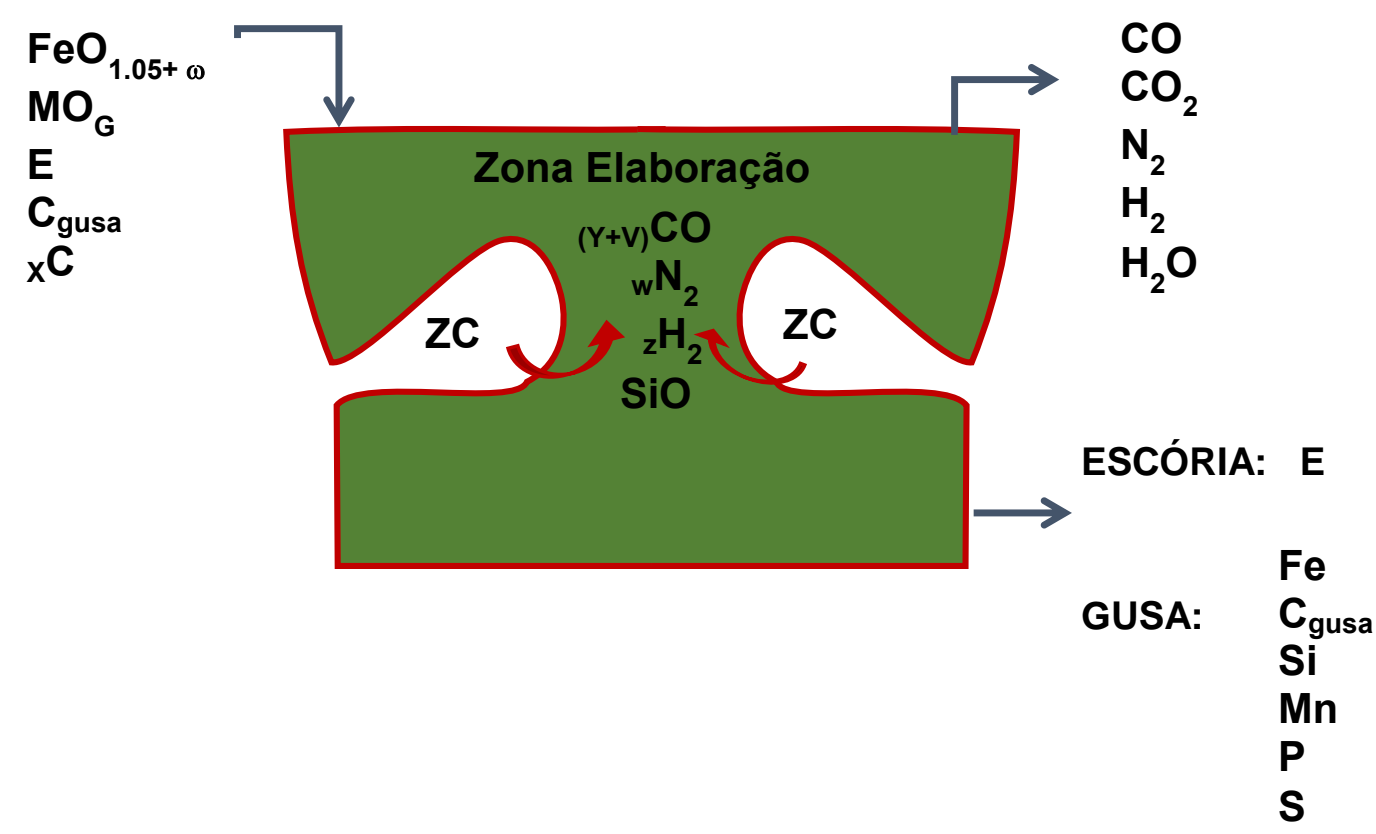

Figura 30 - Diagrama utilizado para o estudo da Zona de Elaboração. 


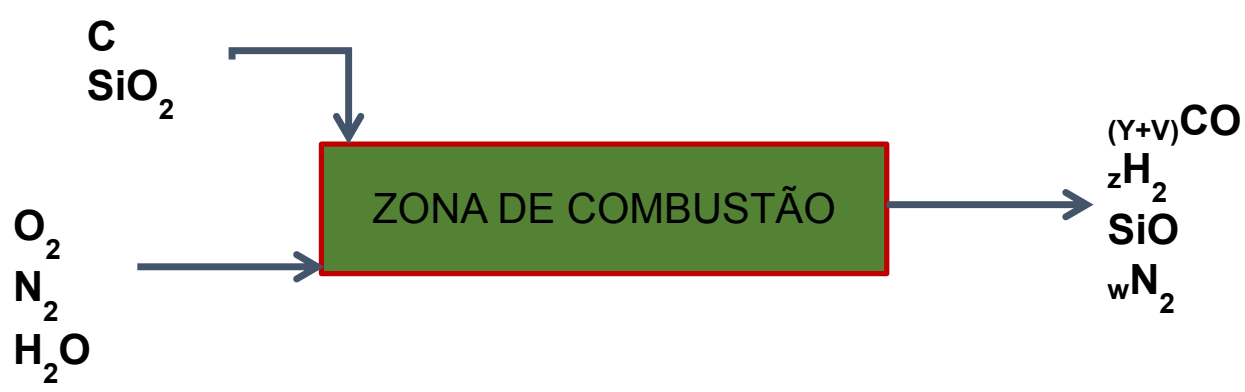

Figura 31 - Diagrama Utilizado para o Estudo da Zona de Combustão.

\subsection{1.}

\section{Estudo das Reduções Diretas dos Óxidos não Ferrosos na Zona de Elaboração}

Da análise da redução dos óxidos não ferrosos com o carbono sólido, reação (51) se determinará a quantidade de carbono consumido para tal redução, esta é equivalente ao oxigênio retirado dos óxidos não ferrosos e seu valor corresponde ao termo G.

$$
\mathrm{MO}_{\mathrm{G}}+{ }_{\mathrm{G}} \mathrm{C}=\mathrm{M}+{ }_{\mathrm{G}} \mathrm{CO}_{(\mathrm{g})}
$$

\subsubsection{1.}

\section{Análise do Oxigênio Contido nos Óxidos não Ferrosos}

$\mathrm{MO}_{\mathrm{G}}$. São os óxidos não ferrosos que ingressam com a carga metálica e que serão reduzidos por Redução Direta na zona de elaboração e os metais incorporados no gusa, $\mathrm{MO}_{\mathrm{G}}$ está composto por $\mathrm{SiO}_{2}, \mathrm{P}_{2} \mathrm{O}_{5}, \mathrm{MnO}$, e o $\mathrm{S}$.

G é a quantidade de oxigênio que será reduzida dos óxidos não ferrosos, seu valor será determinado pela composição do gusa.

O pressuposto é que todas as reduções dos óxidos não ferrosos ocorram via Redução Direta pelo carbono sólido. 


\subsubsection{1.}

\section{Redução do $\mathrm{SiO}_{2}$}

A redução do $\mathrm{SiO}_{2}$ ocorre em duas etapas:

$$
\begin{gathered}
\mathrm{SiO}_{2(s)}+C_{(s)}=\mathrm{SiO}_{(g)}+\mathrm{CO}_{(g)} \quad \text { Na zona de combustão (altas temperaturas) } \\
\Delta \mathrm{H}=154,610 \mathrm{kcal} / \mathrm{mol}\left(\mathrm{T}=1900{ }^{\circ} \mathrm{C}\right) \\
\mathrm{SiO}_{(g)}+[\mathrm{C}]=[\mathrm{Si}]+\mathrm{CO}_{(g)} \quad \text { Através do C dissolvido no gusa } \\
\begin{array}{c}
\Delta \mathrm{H}=10,496 \mathrm{kcal} / \mathrm{mol}\left(\mathrm{T}=1600{ }^{\circ} \mathrm{C}\right)
\end{array}
\end{gathered}
$$

A transferência do Si para o gusa será realizada através de duas etapas:

- A redução do $\mathrm{SiO}_{2(\mathrm{~s})}$ das cinzas do coque pelo carbono do coque, gerando $\mathrm{SiO}_{(\mathrm{g})}$, reação (52) ocorre a altas temperaturas, como as condições reinantes no interior da zona de combustão.

- A redução do $\mathrm{SiO}_{(\mathrm{g})}$ é realizada através do carbono sólido dissolvido no gusa (53), esse carbono é proveniente do coque.

Será estudada a reação (53), na qual teremos a seguinte análise:

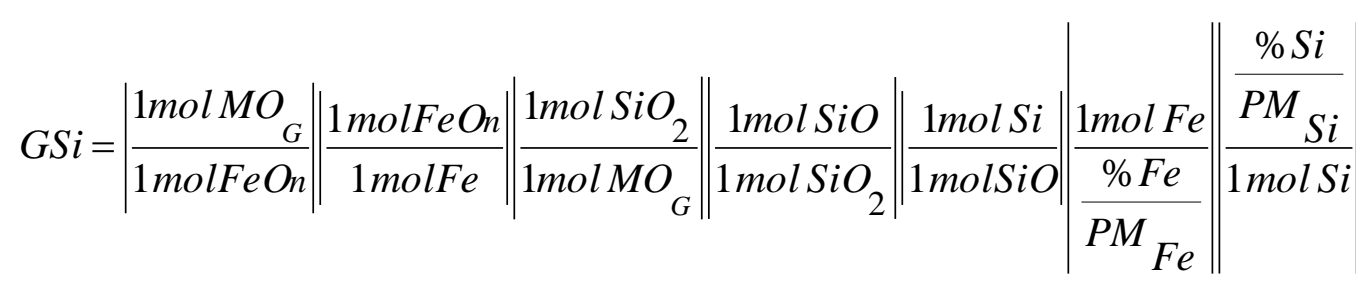

$\mathrm{G}_{\mathrm{Si}}=\frac{\% \mathrm{Si} \times 56}{\% \mathrm{Fe} \times 28}$

$G_{S i}==2 \times \frac{\% \mathrm{Si}}{\% \mathrm{Fe}}$

Onde:

$\mathrm{G}_{\mathrm{si}}$ : Átomos de oxigênio reduzidos do $\mathrm{SiO}_{2}$ nos óxidos não ferrosos carregados 
$\% \mathrm{Si}:$ Porcentagem de silício no gusa.

$\% \mathrm{Fe}$ : Porcentagem de ferro no gusa.

$\mathrm{PM}_{\mathrm{Fe}}$ : Peso molecular do Fe.

$\mathrm{PM}_{\mathrm{Si}}$ : Peso molecular do Si.

\subsubsection{2.}

Redução do $\mathrm{P}_{2} \mathrm{O}_{5}$

A redução do $\mathrm{P}_{2} \mathrm{O}_{5}$ ocorre segundo a seguinte equação:

$$
\mathrm{P}_{2} \mathrm{O}_{5}+5 \mathrm{C}=2 \mathrm{P}+5 \mathrm{CO}_{(\mathrm{g})}
$$

Logo:

$$
G_{P}=\frac{\% P \times 56}{\% F e \times 31}
$$

$$
G_{P}=1.81 \times \frac{\% P}{\% \mathrm{Fe}}
$$

Onde:

$\mathrm{G}_{\mathrm{P}}$ : Átomos de oxigênio reduzidos do $\mathrm{P}_{2} \mathrm{O}_{5}$ nos óxidos não ferrosos carregados.

\%: Porcentagem de fósforo no gusa.

$\% \mathrm{Fe}$ : Porcentagem de ferro no gusa.

\subsubsection{3.}

\section{Redução do MnO}

A redução do $\mathrm{MnO}$ ocorre segundo a seguinte equação:

$$
\mathrm{MnO}+\mathrm{C}=\mathrm{Mn}+\mathrm{CO}_{(\mathrm{g})}
$$

Logo: 


$$
\begin{aligned}
& G_{M n}=\frac{\% M n \times 56}{\% F e \times 55} \\
& G_{M n}=1.02 \times \frac{\% M n}{\% F e}
\end{aligned}
$$

Onde:

$\mathrm{G}_{\mathrm{Mn}}$ : Átomos de oxigênio reduzidos do $\mathrm{MnO}$ nos óxidos não ferrosos carregados.

$\% \mathrm{Mn}$ : Porcentagem de manganês na gusa.

$\% \mathrm{Fe}$ : Porcentagem de ferro na gusa.

\subsubsection{4.}

\section{Dessulfuração do Enxofre}

Embora o S não seja obtido (levado desde os óxidos não ferrosos para a escória) por redução dos óxidos não ferrosos, o seu comportamento quanto ao consumo de Carbono e geração de CO é semelhante ao dos óxidos estudados até agora.

O mecanismo proposto é:

$$
\mathrm{C}+\mathrm{S}+\mathrm{CaO}=\mathrm{CaS}+\mathrm{CO}_{(\mathrm{g})}
$$

Logo:

$$
\mathrm{G}_{\mathbf{S}}=\frac{\% \mathrm{~S}_{\mathrm{E}} \times 56}{\% \mathrm{Fe} \times 32}
$$

$$
G_{S}=1.75 \times 10^{-3} \times v_{E} \times \frac{\% S_{E}}{\% F e}
$$

Onde:

G : Átomos de oxigênio reduzidos pela transferência do enxofre para a escória.

$\% \mathrm{~S}_{\mathrm{E}} \quad$ : Porcentagem de enxofre na escória. 
$\% \mathrm{Fe} \quad$ : Porcentagem de ferro no gusa.

$\mathrm{V}_{\mathrm{E}} \quad$ : Volume de escória. ( $\mathrm{Kg} / \mathrm{t}$ gusa)

O termo $\mathrm{G}$ (átomos de oxigênio dos óxidos não ferrosos), considerando as relações estequiométricas do oxigênio, pode ser representado por:

$$
\mathrm{G}=\mathrm{G}_{\mathrm{Si}}+2.5 \mathrm{G}_{\mathrm{P}}+\mathrm{G}_{\mathrm{Mn}}+\mathrm{G}_{\mathrm{S}}
$$

Que em forma algébrica é igual à soma das equações (54), (56), (58), (60):

$$
G=\frac{1}{\% F e} \times\left[2 \times \% \mathbf{S i}+4.53 \times \%+1.02 \times \% M n+1.75 \times 10^{-3} \times V_{E} \times \% S_{E}\right]
$$

Onde:

G: Átomos de Oxigênio presente nos óxidos não ferrosos

\subsection{2. Estudo da Redução Direta dos Óxidos Ferrosos na Zona de Elaboração}

Do estudo do balanço de massa equação (35) tem-se para a fração de redução direta:

$R D=\frac{X}{n+G}$

$X=R D(n+G)$

Onde:

n: relação at $\mathrm{O} / \mathrm{at} \mathrm{Fe}$ inicial nos óxidos ferrosos.

G: é dado pela equação (62) e são os átomos de oxigênio nos óxidos não ferrosos.

X: é o consumo de carbono pela redução direta dos óxidos ferrosos e não ferrosos. 
Substituindo o valor de $\mathrm{n}$ pela relação de at O/at Fe que entram na zona de elaboração obtém-se:

$$
X=R D[(1.05+\omega)+G]
$$

Onde:

$\omega=$ fator ômega (desvio de Rist) desvio da idealidade

Considerando que na Zona de Elaboração ocorrerá a redução direta dos óxidos ferrosos e não ferrosos, na sequência pode-se fazer a seguinte análise logo de obtido o carbono necessário para a redução dos óxidos não ferrosos:

Se X átomos de carbono foram consumidos por Redução Direta na Zona de Elaboração pelos óxidos ferrosos e não ferrosos, e $\mathrm{G}$ átomos de carbono foram consumidos pela redução direta dos óxidos não ferrosos e a transferência de $S$ para o gusa, então (X-G) serão os átomos de carbono consumidos pela redução direta dos óxidos de ferro que ingressam na $\mathrm{ZE}$.

A equação da redução dos óxidos de ferro na Zona de Elaboração via Redução Direta pode ser representada como:

$$
\mathrm{FeO}_{1.05}+1.05 \mathrm{C}=\mathrm{Fe}+1.05 \mathrm{CO}_{(\mathrm{g})}
$$

Na equação (64) observa-se que:

1.05 átomos de Carbono reduzem 1.05 átomos de Oxigênio e geram 1.05 moles de $\mathrm{CO}$

Logo de forma análoga:

Para (X-G) átomos de $\mathrm{C}$ consumidos na redução dos óxidos de ferro teremos $(\mathrm{X}-\mathrm{G})$ átomos de Oxigênio tratados, ou seja, foram reduzidos $(\mathrm{X}-\mathrm{G})$ átomos de oxigênio do $\mathrm{FeO}_{1.05}$. 
Por outro lado, considerou-se que todos os óxidos de ferro que ingressam na zona de elaboração foram reduzidos até wustita na zona de preparação, assim teremos ingressando na zona de elaboração; $\mathrm{FeO}_{1.05}(\omega=0)$.

Pode ser feita uma análise do oxigênio que ingressa na zona de elaboração e o oxigênio dos óxidos de ferro que foram tratados pelo carbono na zona de elaboração, esta diferença fornecerá a quantidade de oxigênio dos óxidos ferrosos que entram na zona de elaboração que deve ser tratado por outros redutores.

$\left[\begin{array}{c}\text { Oxigênio dos óxidos de } \\ \text { Ferro que entram na ZE } \\ (1.05)\end{array}\right]-\left[\begin{array}{c}\text { Oxigênios tratados dos } \\ \text { oxidos de Ferro que } \\ \text { entram na ZE } \\ (X-G)\end{array}\right]=\left[\begin{array}{c}\text { Oxigênio dos óxidos de Ferro } \\ \text { que serão tratados } \\ \text { por outros redutores } \\ \text { na ZE }\end{array}\right]$

Logo $[1,05-(\mathrm{X}-\mathrm{G})]$ são os átomos de oxigênio dos óxidos de ferro que entraram na zona de elaboração que foram tratados por outros redutores como mostra o resumo na seguinte tabela:

Tabela 1 - Resumo da Análise da Redução Direta dos Óxidos de Ferro e não Ferrosos.

\begin{tabular}{|l|l|c|}
\hline $\begin{array}{l}\text { Carbono gasto nas Reduções } \\
\text { Diretas dos óxidos ferrosos e } \\
\text { não ferrosos na ZE }\end{array}$ & $\begin{array}{l}\text { Oxigênio tratado por Redução Direta } \\
\text { dos óxidos ferrosos e não ferrosos na } \\
\text { ZE }\end{array}$ & X \\
\hline $\begin{array}{l}\text { Carbono gasto nas Reduções } \\
\text { Diretas dos óxidos não } \\
\text { ferrosos na ZE }\end{array}$ & $\begin{array}{l}\text { Oxigênio tratado por Redução Direta } \\
\text { dos óxidos não ferrosos na ZE }\end{array}$ & G \\
\hline $\begin{array}{l}\text { Carbono gasto nas Reduções } \\
\text { Diretas dos óxidos ferrosos na } \\
\text { ZE }\end{array}$ & $\begin{array}{l}\text { Oxigênio tratado por Redução Direta } \\
\text { dosidos ferrosos na ZE }\end{array}$ & X-G \\
\hline & Oxigênio que serão tratados dos \\
óxidos de ferro por outras reduções na & $1,05-(\mathrm{X}-\mathrm{G})$ \\
\hline
\end{tabular}




\subsection{3.}

\section{Estudo da Redução por $\mathrm{H}_{2}$ dos Óxidos Ferrosos na Zona de} Elaboração

$\mathrm{Na}$ zona de elaboração ainda deve ser feita a retirada de oxigênio dos óxidos de ferro restantes, estas serão retiradas pelo redutor $\mathrm{H}_{2}$. A equação da redução dos óxidos de ferro via $\mathrm{H}_{2}$ pode ser representada como:

$$
\mathrm{FeO}_{(\mathrm{s})}+\mathrm{H}_{2(\mathrm{~g})}=\mathrm{Fe}_{(\mathrm{s})}+\mathrm{H}_{2} \mathrm{O}_{(\mathrm{v})}
$$

Logo a constante de equilíbrio da redução por hidrogênio será dada por:

$$
K_{\mathrm{H}}=\frac{P_{\mathrm{H}_{2} \mathrm{O}} \times a_{\mathrm{Fe}}}{P_{\mathrm{H}_{2}} \times a_{\mathrm{FeO}}}
$$

Considerando as atividades do $\mathrm{Fe}$ e $\mathrm{FeO}$ como a unidade (sólidos puros) a equação (66) fica como:

$$
K_{H}=\frac{N_{H_{2} O}}{N_{H_{2}}}
$$

Onde:

$\mathrm{N}_{\mathrm{H} 2 \mathrm{O}}$ : Moles da água/at Fe

$\mathrm{N}_{\mathrm{H} 2}$ : Moles de hidrogênio/at Fe

Também do balanço de massa com respeito ao hidrogênio temos:

$$
N_{\mathrm{H}_{2} \mathrm{O}}+N_{\mathrm{H}_{2}}=z
$$

Logo resolvendo as equações 67 e 68 :

$$
K_{H}=\frac{N_{H_{2} O}}{N_{H_{2}}}
$$

$$
\text { e } \quad N_{\mathrm{H}_{2} \mathrm{O}}+N_{\mathrm{H}_{2}}=z
$$


Equalizando (67) e (68) para: $N_{\mathrm{H}_{2} \mathrm{O}}$ e equalizando (67) e (68) para: $N_{\mathrm{H}_{2}}$

$$
\begin{aligned}
& K_{H} \times N_{H_{2}}=z-N_{H_{2}} \\
& \frac{N_{\mathrm{H}_{2} \mathrm{O}}}{K_{\mathrm{H}}}=z-N_{\mathrm{H}_{2} \mathrm{O}} \\
& N_{H_{2}}=\frac{z}{K_{H}+1} \\
& N_{H_{2} O}=\frac{z}{K_{H}+1} \times K_{H}
\end{aligned}
$$

Logo a redução por $\mathrm{H}_{2}$, equação (65) ficará da seguinte forma:

$$
\begin{gathered}
\mathrm{FeO}_{(\mathrm{s})}+\mathrm{H}_{2(\mathrm{~g})}=\mathrm{Fe}(\mathrm{s})+\mathrm{H}_{2} \mathrm{O}_{(\mathrm{v})} \\
{\left[\frac{z}{K_{H}+1} \times K_{H}\right] \mathrm{FeO}_{(s)}+\left[\frac{z}{K_{H}+1}\right] H_{2(g)}=\left[\frac{z}{K_{H}+1} \times K_{H}\right] \mathrm{Fe}_{(s)}+\left[\frac{z}{K_{H}+1} \times K_{H}\right] H_{2} O_{(v)}}
\end{gathered}
$$

Então:

$\mathrm{O}$ número de átomos de Oxigênio retirados dos óxidos de Ferro por $\mathrm{H}_{2}$ na Zona de Elaboração será igual:

$\frac{z}{K_{H}+1} \times K_{H}$

Porém o número de átomos de Oxigênio que ainda falta tratar dos óxidos de Ferro depois da Redução Direta e da redução por $\mathrm{H}_{2}$ na Zona de Elaboração é igual ao número de átomos de Oxigênio que ingressaram na ZE menos o número de Oxigênios retirados por Redução Direta e por redução com Hidrogênio, como mostrado na equação (72).

$$
1.05-(X-G)-\frac{z}{K_{H}+1} \times K_{H}
$$

Onde:

1,05: Átomos de oxigênio que entram com os óxidos ferrosos na ZE (idealmente).

X-G: $\quad$ Átomos de oxigênio retirados dos óxidos ferrosos por R.D. na ZE 
$\frac{z}{K_{H}+1} \times K_{H} \quad$ : Átomos de oxigênio retirados dos óxidos ferrosos pelo hidrogênio

\subsection{4.}

\section{Estudo da Redução por CO na Zona de Preparação}

A equação que representa a redução dos óxidos de ferro por $\mathrm{CO}$ pode ser representada em forma geral como:

$$
\mathrm{FeO}_{\mathrm{n}}+{ }_{(\mathrm{n}-1.05-\omega)} \mathrm{CO}_{(\mathrm{g})}=\mathrm{FeO}_{1.05+\omega}+{ }_{(\mathrm{n}-1.05-\omega)} \mathrm{CO}_{2(\mathrm{~g})}
$$

Considerando que a redução dos óxidos de ferro na Zona de Preparação são todas reduzidas até wustita $(\omega=0)$, então a equação (73) fica como:

$$
\mathrm{FeO}_{\mathrm{n}}+{ }_{(\mathrm{n}-1.05)} \mathrm{CO}_{(\mathrm{g})}=\mathrm{FeO}_{1.05}+{ }_{(\mathrm{n}-1.05)} \mathrm{CO}_{2(\mathrm{~g})}
$$

$\mathrm{Na}$ equação (74) observa-se que cada (n-1.05) moles de $\mathrm{CO}_{2}$ gerados correspondem para (n-1.05) moles de CO utilizados na Redução Indireta de "n" átomos de oxigênio contidos nos óxidos de Ferro que ingressaram na Zona de Preparação.

Assim a quantidade de $\mathrm{CO}_{2}$ gerada na Zona de Preparação é igual à quantidade de Oxigênio retirado dos óxidos de ferro por redução indireta na ZP, e é equivalente à quantidade de $\mathrm{CO}$ consumido na $\mathrm{ZP}$.

A quantidade de CO necessária para a Redução Indireta na ZP está diretamente ligada à quantidade de $\mathrm{O}_{2}$ que deverá ser tratada na zona de elaboração.

$\mathrm{Na}$ sequência calcularemos a constante de equilíbrio para a redução da equação (74) de uma forma análoga à redução dos óxidos ferrosos na $\mathrm{ZE}$ pelo $\mathrm{H}_{2}$. Foram consideradas as atividades dos óxidos de ferro puros, então a constante de equilíbrio para a redução pelo CO ficará como: 
$K_{C O}=\left[\frac{N_{\mathrm{CO}_{2}}}{N_{C O}}\right]^{(n-1.05)}$

Isolando $\mathrm{N}_{\mathrm{CO}}$ :

$$
N_{C O}=\frac{N_{\mathrm{CO}_{2}}}{\left(K_{C O}\right)\left(\frac{1}{n-1.05}\right)}
$$

As tabelas 2 e 3 mostram um resumo das Reduções Diretas e via $\mathrm{H}_{2}$ na $\mathrm{ZE}$ e as Reduções Indiretas da ZP até aqui estudadas

Tabela 2 - Resumo das Reduções Diretas e pelo $\mathrm{H}_{2}$ na ZE.

\begin{tabular}{|c|c|c|c|c|}
\hline $\operatorname{do}(s)$ & & $\begin{array}{l}\text { Oxigênio } \\
\text { tratado } \\
\text { na ZE }\end{array}$ & $\begin{array}{l}\text { Carbono } \\
\text { consumid } \\
\text { o } \\
\text { na ZE }\end{array}$ & $\begin{array}{l}\text { CO } \\
\text { gerado } \\
\text { Na ZE }\end{array}$ \\
\hline \multirow{5}{*}{$\begin{array}{l}\text { Óxidos } \\
+ \text { Não ferrosos }\end{array}$} & $\mathrm{SiO}_{2}(\mathrm{Via} \mathrm{C})$ & $\mathrm{G}_{\mathrm{Si}}$ & $\mathrm{G}_{\mathrm{Si}}$ & $\mathrm{G}_{\mathrm{Si}}$ \\
\hline & $\mathrm{P}_{2} \mathrm{O}_{5}(\mathrm{Via} \mathrm{C})$ & $2,5 \mathrm{G}_{\mathrm{P}}$ & $2,5 \mathrm{G}_{\mathrm{P}}$ & $2,5 \mathrm{G}_{\mathrm{P}}$ \\
\hline & $\mathrm{MnO}(\mathrm{Via} \mathrm{C})$ & $\mathrm{G}_{\mathrm{Mn}}$ & $\mathrm{G}_{\mathrm{Mn}}$ & $\mathrm{G}_{\mathrm{Mn}}$ \\
\hline & $\mathrm{S}$ (Via C) & $\mathrm{G}_{\mathrm{S}}$ & $\mathrm{G}_{\mathrm{S}}$ & $\mathrm{G}_{\mathrm{S}}$ \\
\hline & Total & $\mathrm{G}$ & $\mathrm{G}$ & G \\
\hline \multirow{2}{*}{$\begin{array}{l}\text { Óxidos } \\
\text { ferrosos }\end{array}$} & Via C & $X-G$ & $X-G$ & $X-G$ \\
\hline & Via $\mathrm{H}_{2}$ & $\frac{K_{H} \times z}{K_{H}+1}$ & - & - \\
\hline \multicolumn{2}{|c|}{$\begin{array}{l}\text { Óxidos ferrosos e não ferrosos } \\
\text { Via } \mathrm{C} \text { e } \mathrm{H}_{2}\end{array}$} & $X+\frac{K_{H} \times z}{K_{H}+1}$ & $\mathrm{X}$ & $\mathrm{X}$ \\
\hline \multicolumn{2}{|c|}{$\begin{array}{l}\text { Total de oxigênio nos óxidos } \\
\text { ferrosos e não ferrosos } \\
\text { entrando na ZE }\end{array}$} & $1,05+\mathrm{G}+\omega$ & & \\
\hline \multicolumn{2}{|c|}{$\begin{array}{l}\text { Total de oxigênio que deve ser } \\
\text { reduzido por RI na Zona } \\
\text { Preparação }\end{array}$} & $1.05+G+\omega-\left[X+\frac{K_{H} \times z}{K_{H}+1}\right]$ & & \\
\hline
\end{tabular}


Tabela 3 - Resumo das Reduções Indiretas na ZP.

\begin{tabular}{|c|c|}
\hline $\begin{array}{l}\text { Oxigênio que faltou tratar na } \\
\mathrm{ZE}=\text { Oxigênio tratado } \mathrm{ZP}=\mathrm{CO} \\
\text { gasto na } \mathrm{ZP}=\mathrm{CO}_{2} \text { gerado } \\
\mathrm{ZP}\left(\text { equivale, ao } \mathrm{N}_{\mathrm{CO} 2} \text { da equação }\right. \\
\text { 75) }\end{array}$ & $\begin{array}{c}\text { CO necessário } \\
N_{C O}=\frac{N_{C_{2}}}{\left(K_{C O}\right)\left(\frac{1}{n-1.05}\right)}\end{array}$ \\
\hline $\begin{array}{l}1.05+G+\omega-\left[X+\frac{K_{H} \times z}{K_{H}+1}\right] \\
\text { Equivalente : } \\
A\left(-\left[X+\frac{K_{H} \times Z}{K_{H}+1}\right]-R D\right)\end{array}$ & $N_{C O}=\left\{1.05+G+\omega-\left[X+\frac{K_{H} \times z}{K_{H}+1}\right]\right\} \times\left(\frac{1}{K_{C O}}\right)^{\frac{1}{n-1.05}}$ \\
\hline & $\mathrm{CO}$ que falta \\
\hline
\end{tabular}

\subsection{5.}

Análise da Geração de CO

O CO que falta será proveniente da zona de combustão onde é gerado por três maneiras diferentes:

\subsubsection{1.}

Reação de $\mathrm{SiO}_{2}$ com Carbono para Gerar SiO

$\mathrm{SiO}_{2}+\mathrm{C}=\mathrm{SiO}+\mathrm{CO}_{(\mathrm{g})}$

Gsi moles de SiO geram Gsi moles de CO

\subsubsection{2.}

Reação da Água com Carbono

$$
{ }_{\mathrm{v}} \mathrm{H}_{2} \mathrm{O}+{ }_{\mathrm{v}} \mathrm{C}={ }_{\mathrm{v}} \mathrm{H}_{2}+{ }_{\mathrm{v}} \mathrm{CO}_{(\mathrm{g})}
$$

$\mathrm{Na}$ reação (77) podemos considerar que toda a água se transforma em $\mathrm{H}_{2}$ e $\mathrm{CO}$

$\mathrm{V}$ moles de $\mathrm{H}_{2} \mathrm{O}$ geram $\mathrm{V}$ moles de $\mathrm{CO}$ e consume $\mathrm{V}$ moles de $\mathrm{C}$ 


\subsubsection{3.}

\section{Queima de Carbono com Oxigênio}

$$
\mathrm{C}+{ }_{1 / 2} \mathrm{O}_{2}=\mathrm{CO}_{(\mathrm{g})}
$$

$\mathrm{Na}$ temperatura em que é realizada a queima existe somente $\mathrm{CO}$ Logo:

1 mol de $\mathrm{CO}$ gerado consome 1 átomo de $\mathrm{C}$ e trata $1 \frac{1}{2} \mathrm{~mol}$ de Oxigênio.

\subsection{6.}

\section{Análise da Necessidade de Carbono para Queima}

A quantidade de CO necessária, gerada por queima, será igual ao que temos no resumo das reduções indiretas ( $\mathrm{CO}$ que falta) menos a gerada nas reduções do $\mathrm{SiO}_{2}$ e $\mathrm{H}_{2} \mathrm{O}$ assim:

$$
C E Q=\left[1,05+G+\omega-X+\frac{K_{H} Z}{K_{H}+1}\right] \frac{1}{K_{C O}}
$$

Onde:

$\mathrm{CEQ}=$ Carbono necessário para satisfazer o equilíbrio gás-sólido e é equivalente a $\mathrm{X}+\mathrm{Y}+\mathrm{V}$ no balanço global de massa, somado ao carbono do gusa.

\section{4 .}

\section{Equacionamento do Balanço de Energia}

O estudo do balanço térmico foi realizado com base na figura 31, na qual consideramos a parte inferior do Alto-Forno. Serão estudadas; a Zona de Elaboração e Zona de combustão. As figuras 32, 33, elucidam as variáveis intervenientes no balanço térmico. 


\subsection{1.}

\section{Equacionamento do Balanço de Energia da Zona de Elaboração}

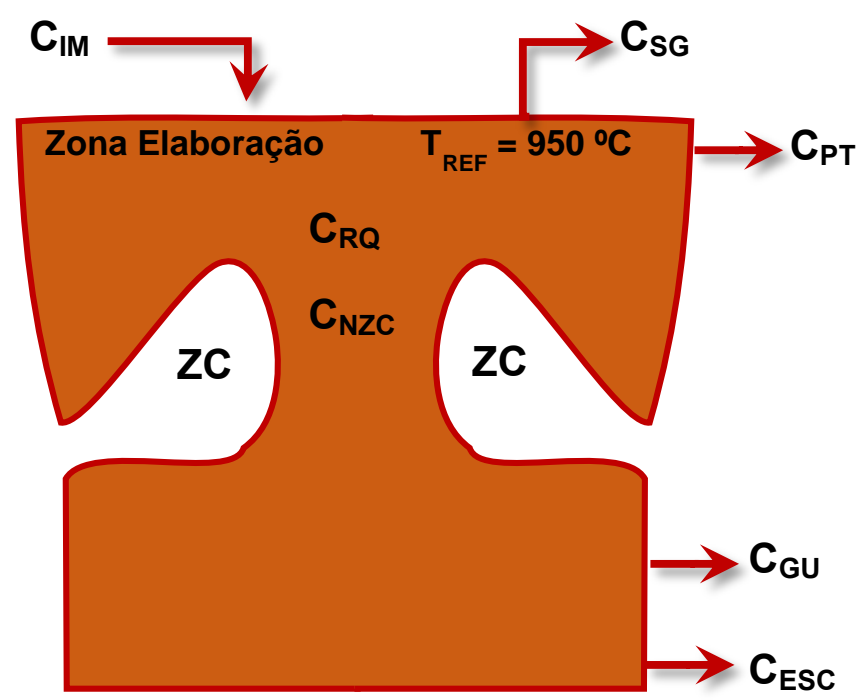

Figura 32 - Diagrama para o Estudo do Balanço Térmico da Zona de Elaboração.

Com base na figura 32 e fazendo um balanço térmico considerando que não existe acumulação teremos:

Entrada de Calor na ZE + Geração de Calor na ZE = Saída de Calor da ZE ---(80)

Considerando as correntes na figura 31 temos:

$C_{I M}+C_{N Z C}+C_{R Q}=C_{P T}+C_{G U S A}+C_{E S C}+C_{S G}$

Onde:

$\mathrm{C}_{\mathrm{IM}}$ : Calor que ingressa com os materiais na Zona de Elaboração (kcal/at-Fe).

$\mathrm{C}_{\mathrm{SG}}$ : Calor que sai com os gases da Zona de Elaboração (kcal/at-Fe).

$\mathrm{C}_{\mathrm{NZC}}$ : Calor necessário proveniente da Zona de Combustão (kcal/at-Fe).

$\mathrm{C}_{\mathrm{PT}}$ : Calor perdido nas paredes da zona de elaboração (kcal/at-Fe)

$\mathrm{C}_{\mathrm{GU}}$ : Calor contido no gusa (kcal/at-Fe).

$\mathrm{C}_{\mathrm{ESC}}$ : Calor contido na escória ( $\left.\mathrm{kcal} / \mathrm{at}-\mathrm{Fe}\right)$.

$\mathrm{C}_{\mathrm{RQ}}$ : Calor gerado pelas reações químicas na Zona de Elaboração. 
Considerando a temperatura de referência de $950{ }^{\circ} \mathrm{C}$, e por ter os materiais que ingressam da Zona de Preparação para a Zona de Elaboração uma temperatura próxima ou igual aos gases que saem da Zona de Elaboração para a Zona de Preparação, então suas respectivas entalpias se tornam iguais ou próximas como se pode olhar na figura 20, porém, a equação (81) ficará do seguinte modo:

$$
C_{N Z C}+C_{R Q}=C_{P T}+C_{G U S A}+C_{E S C}
$$

Ordenando:

$$
C_{N Z C}=C_{P T}+C_{G U S A}+C_{E S C}-C_{R Q}
$$

Na continuação serão calculados os valores para os calores do lado direito da equação (83).

\subsubsection{1.}

\section{Calor por Perdas Térmicas na Zona de Elaboração}

O Calor por perdas térmicas da Zona de Elaboração $\mathrm{C}_{\mathrm{PT}}$ será calculado para a usina a partir de um valor conhecido e medido da operação denominada $\mathrm{C}_{\mathrm{BE}} \mathrm{e}$ seu valor e um "input" como se mostra na equação seguinte.

$\mathrm{C}_{\mathrm{PT}}=\frac{\mathrm{C}_{\mathrm{BE}} \times 55,85 \times 100}{10^{6} \times \% \mathrm{Fe}}$

Onde :

$\mathrm{C}_{\mathrm{BE}}$ : é um valor medido e expresso em $\mathrm{kcal} / \mathrm{t}$ gusa

Transformando as unidades para kcal/at-Fe obtêm-se:

$$
\mathrm{C}_{\mathrm{PT}}=55,85 \times 10^{-3} \times \frac{\mathrm{C}_{\mathrm{BE}}}{\% \mathrm{Fe}}
$$




\subsubsection{2.}

\section{Calor Contido no Gusa que Sai da Zona de Elaboração}

O calor total contido no gusa que sai da Zona de Elaboração será calculado considerando o gusa como uma liga de elementos dissolvidos no ferro, então deve-se considerar o calor de dissolução dos elementos somado à entalpia da liga na temperatura do gusa.

\subsubsection{1.}

\section{Entalpia da Liga}

O cálculo da entalpia será feito para $1 \mathrm{~mol}$ de gusa, porém são considerados as frações molares dos elementos que a compõem (Fe, C, Si, P, Mn, S). A entalpia da liga é calculada para a temperatura do gusa como mostrado na equação (86).

$$
\begin{gathered}
\Delta H_{G U S A}=X_{F e} \int_{T r e f}^{T g u s a} C p_{F e} d T+X_{C} \int_{T r e f}^{T g u s a} C p_{C} d T+X_{S i} \int_{T r e f}^{T g u s a} C p_{S i} d T+ \\
X_{P} \int_{T r e f}^{T g u s a} C p_{P} d T+X_{M n} \int_{\text {Tref }}^{T g u s a} C p_{M n} d T+X_{S} \int_{\text {Tref }}^{T g u s a} C p_{S} d T
\end{gathered}
$$

Onde:

$\Delta \mathrm{H}_{\mathrm{GUSA}}$ :

$\mathrm{X}_{F e}, \mathrm{X}_{C}, \mathrm{X}_{S i}, \mathrm{X}_{P}, \mathrm{X}_{M n}, \mathrm{X}_{S}$ :

$\mathrm{Cp}_{F e}, \mathrm{Cp}_{C}, \mathrm{Cp}_{S i}, \mathrm{Cp}_{P}, \mathrm{Cp}_{M n}, \mathrm{Cp}_{s}:$
Entalpia da liga Frações molares do Fe, C, Si, P, Mn e S Poder calorífico de cada um dos compostos que constituem a liga

\subsection{1.}

\section{Cálculo das Frações Molares dos Componentes da Liga}

- $\quad$ Fração molar do Ferro:

$$
X_{F e}=\frac{\% F e \times 56}{(\% F e \times 56)+(\% C \times 12)+(\% S i \times 28)+(\% P \times 31)+(\% M n \times 55)+(\% S \times 32)}
$$

Fazendo o denominador como $\mathrm{PM}_{\mathrm{GUSA}}$

$$
X_{F e}=\frac{\% F e \times 56}{P M_{G U S A}}
$$

E de forma análoga para os demais compostos da liga: 
- $\quad$ Fração molar do Carbono:

$$
X_{C}=\frac{\% C \times 12}{P M_{G U S A}}
$$

- $\quad$ Fração molar do Silício:

$$
X_{S i}=\frac{\% S i \times 28}{P M_{G U S A}}
$$

- $\quad$ Fração molar do Fósforo:

$$
X_{P}=\frac{\% P \times 31}{P M_{G U S A}}
$$

- Fração molar do Manganês:

$$
X_{M n}=\frac{\% M n \times 55}{P M_{G U S A}}
$$

- $\quad$ Fração molar do Enxofre:

$$
X_{S}=\frac{\% S \times 32}{P M_{G U S A}}
$$

\subsection{2.}

\section{Cálculo do Poder Calorífico dos Componentes da liga}

Para o cálculo das funções dos poderes caloríficos para cada componente da liga foram utilizados valores fornecidos na tabela do anexo 1 que corresponde ao livro de Kubaschevski e que estão como uma função do tipo:

$$
C p=a+b \times T+c \times T^{2}
$$

O início do cálculo é feito pela parte correspondente à função da integral dos poderes caloríficos de cada um dos compostos da liga na equação (86) a partir dos valores fornecidos para as constantes a, b e c na equação (94) para cada um dos compostos da liga nas temperaturas correspondentes.

- $\quad X_{F e} \int_{T_{R E F}}^{T_{G U S A}}\left(C p_{F e}\right) d T$ 
Os valores de a, b e c, são 10, 0,0 respectivamente para a função de $\mathrm{Cp}_{F e}$, então a expressão (95) fica como:

$$
\begin{aligned}
& X_{F e} \int_{T_{R E F}}^{T_{G U S A}}(10) d T \quad \text { logo: } \\
& X_{F e} \int_{T_{R E F}}^{T_{G U S A}}(10) d T=10 X_{F e}\left(T_{G U S A}-T_{R E F}\right) \\
& \text { - } \quad X_{C} \int_{T_{R E F}}^{T_{G U S A}}\left(C p_{C}\right) d T
\end{aligned}
$$

Os valores de a, b e c, são: 4.1, 1.02, 2.1 respectivamente para a função de $\mathrm{Cp}_{C}$, então a expressão (97) fica como:

$$
X_{C} \int_{T_{R E F}}^{T_{G U S A}}\left(4.1+1.02 T+\frac{2.1}{T^{2}}\right) d T \quad \quad \text { logo: }
$$

$$
\begin{aligned}
& X_{C} \int_{T_{R E F}}^{T_{G U S A}}\left(4.1+1.02 T+\frac{2.1}{T^{2}}\right) d T=X_{C}\left[4.1\left(T_{G U S A}-T_{R E F}\right)+0.5\left(T_{G U S A}{ }^{2}-\right.\right. \\
& \left.\left.T_{R E F}{ }^{2}\right)-2.1\left(\frac{1}{T_{G U S A}}-\frac{1}{T_{R E F}}\right)\right]
\end{aligned}
$$

- $\quad X_{S i} \int_{T_{R E F}}^{T_{G U S A}}\left(C p_{S i}\right) d T$

Os valores de a, b e c, são: 6.2, 0, 0 respectivamente para a função de $\mathrm{Cp}_{S i}$, então a expressão (99) fica como:

$$
\begin{array}{ll}
X_{S i} \int_{T_{R E F}}^{T_{G U S A}}(6.12) d T & \text { logo: } \\
X_{S i} \int_{T_{R E F}}^{T_{G U S A}}(6.12) d T=6.12 X_{S i}\left(T_{G U S A}-T_{R E F}\right) \\
\text { • } X_{P} \int_{T_{R E F}}^{T_{G U S A}}\left(C p_{P}\right) d T
\end{array}
$$

Os valores de a, b e c, são: 4.97, 0, 0 respectivamente para a função de $\mathrm{Cp}_{P}$, então a expressão (101) fica como:

$$
X_{P} \int_{T_{R E F}}^{T_{G U S A}}(4.97) d T \quad \text { logo: }
$$


$X_{P} \int_{T_{R E F}}^{T_{G U S A}}(4.97) d T=4.97 X_{P}\left(T_{G U S A}-T_{R E F}\right)$

- $\quad X_{M n} \int_{T_{R E F}}^{T_{G U S A}}\left(C p_{M n}\right) d T$

Os valores de a, b e c, são: $11,0,0$ respectivamente para a função de $\mathrm{Cp}_{M n}$ então a expressão (103) fica como:

$$
\begin{aligned}
& X_{M n} \int_{T_{R E F}}^{T_{G U S A}}(11) d T \\
& X_{M n} \int_{T_{R E F}}^{T_{G U S A}}(11) d T=11 X_{M n}\left(T_{G U S A}-T_{R E F}\right) \\
& \text { - } \quad X_{S} \int_{T_{R E F}}^{T_{G U S A}}\left(C p_{S}\right) d T
\end{aligned}
$$

Os valores de a, b e c, são: 5.4, 5.5, 0 respectivamente para a função de $\mathrm{Cp}_{s}$ então a expressão (105) fica como:

$$
\begin{array}{cc}
X_{S} \int_{T_{R E F}}^{T_{G U S A}}(5.4+5.5 T) d T & \text { logo: } \\
X_{S} \int_{T_{R E F}}^{T_{G U S A}}(5.4+5.5 T) d T=5.4 X_{S}\left(T_{G U S A}-T_{R E F}\right)+2.75 X_{S}\left(T_{G U S A}{ }^{2}-T_{R E F}^{2}\right)
\end{array}
$$

Utilizando as equações correspondentes as frações molares: (88), (89),(90), (91), (92), (93), às das integrações dos respectivos Cps (95), (98), (100), (102), (104), (106), e substituindo na equação (86) a entalpia do gusa ficará expressado como:

$$
\begin{aligned}
& H_{G U S A}=\frac{T_{G U S A}-T_{R E F}}{P M_{G U S A}}[560 \times \% F e+170.8 \times \% S i+605 \times \% M n+49.2 \times \\
& \% C+172.8 \times \% S]+\frac{T_{G U S A}{ }^{2}-T_{R E F}{ }^{2}}{P M_{G U S A}}\left[6 \times 10^{-3} \times \% C+88 \times 10^{-3} \times \% S\right]- \\
& \frac{25.2 \times 10^{5} \times \% C}{P M_{G U S A}}\left[\frac{1}{T_{G U S A}}-\frac{1}{T_{R E F}}\right]
\end{aligned}
$$


4.4.1.2.2.

Cálculo do Calor de Dissolução dos Elementos Si, S, Mn, P e C no Ferro

O calor por dissolução será calculado a partir da equação (108)

$\Delta H_{G U S A}=5.585 \times 10^{-2} \times \frac{\Delta H_{G U S A}{ }^{M}}{\% F e}$

Onde:

$$
\begin{aligned}
& \Delta H_{G U S A}{ }^{M}=\Delta H_{C}{ }^{M}+\Delta H_{S i}{ }^{M}+\Delta H_{P}{ }^{M}+\Delta H_{M n}{ }^{M}+\Delta H_{S}{ }^{M} \\
& \Delta H_{C}{ }^{M}=1000 \times \frac{58.5 \times(\% C)^{2}+156.6 \times \% C+141}{2.5 \times \% C+67.2} \quad\left[\frac{\text { Kcal }}{t_{\text {gusa }}}\right]
\end{aligned}
$$

$\Delta H_{S i}{ }^{M}=-30907 \times N_{S i} \times \frac{\% S i}{100} \times \frac{1000}{28 \times N_{S i}}$

$$
\Delta H_{S i}{ }^{M}=-11038.2 \times \% S i \quad\left[\frac{\text { Kcal }}{t_{\text {gusa }}}\right]
$$

$\Delta H_{P}{ }^{M}=\left(N_{P}\right) \times(-29.200)$

$$
\Delta H_{P}{ }^{M}=-9428.48 \times \% P \quad\left[\frac{\mathrm{Kcal}}{t_{\text {gusa }}}\right]
$$

$\Delta H_{M n}{ }^{M}=976 \times N_{M n}$

$\Delta H_{M n}{ }^{M}=177.45 \times \% M n \quad\left[\frac{\text { Kcal }}{t_{\text {gusa }}}\right]$

$\Delta H_{S}{ }^{M}=-34310 \times N_{S}$

$\Delta H_{S}{ }^{M}=-10721.88 \times \% S \quad\left[\frac{\text { Kcal }}{t_{\text {gusa }}}\right]$ 
Substituindo as equações (110), (111), (112), (113), (114) em (108) pode-se encontrar a entalpia de dissolução.

$$
\begin{aligned}
& \Delta H_{\text {GUSA }}=\frac{5.585 \times 10^{-2}}{\% F e} \times\left[\left(1000 \times \frac{58.5 \times(\% C)^{2}+156.6 \times \% C+141}{2.5 \times \% C+67.2}\right)-(11038.2 \times\right. \\
& \% S i)-(9428.48 \times \% P)+(177.45 \times \% M n)-(10721.88 \times \% S)]
\end{aligned}
$$

Para o cálculo do Calor Contido no gusa somamos as equações (107) e (115)

$$
\begin{aligned}
& \boldsymbol{C}_{\text {GUSA }}=\left\{\frac{T_{G U S A}-T_{R E F}}{P M_{G U S A}}[560 \times \% F e+170.8 \times \% S i+605 \times \% M n+49.2 \times\right. \\
& \% C+172.8 \times \% S]+\frac{T_{G U S A}{ }^{2}-T_{R E F}{ }^{2}}{P M_{G U S A}}\left[6 \times 10^{-3} \times \% C+88 \times 10^{-3} \times \% S\right]- \\
& \left.\frac{25.2 \times 10^{5} \times \% C}{P M_{G U S A}}\left[\frac{1}{T_{G U S A}}-\frac{1}{T_{R E F}}\right]\right\}+ \\
& \left\{\frac{5.585 \times 10^{-2}}{\% F e} \times\left[\left(1000 \times \frac{58.5 \times(\% C)^{2}+156.6 \times \% C+141}{2.5 \times \% C+67.2}\right)-(11038.2 \times \% S i)-\right.\right. \\
& (9428.48 \times \% P)+(177.45 \times \% M n)-(10721.88 \times \% S)]\}
\end{aligned}
$$

\subsubsection{3. \\ Calor Contido na Escória que Sai da Zona de Elaboração}

A escória é uma mistura de óxidos em estado líquido, o procedimento feito para o cálculo do calor contido no gusa é similar para a escória. O calor contido na escória é igual à entalpia que possui a escória na temperatura que sai da Zona de Elaboração somada ao calor de formação da escória.

\subsubsection{1.}

\section{Entalpia da Escória}

A escória esta composta por os seguintes compostos: $\mathrm{FeO}, \mathrm{CaO}, \mathrm{SiO}_{2}$, $\mathrm{Al}_{2} \mathrm{O}_{3}, \mathrm{MgO}, \mathrm{MnO}$, e $\mathrm{S}$ (na forma de $\mathrm{CaS}$ ).

O cálculo da entalpia será feita para 1 mol de escória, porém são consideradas as frações molares dos elementos que a compõem. A entalpia da escória é calculada para a temperatura da escória como mostrado na equação (117). 


$$
\begin{aligned}
\Delta H_{\text {ESCORIA }} & =X_{\mathrm{FeO}} \int_{\text {Tref }}^{\text {Tescoria }} C p_{\mathrm{FeO}} d T+X_{\mathrm{CaO}} \int_{\text {Tref }}^{\text {Tescoria }} C p_{\mathrm{CaO}} d T+X_{\mathrm{SiO}_{2}} \int_{\mathrm{Tref}^{T e s c o r i a}}^{\text {Tref }} C p_{\mathrm{SiO}_{2}} d T+ \\
& X_{\mathrm{Al}_{2} \mathrm{O}_{3}} \int_{\text {Tref }}^{\text {Tescoria }} C p_{\mathrm{Al}_{2} \mathrm{O}_{3}} d T+X_{\mathrm{MgO} \mathrm{O}} \int_{\text {Tref }}^{\text {Tescoria }} C p_{\mathrm{MgO}} d T+X_{\mathrm{MnO}} \int_{\text {Tref }}^{\text {Tescoria }} C p_{\mathrm{MnO}} d T+ \\
& X_{\mathrm{CaS}} \int_{\text {Tref }}^{\text {Tescoria }} C p_{\mathrm{CaS}} d T
\end{aligned}
$$

Onde:

$\Delta \mathrm{H}_{\mathrm{ESCORIA}}:$

Entalpia da escória.

$\mathrm{X}_{\mathrm{FeO}}, \mathrm{X}_{\mathrm{CaO}}, \mathrm{X}_{\mathrm{SiO} 2}, \mathrm{X}_{\mathrm{Al2O} 3}, \mathrm{X}_{\mathrm{MgO} O}$ : $\quad$ Frações molares do $\mathrm{FeO}, \mathrm{CaO}, \mathrm{SiO}_{2}, \mathrm{Al}_{2} \mathrm{O}_{3}$, $\mathrm{X}_{\mathrm{MnO},}, \mathrm{X}_{S}$ $\mathrm{MgO}, \mathrm{MnO}$, e S.

$\mathrm{Cp}_{\mathrm{FeO}}, \mathrm{Cp}_{\mathrm{CaO}}, \mathrm{Cp}_{\mathrm{SiO} 2}, \mathrm{Cp}_{\mathrm{Al2O} 3}, \quad$ Poder calorífico de cada um dos compostos $\mathrm{Cp}_{M g O}, \mathrm{Cp}_{M n O}, \mathrm{Cp}_{S}: \quad$ que constituem a escória

\subsection{1.}

\section{Cálculo das Frações Molares que Compõem a Escória}

- $\quad$ Fração molar do $\mathrm{FeO}$

$X_{\mathrm{FeO}}=$

$\overline{(71.85 \times \% \mathrm{FeO})+(56 \% \times \mathrm{CaO})+\left(60 \% \times \mathrm{SiO}_{2}\right)+\left(102 \% \times \mathrm{Al}_{2} \mathrm{O}_{3}\right)+(40 \times \% \mathrm{MgO})+(71 \% \times \mathrm{MnO})+(2,25 \times 72 \times \% \mathrm{CaS})}$

Fazendo o denominador como PM $\mathrm{ESCÓRIA}_{\mathrm{A}}$

$X_{F e O}=\frac{71.85 \times \% F e}{P M_{E S C O R I A}}$

E de forma análoga para os demais compostos da escória:

- $\quad$ Fração molar do $\mathrm{CaO}$

$X_{C a O}=\frac{56 \times \% C a O}{P M_{E S C O ́ R I A}}$ 
- $\quad$ Fração molar do $\mathrm{SiO}_{2}$

$X_{\mathrm{SiO}_{2}}=\frac{60 \% \times \mathrm{SiO}_{2}}{P M_{E S C O ́ R I A}}$

- $\quad$ Fração molar do $\mathrm{Al}_{2} \mathrm{O}_{3}$

$X_{\mathrm{Al}_{2} \mathrm{O}_{3}}=\frac{102 \% \times \mathrm{Al}_{2} \mathrm{O}_{3}}{P M_{\text {ESCÓRIA }}}$

- $\quad$ Fração molar do $\mathrm{MgO}$

$$
X_{M g O}=\frac{40 \times \% M g O}{P M_{E S C O ́ R I A}}
$$

- $\quad$ Fração molar do $\mathrm{MnO}$

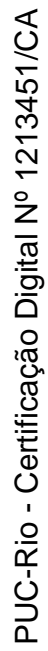

$$
X_{M n O}=\frac{71 \% \times M n O}{P M_{E S C O ́ R I A}}
$$

- $\quad$ Fração molar do CaS

$$
X_{C a S}=\frac{162 \times \% C a S}{P M_{E S C O ́ R I A}}
$$

\subsection{2.}

\section{Cálculo do Poder Calorífico dos Compostos que Formam a Escória}

O cálculo das funções dos poderes calorífico para cada componente da escória é feito utilizando os valores fornecidos na tabela do anexo 1 que corresponde ao livro de Kubaschevski e que estão como uma função do tipo: $C p=$ $a+b \times T+c \times T^{2}$.

A partir dos valores fornecidos para a, b e c na equação (94) para cada um dos compostos da escória nas temperaturas correspondentes, é possível iniciar o 
cálculo da parte correspondente da integral dos Cps de cada um de estes compostos da escória na equação (117).

- $\quad X_{F e O} \int_{T_{R E F}}^{T_{\text {ESCÓRIA }}}\left(C p_{\mathrm{FeO}}\right) d T$

Os valores de a, b e c, são 16.3, 0, 0 respectivamente para a função de $\mathrm{Cp}_{F e O}$, então a expressão (126) fica como:

$$
\begin{aligned}
& X_{F e O} \int_{T_{R E F}}^{T_{E S C O ́ R I A}}(16.3) d T \\
& X_{F e O} \int_{T_{R E F}}^{T_{E S C O ́ R I A}}(16.3) d T=16.3 X_{F e O}\left(T_{E S C O ́ R I A}-T_{R E F}\right)
\end{aligned}
$$

- $\quad X_{C a O} \int_{T_{R E F}}^{T_{E S C O R I A}}\left(C p_{C a O}\right) d T$

Os valores de a, b e c, são 11.86, 1.08, -1.66 respectivamente para a função de $\mathrm{Cp}_{\mathrm{CaO}}$, então a expressão (128) fica como:

$$
X_{C a O} \int_{T_{R E F}}^{T_{E S C O ́ R I A}}\left(11.86+1.08 T-1.66 T^{-2}\right) d T \quad \text { logo: }
$$

$$
\begin{aligned}
& X_{C a O} \int_{T_{R E F}}^{T_{E S C O ́ R I A}}\left(11.86+1.08 T-1.66 T^{-2}\right) d T=X_{C a O}\left[1 1 . 8 6 \left(T_{E S C O ́ R I A}-\right.\right. \\
& \left.\left.T_{R E F}\right)+0.54\left(T_{E S C O ́ R I A}{ }^{2}-{T_{R E F}}^{2}\right)+1.66\left(\frac{1}{T_{E S C O ́ R I A}}-\frac{1}{T_{R E F}}\right)\right]
\end{aligned}
$$

- $\quad X_{\mathrm{SiO}_{2}} \int_{T_{\mathrm{REF}}}^{T_{E S C O R I A}}\left(\mathrm{Cp}_{\mathrm{SiO}_{2}}\right) d T$

Os valores de a, b e c, são 14.41, 1.94, 0 respectivamente para a função de $\mathrm{Cp}_{\mathrm{SiO} 2}$, então a expressão (130) fica como:

$$
\begin{aligned}
& X_{\text {SiO }_{2}} \int_{T_{R E F}}^{T_{E S C O ́ R I A}}(14.41+1.94 T) d T \quad \text { logo: } \\
& X_{\text {SiO }_{2}} \int_{T_{R E F}}^{T_{E S C O ́ R I A}}(14.41+1.94 T) d T=X_{\text {SiO }_{2}}\left[14.41\left(T_{E S C O ́ R I A}-T_{R E F}\right)+\right. \\
& \left.0.97\left(T_{\text {ESCÓRIA }}^{2}-T_{R E F}^{2}\right)\right]
\end{aligned}
$$


- $\quad X_{\mathrm{Al}_{2} \mathrm{O}_{3}} \int_{T_{R E F}}^{T_{E S C O ́ R I A}}\left(\mathrm{Cp}_{\mathrm{Al}_{2} \mathrm{O}_{3}}\right) d T$

Os valores de a, b e c, são $25.48,4.25,-6.82$ respectivamente para a função de $\mathrm{Cp}_{\mathrm{Al2O}}$, então a expressão (132) fica como:

$$
\begin{aligned}
& X_{A l_{2} O_{3}} \int_{T_{R E F}}^{T_{E S C O ́ R I A}}\left(25.48+4.25 T-6.82 T^{-2}\right) d T \quad \text { logo: } \\
& X_{A l_{2} O_{3}} \int_{T_{R E F}}^{T_{E S C O ́ R I A}}\left(25.48+4.25 T-6.82 T^{-2}\right) d T=X_{A l_{2} O_{3}}\left[2 5 . 4 8 \left(T_{E S C O ́ R I A}-\right.\right. \\
& \left.\left.T_{R E F}\right)+2.125\left(T_{E S C O ́ R I A}{ }^{2}-T_{R E F}{ }^{2}\right)+6.82\left(\frac{1}{T_{E S C O ́ R I A}}-\frac{1}{T_{R E F}}\right)\right]
\end{aligned}
$$

- $\quad X_{M g O} \int_{T_{R E F}}^{T}$ ESCÓRIA $\left(C p_{M g O}\right) d T$

Os valores de a, b e c, são 10.74, 2.435, -2.26 respectivamente para a função de $\mathrm{Cp}_{M g O}$, então a expressão (134) fica como:

$$
X_{M g O} \int_{T_{R E F}}^{T_{E S C O ́ R I A}}\left(10.74+2.435 T-2.26 T^{2}\right) d T \quad \text { logo: }
$$

$$
X_{M g O} \int_{T_{R E F}}^{T_{E S C O ́ R I A}}\left(10.74+2.435 T-2.26 T^{2}\right) d T=X_{M g O}\left[1 0 . 7 4 \left(T_{E S C O ́ R I A}-\right.\right.
$$$$
\left.\left.T_{R E F}\right)+1.2175\left(T_{E S C O ́ R I A}{ }^{2}-{T_{R E F}}^{2}\right)-0.75\left(T_{E S C O ́ R I A}{ }^{3}-T_{R E F}{ }^{3}\right)\right]
$$

- $\quad X_{M n O} \int_{T_{R E F}}^{T_{E S C O ́ R I A}}\left(C p_{M n O}\right) d T$

Os valores de a, b e c, são 11.11, 1.94, -0.88 respectivamente para a função de $\mathrm{Cp}_{M n O}$, então a expressão (136) fica como:

$$
\begin{aligned}
& X_{M n O} \int_{T_{R E F}}^{T_{E S C O ́ R I A}}\left(11.11+1.94 T-0.88 T^{-2}\right) d T \\
& X_{M n O} \int_{T_{R E F}}^{T_{E S C O ́ R I A}}\left(11.11+1.94 T-0.88 T^{-2}\right) d T=X_{M n O}\left[1 1 . 1 1 \left(T_{E S C O ́ R I A}-\right.\right. \\
& \left.\left.T_{R E F}\right)+0.97\left(T_{E S C O ́ R I A}{ }^{2}-T_{R E F}{ }^{2}\right)+0.88\left(\frac{1}{T_{E S C O ́ R I A}}-\frac{1}{T_{R E F}}\right)\right]
\end{aligned}
$$


- $\quad X_{C a S} \int_{T_{R E F}}^{T_{E S C O ́ R I A}}\left(C p_{C a S}\right) d T$

Os valores de a, b e c, são 10.72, 3.8, 0 respectivamente para a função de $\mathrm{Cp}_{\text {CaS }}$, então a expressão (138) fica como:

$$
\begin{array}{cc}
X_{C a S} \int_{T_{R E F}}^{T_{E S C O ́ R I A}}(10.72+3.8 T) d T & \text { logo: } \\
X_{C a S} \int_{T_{R E F}}^{T_{E S C O ́ R I A}}(10.72+3.8 T) d T= & X_{C a S}\left[10.72\left(T_{E S C O ́ R I A}-T_{R E F}\right)+\right. \\
& \left.1.9\left(T_{E S C O ́ R I A}{ }^{2}-T_{R E F}{ }^{2}\right)\right]
\end{array}
$$

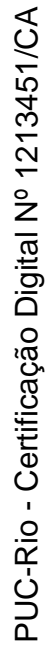

Utilizando as equações correspondentes as frações molares: (119), (120),(121), (122), (123), (124), (125), as das integrações dos respectivos Cps (127), (129), (131), (133), (135), (137), (139) e substituindo na equação (117) a entalpia da escória ficará expressada como:

$$
\begin{aligned}
& \Delta H_{\text {ESCORIA }}=\left\{\frac{71.85 \times \% F e}{P M_{E S C O R I A}} \times 16.3\left(T_{\text {ESCÓRIA }}-T_{R E F}\right)\right\}+\left\{\frac{56 \times \% C a O}{P M_{\text {ESCÓRIA }}} \times\right. \\
& {\left[11.86\left(T_{E S C O ́ R I A}-T_{R E F}\right)+0.54\left(T_{E S C O ́ R I A}{ }^{2}-T_{R E F}{ }^{2}\right)+1.66\left(\frac{1}{T_{E S C O ́ R I A}}-\right.\right.}
\end{aligned}
$$

$\left.\left.\left.\frac{1}{T_{R E F}}\right)\right]\right\}+\left\{\frac{60 \% \times S^{2} O_{2}}{P M_{E S C O ́ R I A}} \times\left[14.41\left(T_{E S C O ́ R I A}-T_{R E F}\right)+0.97\left(T_{E S C O ́ R I A}{ }^{2}-\right.\right.\right.$

$\left.\left.\left.T_{R E F}^{2}\right)\right]\right\}+\left\{\frac{102 \% \times \mathrm{Al}_{2} \mathrm{O}_{3}}{P M_{\text {ESCÓRIA }}} \times\left[25.48\left(T_{\text {ESCÓRIA }}-T_{R E F}\right)+2.125\left(T_{\text {ESCÓRIA }}{ }^{2}-\right.\right.\right.$

$\left.\left.\left.T_{R E F}^{2}\right)+6.82\left(\frac{1}{T_{E S C O ́ R I A}}-\frac{1}{T_{R E F}}\right)\right]\right\}+\left\{\frac{40 \times \% M g O}{P M_{E S C O ́ R I A}} \times\left[10.74\left(T_{E S C O ́ R I A}-T_{R E F}\right)+\right.\right.$

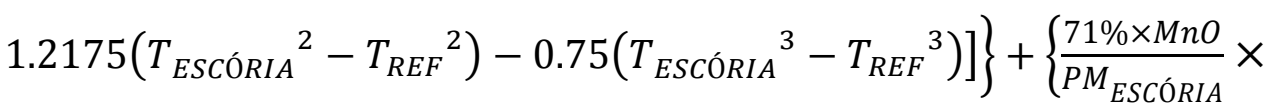

$\left[11.11\left(T_{E S C O ́ R I A}-T_{R E F}\right)+0.97\left(T_{E S C O ́ R I A}{ }^{2}-T_{R E F}{ }^{2}\right)+0.88\left(\frac{1}{T_{E S C O ́ R I A}}-\right.\right.$

$\left.\left.\left.\frac{1}{T_{R E F}}\right)\right]\right\}+\left\{\frac{162 \times \% C a S}{P M_{E S C O ́ R I A}} \times\left[10.72\left(T_{E S C O ́ R I A}-T_{R E F}\right)+1.9\left(T_{E S C O ́ R I A}{ }^{2}-T_{R E F}{ }^{2}\right)\right]\right\}$ 


\subsubsection{2.}

\section{Entalpia da formação da Escória}

A entalpia da formação da escória corresponde a um dado pratico avaliado no laboratório e será definida utilizando a referência 19 (Rist, A., Meysson, N.) é igual a:

$$
\Delta H_{F . E S C}=125000 \times V_{E S C} \quad \mathrm{kcal} / \mathrm{t} \text {-gusa }
$$

Onde:

$\mathrm{V}_{\text {ESC }}$ : Volume de escória expressado em kg/t-gusa

Que mudando de unidades para kcal/at-Ferro será igual a:

$$
\Delta H_{F . E S C}=6.98 \times 10^{-3} \times \frac{V_{E S C}}{\% F e} \quad \mathrm{kcal} / \mathrm{at}-\text { Ferro }
$$

A soma das equações 140 e 142 representam o calor contido na escória que sai da Zona de elaboração

$$
\begin{aligned}
& C_{\text {ESCÓRIA }}=\left\{\frac{5.585 \times 10^{-3} \times V_{E S C}}{P M_{E S C} \times \% F e}\right\} \times\left\langle\left\{\frac{71.85 \times \% F e}{P M_{E S C O ́ R I A}} \times 16.3\left(T_{E S C O ́ R I A}-T_{R E F}\right)\right\}+\right. \\
& \left\{\frac{56 \times \% C a O}{P M_{E S C O ́ R I A}} \times\left[11.86\left(T_{E S C O ́ R I A}-T_{R E F}\right)+0.54\left(T_{E S C O ́ R I A}{ }^{2}-T_{R E F}{ }^{2}\right)+\right.\right. \\
& \left.\left.1.66\left(\frac{1}{T_{E S C O ́ R I A}}-\frac{1}{T_{R E F}}\right)\right]\right\}+\left\{\frac{60 \% \times S i O_{2}}{P M_{E S C O ́ R I A}} \times\left[14.41\left(T_{E S C O ́ R I A}-T_{R E F}\right)+\right.\right. \\
& \left.\left.0.97\left(T_{E S C O ́ R I A}{ }^{2}-T_{R E F}{ }^{2}\right)\right]\right\}+\left\{\frac{102 \% \times A l_{2} O_{3}}{P M_{E S C O ́ R I A}} \times\left[25.48\left(T_{E S C O ́ R I A}-T_{R E F}\right)+\right.\right. \\
& \left.\left.2.125\left(T_{E S C O ́ R I A}{ }^{2}-T_{R E F}{ }^{2}\right)+6.82\left(\frac{1}{T_{E S C O ́ R I A}}-\frac{1}{T_{R E F}}\right)\right]\right\}+\left\{\frac{40 \times \% M g O}{P M_{E S C O ́ R I A}} \times\right. \\
& {\left[10.74\left(T_{E S C O ́ R I A}-T_{R E F}\right)+1.2175\left(T_{E S C O ́ R I A}{ }^{2}-T_{R E F}{ }^{2}\right)-0.75\left(T_{E S C O ́ R I A}{ }^{3}-\right.\right.} \\
& \left.\left.\left.T_{R E F}^{3}\right)\right]\right\}+\left\{\frac{71 \% \times M n O}{P M_{E S C O ́ R I A}} \times\left[11.11\left(T_{E S C O ́ R I A}-T_{R E F}\right)+0.97\left(T_{E S C O ́ R I A}{ }^{2}-\right.\right.\right. \\
& \left.\left.\left.T_{R E F}^{2}\right)+0.88\left(\frac{1}{T_{E S C O ́ R I A}}-\frac{1}{T_{R E F}}\right)\right]\right\}+\left\{\frac{162 \times \% C a S}{P M_{E S C O ́ R I A}} \times\left[10.72\left(T_{E S C O ́ R I A}-T_{R E F}\right)+\right.\right. \\
& \left.\left.\left.1.9\left(T_{E S C O ́ R I A}^{2}-T_{R E F}{ }^{2}\right)\right]\right\}\right\rangle
\end{aligned}
$$


4.4.1.4.

Calor Produzido pelas Reações Químicas na Zona de Elaboração

As reações químicas que ocorrem na Zona de Elaboração são de Redução Direta, tanto dos óxidos ferrosos como dos óxidos não ferrosos. Do estudo de equilíbrio são considerados estas reações, cuja soma de suas respetivas entalpias nos fornecerão o calor produzido pelas reações químicas na Zona de Elaboração:

Óxidos não Ferrosos:

$$
\begin{array}{ll}
\mathrm{SiO}_{(\mathrm{g})}+\mathrm{C}=\mathrm{Si}+\mathrm{CO}_{(\mathrm{g})} & ---\Delta \mathrm{H}_{\mathrm{Si}} \\
\mathrm{P}_{2} \mathrm{O}_{5}+\mathrm{C}={ }_{2} \mathrm{P}+{ }_{5} \mathrm{CO}_{(\mathrm{g})} & ---\Delta \mathrm{H}_{\mathrm{P}} \\
\mathrm{MnO}+\mathrm{C}=\mathrm{Mn}+\mathrm{CO}_{(\mathrm{g})} & ---\Delta \mathrm{H}_{\mathrm{Mn}} \\
\mathrm{C}+\mathrm{S}+\mathrm{CaO}=\mathrm{CaS}+\mathrm{CO}_{(\mathrm{g})} & ---\Delta \mathrm{H}_{\mathrm{S}}
\end{array}
$$

Óxidos Ferrosos:

$$
\begin{array}{ll}
\mathrm{FeO}+\mathrm{C}=\mathrm{Fe}+\mathrm{CO}_{2(\mathrm{~g})} & ---\Delta \mathrm{H}_{\mathrm{C}}=\Delta \mathrm{H}_{\mathrm{RD}} \\
\mathrm{FeO}+\mathrm{H}_{2(\mathrm{~g})}=\mathrm{Fe}+\mathrm{H}_{2} \mathrm{O}_{(\mathrm{v})} & ---\Delta \mathrm{H}_{\mathrm{H} 2} \\
\mathrm{FeO}+\mathrm{CO}_{(\mathrm{g})}=\mathrm{Fe}+\mathrm{CO}_{2(\mathrm{~g})} & ---\Delta \mathrm{H}_{\mathrm{CO}}=\Delta \mathrm{H}_{\mathrm{RI}}
\end{array}
$$

$\mathrm{C}_{\mathrm{RQ}}=\Delta \mathrm{H}_{\mathrm{Si}}+\Delta \mathrm{H}_{\mathrm{P}}+\Delta \mathrm{H}_{\mathrm{Mn}}+\Delta \mathrm{H}_{\mathrm{S}}+\Delta \mathrm{H}_{\mathrm{RD}}+\Delta \mathrm{H}_{\mathrm{H} 2}+\Delta \mathrm{H}_{\mathrm{RI}}$

\subsubsection{1.} Fração-Porcentagem de Redução das Reações que Ocorrem na Zona de Elaboração

Para calcular cada uma das entalpias das reações necessitamos determinar a fração ou porcentagem de contribuição de cada reação para a redução de um átomo de ferro.

\subsection{1.}

Fração de Contribuição das Reações de Redução dos óxidos não Ferrosos na Zona de Elaboração

Do estudo do Equilíbrio percebe-se que as reduções dos óxidos não ferrosos podem ser consideradas como do tipo:

$\mathrm{MO}+\mathrm{C}=\mathrm{M}+\mathrm{CO}_{(\mathrm{g})}$ 
É possível observar que a reação está relacionada a um mol de ferro, de modo que o valor de contribuição resulta de multiplicar a quantidade de oxigênio tratado, esta quantidade pode ser obtida da tabela (1) de resumo das Reduções Diretas e que serão: $G_{S i}, 2,5 G_{P}, G_{M n}, G_{S}$, respectivamente para as reações dos óxidos não ferrosos.

$\begin{array}{lll} & & \text { Fração de contribuição } \\ \mathrm{SiO}_{(\mathrm{g})}+\mathrm{C}=\mathrm{Si}+\mathrm{CO}_{(\mathrm{g})} & \rightarrow & \mathrm{G}_{\mathrm{Si}} \\ \mathrm{P}_{2} \mathrm{O}_{5}+\mathrm{C}={ }_{2} \mathrm{P}+{ }_{5} \mathrm{CO}_{(\mathrm{g})} & \rightarrow & 2,5 \mathrm{G}_{\mathrm{P}} \\ \mathrm{MnO}+\mathrm{C}=\mathrm{Mn}+\mathrm{CO}_{(\mathrm{g})} & \rightarrow & \mathrm{G}_{\mathrm{Mn}} \\ \mathrm{C}+\mathrm{S}+\mathrm{CaO}=\mathrm{CaS}+\mathrm{CO}_{(\mathrm{g})} & \rightarrow & \mathrm{G}_{\mathrm{S}}\end{array}$

\subsection{2. \\ Fração de Contribuição das Reações de Redução dos Óxidos Ferrosos na Zona de Elaboração}

Também do estudo do equilíbrio, as reações de redução dos óxidos ferrosos podem ser descritas em forma geral como:

$\mathrm{FeO}+$ Redutor $=\mathrm{Fe}+$ Produto Oxidado

É possível Observar que a reação relaciona cada átomo de oxigênio (de cada mol de óxido de ferro) que é reduzido por mol de redutor. Assim cada mol de óxido de ferro é reduzido por três tipos de redutores como mostrado nas equações (149-151); logo, a porcentagem de contribuição de cada reação corresponderá a dividir a quantidade de oxigênio (tratados por redutor) por o total de oxigênios tratados pelos três redutores.

\section{Oxigênio tratado Porcentagem de contribuição}

$$
\begin{array}{ll}
\mathrm{FeO}+\mathrm{C}=\mathrm{Fe}+\mathrm{CO}_{(\mathrm{g})} & \rightarrow X-G \\
\mathrm{FeO}+\mathrm{H}_{2(\mathrm{~g})}=\mathrm{Fe}+\mathrm{H}_{2} \mathrm{O}_{(\mathrm{v})} \rightarrow \frac{K_{H} \times Z}{K_{H+1}} & \frac{X-G}{1.05+\omega} \\
\mathrm{FeO}+\mathrm{CO}_{(\mathrm{g})}=\mathrm{Fe}+\mathrm{CO}_{2(\mathrm{~g})} \rightarrow 1.05+\omega+G-\left[X+\frac{K_{H} \times Z}{K_{H+1}}\right] & \frac{1.05+\omega+G-\left[X+\frac{K_{H} \times Z}{K_{H+1}}\right]}{1.05+\omega}
\end{array}
$$


4.4.1.4.2.

Entalpia das Reações de Redução dos Óxidos não Ferrosos

na Zona de Elaboração

- $\quad$ Para o $\mathrm{SiO} \quad \mathrm{SiO}_{(\mathrm{g})}+\mathrm{C}=\mathrm{Si}+\mathrm{CO}_{(\mathrm{g})}$

$\Delta H_{S i}{ }^{\prime}=\Delta H_{C O}{ }^{\circ}-\Delta H_{S i O}{ }^{\circ}+\int_{298}^{T}{ }_{S i}\left[\left(C p_{S i}+C p_{C O}\right)-\left(C p_{S i O}+C p_{C}\right)\right] d T$

Levando em conta os valores dos poderes caloríficos temos:

$$
\begin{aligned}
& \Delta H_{S i}{ }^{\prime}=-3.2 \times 10^{3}+0.78 \times\left(T_{S i}-298\right)+0.67 \times 10^{-3} \times\left(T_{S i}{ }^{2}-298^{2}\right)- \\
& 1 \times 10^{5} \times\left(\frac{1}{T_{S i}}-\frac{1}{298}\right) \quad\left(\frac{\mathrm{cal}}{\mathrm{mol}}\right)
\end{aligned}
$$

A entalpia da redução do $\mathrm{SiO}$ em kcal/at-ferro considerando a fração de contribuição da reação pode ser então expressada como:

- $\quad$ Para o $\mathrm{P}_{2} \mathrm{O}_{5}: \quad \mathrm{P}_{2} \mathrm{O}_{5}+\mathrm{C}={ }_{2} \mathrm{P}+{ }_{5} \mathrm{CO}_{(\mathrm{g})}$

$$
\Delta H_{P}{ }^{\prime}=\Delta H_{C O}{ }^{\circ}-\Delta H_{P_{2} O_{5}}{ }^{\circ}+\int_{298}^{T_{P}}\left[\left(2 C p_{P}+5 C p_{C O}\right)-\left(C p_{P_{2} O_{5}}+5 C p_{C}\right)\right] d T
$$

Levando em conta os valores dos poderes caloríficos temos:

$$
\begin{aligned}
& \Delta H_{P}{ }^{\prime}=-22.6 \times 10^{3}+15.02 \times\left(T_{P}-298\right)+27.1 \times 10^{-3} \times\left(T_{P}{ }^{2}-298^{2}\right)+ \\
& 9.55 \times 10^{5} \times\left(\frac{1}{T_{P}}-\frac{1}{298}\right) \quad\left(\frac{\mathrm{cal}}{\mathrm{mol}}\right)
\end{aligned}
$$

A entalpia da redução do $\mathrm{P}_{2} \mathrm{O}_{5}$ em kcal/at-ferro considerando a fração de contribuição da reação pode ser então expressada como: 


$$
\begin{gathered}
\Delta H_{P}=\frac{2.5 \times G_{P}}{1000} \times\left[-22.6 \times 10^{3}+15.02 \times\left(T_{P}-298\right)+27.1 \times 10^{-3} \times\right. \\
\left.\left(T_{P}{ }^{2}-298^{2}\right)+\quad 9.55 \times 10^{5} \times\left(\frac{1}{T_{P}}-\frac{1}{298}\right)\right]
\end{gathered}
$$

- $\quad$ Para o $\mathrm{MnO} \quad \mathrm{MnO}+\mathrm{C}=\mathrm{Mn}+\mathrm{CO}_{(\mathrm{g})}$

$\Delta H_{M n}{ }^{\prime}=\Delta H_{C O}{ }^{\circ}-\Delta H_{M n}{ }^{\circ}+\int_{298}^{T_{M n}}\left[\left(C p_{M n}+C p_{C O}\right)-\left(C p_{M n O}+C p_{C}\right)\right] d T--(158)$

Levando em conta os valores dos poderes caloríficos temos:

$$
\begin{gathered}
\Delta H_{M n}{ }^{\prime}=65.75 \times 10^{3}+2.98 \times\left(T_{M n}-1410\right)+0.97 \times 10^{-3} \times\left(T_{M n}{ }^{2}-\right. \\
\left.1410^{2}\right)-2.87 \times 10^{5} \times\left(\frac{1}{T_{M n}}-\frac{1}{1410}\right) \quad\left(\frac{\mathrm{cal}}{\mathrm{mol}}\right)
\end{gathered}
$$

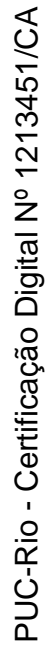

A entalpia da redução do $\mathrm{MnO}$ em kcal/at-ferro considerando a fração de contribuição da reação pode ser então expressada como:

$$
\begin{aligned}
\Delta H_{M n}= & \frac{G_{M n}}{1000} \times\left[65.75 \times 10^{3}+2.98 \times\left(T_{M n}-1410\right)+0.97 \times 10^{-3} \times\right. \\
& \left.\left(T_{M n}{ }^{2}-1410^{2}\right)-2.87 \times 10^{5} \times\left(\frac{1}{T_{M n}}-\frac{1}{1410}\right)\right]
\end{aligned}
$$

- $\quad$ Para a reação de dessulfuração:

$$
\mathrm{C}+\mathrm{S}+\mathrm{CaO}=\mathrm{CaS}+\mathrm{CO}_{(\mathrm{g})}
$$

$$
\begin{aligned}
\Delta H_{S}{ }^{\prime}= & \Delta H_{C a S}{ }^{\circ}+\Delta H_{C O}{ }^{\circ}-\Delta H_{C a O}{ }^{\circ}+\int_{298}^{T S}\left[\left(C p_{C a S}+C p_{C O}\right)-\left(C p_{C a O}+\right.\right. \\
& \left.\left.C p_{S}+C p_{C}\right)\right] d T
\end{aligned}
$$

Levando em conta os valores dos poderes caloríficos temos:

$$
\begin{gathered}
\Delta H_{S}{ }^{\prime}=15200-5.09 \times\left(T_{S}-298\right)+1.34 \times 10^{-3} \times\left(T_{S}{ }^{2}-298^{2}\right)-3.65 \times \\
10^{5} \times\left(\frac{1}{T_{S i}}-\frac{1}{298}\right) \\
\left(\frac{\mathrm{cal}}{\mathrm{mol}}\right)
\end{gathered}
$$

A entalpia da reação de dessulfuração do $\mathrm{S}$ em kcal/at-ferro considerando a fração de contribuição da reação pode ser então expressada como: 


$$
\begin{aligned}
\Delta H_{S}= & \frac{G_{S}}{1000} \times\left[15200-5.09 \times\left(T_{S}-298\right)+1.34 \times 10^{-3} \times\left(T_{S}{ }^{2}-298^{2}\right)-\right. \\
& \left.3.65 \times 10^{5} \times\left(\frac{1}{T_{S i}}-\frac{1}{298}\right)\right]
\end{aligned}
$$

\subsubsection{3.}

\section{Entalpia das Reações de Redução dos Óxidos Ferrosos na Zona de Elaboração}

- Para a redução com o Carbono: $\quad \mathrm{FeO}+\mathrm{C}=\mathrm{Fe}+\mathrm{CO}_{(\mathrm{g})}$

$$
\Delta H_{R D}{ }^{\prime}=\Delta H_{C O}{ }^{\circ}-\Delta H_{F e O}{ }^{\circ}+\int_{298}^{T_{R D}}\left[\left(C p_{C O}+C p_{F e}\right)-\left(C p_{F e O}+C p_{C}\right)\right] d T
$$

Levando em conta os valores dos poderes caloríficos a equação (164) fica como:

$$
\begin{gathered}
\Delta H_{R D}{ }^{\prime}=36.94 \times 10^{3}-7.13 \times\left(T_{R D}-1181\right)+1.31 \times 10^{-3} \times\left(T_{R D}{ }^{2}-\right. \\
\left.1181^{2}\right)-2.62 \times 10^{5} \times\left(\frac{1}{T_{R D}}-\frac{1}{1181}\right) \quad\left(\frac{\mathrm{cal}}{\mathrm{mol}}\right)
\end{gathered}
$$

A entalpia da redução do $\mathrm{FeO}$ pelo Carbono em kcal/at-ferro considerando a fração de contribuição da reação pode ser então expressada como:

$$
\begin{aligned}
\Delta H_{R D}= & \frac{X-G}{1.05+\omega} \times\left[36.94 \times 10^{3}-7.13 \times\left(T_{R D}-1181\right)+1.31 \times 10^{-3} \times\right. \\
& \left.\left(T_{R D}^{2}-1181^{2}\right)-2.62 \times 10^{5} \times\left(\frac{1}{T_{R D}}-\frac{1}{1181}\right)\right]
\end{aligned}
$$

- $\quad$ Para o $\mathrm{H}_{2}$ : $\quad \mathrm{FeO}+\mathrm{H}_{2(\mathrm{~g})} \quad=\mathrm{Fe}+\mathrm{H}_{2} \mathrm{O}_{(\mathrm{g})}$

$$
\Delta H_{\mathrm{H}_{2}}{ }^{\prime}=\Delta H_{\mathrm{H}_{2} \mathrm{O}}{ }^{\circ}-\Delta H_{\mathrm{FeO}}{ }^{\circ}+\int_{298}^{T_{H_{2}}}\left[\left(C p_{\mathrm{H}_{2} \mathrm{O}}+C p_{\mathrm{Fe}}\right)-\left(C p_{\mathrm{H}_{2}}+C p_{\mathrm{FeO}}\right)\right] d T
$$

Levando em conta os valores dos poderes caloríficos a equação (167) fica como: 


$$
\begin{gathered}
\Delta H_{H_{2}}{ }^{\prime}= \\
4.41 \times 10^{3}-9.17 \times\left(T_{H_{2}}-1181\right)+2.22 \times 10^{-3} \times\left({T_{H_{2}}}^{2}-\right. \\
\left.1181^{2}\right)-0.63 \times 10^{5} \times\left(\frac{1}{T_{H_{2}}}-\frac{1}{1181}\right) \quad\left(\frac{\mathrm{cal}}{\mathrm{mol}}\right)
\end{gathered}
$$

A entalpia da redução do $\mathrm{FeO}$ pela $\mathrm{H}_{2} \mathrm{O}$ em kcal/at-ferro considerando a fração de contribuição da reação pode ser então expressada como:

$$
\begin{aligned}
\Delta H_{H_{2}}= & \frac{K_{H} \times Z}{1000 \times\left(K_{H+1}\right)(1.05+\omega)} \times\left[4.41 \times 10^{3}-9.17 \times\left(T_{H_{2}}-1181\right)+2.22 \times\right. \\
& \left.10^{-3} \times\left({T_{H_{2}}}^{2}-1181^{2}\right)-0.63 \times 10^{5} \times\left(\frac{1}{T_{H_{2}}}-\frac{1}{1181}\right)\right]
\end{aligned}
$$

- $\quad$ Para a redução com o CO: $\quad \mathrm{FeO}+\mathrm{CO}_{(\mathrm{g})} \quad=\mathrm{Fe}+\mathrm{CO}_{2(\mathrm{~g})}$

$$
\Delta H_{R I}{ }^{\prime}=\Delta H_{C_{2}{ }^{\circ}}{ }^{\circ}-\Delta H_{F e O}{ }^{\circ}+\int_{298}^{T_{R I}}\left[\left(C p_{C O_{2}}+C p_{F e}\right)-\left(C p_{F e O}+C p_{C O}\right)\right] d T
$$

Levando em conta os valores dos poderes caloríficos temos:

$$
\begin{gathered}
\Delta H_{R I}{ }^{\prime}=3.56 \times 10^{3}-6.06 \times\left(T_{R I}-1181\right)+1.9 \times 10^{-3} \times\left(T_{R I}{ }^{2}-\right. \\
\left.1181^{2}\right)+3 \times 10^{5} \times\left(\frac{1}{T_{R I}}-\frac{1}{1181}\right) \quad\left(\frac{\mathrm{cal}}{\mathrm{mol}}\right)
\end{gathered}
$$

A entalpia da redução do $\mathrm{FeO}$ pelo $\mathrm{CO}$ em kcal/at-ferro considerando a fração de contribuição da reação pode ser então expressada como:

$$
\begin{aligned}
\Delta H_{H_{2}}= & \frac{1.05+\omega+G-\left[X+\frac{K_{H} \times Z}{K_{H+1}}\right]}{1.05+\omega} \times\left[3.56 \times 10^{3}-6.06 \times\left(T_{R I}-1181\right)+1.9 \times\right. \\
& \left.10^{-3} \times\left(T_{R I}^{2}-1181^{2}\right)+3 \times 10^{5} \times\left(\frac{1}{T_{R I}}-\frac{1}{1181}\right)\right]
\end{aligned}
$$

$\mathrm{O}$ cálculo do calor produzido pelas reações químicas na Zona de Elaboração, $\mathrm{C}_{\mathrm{RQ}}$ é igual à soma das equações: (154), (157), (160), (163), (166), (169), (172) 


$$
\begin{aligned}
& C_{R Q}=\left\{\frac{G_{S i}}{1000} \times\left[-3.2 \times 10^{3}+0.78 \times\left(T_{S i}-298\right)+0.67 \times 10^{-3} \times\right.\right. \\
& \left.\left.\left(T_{S i}{ }^{2}-298^{2}\right)-1 \times 10^{5} \times\left(\frac{1}{T_{S i}}-\frac{1}{298}\right)\right]\right\}+\left\{\frac{2.5 \times G_{P}}{1000} \times\left[-22.6 \times 10^{3}+\right.\right. \\
& 15.02 \times\left(T_{P}-298\right)+27.1 \times 10^{-3} \times\left(T_{P}{ }^{2}-298^{2}\right)+9.55 \times 10^{5} \times \\
& \left.\left.\left(\frac{1}{T_{P}}-\frac{1}{298}\right)\right]\right\}+\left\{\frac{G_{M n}}{1000} \times\left[65.75 \times 10^{3}+2.98 \times\left(T_{M n}-1410\right)+0.97 \times\right.\right. \\
& \left.\left.10^{-3} \times\left(T_{M n}{ }^{2}-1410^{2}\right)-2.87 \times 10^{5} \times\left(\frac{1}{T_{M n}}-\frac{1}{1410}\right)\right]\right\}+ \\
& \left\{\frac{G_{S}}{1000} \times\left[15200-5.09 \times\left(T_{S}-298\right)+1.34 \times 10^{-3} \times\left(T_{S}{ }^{2}-298^{2}\right)-\right.\right. \\
& \left.\left.3.65 \times 10^{5} \times\left(\frac{1}{T_{S i}}-\frac{1}{298}\right)\right]\right\}+\left\{\frac{X-G}{1.05+\omega} \times\left[36.94 \times 10^{3}-7.13 \times\right.\right. \\
& \left(T_{R D}-1181\right)+1.31 \times 10^{-3} \times\left(T_{R D}{ }^{2}-1181^{2}\right)-2.62 \times 10^{5} \times \\
& \left.\left.\left(\frac{1}{T_{R D}}-\frac{1}{1181}\right)\right]\right\}+\left\{\frac{K_{H} \times Z}{1000 \times\left(K_{H+1}\right)(1.05+\omega)} \times\left[4.41 \times 10^{3}-9.17 \times\right.\right. \\
& \left(T_{H_{2}}-1181\right)+2.22 \times \quad 10^{-3} \times\left(T_{H_{2}}{ }^{2}-1181^{2}\right)-0.63 \times 10^{5} \times \\
& \left.\left.\left(\frac{1}{T_{H_{2}}}-\frac{1}{1181}\right)\right]\right\}+\left\{\frac{1.05+\omega+G-\left[X+\frac{K_{H} \times Z}{K_{H+1}}\right]}{1.05+\omega} \times\left[3.56 \times 10^{3}-6.06 \times\left(T_{R I}-1181\right)+\right.\right. \\
& \left.\left.1.9 \times 10^{-3} \times\left(T_{R I}^{2}-1181^{2}\right)+3 \times 10^{5} \times\left(\frac{1}{T_{R I}}-\frac{1}{1181}\right)\right]\right\}
\end{aligned}
$$

Até aqui foi realizado o estudo do balanço térmico da Zona de Elaboração. Como resultado deste estudo poderemos calcular na equação (83) o Calor necessário proveniente da Zona de Combustão $\mathbf{C}_{\mathbf{N Z C}}$ em (kcal/at-Fe).

\subsection{2. \\ Balanço Térmico da Zona de Combustão}

Para o estudo do balanço térmico na Zona de Combustão considera-se a temperatura entre 1400 e $1600{ }^{\circ} \mathrm{C}{ }^{(31)}$ como a temperatura que corresponde ao coque no momento que ingressa na Zona de Combustão. Adotou-se $1500{ }^{\circ} \mathrm{C}$ como uma medida média da temperatura de referência.

A figura 33 ajudará com o entendimento do balanço na zona de combustão. 


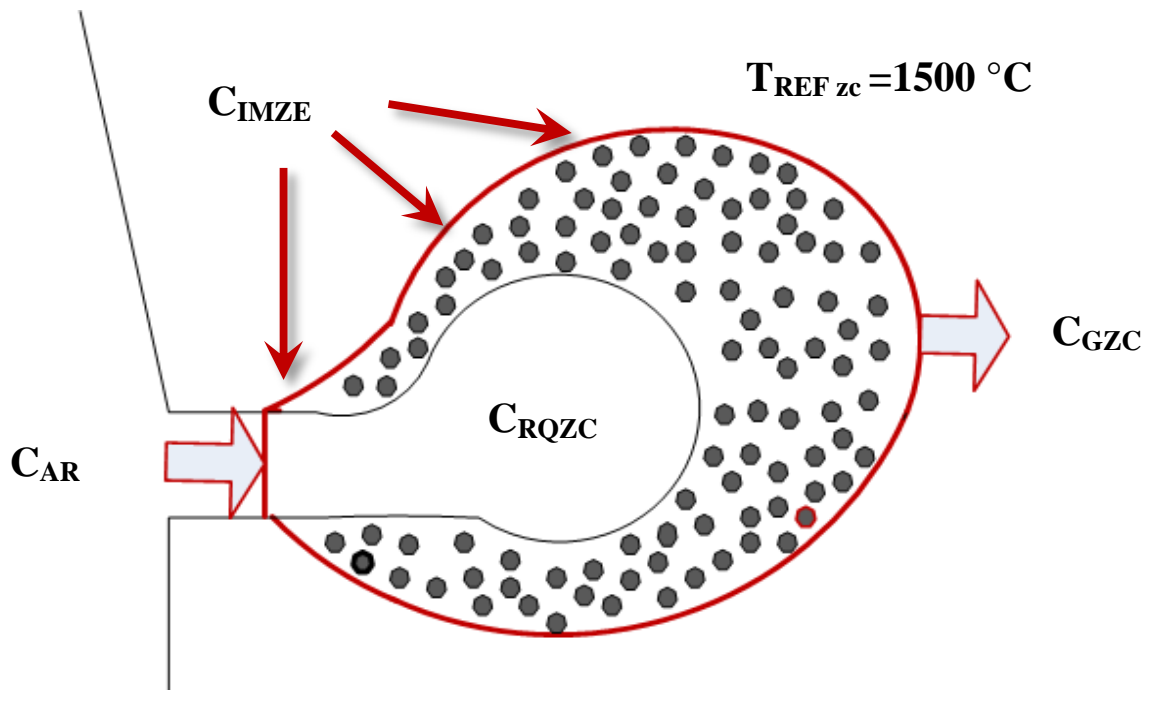

Figura 33 - Diagrama da Zona de Combustão.

A reação global para 1 átomo de Carbono que ingressa na Zona de Combustão é representada na equação (174)

$\mathrm{C}+{ }_{\mathrm{V}} \mathrm{H}_{2} \mathrm{O}+{ }_{\mathrm{GSi}} \mathrm{SiO}_{2}+{ }_{0.5(1-\mathrm{V}-\mathrm{GSi})} \mathrm{O}_{2}+0.5(79 / 21)(1-\mathrm{V}-\mathrm{GSi})$
${ }_{\mathrm{V}} \mathrm{H}_{2}+\mathrm{CO}+1.881\left(1-\mathrm{V}-\mathrm{GSi}_{2}\right) \mathrm{N}_{2}+{ }_{\mathrm{GSi}} \mathrm{SiO}$

O balanço térmico na Zona de Combustão será feito considerando que as reações químicas ocorrem adiabaticamente, sendo que todo o calor que entra na zona de Combustão, sai para a Zona de Elaboração.

A partir da figura 33 podemos fazer o seguinte analise:

$\mathrm{C}_{\mathrm{AR}}+\mathrm{C}_{\mathrm{RQZC}}+\mathrm{C}_{\mathrm{IMZE}}=\mathrm{C}_{\mathrm{GZC}}$

Onde:

$\mathrm{C}_{\mathrm{AR}}$ : Calor contido no ar de sopro que ingressa na Zona de Combustão.

$\mathrm{C}_{\mathrm{RQZC}}$ : Calor produzido pelas reações químicas na Zona de Combustão.

$\mathrm{C}_{\mathrm{IMZE}}$ : Calor contido nos materiais que ingressam da Zona de Elaboração.

$\mathrm{C}_{\mathrm{GZC}}$ : Calor Gerado na Zona de Combustão e que sai para a Zona de Elaboração.

$\mathrm{Na}$ equação (175) o termo $\mathrm{C}_{\mathrm{IMZE}}$ é igual a zero devido à temperatura de referência adotada para análise desta região $\left(1500^{\circ} \mathrm{C}\right)$ é igual à temperatura dos materiais que ingressam provenientes da Zona de Elaboração $\left(1500{ }^{\circ} \mathrm{C}\right)$. 
Logo a equação (175) ficará como:

$\mathrm{C}_{\mathrm{GZC}}=\mathrm{C}_{\mathrm{AR}}+\mathrm{C}_{\mathrm{RQZC}}$

\subsubsection{1.}

\section{Calor Contido no ar de Sopro que Ingressa na Zona de Combustão}

O calor contido no ar de sopro será calculado a partir da equação (177). O calor será calculado considerando as frações de cada composto que a compõe e o calor que aporta cada um dos mesmos.

Para os cálculos, o ar será considerado como uma mistura de gases e que contêm os seguintes compostos: $\mathrm{O}_{2}, \mathrm{~N}_{2}, \mathrm{H}_{2} \mathrm{O}$ (vapor). Os gases nobres serão considerados como somados ao $\mathrm{N}_{2}$.

$$
C_{A R}=X_{O_{2}} \int_{T R E F_{Z C}}^{T_{S O P R O}} C p_{O_{2}} d T+X_{N_{2}} \int_{T R E F_{Z C}}^{T_{S O P O}} C p_{N_{2}} d T+X_{H_{2} O} \int_{T R E F_{Z C}}^{T_{S O P R O}} C p_{\mathrm{H}_{2} \mathrm{O}} d T
$$

\subsubsection{1. \\ Fração Molar dos Compostos do ar que Ingressa na Zona de Combustão}

A partir da equação geral para a Zona de Combustão, equação (174)

$$
\begin{aligned}
& X_{O_{2}}=\frac{0.5\left(1-V-G_{S i}\right)}{2.381\left(1-G_{S i}\right)-1.381 V} \\
& X_{N_{2}}=\frac{1.881\left(1-V-G_{S i}\right)}{2.381\left(1-G_{S i}\right)-1.381 V} \\
& X_{H_{2} O}=\frac{V}{2.381\left(1-G_{S i}\right)-1.381 V}
\end{aligned}
$$




\subsubsection{2.}

Cálculo do Poder Calorífico dos Compostos que Constituem o Ar de Sopro que Ingressa na Zona de Combustão

- $\quad X_{O_{2}} \int_{T R E F_{Z C}}^{T_{S O P R O}}\left(C p_{O_{2}}\right) d T$

Os valores de a, b e c, são; 7.16, 1, - 0.4 respectivamente para a função de Cp $\mathrm{p}_{O 2}$, então a expressão (181) fica como:

$$
\begin{aligned}
& X_{O_{2}} \int_{T R E F_{Z C}}^{T_{S O P R O}}\left(7.16+T-0.4 T^{-2}\right) d T \quad \text { logo: } \\
& X_{O_{2}} \int_{T R E F_{Z C}}^{T_{S O P R O}}\left(7.16+T-0.4 T^{-2}\right) d T=X_{O_{2}}\left[7.16\left(T_{S O P R O}-T_{T R E F_{Z C}}\right)+\right. \\
& \left.0.5\left(T_{S O P R O}^{2}-T_{T R E F_{Z C}}{ }^{2}\right)+0.4\left(\frac{1}{T_{S O P R O}}-\frac{1}{T_{T R E F} Z C}\right)\right]
\end{aligned}
$$

- $\quad X_{N_{2}} \int_{T R E F_{Z C}}^{T_{S O P R O}}\left(C p_{N_{2}}\right) d T$

Os valores de a, b e c, são; 6.66, 1.02, 0, respectivamente para a função de $\mathrm{Cp}_{N 2}$, então a expressão (183) fica como:

$X_{N_{2}} \int_{T R E F_{Z C}}^{T S O P R O}(6.66+1.02 T) d T$

Logo:

$$
\begin{aligned}
X_{N_{2}} \int_{T R E F_{Z C}}^{T_{S O P O}}(6.66+1.02 T) d T & =X_{N_{2}}\left[6.66\left(T_{S O P R O}-T_{T R E F_{Z C}}\right)+\right. \\
& \left.0.51\left(T_{S O P R O}{ }^{2}-T_{T R E F_{Z C}}{ }^{2}\right)\right]
\end{aligned}
$$

- $\quad X_{\mathrm{H}_{2} \mathrm{O}} \int_{T R E F_{Z C}}^{T_{S O P R O}}\left(C p_{\mathrm{H}_{2} \mathrm{O}}\right) d T$

Os valores de a, b e c, são; 7.17, 2.56, 0.8, respectivamente para a função de $\mathrm{Cp}_{\text {H2O }}$, então a expressão (185) fica como: 
$X_{\mathrm{H}_{2} O} \int_{T R E F_{Z C}}^{T_{S O P R O}}\left(7.17+2.56 \mp 0.8 T^{-2}\right) d T$

logo:

$$
\begin{aligned}
X_{\mathrm{H}_{2} O} \int_{T_{\text {SREF }} T_{\mathrm{ZC} C}}(7.16+T- & \left.0.4 T^{-2}\right) d T=X_{\mathrm{H}_{2} O}\left[7.17\left(T_{S O P R O}-T_{T R E F_{Z C}}\right)+\right. \\
& \left.1.28\left(T_{\text {SOPRO }}{ }^{2}-T_{T_{R E F_{Z C}}}{ }^{2}\right)-0.8\left(\frac{1}{T_{S O P R O}}-\frac{1}{T_{T R E F_{Z C}}}\right)\right]
\end{aligned}
$$

O calor contido no ar de sopro que ingressa na Zona de Combustão será calculado na equação (177), a partir das equações: (178), (179), (180), (182), (184), (186).

$$
\boldsymbol{C}_{A \boldsymbol{R}}=\left\{( \frac { 0 . 5 ( 1 - V - G _ { S i } ) } { 2 . 3 8 1 ( 1 - G _ { S i } ) - 1 . 3 8 1 V } ) \left[7.16\left(T_{S O P R O}-T_{T R E F_{Z C}}\right)+0.5\left(T_{S O P R O}{ }^{2}-\right.\right.\right.
$$

$$
\begin{aligned}
& \left.\left.\left.T_{T_{R E F_{Z C}}}{ }^{2}\right)+0.4\left(\frac{1}{T_{S O P R O}}-\frac{1}{T_{T R E F} Z C}\right)\right]\right\}+\left\{( \frac { 1 . 8 8 1 ( 1 - V - G _ { S i } ) } { 2 . 3 8 1 ( 1 - G _ { S i } ) - 1 . 3 8 1 V } ) \left[6 . 6 6 \left(T_{S O P R O}-\right.\right.\right. \\
& \left.\left.\left.T_{T_{R E F_{Z C}}}\right)+0.51\left(T_{S O P R O}{ }^{2}-T_{T_{R E F_{Z C}}}^{2}\right)\right]\right\}+ \\
& \left\{( \frac { V } { 2 . 3 8 1 ( 1 - G _ { S i } ) - 1 . 3 8 1 V } ) \left[7.17\left(T_{S O P R O}-T_{T_{R E F} Z C}\right)+1.28\left(T_{S O P R O}{ }^{2}-\right.\right.\right. \\
& \left.\left.\left.T_{T R E F_{Z C}}{ }^{2}\right)-0.8\left(\frac{1}{T_{S O P R O}}-\frac{1}{T_{T R E F} Z C}\right)\right]\right\} \text {. }
\end{aligned}
$$

\subsubsection{2.}

\section{Calor Gerado pelas Reações Químicas na Zona de Combustão}

O calor gerado pelas reações químicas na Zona de Combustão corresponde à soma do calor de três contribuições: combustão do ar, reação da $\mathrm{H}_{2} \mathrm{O}$ com $\mathrm{C}$, e reação do $\mathrm{SiO}_{2}$ com $\mathrm{C}$. O cálculo do calor produzido pelas reações químicas na Zona de Combustão pode ser representado pela equação (188).

$$
C_{R Q Z C}=X_{(A R)_{Z C}} \times \Delta H_{(C-A R)_{Z C}}+X_{\left(\mathrm{H}_{2} \mathrm{O}\right)_{Z C}} \times \Delta H_{\left(\mathrm{H}_{2} \mathrm{O}\right)_{Z C}}+X_{\left(\mathrm{SiO}_{2}\right)_{Z C}} \Delta H_{\left(\mathrm{SiO}_{2}\right)_{Z C}}
$$

Onde:

$C_{R Q Z C}: \quad$ Calor produzido pelas reações químicas na Zona de Combustão. 
$\Delta H_{(C-A R)_{Z C}}:$ Calor produzido pela reação do carbono com o ar.

$\Delta H_{\left(H_{2} \mathrm{O}\right)_{Z C}}$ : Calor produzido pela reação de redução da água com o carbono.

$\Delta H_{\left(\mathrm{SiO}_{2}\right)_{Z C}}: \quad$ Calor produzido pela reação do $\mathrm{SiO}_{2}$ com o carbono.

$X_{(A R)_{Z C}}: \quad$ Fração molar do ar que reage com um átomo de carbono.

$X_{\left(\mathrm{H}_{2} \mathrm{O}\right)_{Z C}}: \quad$ Fração molar da água que reage com um átomo de carbono.

$X_{\left(\mathrm{SiO}_{2}\right)_{Z C}}: \quad$ Fração molar da $\mathrm{SiO}_{2}$ que reage com um átomo de carbono.

Para o cálculo do calor produzido por cada uma destas reações, é necessário conhecer a fração de contribuição de cada uma.

\subsubsection{1.}

\section{Fração de Contribuição das Reações na Zona de Combustão}

A fração de contribuição de cada reação será calculada a partir da equação da reação geral da Zona de Combustão representada pela equação (174).

- Combustão do Carbono com o ar:

$X_{(A R)_{Z C}}=\frac{\left(1-V-G_{S i}\right)}{1000}$

- $\quad$ Redução da água:

$$
X_{\left(H_{2} \mathrm{O}\right)_{Z C}}=\frac{V}{1000}
$$

- Redução do $\mathrm{SiO}_{2}$ :

$$
X_{\left(\mathrm{SiO}_{2}\right)_{Z C}}=\frac{G_{S i}}{1000}
$$




\subsubsection{2.}

\section{Calor das Reações Químicas que Ocorrem na Zona de Combustão}

- $\quad$ Combustão do Carbono com o ar: $\quad \mathrm{C}_{1 / 2} \mathrm{O}_{2}=\mathrm{CO}$

$$
\begin{aligned}
& \Delta H_{(C-A R)_{Z C}}=X_{(A R)_{Z C}} \times \Delta H^{\prime \prime}{ }_{(C-A R)_{Z C}} \\
& \Delta H^{\prime \prime}{ }_{(C-A R)_{Z C}}=\Delta H_{C O}^{\circ}+\int_{298}^{T_{C . A R}}\left(C p_{C O}+0.5 C p_{O_{2}}\right) d T
\end{aligned}
$$

$$
\begin{aligned}
\Delta H^{\prime \prime}{ }_{(C-A R)_{Z C}=} & {\left[-26.4 \times 10^{3}-0.89\left(T_{C . A R}-298\right)+\left(0.27 \times 10^{-3}\right)\left(T_{C . A R}{ }^{2}-\right.\right.} \\
& \left.\left.298^{2}\right)+2.19 \times 10^{5}\left(\frac{1}{T_{C . A R}}-\frac{1}{298}\right)\right]
\end{aligned}
$$

Substituindo (189) e (194) em (192)

$$
\begin{aligned}
& \Delta H_{(C-A R)_{Z C}}=\frac{\left(1-V-G_{S i}\right)}{1000} \times\left[-26.4 \times 10^{3}-0.89\left(T_{C . A R}-298\right)+(0.27 \times\right. \\
& \left.\left.10^{-3}\right)\left(T_{C . A R}{ }^{2}-298^{2}\right)+2.19 \times 10^{5}\left(\frac{1}{T_{C . A R}}-\frac{1}{298}\right)\right]
\end{aligned}
$$

- $\quad$ Redução da água: $\quad \mathrm{C}+\mathrm{H}_{2} \mathrm{O}_{(\mathrm{v})}=\mathrm{CO}_{(\mathrm{g})}+\mathrm{H}_{2(\mathrm{~g})}$

$$
\Delta H_{\left(\mathrm{H}_{2} \mathrm{O}\right)_{Z C}}=X_{\left(\mathrm{H}_{2} \mathrm{O}\right)_{Z C}} \times \Delta H^{\prime \prime}{ }_{\left(\mathrm{H}_{2} \mathrm{O}\right)_{Z C}}
$$

$$
\Delta H^{\prime \prime}{ }_{\left(H_{2} \mathrm{O}\right)_{Z C}}=\Delta H_{C O}^{\circ}-\Delta H_{H_{2} O}^{\circ}+\int_{298}^{T_{R . H_{2} O} O}\left[\left(C p_{C O}+C p_{H_{2}}\right)-\left(C p_{C}+C p_{H_{2} O}\right)\right] d T
$$

$$
\begin{aligned}
\Delta H^{\prime \prime}{ }_{\left(H_{2} O\right)_{Z C}=} & {\left[3.14 \times 10^{4}+2.11\left(T_{R . H_{2} O}-298\right)+\left(-0.91 \times 10^{-3}\right)\left(T_{R . H_{2} O}{ }^{2}-\right.\right.} \\
& \left.\left.298^{2}\right)+2.03 \times 10^{5}\left(\frac{1}{T_{R . H_{2} O}}-\frac{1}{298}\right)\right]
\end{aligned}
$$

Substituindo (190) e (198) em (196)

$$
\begin{aligned}
\Delta H_{\left(H_{2} \mathrm{O}\right)_{Z C}=} & \frac{V}{1000} \times\left[3.14 \times 10^{4}+2.11\left(T_{R . H_{2} O}-298\right)+(-0.91 \times\right. \\
& \left.\left.10^{-3}\right)\left(T_{R . H_{2} O}{ }^{2}-298^{2}\right)+2.03 \times 10^{5}\left(\frac{1}{T_{R \cdot H_{2} O}}-\frac{1}{298}\right)\right]
\end{aligned}
$$


- Redução do $\mathrm{SiO}_{2}: \quad \mathrm{SiO}_{2}+\mathrm{C}=\mathrm{SiO}+\mathrm{CO}_{(\mathrm{g})}$

$\Delta H_{\left(\mathrm{SiO}_{2}\right)_{Z C}}=X_{\left(\mathrm{SiO}_{2}\right)_{Z C}} \times \Delta H^{\prime \prime}{ }_{\left(\mathrm{SiO}_{2}\right)_{Z C}}$

$\Delta H^{\prime \prime}{ }_{\left(\mathrm{SiO}_{2}\right)_{\mathrm{ZC}}}=\Delta H_{\mathrm{CO}}^{\circ}+\Delta H_{\mathrm{SiO}}^{\circ}-\Delta H_{\mathrm{SiO}_{2}}^{\circ}+\int_{298}^{T_{R . S i O}}\left[\left(\mathrm{Cp}_{\mathrm{CO}}+C p_{\mathrm{SiO}}\right)-\right.$ $\left.\left(C p_{C}+C p_{S i O_{2}}\right)\right] d T$

$\Delta H^{\prime \prime}{ }_{\left(\mathrm{SiO}_{2}\right)_{Z C}}=$

$\left[167.4 \times 10^{3}-4.02\left(T_{T_{R . S i O}}-298\right)+\left(-0.81 \times 10^{-3}\right)\left(T_{T_{R . S i O}}{ }^{2}-\right.\right.$

$$
\left.\left.298^{2}\right)+2.69 \times 10^{5}\left(\frac{1}{T_{R . S i O_{2}}}-\frac{1}{298}\right)\right]
$$

Substituindo (191) e (202) em (200)

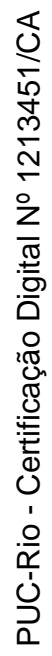

$$
\begin{gathered}
\Delta H_{\left(\mathrm{SiO}_{2}\right)_{Z C}}=\frac{G_{S i}}{1000} \times\left[167.4 \times 10^{3}-4.02\left(T_{T_{R . S i O_{2}}}-298\right)+(-0.81 \times\right. \\
\left.\left.10^{-3}\right)\left(T_{T_{R . S i O_{2}}}{ }^{2}-298^{2}\right)+2.69 \times 10^{5}\left(\frac{1}{T_{\text {R.SiO }}}-\frac{1}{298}\right)\right]
\end{gathered}
$$

Substituindo as equações (195), (199), (203) na equação (188) encontraremos o calor produzido pelas reações na Zona de Combustão.

$$
\begin{aligned}
& C_{R Q Z C}=\left\{\frac{\left(1-V-G_{S i}\right)}{1000} \times\left[-26.4 \times 10^{3}-0.89\left(T_{C . A R}-298\right)+(0.27 \times\right.\right. \\
& \left.\left.\left.10^{-3}\right)\left(T_{C . A R}{ }^{2}-298^{2}\right)+2.19 \times 10^{5}\left(\frac{1}{T_{C . A R}}-\frac{1}{298}\right)\right]\right\}+\left\{\frac{V}{1000} \times\left[3.14 \times 10^{4}+\right.\right. \\
& 2.11\left(T_{R . H_{2} O}-298\right)+\left(-0.91 \times 10^{-3}\right)\left(T_{R . H_{2} O}{ }^{2}-298^{2}\right)+2.03 \times \\
& \left.\left.10^{5}\left(\frac{1}{T_{R . H_{2} O}}-\frac{1}{298}\right)\right]\right\}+\left\{\frac{G_{S i}}{1000} \times\left[167.4 \times 10^{3}-4.02\left(T_{T_{R . S i O_{2}}}-298\right)+\right.\right. \\
& \left.\left.\left(-0.81 \times 10^{-3}\right) \quad\left(T_{T_{R . S i O_{2}}}^{2}-298^{2}\right)+2.69 \times 10^{5}\left(\frac{1}{T_{R . S i O_{2}}}-\frac{1}{298}\right)\right]\right\}
\end{aligned}
$$


Como mencionado na equação (176), o calor gerado na Zona de combustão é igual à soma das equações (187) calor contido no ar, mais a equação (204), calor produzido pelas reações químicas na zona de combustão.

$\mathrm{C}_{\mathrm{GZC}}=\mathrm{C}_{\mathrm{AR}}+\mathrm{C}_{\mathrm{RQZC}}$

$C_{G Z C}=\left\langle\left\{\left(\frac{0.5\left(1-V-G_{S i}\right)}{2.381\left(1-G_{S i}\right)-1.381 V}\right)\left[7.16\left(T_{S O P R O}-T_{T R E F_{Z C}}\right)+0.5\left(T_{S O P R O}{ }^{2}-\right.\right.\right.\right.$

$\left.\left.\left.T_{T_{R E F_{Z C}}}{ }^{2}\right)+0.4\left(\frac{1}{T_{S O P R O}}-\frac{1}{T_{T R E F} Z C}\right)\right]\right\}+\left\{\left(\frac{1.881\left(1-V-G_{S i}\right)}{2.381\left(1-G_{S i}\right)-1.381 V}\right)\left[6.66\left(T_{S O P R O}-\right.\right.\right.$

$\left.\left.\left.T_{T_{R E F_{Z C}}}\right)+0.51\left(T_{S O P R O}{ }^{2}-T_{T_{R E F_{Z C}}}^{2}\right)\right]\right\}+$

$\left\{\left(\frac{V}{2.381\left(1-G_{S i}\right)-1.381 V}\right)\left[7.17\left(T_{\text {SOPRO }}-T_{T_{R E F} Z}\right)+1.28\left(T_{S O P R O}{ }^{2}-\right.\right.\right.$

$\left.\left.\left.\left.T_{T_{R E F_{Z C}}{ }^{2}}\right)-0.8\left(\frac{1}{T_{S O P R O}}-\frac{1}{T_{T R E F} Z C}\right)\right]\right\}\right\rangle+\left\langle\left\{\frac{\left(1-V-G_{S i}\right)}{1000} \times\left[-26.4 \times 10^{3}-\right.\right.\right.$

$0.89\left(T_{C . A R}-298\right)+\left(0.27 \times 10^{-3}\right)\left(T_{C . A R}^{2}-298^{2}\right)+2.19 \times 10^{5}\left(\frac{1}{T_{C . A R}}-\right.$

$\left.\left.\left.\frac{1}{298}\right)\right]\right\}+$

$\left\{\frac{V}{1000} \times\left[3.14 \times 10^{4}+2.11\left(T_{R . H_{2} O}-298\right)+\left(-0.91 \times 10^{-3}\right)\left(T_{R . H_{2} O}{ }^{2}-\right.\right.\right.$

$\left.\left.\left.298^{2}\right)+2.03 \times 10^{5}\left(\frac{1}{T_{R . H_{2} O}}-\frac{1}{298}\right)\right]\right\}+\left\{\frac{G_{S i}}{1000} \times\left[167.4 \times 10^{3}-4.02\left(T_{T_{R . S i O}}-\right.\right.\right.$

$\left.\left.\left.298)+\left(-0.81 \times 10^{-3}\right) \quad\left(T_{T_{R . S i O_{2}}}{ }^{2}-298^{2}\right)+2.69 \times 10^{5}\left(\frac{1}{T_{R . S i O_{2}}}-\frac{1}{298}\right)\right]\right\}\right\rangle$

\subsection{3.}

Fechamento do Balanço Térmico da Zona de Elaboração

O fechamento do balanço térmico da Zona de Elaboração permitirá calcular o carbono necessário para satisfazer a demanda térmica (CBT).

O CBT será obtido da relação do calor demandado da zona de combustão $\mathbf{C}_{\text {NZC }}$ (kcal/at-Ferro) que foi calculado no estudo do balanço térmico da Zona de Elaboração(equação 83), e do calor gerado na Zona de Combustão $\mathbf{C}_{\mathbf{G Z C}}$ (kcal/atC). O cálculo do CBT tem fundamentação na análise dimensional que foi realizada com o intuito de obter o consumo de carbono por átomo de ferro que fecha o balanço térmico. 
$C B T=\frac{\mathrm{C}_{\mathrm{NZC}}}{\mathrm{C}_{\mathrm{GZC}}} \quad\left|\frac{\frac{k c a l}{\text { at-Ferro }}}{\frac{\text { kcal }}{a t-C}}\right|=\left|\frac{a t-C}{a t-F e r r o}\right|$

Onde:

CBT: Quantidade de carbono necessário para satisfazer o balanço térmico.

$\mathrm{C}_{\mathrm{NZC}}$ : Calor demandado da zona de combustão.

$\mathrm{C}_{\mathrm{GZC}}$ : Calor total gerado na zona de combustão.

\section{5.}

\section{Equacionamento do Modelo de Geração da SMCC}

Do estudo do equilíbrio das reações temos:

$$
C E Q=\frac{1}{K_{C O}}\left[A(1-R D)-\frac{K_{H} \times z}{K_{H}+1}\right]
$$

Ordenando:

$$
C E Q \times K_{C O}=\left[A(1-R D)-\frac{K_{H} \times z}{K_{H}+1}\right]
$$

Onde:

CEQ: Carbono que satisfaz o equilíbrio

$\mathrm{K}_{\mathrm{CO}}$ : Constante de equilíbrio da redução da wustita com $\mathrm{CO}$

A: Fator igual a; $1,05+\omega+\mathrm{G}$

RD: Fração de Redução Direta

$\mathrm{K}_{\mathrm{H}}$ : Constante de equilíbrio da redução de wustita com hidrogênio.

Z: Número de átomos de hidrogênio que ingressam com a água, por átomo de ferro.

Do balanço de energia temos a equação (208) logo de ter feito um análise e incorporação da variável $\gamma$ como pode-se mostrar no apêndice II: 


$$
\begin{aligned}
& C B T=\frac{1}{C_{C Z C}}\left\{\gamma-\frac{1}{1000(1,05+\omega)}\left[(R D(A)-G) \Delta H^{\prime \prime}{ }_{R D}+(A(1-R D)-\right.\right. \\
& \left.\left.\left.\frac{K_{H} \times Z}{K_{H}+1}\right) \Delta H^{\prime \prime}{ }_{R I}\right]\right\}
\end{aligned}
$$

Ordenando:

$$
\left[A(1-R D)-\frac{K_{H} \times z}{K_{H}+1}\right]=\frac{-\left(C B T \times C_{G Z C}-\gamma\right)[1000(1,05+\omega)]-(R D(A)-G) \Delta H^{\prime \prime}{ }_{R D}}{\Delta H_{R I}}
$$

Onde:

CBT: Carbono necessário para satisfazer o balanço de energia.

$\mathrm{C}_{\mathrm{GZC}}$ : Calor fornecido pela combustão por átomo de carbono.

$\gamma: \quad$ fator igual a; (calor por perdas térmicas + calor contido no gusa + calor Contido na escória) menos (a soma das entalpias Si, Mn, P, S, $\mathrm{H}_{2}$ ).

$\omega: \quad$ fator ômega de Rist.

RD: fração de Redução Direta.

A: fator igual a; $1,05+\omega+G$

$\Delta \mathrm{H}_{\mathrm{RD}}$ : Entalpia para a Redução Direta.

$\Delta \mathrm{H}_{\mathrm{RI}}$ : Entalpia para a Redução Indireta

$\mathrm{K}_{\mathrm{H}}$ : $\quad$ Constante de equilíbrio da redução de wustita com hidrogênio.

Z: $\quad$ Número de átomos de hidrogênio que ingressam com a água, por átomo de ferro.

\subsection{1.}

\section{Estudo do Valor Mínimo do Rendimento do Gás de topo (Minimização do Valor da Relação R de Gases de topo)}

Para traçar a superfície de Mínimo consumo de carbono, é necessário encontrar os valores mínimos para a relação $\mathrm{R}$ de gases que saem pelo topo do Alto-Forno, equação (209).

$$
R_{\min }=\left(\frac{\mathrm{CO}}{\mathrm{CO}_{2}}\right) \times\left(\frac{\mathrm{H}_{2} \mathrm{O}}{\mathrm{H}_{2}}\right)
$$


O valor de $R_{\min }$ mínimo da equação (209) responderá pelo menor consumo de carbono e sua minimização será obtida com valores mínimos para $\mathrm{CO}, \mathrm{H}_{2} \mathrm{O}$ e valores máximos de $\mathrm{CO}_{2}, \mathrm{H}_{2}$ com a seguinte análise:

CO: Moles de $\mathrm{CO}$ que saem pelo gás de topo, numericamente igual aos átomos de carbono que não foram gastos na Redução Indireta. Sua minimização no gás de topo significa maiores índices de redução via Redução Indireta (exotérmicas).

$\mathrm{CO}_{2}$ : Moles de $\mathrm{CO}_{2}$ que saem pelo gás de topo, numericamente igual aos átomos de oxigênio tratados via $\mathrm{CO}$, sua maximização significa altos índices de redução via Redução Indireta.

$\mathrm{H}_{2} \mathrm{O}$ : Moles de $\mathrm{H}_{2} \mathrm{O}$ que saem pelo gás de topo, numericamente igual aos átomos de oxigênio tratados via $\mathrm{H}_{2}$, sua minimização significa uma menor demanda de energia (reações endotérmicas) $\left(\mathrm{H}_{2} \mathrm{O}_{(\mathrm{v})}+\mathrm{C} \rightarrow \mathrm{H}_{2(\mathrm{~g})}+\mathrm{CO}_{(\mathrm{g})} \quad\right.$; $\left.\mathrm{FeO}+\mathrm{H}_{2(\mathrm{~g})}=\mathrm{Fe}+\mathrm{H}_{2} \mathrm{O}_{(\mathrm{g})}\right)$.

$\mathrm{H}_{2}$ : Moles de $\mathrm{H}_{2}$ que saem pelo gás de topo, sua maximização, por ser cineticamente favorável e pouco endotérmica $\left(\mathrm{FeO}+\mathrm{H}_{2} \rightarrow \mathrm{Fe}+\mathrm{H}_{2} \mathrm{O}\right.$ $+5,7 \mathrm{kcal} / \mathrm{mol})$, minimiza o valor de $\mathrm{R}$.

\section{- Encontrando os Valores de $\mathrm{CO}, \mathrm{CO}_{2}, \mathrm{H}_{2}, \mathrm{H}_{2} \mathrm{O}$}

Lembrando que do estudo de equilíbrio das reações, para a redução do óxido de ferro na zona de elaboração equação (71) tinha-se:

$$
\left[\frac{z}{K_{H}+1} \times K_{H}\right] \mathrm{FeO}+\left[\frac{z}{K_{H}+1}\right] H_{2}=\left[\frac{z}{K_{H}+1} \times K_{H}\right] \mathrm{Fe}+\left[\frac{z}{K_{H}+1} \times K_{H}\right] H_{2} O_{-}
$$

Logo os valores para a $\mathrm{H}_{2} \mathrm{O}$ e $\mathrm{H}_{2}$ são:

$$
H_{2} O=\frac{K_{H} \times z}{K_{H}+1} \quad e \quad H_{2}=\frac{z}{K_{H}+1}
$$

Por outro lado:

$\mathbf{C O}_{2}$ : Este termo representa a quantidade de $\mathrm{CO}_{2}$ no gás de topo do Alto Forno e é proveniente da Redução Indireta dos óxidos de ferro pelo $\mathrm{CO}$, seu valor e igual a 
quantidade de oxigênio tratado por $\mathrm{CO}$, sendo seu valor igual ao obtido na tabela 2 do resumo das Reduções diretas (oxigênio que falta retirar via RI):

$C O_{2}=1,05+\omega+G-\left(X+\frac{K_{H} \times z}{K_{H}+1}\right)$

CO: É o CO que sobra e sai pelo gás de topo. É igual ao total de CO gerado na zona de combustão mais as geradas pelas RD na zona de elaboração menos o CO utilizado nas Reduções Indiretas da zona de Preparação. E é equivalente ao número de átomos de carbono contidos no gás $\mathrm{CO}$.

A partir da figura 34 pode ser feito um balanço do carbono e determinar o consumo mínimo de carbono considerando a relação Rmin com o valor mínimo.

- $\mathrm{C}_{\text {in }}$ : Carbono que ingressa para satisfazer o equilíbrio das reações e o Balanço Térmico

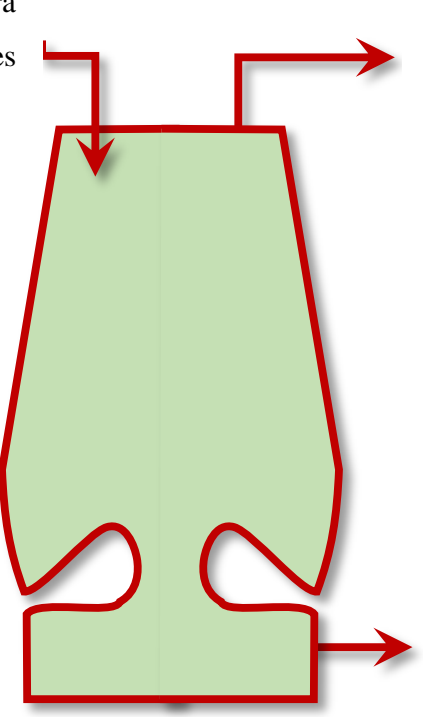
- $\mathrm{C}_{\mathrm{CO} 2}$ :Carbono que sai como parte do gás $\mathrm{CO}_{2}$ e que é produto da $\mathrm{RI}$ - $\mathrm{C}_{\mathrm{CO}}$ : Carbono que sai como parte do gás $\mathrm{CO}$ e é igual ao $\mathrm{CO}$ gerado na ZC mais o CO gerados pelas RD na zona de elaboração e menos as utilizadas nas RI

- $\mathrm{C}_{\text {gusa }}$ : Carbono que sai do AF formando parte do gusa

Figura 34 - Balanço de Carbono.

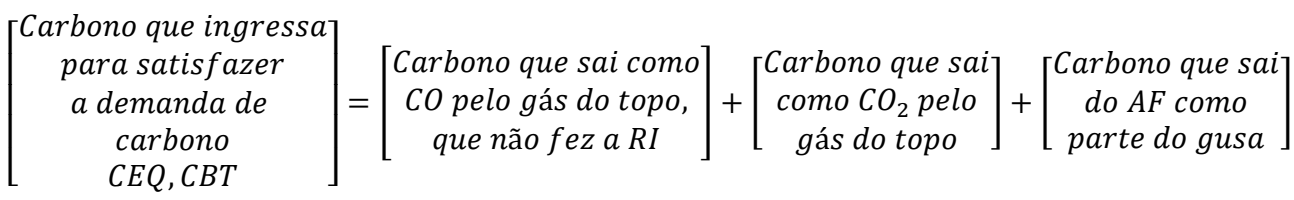

ordenando:

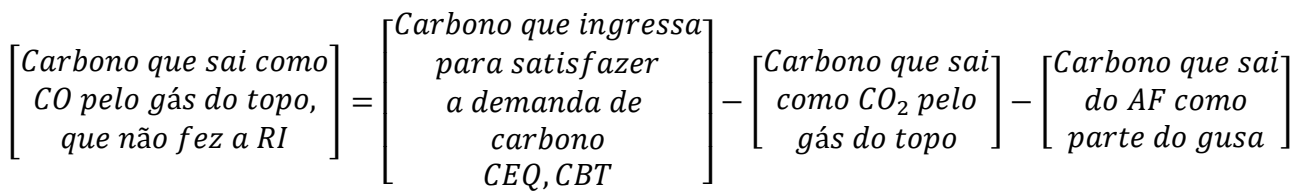


$C_{C O}=\left[\begin{array}{l}C E Q \\ \text { ou } \\ C B T\end{array}\right]-\left\{1,05+\omega+G-\left[X+\frac{K_{H} \times Z}{K_{H}+1}\right]\right\}-C_{\text {gusa }}$

Onde: $\mathrm{C}_{\mathrm{CO}}$ : e o carbono que sai como parte do gás $\mathrm{CO}$, pelo gás do topo

Fazendo $1,05+\omega+\mathrm{G}=\mathrm{A}$

e lembrando que

$X=R D(n+G)$

Na zona de Elaboração: $n=1.05+\omega$

Logo:

$X=R D_{Z E}(1.05+\omega+G)$

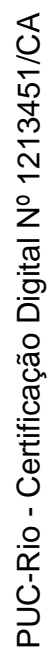

Relacionando as equações (214), (213) em (212)

$C_{C O}=\left[\begin{array}{l}C E Q \\ o u \\ C B T\end{array}\right]-\left\{1,05+\omega+G-\left[R D_{Z E}(1,05+\omega+G)+\frac{K_{H} \times Z}{K_{H}+1}\right]\right\}-C_{\text {gusa }}$

$C_{C O}=\left[\begin{array}{l}C E Q \\ \text { ou } \\ C B T\end{array}\right]-A\left(1-R D_{Z E}\right)+\frac{K_{H} \times z}{K_{H}+1}-C_{\text {gusa }}$

Onde:

$\mathrm{C}_{\mathrm{CO}}$ : $\quad$ Carbono que sai pelo gás de topo como $\mathrm{CO}$, numericamente igual ao número de moles de $\mathrm{CO}$ que sai pelo gás de topo.

CEQ: $\quad$ Carbono que ingressa para satisfazer a demanda do equilíbrio.

CBT: $\quad$ Carbono que ingressa para satisfazer o balanço energético.

Cgusa: $\quad$ Carbono que sai como parte do gusa.

$\mathrm{A}(1-\mathrm{RD})$ : Carbono gasto para à RI.

$\mathrm{K}_{\mathrm{H}} \times \mathrm{Z} /\left(\mathrm{K}_{\mathrm{H}}+1\right)$ : $\quad$ Hidrogênio gasto na redução do $\mathrm{FeO}$ 
Substituindo os valores de $\mathrm{CO}, \mathrm{CO}_{2}, \mathrm{H}_{2}, \mathrm{H}_{2} \mathrm{O}$ no valor de $\mathrm{R}$ mínimo de tal modo Que CEQ ou CBT sejam mínimos (equações 216, 211,210 em 209).

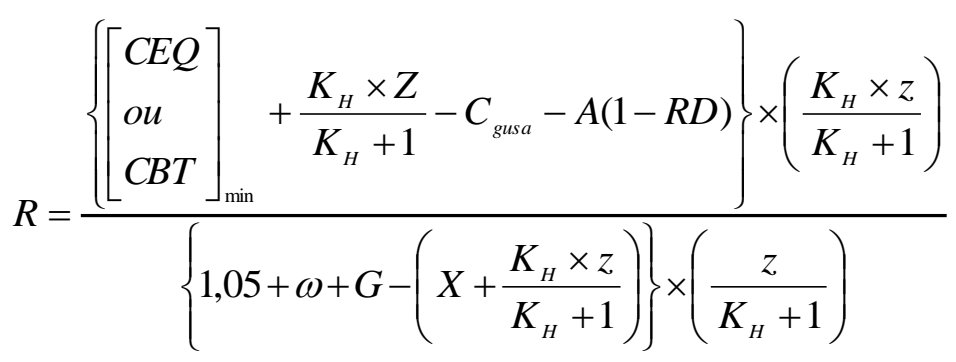

Fazendo $\mathrm{CEQmin}=\mathrm{CCeq}=$ Carbono mínimo consumido para satisfazer $\mathrm{o}$ equilíbrio, e/ou CBTmin $=\mathrm{CCen}=$ Carbono mínimo consumido para satisfazer o balanço térmico

\subsection{2.}

\section{Determinação do Consumo Mínimo de Carbono que Satisfaz o}

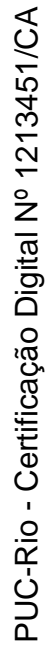

\section{Equilíbrio das Reações}

A partir da equação (217) e lembrando que: $1,05+\omega+\mathrm{G}=\mathrm{A}$

Além disso, como $\mathrm{RD}=\mathrm{X} /(\mathrm{n}+\mathrm{G})$ e como $\mathrm{n}=1,05+\mathrm{w}$ logo: $\mathrm{X}=\mathrm{A}(\mathrm{RD})$, a equação (217) torna-se:

$$
R=\frac{\left[C C e q-C_{\text {gusa }}-A(1-R D)+\frac{K_{H} \times z}{K_{H}+1}\right] \times K_{H}}{1,05+\omega+G-\left(X+\frac{K_{H} \times z}{K_{H}+1}\right)}
$$

$$
R=\frac{\left[C C e q-C_{\text {gusa }}-A(1-R D)+\frac{K_{H} \times z}{K_{H}+1}\right] \times K_{H}}{A(1-R D)-\left(\frac{K_{H} \times z}{K_{H}+1}\right)}
$$




$$
R=\frac{\left\{C C e q-C_{\text {gusa }}-\left[A(1-R D)-\frac{K_{H} \times z}{K_{H}+1}\right]\right\} \times K_{H}}{A(1-R D)-\left(\frac{K_{H} \times z}{K_{H}+1}\right)}
$$

Fazendo: $\phi=C$ Ceq-Cgusa e

$$
a=A(1-R D)-\frac{K_{H} \times z}{K_{H}+1}
$$

Na equação (215)

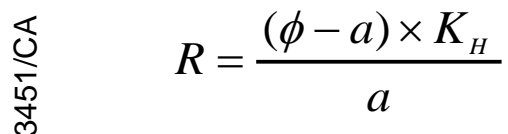

Isolando $\phi$

$$
\phi=a\left(\frac{R}{K_{H}}+1\right)
$$

Voltando para os valores originais:

$$
\begin{aligned}
& \text { CCeq-Cgusa }=\left[A(1-R D)-\frac{K_{H} \times z}{K_{H}+1}\right] \times\left(\frac{R}{K_{H}}+1\right) \\
& C \text { Ceq }=\left[A(1-R D)-\frac{K_{H} \times z}{K_{H}+1}\right] \times\left(\frac{R}{K_{H}}+1\right)+\text { Cgusa }
\end{aligned}
$$

Substituindo a equação (207) em (220) 
$C C e q=C E Q \times K_{C O} \times\left(\frac{R}{K_{H}}+1\right)+C g u s a$

\subsection{3.}

Determinação do Consumo Mínimo de Carbono que Satisfaz o Balanço Térmico

O consumo de carbono mínimo que satisfaz o balanço térmico tem forma similar a equação (220), considerando CCen assim:

$$
\text { CCen }=\left[A(1-R D)-\frac{K_{H} \times z}{K_{H}+1}\right] \times\left(\frac{R}{K_{H}}+1\right)+\text { Cgusa }
$$

CCen $=\left\{\frac{-\left(C B T \times C_{G Z C}-\gamma\right)[1000(1,05+\omega)]-(A \times R D-G) \Delta H^{\prime \prime}{ }_{R D}}{\Delta H^{\prime \prime}{ }_{R I}}\right\} \times\left(\frac{R}{K_{H}}+1\right)+C g u s a$

Com as equações (221) e (223), é possível traçar a superfície de mínimo consumo de carbono (figura 35) considerando os maiores valores para cada uma das equações que satisfazem os consumos mínimos tanto do equilíbrio como do balanço térmico assim como mostrado na equação (224.)

$\mathrm{CC}_{\mathrm{eff}}=\left\{\mathrm{CC}_{\mathrm{eq}}, \mathrm{CC}_{\mathrm{en}}\right\}_{\text {supremo } \forall \mathrm{R}, \mathrm{RD}}$ 


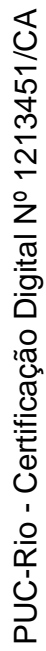

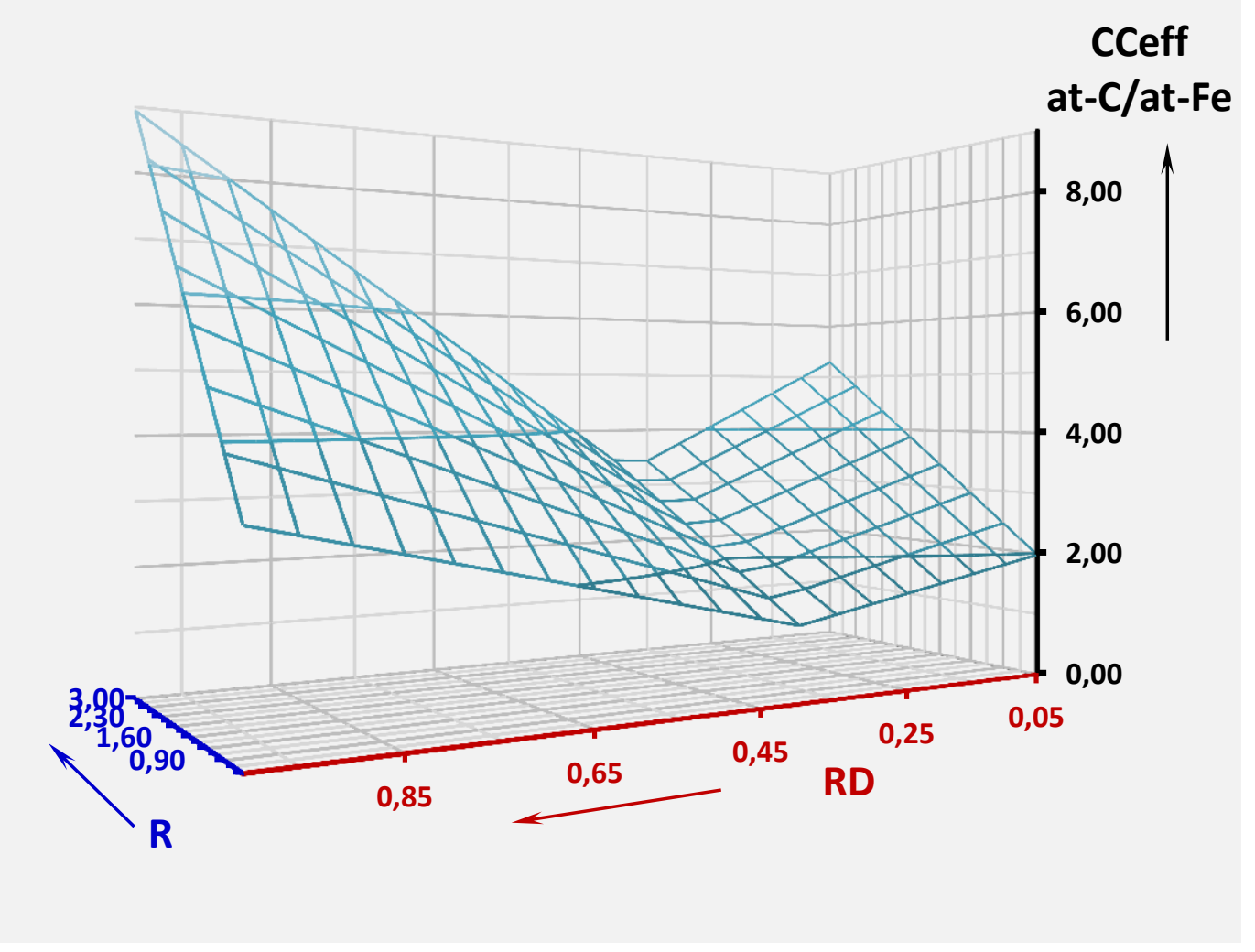

Figura 35 - Gráfico da Superfície de Mínimo Consumo de Carbono ( at-C / at-Fe). 


\section{6. \\ Diagrama do Consumo Mínimo de Coque por Fração de Redução Direta}

No dia a dia das operações numa indústria siderúrgica e mais precisamente na operação do Alto-Forno é muito mais prático ter um gráfico que proporcione as informações de consumo de carbono e a fração de Redução Direta no Alto-Forno. Este tipo de gráfico CR vs RD é possível de ser feito conhecendo valores de operação para os gases que saem pelo topo do Alto-Forno $(\mathrm{R}=1,012$ por exemplo para a figura 35). Assim a figura 36 mostra um gráfico que resulta da equação (224) considerando um valor conhecido da operação para R.

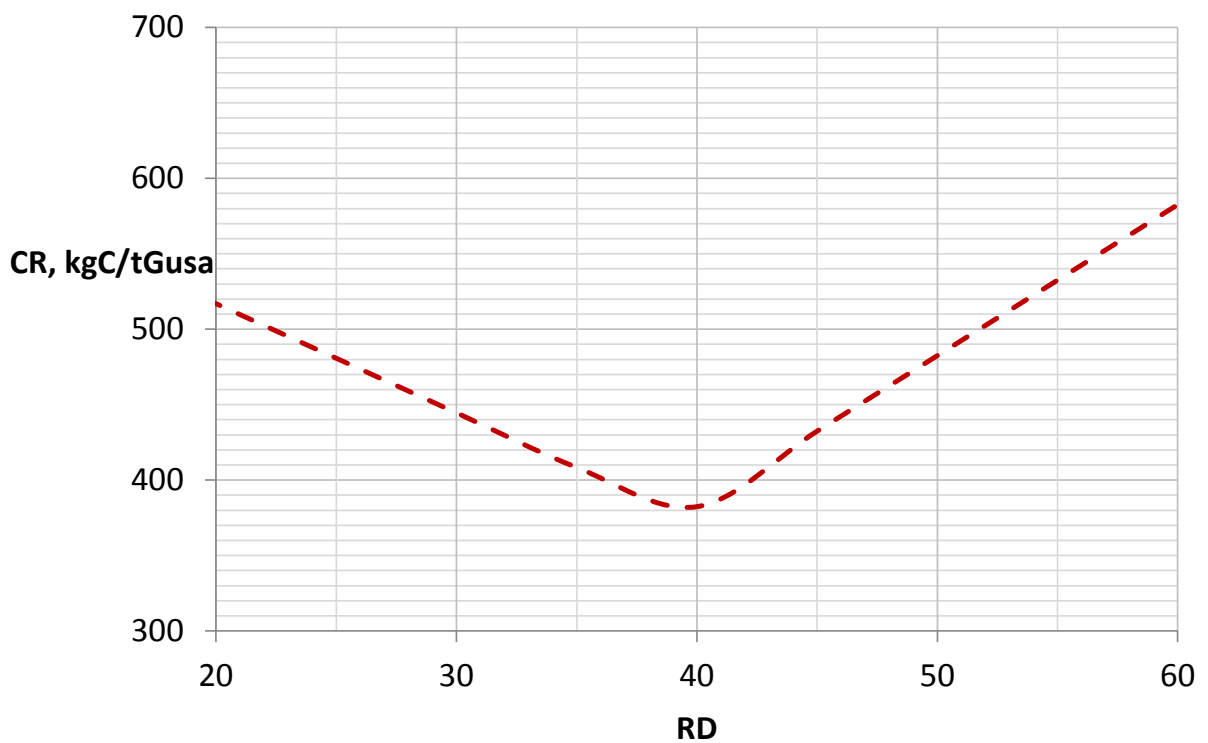

Figura 36 - Gráfico CR vs RD

\section{7.}

\section{Determinação gráfica do Ponto Operacional do Alto-Forno}

O ponto operacional de um Alto-Forno é uma representação das condições operacionais do Alto-Forno expressadas em termos de consumo de carbono (coque rate) e fração de Redução Direta (RD). O ponto operacional de um AltoForno localizado nas coordenadas: CR vs RD pode ser mostrado num gráfico tipo: consumo mínimo de carbono vs fração de RD como mostrado na figura 37 que foi traçada a partir da função que determina a superfície de consumo mínimo de carbono dado uma condição de operação (valor de R conhecido). 


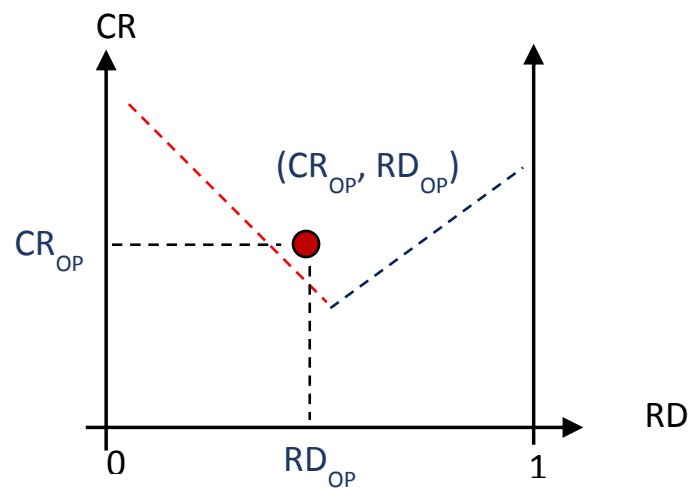

Figura 37 - Ponto Operacional do Alto-Forno (em vermelho).

Na Figura 37 pode-se olhar a linha modelada de consumo de carbono pelo Balanço Térmico (vermelho), e do equilíbrio (azul). Porém precisam-se encontrar os valores de $\mathrm{CR}_{\mathrm{OP}}$ e $\mathrm{RD}_{\mathrm{OP}}$ pertencentes à operação do Alto-Forno.

\subsection{1.}

Coque Rate da Operação: CRoP

O coque rate da operação é um dado conhecido da operação do Alto-Forno. Seu valor em quilogramas de carbono por tonelada de ferro é equivalente aos átomos de carbono gastos na redução dos óxidos ferrosos e não ferrosos menos os átomos de hidrogênio gastos na redução dos óxidos ferrosos trocados de unidade ( $\mathrm{kg} / \mathrm{tn}$ ferro) e somados à quantidade de carbono recuperada na lama do Venturi e no pó do coletor que saíram pelo topo do Alto-Forno (LAPO). Assim o coque rate e representado pela equação (224):

$$
C R_{O P}=\frac{214869(\mu-Z) \times \% F e}{C f i x}+L A P O
$$

Sendo que o $\mathrm{CR}_{\mathrm{OP}}$ é conhecido pela operação, e onde também:

Cfix: $\quad$ Conteúdo de carbono fixo no coque, que é obtido da operação. 
\%Fe: $\quad$ Porcentagem de ferro no gusa, obtido da operação.

LAPO: Conteúdo de carbono ( $\mathrm{kg} \mathrm{C} / \mathrm{t}$ gusa) no pó e a lama nos gases de saída do alto forno coletados. Dados obtidos da operação.

\subsection{2.}

Fração de Redução Direta da Operação: $\mathbf{R D}_{\mathrm{OP}}$

A fração de Redução Direta total da operação será obtida com ajuda da reta operacional de Rist (figura 38).

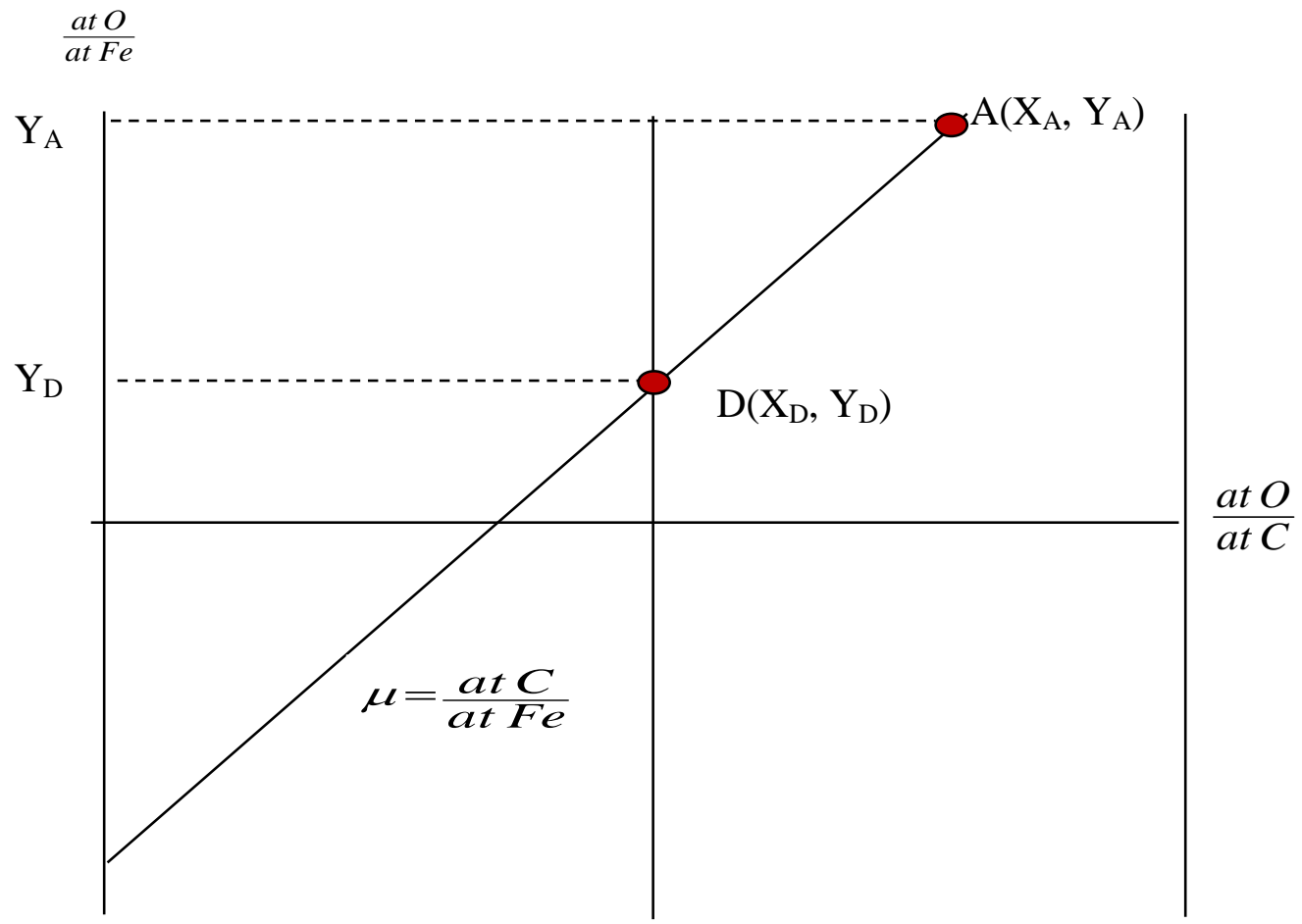

Figura 38 - Reta Operacional de Rist.

A Fração de Redução Direta na linha de operação de Rist é igual à relação: $\mathrm{Y}_{\mathrm{D}} / \mathrm{Y}_{\mathrm{A}}$ (figura 38) e é representada pela equação (225)

$$
R D_{Z E}=\frac{Y_{D}}{Y_{A}}
$$


Para analisar o $\mathrm{RD}_{\mathrm{OP}}$ total e $\mathrm{RD}_{\mathrm{ZE}}$ (equação 225) foi criado um fator de correção que correlaciona o oxigênio que entra no Alto-Forno e o que entra na Zona de Elaboração (equação 226).

$$
F C=\frac{(1.05+\omega)-K_{H} \times z}{\left(K_{H}+1\right) \times \beta}
$$

Ordenando (225)

$$
R D_{O P}=\frac{Y_{D}}{Y_{A} \times F C}
$$

Onde:

$\mathrm{Y}_{\mathrm{A}}$ : são os átomos de oxigênio na carga metálica e não metálica também conhecida como $\beta$, podendo ser calculada ou fornecida pela operação.

$\mathrm{X}_{\mathrm{A}}$ : Corresponde a: $\quad X_{A}=1+\frac{V_{\mathrm{CO}_{2}}+V_{\mathrm{H}_{2} \mathrm{O}}}{V_{\mathrm{CO}}+V_{\mathrm{CO}_{2}}+V_{\mathrm{H}_{2}}+V_{\mathrm{H}_{2} \mathrm{O}}} \quad$ onde $V_{\mathrm{CO}}, V_{\mathrm{CO}_{2}}, V_{\mathrm{H}_{2}}, V_{\mathrm{H}_{2} \mathrm{O}}$ são os volumes dos gases correspondentes no topo do Alto-Forno, e que são conhecidos da operação.

$\mathrm{X}_{\mathrm{D}}$ : interseção da reta operacional no ponto $\mathrm{D}$ quando o valor de $\mathrm{X}_{\mathrm{D}}$ e 1 (começo de produção de $\mathrm{CO}_{2}$.

FC: Fator de correção, a ser calculado pela equação 226.

$\omega$ : fator ômega de Rist da operação. Conhecido da operação.

$\mathrm{K}_{\mathrm{H}}$ : constante de equilíbrio da redução da wustita pelo hidrogênio. Calculado com os dados de operação.

z: átomos de hidrogênio que ingressam no Alto-Forno produto da umidade do ar injetado. Calculado com os dados de operação.

Como podemos observar até agora na equação (227) só falta o valor de $\mathrm{Y}_{\mathrm{D}}$ correspondente ao ponto $\mathrm{D}$ na reta operacional de Rist que é necessário para calcular o valor de $\mathrm{RD}_{\mathrm{OP}}$ na equação (227). 
$\mathrm{O}$ valor de $\mathrm{Y}_{\mathrm{D}}$ será calculado a partir da equação da reta operacional (equação 228) no gráfico de Rist, já que possuímos um ponto e também o Coque rate do processo $(\mathrm{CRP}=$ pendente $)$,

$$
Y_{D}=Y_{A}-\mu\left(X_{A}-1\right)
$$

Onde: $\mu=$ são os átomos de carbono consumidos na produção de átomos de ferro, que representa a pendente na reta de Rist.

O valor de $\mu$ será obtido colocando-o em evidência a partir da equação (224)

$$
\mu=\frac{(C R P-L A P O) \times C f i x}{214869 \times \% F e}+Z
$$

Onde:

Cfix: conteúdo de carbono fixo no coque, que é obtido da operação.

\%Fe: porcentagem de ferro no gusa (obtido da operação).

LAPO: conteúdo de carbono ( $\mathrm{kg} \mathrm{C} / \mathrm{t}$ gusa) no pó e a lama nos gases de saída do Alto-Forno coletados (dados obtidos da operação).

Então substituindo os valores de $\mu$ obtido a partir da equação (229), $\mathrm{X}_{\mathrm{A}} \mathrm{e}$ $\mathrm{Y}_{\mathrm{A}}$, calculados anteriormente, é possível determinar $\mathrm{Y}_{\mathrm{D}}$ em (228).

Consequentemente com os valores de: $\mathrm{Y}_{\mathrm{A}}, \mathrm{Y}_{\mathrm{D}}$, e FC (calculado na equação (226)), é possível determinar o valor de $\mathrm{RD}_{\mathrm{OP}}$.na equação (227).

Finalmente temos a possibilidade de traçar o ponto operacional conhecido $\mathrm{CRP}$, e RD op num gráfico do tipo $\mathrm{CR}$ vs $\mathrm{RD}$ calculado pelo modelo como mostrado na figura 39 . 


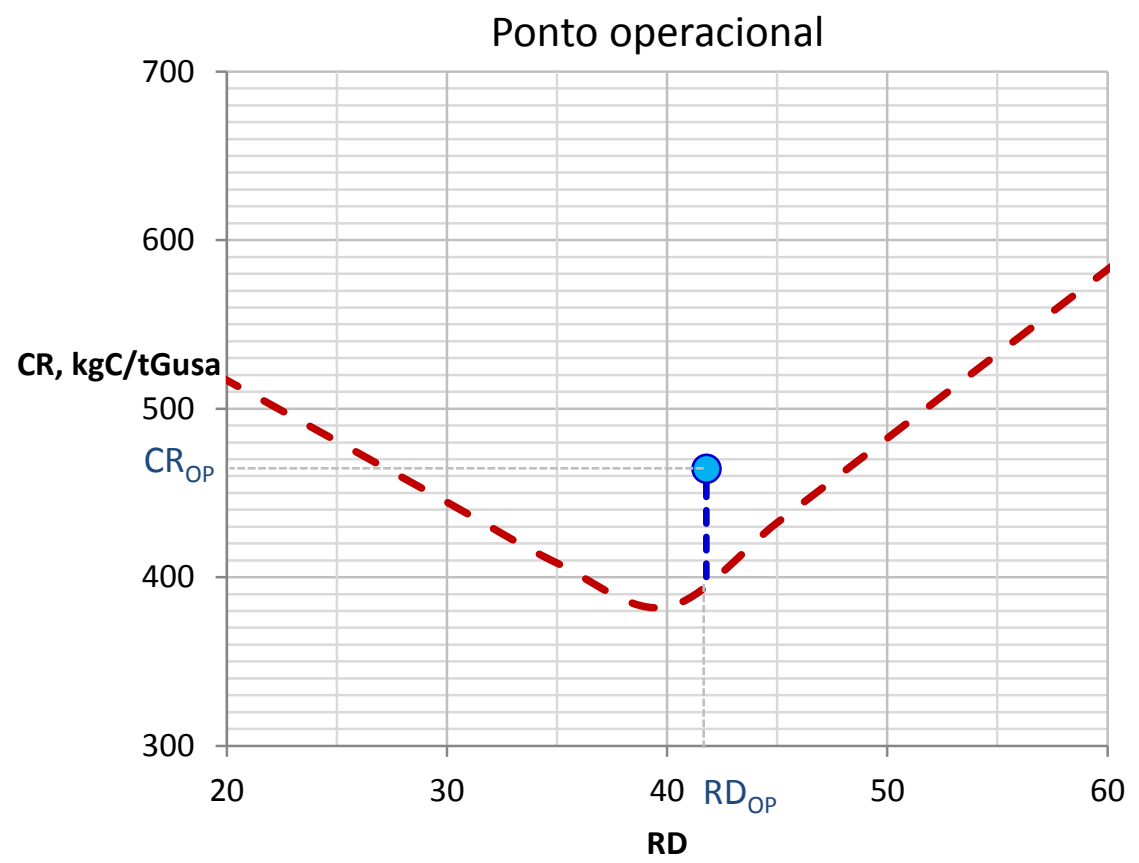

Figura 39 - Ponto Operacional (o) Junto à Curva que Satisfaz o Equilíbrio e

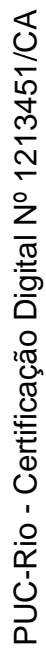
Balanço Térmico (para $\mathrm{R}=1,012$ ). 


\section{5. \\ Resultados e Discussões}

\section{1.}

Traçado da SMCC Usando as Equações do Equilíbrio, Balanço Térmico e suas Inter-Relações

Como foi determinado no capítulo 4 do desenvolvimento, o sequenciamento para a obtenção da equação (224) que permitirá obter a superfície mínima de consumo de carbono é mostrado no gráfico metodológico da figura (40).

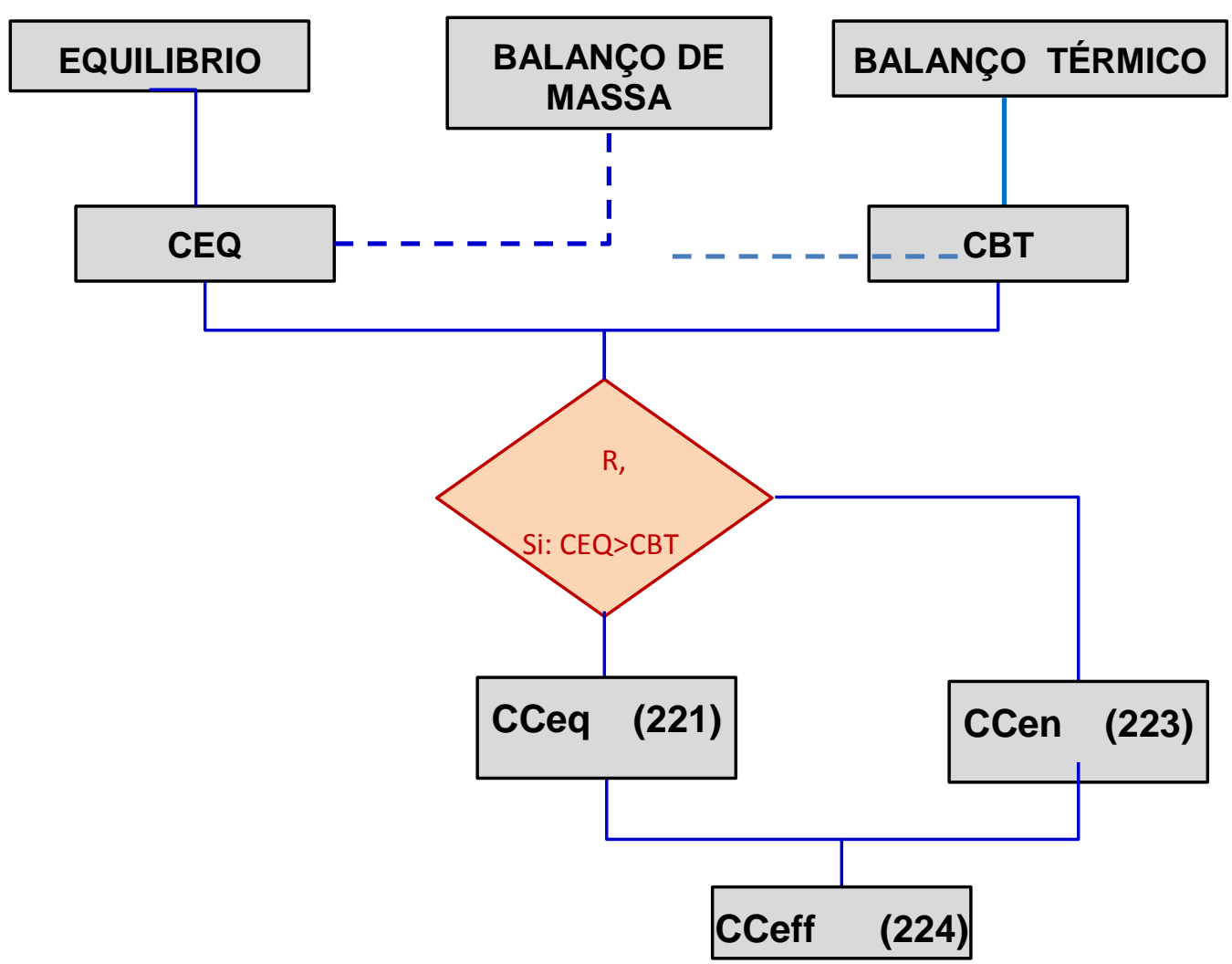

Figura 40 - Visão gráfica da metodologia do trabalho para obtenção das equações que serviram para traçar a SMCC.

Para o traçado tanto da superfície que satisfaz o equilíbrio como da demanda térmica aplicando os modelos desenvolvidos, foram consideradas as cargas alimentadas pelo topo do Alto-Forno como tendo caraterísticas definidas, assim 
como também foram definidos os produtos; ferro gusa, gás de topo e pó no gás de topo, ou seja, o modelo não determina nenhum dos elementos ou substâncias químicas das cargas metálicas.

Cabe ressaltar que neste trabalho foi adotada a metodologia clássica do modelo termoquímico estagiado do Alto-Forno (modelo IRSID) com o intuito de encontrar a satisfação dos detalhados balanços de massa, energia e equilíbrio das reações.

De acordo com Mendonça 1. Augusto ${ }^{(9)}$ as principais variáveis que estão relacionadas aos balanços de massa e energia levando em conta os ingressos e saídas definidas no Alto-Forno são:

- Total de carbono consumido.

- Composição carga metálica.

- Composição escória.

- Volume e composição do ar de sopro.

- Volume e composição do gás de topo.

- Temperaturas de referência da Zona de Elaboração e de combustão.

Considerando as relações anteriores é necessário definir os dados de entrada "inputs", que seguem listados abaixo:

- Porcentual e análise química das cargas metálicas.

- Análise química do agente redutor carregado.

- Umidade do ar, temperatura do gás de sopro.

- Composição, teor e temperatura do ferro gusa e escória produzidos.

- Massa e análise química do pó nos gases de topo do Alto-Forno.

- Porcentagem de $\mathrm{H}_{2}, \mathrm{H}_{2} \mathrm{O}, \mathrm{CO}, \mathrm{CO}_{2}$ e temperatura do gás de topo.

- Perdas térmicas da Zona de Elaboração no processo Alto-Forno. 


\subsection{1.}

\section{Traçado da Superfície que Satisfaz o Equilíbrio das Reações}

A equação (221) que satisfaz as condições de equilíbrio permitiu traçar uma superfície nos eixos $R\left(\frac{\mathrm{CO} \times \mathrm{H}_{2} \mathrm{O}}{\mathrm{CO}_{2} \times \mathrm{H}_{2}}\right)$, CCeq (at-C/at-Fe), e RD como se mostra na figura (41), essa superfície atende as demandas de carbono para o equilíbrio das reações, sendo que a viabilidade do equilíbrio é representada pelos pontos situados acima desta superfície.

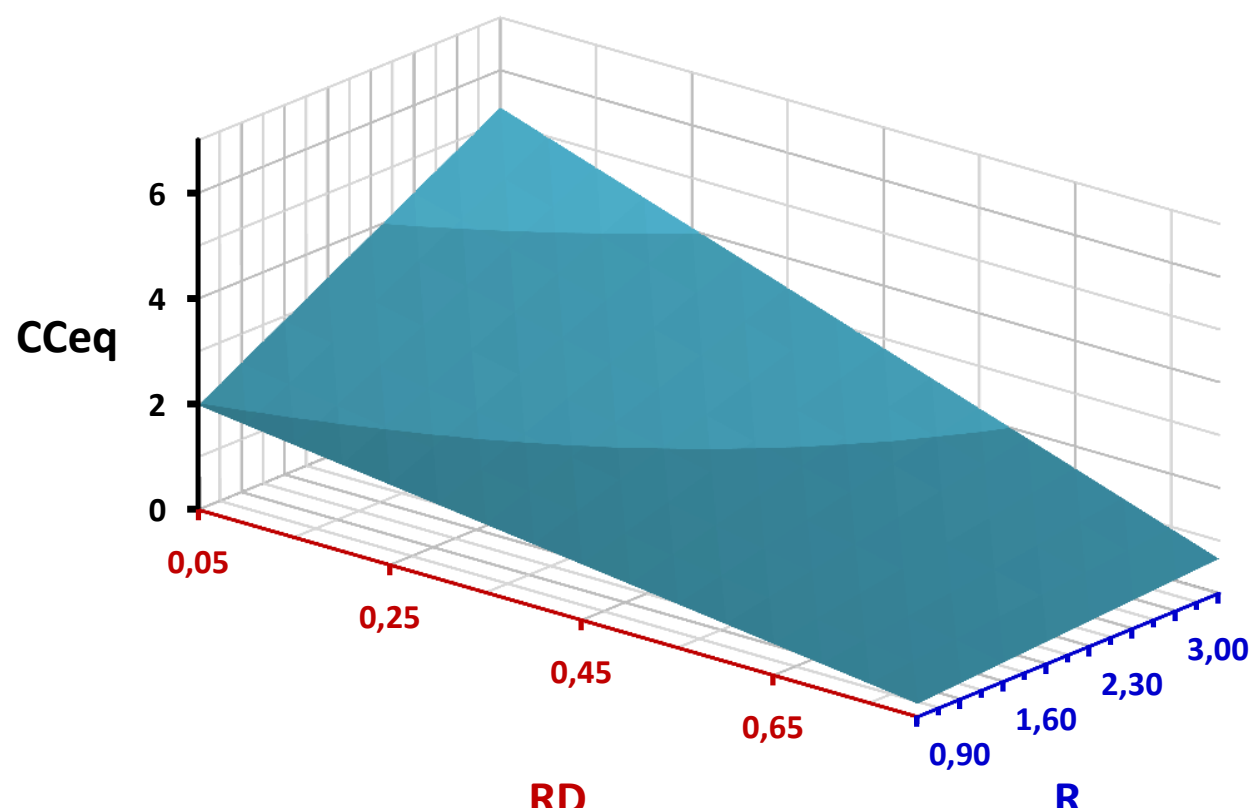

Figura 41 - Diagrama que Mostra a Superfície que Satisfaz o Equilíbrio.

\subsection{2.}

\section{Traçado da Superfície que Satisfaz o Balanço Térmico}

A equação (223) que satisfaz as condições de Balanço Térmico permitiu traçar uma superfície nos eixos $R\left(\frac{{\mathrm{CO} \times \mathrm{H}_{2} \mathrm{O}}_{\mathrm{O}_{2} \times \mathrm{H}_{2}}}{\mathrm{C}}\right.$, CCen (at-C/at-Fe), e RD como se mostra na figura (42), essa superfície atende as demandas de carbono para satisfazer o Balanço Térmico, sendo que a viabilidade térmica é representada pelos pontos situados acima desta superfície. 


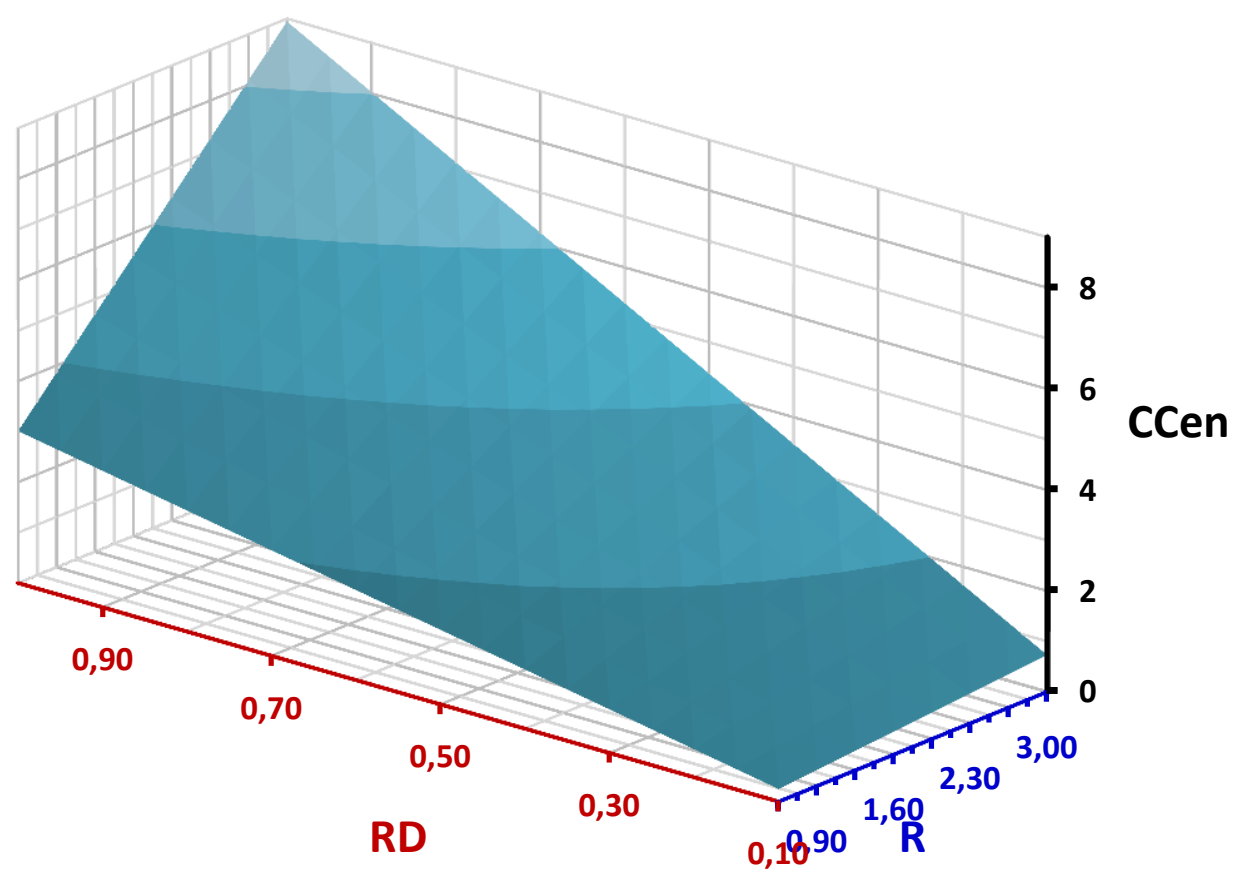

Figura 42 - Diagrama que Mostra a Superfície que Satisfaz o Balanço Térmico.

\subsection{3.}

\section{Traçado da Superfície de Mínimo Consumo de Carbono- SMCC}

Levando em conta a equação (224) que satisfaz as condições de equilíbrio e do Balanço Térmico foi possível traçar uma superfície nos eixos $R\left(\frac{\mathrm{CO} \times \mathrm{H}_{2} \mathrm{O}}{\mathrm{CO}_{2} \times \mathrm{H}_{2}}\right)$, CCeff (at-C/at-Fe), e RD como se mostra na figura (43), essa superfície atende as demandas minimas de carbono para satisfazer o Balanço Térmico e também as demandas de carbono que satisfaz o equilíbrio, sendo que a viabilidade térmica é representada pelos pontos situados acima desta superfície. 


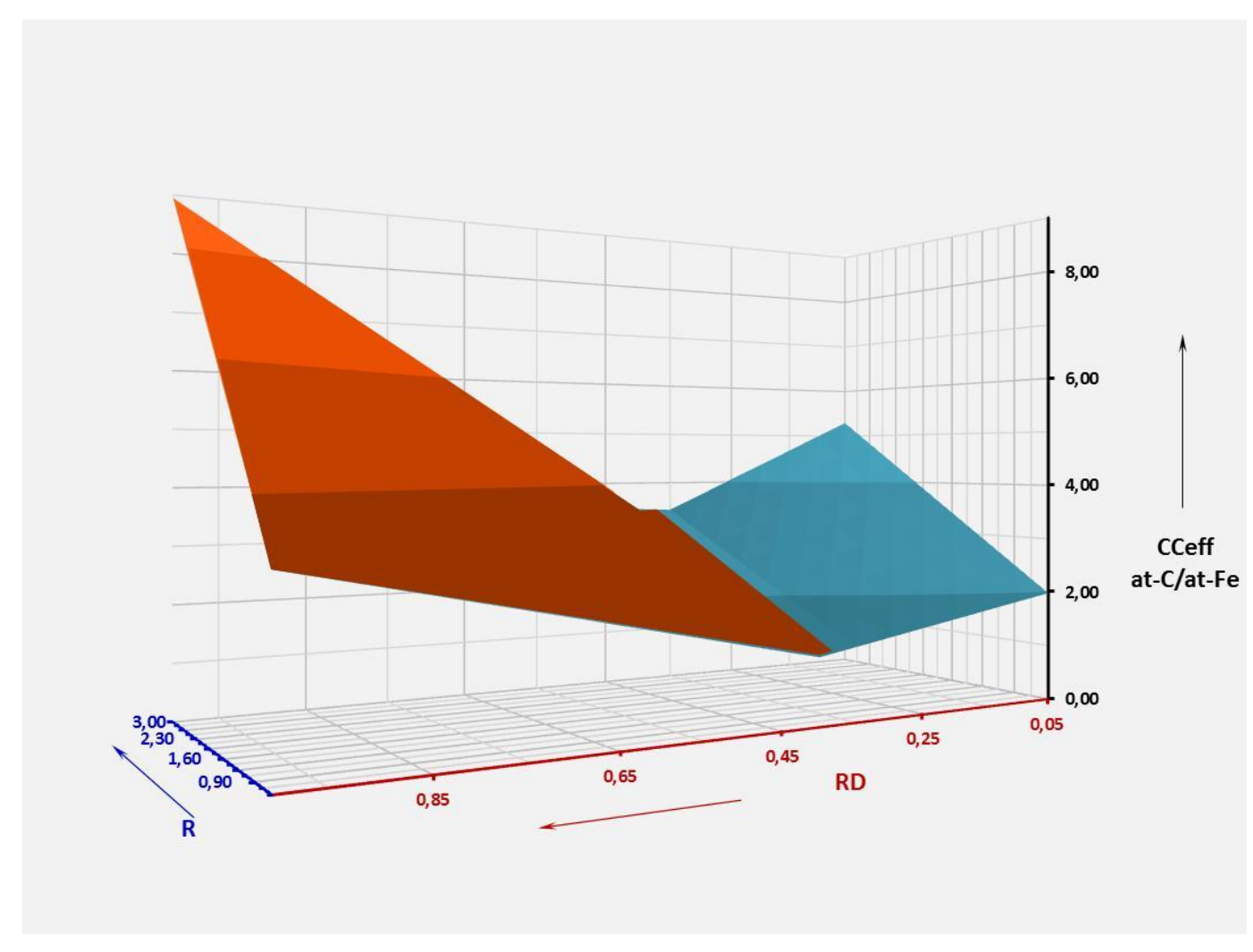

Figura 43 - Diagrama que Mostra a Superfície que Satisfaz o Equilíbrio (em azul) e o Balanço Térmico (em laranja).

\subsection{4.}

\section{Traçado das Curvas tipo CR-RD}

$\mathrm{Na}$ equação (224) que gerou a SMCC e fixando o valor de R (relação conhecida

dos gases de operação no topo do Alto-Forno igual a: $R=\frac{{\mathrm{CO} \times \mathrm{H}_{2} \mathrm{O}}_{2}}{\mathrm{CO}_{2} \times \mathrm{H}_{2}} \quad$ encontra-se o gráfico da figura (44) nas coordenadas $\mathrm{CR}(\mathrm{kg} \mathrm{C} / \mathrm{t}$ gusa) vs RD que é mais amigável para a análise da operação dos Alto-Fornos pelos operadores. 


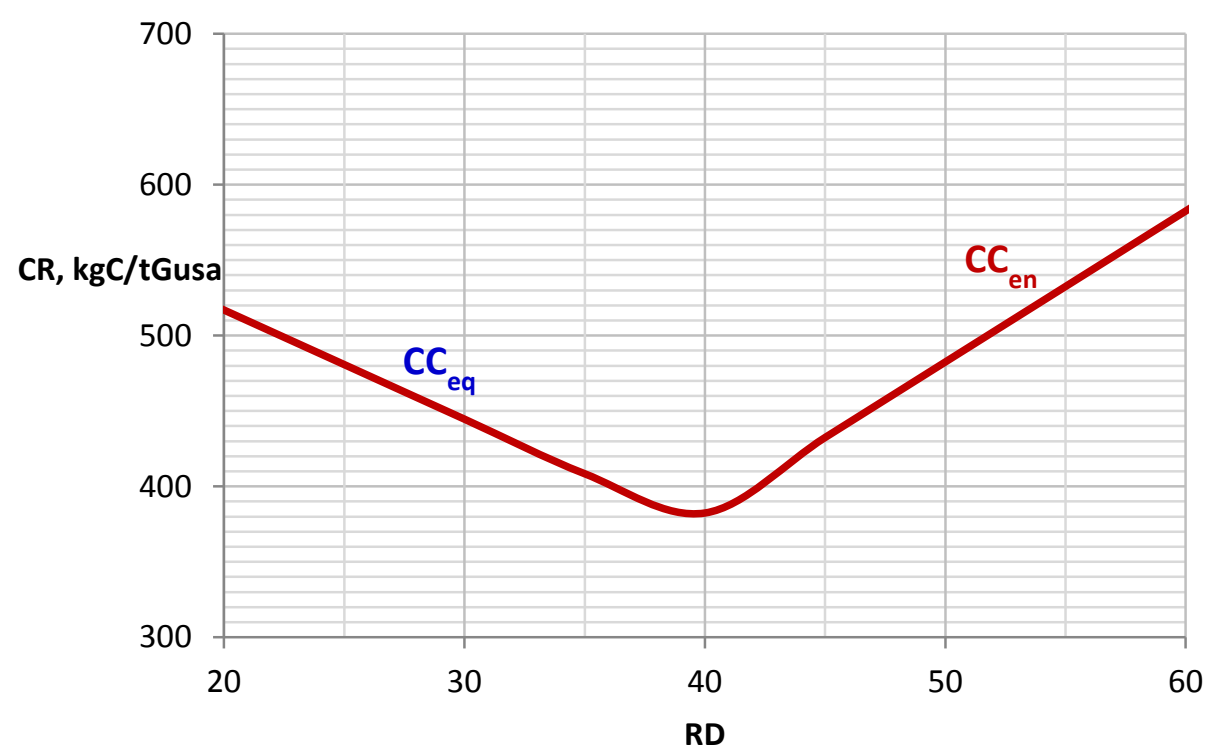

Figura 44 - Diagrama que Mostra a Curva de Demanda de Carbono Cumprindo as Restrições do Equilíbrio e Balanço Térmico (para um valor de $R=1,012$ ).

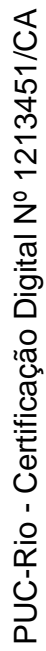

Pode-se observar também que uma variação (simulações no modelo) para diferentes valores de $\mathrm{R}$ (relação dos gases do topo) afeta a curva de demanda de carbono como é mostrado na figura (45).

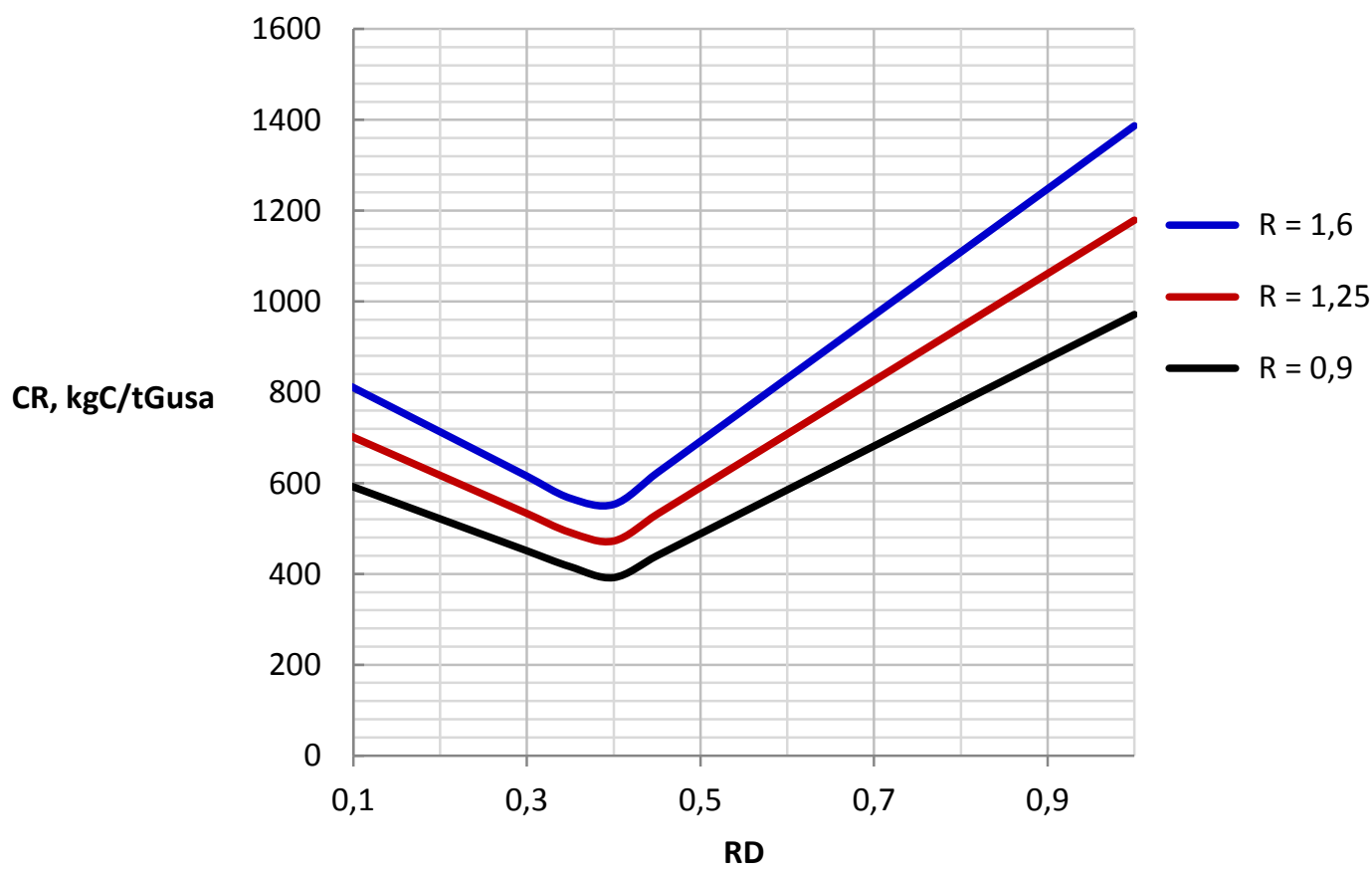

Figura 45 - Diagrama que Mostra a Variação na Curva de Demanda de Carbono para Diferentes Valores da Relação de Gases do Topo do Alto-Forno. 
Observando a figura 45 podemos corroborar que quanto maior a relação de gases no topo do Alto-Forno, maior valor de R, maior é o consumo de carbono no Alto-Forno. O que pode ser explicado como maiores valores de $\mathrm{CO}$ frente ao $\mathrm{CO}_{2}$ no gás do topo.

\section{2. \\ Validação do modelo: Diagramas tipo CR-RD para condições reais dos processos em Altos-Fornos com marchas industriais típicas}

Para validar a superfície de mínimo consumo de carbono obtida pelo modelo, traçaram-se pontos operacionais reais de uma usina siderúrgica com o intuito de mostrar como em condições normais de operação e de resfriamentos do forno ("geladas"), as SMCC correspondentes acompanharam e descreveram muito bem, e de forma dinâmica, o comportamento real de cada operação.

\subsection{1.}

\section{CASO A: Traçado de Diagramas tipo CR-RD para condições operacionais reais de um Alto-Forno exibindo marcha industrial normal.}

Foram coletados dados operacionais diários de um Alto-Forno a coque em condições normais de processo que são mostrados nas tabelas (4) e (5).

Tabela 4 - Dados Operacionais Normais (Operação 1).

\begin{tabular}{|l|l|}
\hline \multicolumn{1}{|c|}{ Variável } & \multicolumn{1}{c|}{ Valor } \\
\hline $\begin{array}{l}\text { Coque “Rate" } \\
\text { (kg coque/t gusa) }\end{array}$ & 464,5 \\
\hline $\left.\mathrm{CO} / \mathrm{CO}_{2}\right]_{\text {topo }}$ & 1,0801 \\
\hline Omega & 0,0132 \\
\hline
\end{tabular}


Tabela 5 - Dados Operacionais Normais (Operação 2).

\begin{tabular}{|l|l|}
\hline \multicolumn{1}{|c|}{ Variável } & \multicolumn{1}{c|}{ Valor } \\
\hline $\begin{array}{l}\text { Coque “Rate" } \\
\text { (kg coque/t gusa) }\end{array}$ & 464,5 \\
\hline $\left.\mathrm{CO} / \mathrm{CO}_{2}\right]_{\text {topo }}$ & 1,0122 \\
\hline Omega & 0,0094 \\
\hline
\end{tabular}

A partir dos dados operacionais da tabela 4 , foi traçado o ponto operacional 1 no diagrama CR-RD que foi obtido para valores de $\mathrm{R}$ igual a 1,0801. A figura 46 mostra a localização do ponto operacional em azul na parte superior (acima) da curva de consumo de carbono projetada pelo modelo que gera a SMCC.

Operação 1

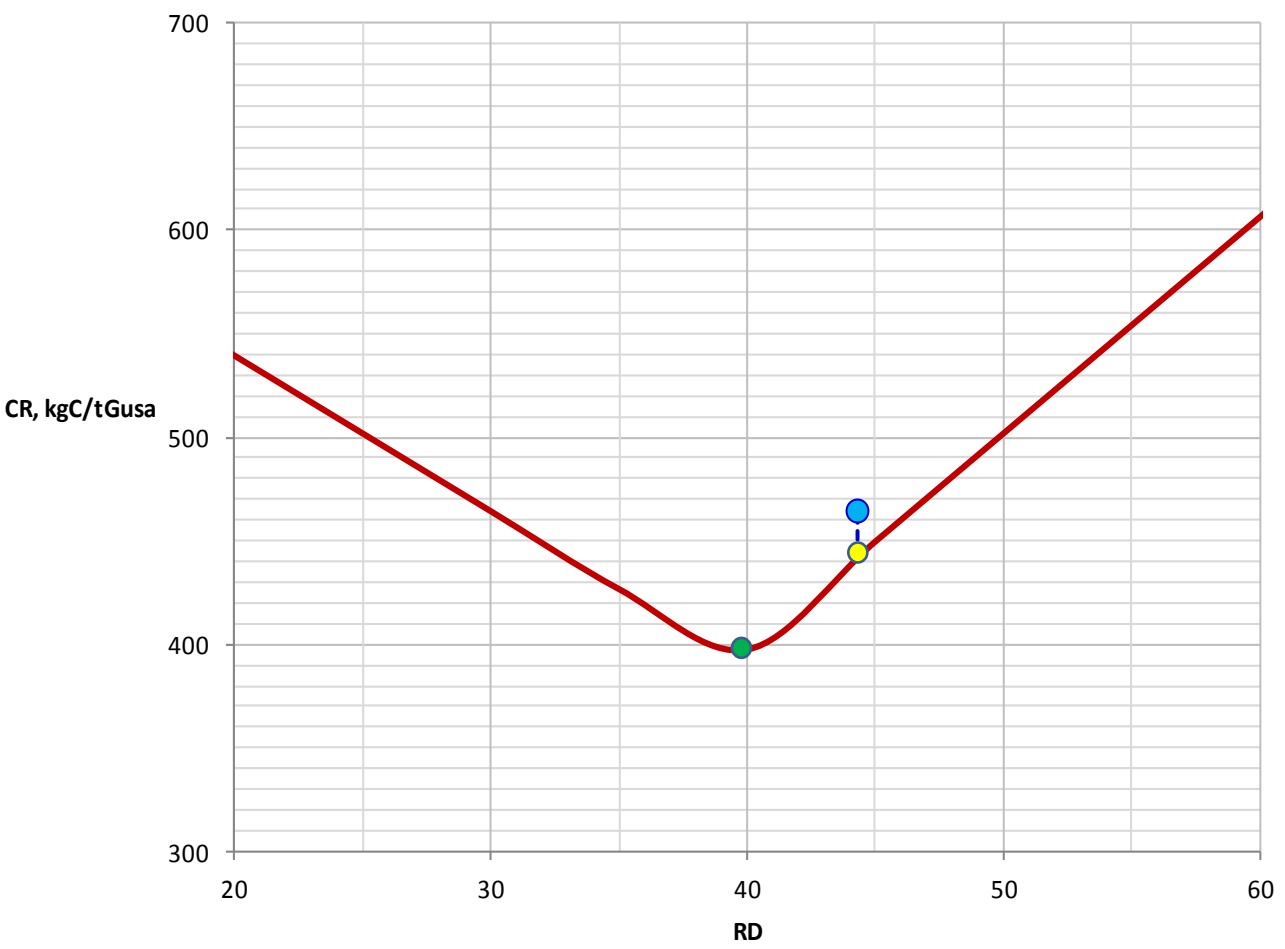

Figura 46 - Diagrama que Mostra o Gráfico do Ponto da Operação Normal 1.

Por outro lado, com os dados operacionais da tabela 5, foi traçado o ponto operacional 2 no diagrama CR-RD que foi obtido para valores de $\mathrm{R}$ igual a 
1,0122. A figura 47 mostra a localização do ponto operacional em azul na parte superior (acima) da curva de consumo de carbono projetada pelo modelo que gera a SMCC.

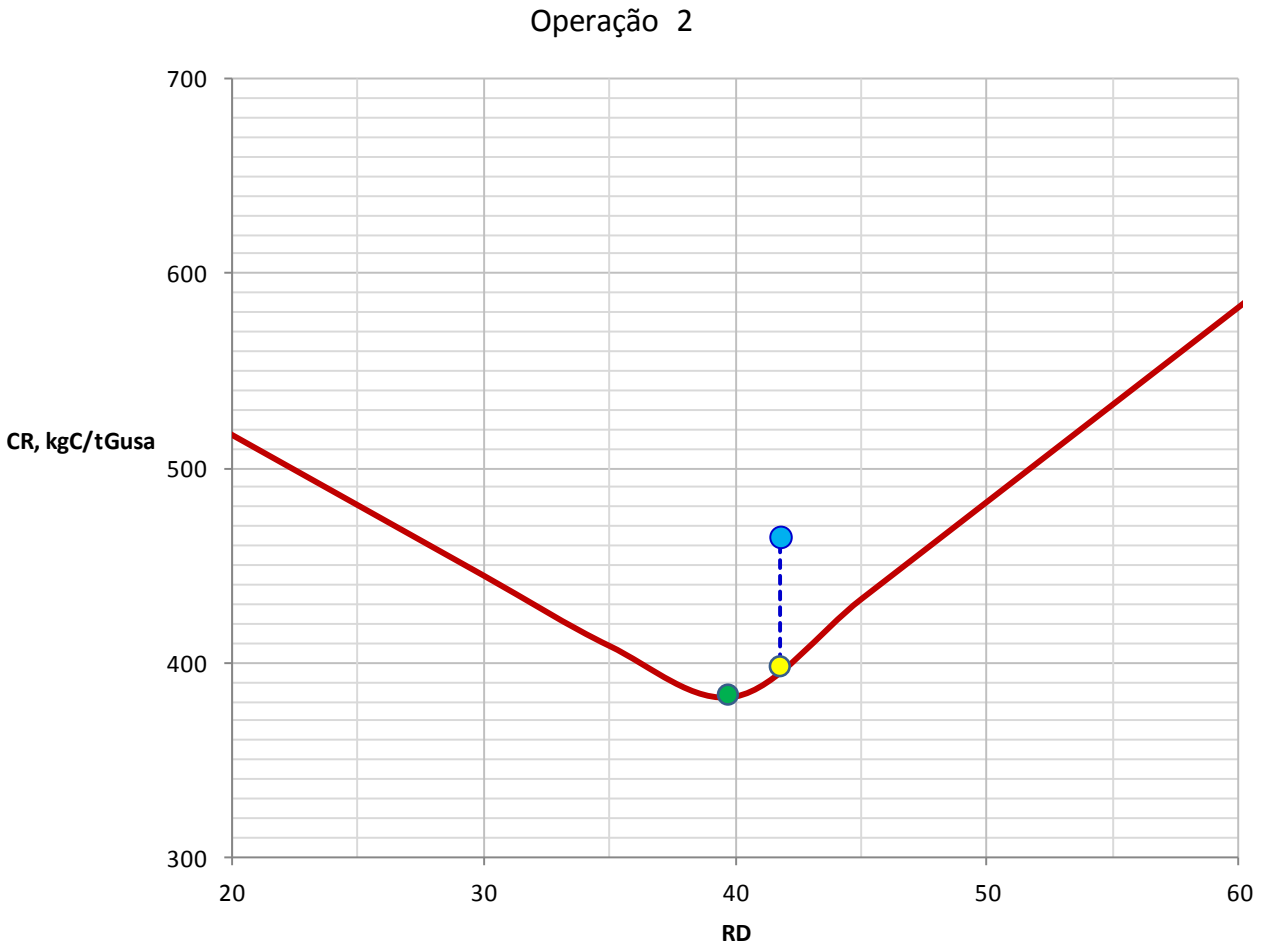

Figura 47 - Diagrama que Mostra o Gráfico do Ponto da Operação Normal 2.

A partir das figuras 46 e 47 resultantes da aplicação do modelo para determinação da SMCC elaborou-se a tabela (6).

Tabela 6 - Dados Calculados pelo Modelo de SMCC para Operações Normais de um Alto-Forno.

\begin{tabular}{|c|c|c|c|c|c|c|c|l|l|}
\hline \multicolumn{2}{|c|}{ OPERAÇÃO } & \multicolumn{9}{c|}{ MODELO } & $\begin{array}{l}\text { Desvio da } \\
\text { Superfície: } \\
\text { Excesso (+) } \\
\text { ou deficiência (-) } \\
\text { de C }\end{array}$ \\
\hline Nro & $\mathrm{R}$ & $\omega$ & $\mathrm{CR}_{\text {op }}$ & $\mathrm{RD}_{\mathrm{op}}$ & $\mathrm{CR}_{\mathrm{RDop}}$ & $\mathrm{CR}_{\text {ótimo }}$ & $\mathrm{RD}_{\text {ótimo }}$ & $\begin{array}{l}\text { do } \\
\mathrm{CR}_{\text {RDop }}\end{array}$ & $\mathrm{CR}_{\text {ótimo }}$ \\
\hline 1 & 1,0801 & 0,0132 & 464,5 & 44,30 & 442,92 & 397,96 & 40,0 & $+21,580$ & $+66,54$ \\
\hline 2 & 1,0122 & 0,0094 & 464,5 & 41,78 & 400,178 & 382,36 & 39,8 & $+64,322$ & $+82,14$ \\
\hline
\end{tabular}


Observa-se que ambas as operações 1 e 2, consideradas normais, estão representadas por cima da curva de consumo de coque prevista pelo modelo.

Pode-se fazer um análise com os dados da tabela 6 correspondentes as figuras 46 e 47, e se afirmar que a operação normal 2 é mais estável que a operação normal 1devido a que se encontra muito mais afastado para acima que da demanda mínima de coque modelada para seus respectivos $\mathrm{RD}$, porém seu consumo de coque e muito maior, sendo de $64,322 \frac{\mathrm{kg} \text { coque }}{\mathrm{t} \text {-ferro }}$ acima do previsto pelo modelo para seu próprio RD. Por outro lado a operação 1 tem um excesso de consumo de coque de $21,58 \frac{\mathrm{kg} \text { coque }}{t \text {-ferro }}$ para sua respetiva taxa de Redução Direta.

\subsection{2.}

\section{CASO B: Traçado de Diagramas tipo CR-RD para condições operacionais reais de um Alto-Forno exibindo marcha industrial anormal ("gelada")}

Foram coletados dados operacionais diários de um Alto-Forno a coque em condições anormais de processo que são mostrados nas tabelas (7) e (8).

Tabela 7 - Dados Operacionais Anormais (Operação 3).

\begin{tabular}{|l|l|}
\hline \multicolumn{1}{|c|}{ Variável } & \multicolumn{1}{c|}{ Valor } \\
\hline $\begin{array}{l}\text { Coque “Rate" } \\
\text { (kg coque/t gusa) }\end{array}$ & 473 \\
\hline $\left.\mathrm{CO} / \mathrm{CO}_{2}\right]_{\text {topo }}$ & 1,1628 \\
\hline Omega & 0,0122 \\
\hline
\end{tabular}

Tabela 8 - Dados Operacionais Anormais (Operação 4).

\begin{tabular}{|l|l|}
\hline \multicolumn{1}{|c|}{ Variável } & \multicolumn{1}{|c|}{ Valor } \\
\hline $\begin{array}{l}\text { Coque “Rate" } \\
\text { (kg coque/t gusa) }\end{array}$ & 472,5 \\
\hline $\left.\mathrm{CO} / \mathrm{CO}_{2}\right]_{\text {topo }}$ & 0,7557 \\
\hline Omega & 0,0272 \\
\hline
\end{tabular}


A partir dos dados operacionais da tabela 7 foi traçado o ponto operacional 3 no diagrama CR-RD que foi obtido para valores de $\mathrm{R}$ igual a 1,1628. A figura 48 mostra a localização do ponto operacional em azul na parte inferior (abaixo) da curva de consumo de carbono projetada pelo modelo que gera a SMCC.

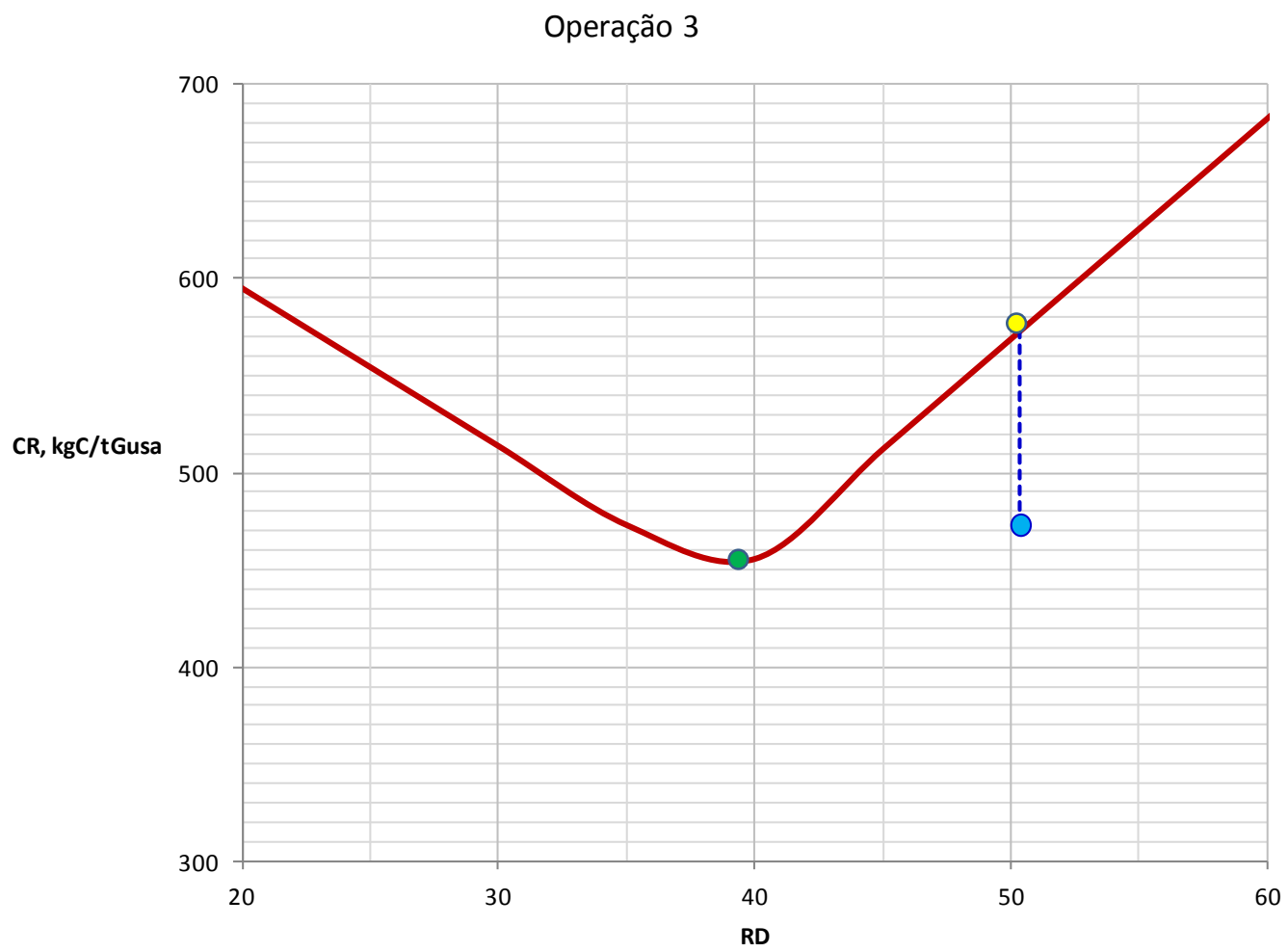

Figura 48 - Diagrama que Mostra o Gráfico do Ponto da Operação Anormal 3.

Por outro, lado com os dados operacionais da tabela 8 , foi traçado o ponto operacional 4 no diagrama CR-RD que foi obtido para valores de $\mathrm{R}$ igual a 0,7557. A figura 49 mostra a localização do ponto operacional em azul na parte inferior (abaixo) da curva de consumo de carbono projetada pelo modelo que gera a SMCC. 


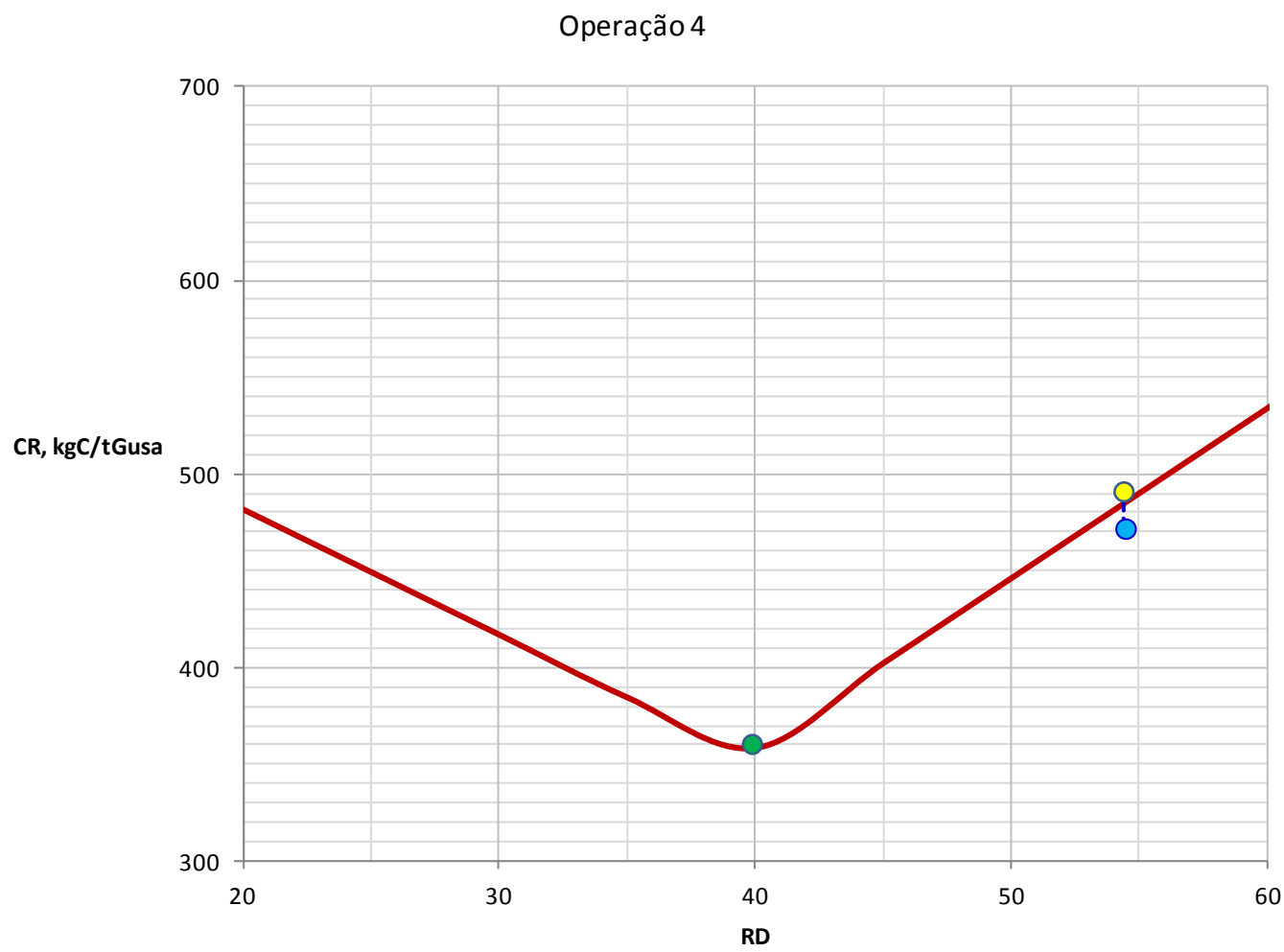

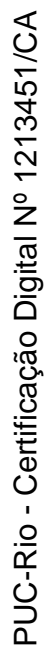

Figura 49 - Diagrama que Mostra o Gráfico do Ponto da Operação Anormal 4.

A partir das figuras 48 e 49 resultantes da aplicação do modelo para determinação da SMCC elaborou-se a tabela (9).

Tabela 9 - Dados Calculados pelo Modelo de SMCC para Operações Anormais de um Alto-Forno.

\begin{tabular}{|c|c|c|c|c|c|c|c|l|l|}
\hline \multicolumn{2}{|c|}{ OPERAÇÃO } & \multicolumn{7}{c|}{ MODELO } & $\begin{array}{l}\text { Desvio da } \\
\text { Superfície: } \\
\text { Excesso (+) } \\
\text { ou deficiência (-) } \\
\text { de C }\end{array}$ \\
\hline Nro & $\mathrm{R}$ & $\omega$ & $\mathrm{CR}_{\text {op }}$ & $\mathrm{RD}_{\text {op }}$ & $\mathrm{CR}_{\mathrm{RDop}}$ & $\mathrm{CR}_{\text {ótimo }}$ & $\mathrm{RD}_{\text {ótimo }}$ & $\begin{array}{l}\text { do } \\
\mathrm{CR}_{\mathrm{RDop}}\end{array}$ & $\begin{array}{l}\text { do } \\
\mathrm{CR}_{\text {otimo }}\end{array}$ \\
\hline 3 & 1,1628 & 0,0122 & 473,0 & 50,34 & 573,23 & 444,63 & 39,0 & $-100,23$ & $+28,370$ \\
\hline 4 & 0,7557 & 0,0272 & 472,3 & 54,43 & 485,52 & 358,75 & 39,8 & $-13,218$ & $+113,55$ \\
\hline
\end{tabular}

Observa-se que ambas as operações 3 e 4, consideradas anormais, estão representadas por baixo da curva de consumo de coque prevista pelo modelo. 
Pode-se fazer uma análise com os dados da tabela B correspondentes as figuras 48 e 49, uma comparação entre os pontos operacionais das operações 3 e 4(geladas) mostra que a operação anormal 4 esta mais próxima para a linha mínima de viabilidade prevista pelo modelo correspondente para seus respetivos $\mathrm{RD}$, também pode-se observar que o consumo de carbono na operação 3 é muito menor frente ao esperado de $573,73 \frac{\mathrm{kg} \text { coque }}{t \text {-ferro }}$ (prevista pelo modelo) observando-se uma deficiência de 100,232 $\frac{\mathrm{kg} \text { coque }}{t \text {-ferro }}$. Por outro lado para a operação 4 o modelo predisse um consumo de carbono de 485,51 $\frac{\mathrm{kg} \text { coque }}{t \text {-ferro }}$ e a operação fornece 472,5 $\frac{\mathrm{kg} \text { coque }}{t \text {-ferro }}$ observando-se uma deficiência de $13,01 \frac{\mathrm{kg} \text { coque }}{t \text {-ferro }}$. Note-se uma maior deficiência de coque na operação 3 comparado com a operação 4 considerando suas respetiva taxas de redução. 


\section{6. \\ Conclusões}

Como resultado deste trabalho pode-se concluir que foi possível conceber o modelo matemático tridimensional em condição de gerar as Superfícies de Mínimo Consumo de Carbono - SMCC, aplicáveis aos processos de redução em Altos-Fornos, tomando por base os equilíbrios das reações, os balanços de massa e energia e o equacionamento de parâmetros operacionais tais como, desvio ômega, fração de reduções direta e indireta, coque rate, gás de topo, condições de sopro, composições do gusa e da escória e perdas energéticas.

O sistema tri-axial de coordenadas adotado para a geração da SMCC para Altos-Fornos utilizou três variáveis caracteristicamente operacionais: Carbono Consumido-CC, Relação $R\left(\frac{\mathrm{CO} \times \mathrm{H}_{2} \mathrm{O}}{\mathrm{CO}_{2} \times \mathrm{H}_{2}}\right)$ no gás de topo e a (\%) Redução Direta-RD. Os resultados abaixo fundamentam esta conclusão.

1) A SMCC, como concebida e gerada no presente trabalho, representa, de forma original, a interpretação geométrica $3 \mathrm{D}$ da fronteira de viabilidade termodinâmica do processo de redução em Altos-Fornos. Assim: enquanto posições operacionais localizadas acima da SMCC indicam processos viáveis, posições abaixo implicam em inviabilidades ("geladas do forno");

2) Para maior praticidade da função resposta, foram considerados no sistema $3 \mathrm{D}$, cortes planares correspondentes a valores constantes da variável $R\left(\frac{\mathrm{CO} \times \mathrm{H}_{2} \mathrm{O}}{\mathrm{CO}_{2} \times \mathrm{H}_{2}}\right)$, característica do gás de topo. Reduzidos a sistemas bidimensionais, do tipo $\mathrm{CC} \mathrm{x}$ (\%) RD, as análises operacionais de controle e manutenção da viabilidade do processo de redução passaram a depender essencialmente da determinação do ponto operacional efetivo da marcha do Alto-Forno e de sua representação gráfica neste sistema 2D; 
3) Ficou evidenciado que a otimização termodinâmica das operações de redução nos Altos-Fornos está representada pelo ponto de interseção das duas curvas do diagrama bidimensional, indicando que a região objetivada pela operação deverá se localizar em seu entorno, mais especificamente na área acima do mesmo;

4) A validação do modelo desenvolvido utilizou dados reais de operação de uma usina siderúrgica integrada nacional, obtidos dos relatórios diários de produção de um de seus Alto-Fornos, envolvendo períodos de marchas regulares e anormais;

5) Para o caso A, de análise das operações do Alto-Forno consideradas normais, foram selecionadas as seguintes caraterísticas de marcha:

\begin{tabular}{|c|c|c|c|}
\hline & Coque rate & $\mathrm{R}$ & Ómega \\
\hline Operação 1 & 464,5 & 1,0801 & 0,0132 \\
\hline Operação 2 & 464,5 & 1,0122 & 0,0094 \\
\hline
\end{tabular}

Embora as duas situações normais analisadas tenham sido confirmadas termodinamicamente pelo modelo SMCC, foram observados maiores e menores índices de segurança operacional, em razão dos diferentes afastamentos dos pontos das suas respectivas fronteiras. Além disso, ambas as marchas também se mostraram igualmente passíveis de melhorias, tendo em vista seus afastamentos do ponto ótimo de operação do forno (interseção dos planos-vale);

6) Para o caso B, de análise das operações do Alto-Forno consideradas anormais, foram selecionadas as seguintes marchas:

\begin{tabular}{|c|c|c|c|}
\hline & Coque rate & $\mathrm{R}$ & Ómega \\
\hline Operação 3 & 473,0 & 1,1628 & 0,0122 \\
\hline Operação 4 & 472,5 & 0,7557 & 0,0272 \\
\hline
\end{tabular}

As duas situações de marchas anormais foram plenamente confirmadas termodinamicamente pelo modelo SMCC (pontos abaixo da fronteira), bem como 
também foram observados maiores e menores afastamentos dessas fronteiras, por parte dos respectivos pontos caraterísticos de cada marcha (distintos índices de segurança operacional). Em relação aos afastamentos do ponto de operação ótima, observou-se uma clara piora, devido ao aumento dessas distâncias;

7) No momento busca-se testar este modelo como uma ferramenta de controle efetivamente operacional, implementando-a "on line" aos bancos de dados formados pelas aquisições automáticas e contínuas da operação de um AltoForno. A implementação do modelo de geração da Superfície de Mínimo Consumo de Carbono-SMCC, permitirá prever, com uma antecedência segura de horas, a tendência da operação estar-se encaminhando para uma inviabilidade termodinâmica ("gelada" do forno), viabilizando, assim, a tomada antecipada das medidas corretivas necessárias.

Sugestões para trabalhos futuros:

1. Recomenda-se aprofundar a validação do modelo, promovendo uma coleta de dados de operação mais abrangente, junto a outros AltosFornos, a fim de verificar a precisão do método e analisar a ocorrência de situações eventualmente complexas, dado a diversidade de fatores influentes na operação de um Alto-Forno;

2. Promover mais estudos e pesquisas que correlacionem os efeitos diretos de outras variáveis operacionais significantes (por exemplo, características das matérias-primas, frequência de vazamento do gusa, injeção de fino etc.) no modelo de predição do Consumo Mínimo de Carbono- SMCC desenvolvido nesta tese. 


\section{7. Referências Bibliográficas}

1 DE AGUIAR MELGAÇO JR., HÉLIO. Aplicação dos métodos gráficos de Rist e Reichardt no controle operacional de Altos Fornos a coque. Dissertação de Mestrado. PUC-RIO, Curso de Pós-Graduação em Engenharia Metalúrgica (orientador: José Carlos D’ABREU). Setembro de 1985.

2 CHICO SANTOS, Conjuntura Econômica, Cojuntura Siderurgia, FGV IBRE, volume 69, $\mathrm{N}^{\mathrm{o}}$ 09, Setembro, 2015

3 APARECIDO C. WELLINGTON, Aplicação de um método de SimulaçãoOtimização na cadeia produtiva de minérios de ferro, Dissertação de Mestrado. EPUSP, Curso de Pós-Graduação em Engenharia de Sistemas Logísticos, agosto, Setembro de 2007.

4 ABM. Introdução a Siderurgia-coleção de livros metalurgia, Materiais e Mineração. $1^{a}$ Edição. São Paulo 2011.

5 DA SILVEIRA RIZZO, ERNANDES MARCOS. Introdução aos processos Siderúrgicos. São Paulo 2005.

6 DA SILVEIRA RIZZO, ERNANDES MARCOS. Processo de Fabricação de ferro-gusa em Alto-Forno. ABM. São Paulo 2009.

7 INSTITUTE FOR INDUSTRIAL PRODUCTIVITY, Direct Iron Ore Smelting Reduction Process (DIOS), Japan Iron and Steel Federation, May 2012.

8 DE CASTRO, L.A., Desenvolvimento De Um Modelo de Controle de Processo Para Altos-Fornos A Carvão Vegetal, Tese de Doutorado. UFMG, Curso de Pós-Graduação em Engenharia Metalúrgica e de Minas, agosto, 2002.

9 MENDONÇA L. AUGUSTO, Avaliação de Valor em Uso de cargas ferríferas para Alto-Forno, Dissertação de Mestrado Departamento de Ciências dos Materiais,PUC-Rio, Agosto, 2009. 
10 DE ARAÚJO, L.A. Manual de siderurgia. $1^{\circ}$ volume. São Paulo: Editora Arte \& Ciencia, 1997.

11 WAKELIN, D.H.; RICKETTS, J.A. The nature of Ironmaking. In: The making, shaping and treating of steel. Chapter 1, 11 th Edition. AISE, USA, 1999. Pp. 01-35.

12 NEVES O. R., CAMISASCA M. M., Aço Brasil: Uma Viagem pela Indústria do aço, Escritório de Histórias, Belo Horizonte, 2013.

13 INSTITUTO AÇO BRASIL, O Aço História, disponivel em: < http://www.acobrasil.org.br/site/portugues/aco/siderurgia-no-brasil-desenvolvimento.asp $>$ acesssdo em 23 nov 2015.

14 Böhm, C.; Kuhnen, M.; Wetzling, H.; “An earthquake in iron making: COREX. Realized improvements and future potentials". 560 Congresso Anual da ABM, Julio 2001, Belo Horizonte, Brasil, p. 1344-1353

15 ABM, Redução de Minério de Ferro em Alto-Forno, 3ra Edição 1976.

16 DAVID HEBERT VIEIRA, Avaliação de Parâmetros que influenciam a taxa de Injeção de Carvão Pulverizado em Altos-Fornos a Carvão Vegetal, Dissertação de Mestrado, Curso de Pós-Graduação em Engenharia Metalúrgica da Universidade Federal de ;minas Gerais, Fevereiro 2012.

17 ANTONIO BALLESTER, LUIS F. V., JOSÉ S. Metalurgia Extractiva, Volume 1-Fundamentos, Editora Sintesis S.A., Madrid 2000, pp 104-110.

18 DE MELO WILSON ROBERTO, Controle do processo de Redução no Alto-Forno II da Cosipa aplicação do diagrama CRRD. Dissertação de Mestrado. PUC-RIO, Curso de Pós-Graduação em Engenharia Metalúrgica , Fevereiro de 1987.

19 A. RIST and N. MEYSSON, A Dual Graphic Representation of the BlastFurnace Mass and Heat Balances, Ironmaking Proceeding, 1966.

20 A. RIST, Seminario PUC-Rio, Agosto 1981.

21 S.C. KORIA, Materials and Energy Balance in Metallurgical Processes , module N 01, Departament of Materials Science and Engineering Indian Institute of Technology, Kanpur. Disponivel em < http://textofvideo.nptel.iitm.ac.in/113104010/lec1.pdf > , acessado em julho 2015.

22 TERKEL ROSENQVIST. Fundamentos de Metalurgia Extractiva, Versión Española: Ernesto G. M. Primeira Edição, 1987, pp 37, 42-57. 
23 MAARTEN G., HISKO T., COR VAN DER V., Modern Blast Furnace Ironmaking an introduction, Second Edition, Netherlands, 2009.

24 MAZZUCCO M. M., Introdução aos Balanços de Massa e Energia, Notas de aula, sistemas Dinâmicos. Disponível em: < :http://www.eqm.unisul.br/prof/marcos/cursos/bme/Introducao_Balancos_M assa_e_energia.pdf> , São Paulo, Brazil, 2013.

25 INSTITUTO AÇO BRASIL, Aço Brasil Informa: Indústria brasileira do aço vive a pior crise de sua história, disponçivel em: < http://www.acobrasil.org.br/siderurgiaemfoco/Aco_Brasil_Informa_Set15.pd $\underline{\mathrm{f}}$, acessado em fev 2016.

26 VALOR ECONÔMICO, Pressão na siderurgia vai perdurar, disponivel em: $<\quad$ http://www.valor.com.br/empresas/4595835/pressao-na-siderurgia-vaiperdurar-dizem-executivos>, acessado em fev 2016.

27 INSTITUTO AÇO BRASIL, Relatório de sustentabilidade, disponivel em: < http://www.acobrasil.org.br/site\%5Cportugues\%5Cbiblioteca\%5CLivro_P olicy_final_2.pdf>, acessado em fev 2016.

28 Instituto Aço Brasil, Relatório de sustentabilidade 2013, disponível em: $<$ http://www.acobrasil.org.br/site/portugues/sustentabilidade/relatorio.asp >, acessado em : 10 mayo 2014.

29 BILIK J.; KRET J.; BEER H.: Application of The Simulating Mathematical Models for Decreasing of The Blast Furnace Fuel Rate; disponivel em: <http://www.ams.tuke.sk/data/ams_online/1998/number1/mag07.pdf>, acessado em nov 2013.

30 FUMITADA NAKATANI, T. MUKAI, F. NAKAMURA, Theoretical Consideration on Coke Ratio of the Blast Furnace Operation, Steel Science Portal. Novembro de 1965.

31 HETANO M, MIYASAKI T, IWANAGA Y, Mathematical Model for Evaluation of the Influence of Coke Properties on the Blast Furnace Operation, Sumitomo Search N ${ }^{0} 23$, Maio 1980

32 LU, W. K., Chemical Reactions in the Blast Furnace as it Happens, AISTech 2004 Procedings, volume 01, pp 395-407.

33 YAMAGUCHI K. ;UENO, H.; MATZUNAGA S.; KAKIUCHI. K.; AMANO. S.; Testo n High-rate Pulverized Coal Injection Operation at 
Kimitsu N 3 Blast Furnace, ISIJ International, ol. 35 (1995), N $^{0} 2$, pp148155.

34 FERNANDO T. PEREIRA de MEDEIROS, Desenvolvimento de um Modelo de predição de condições operacionais de Altos-Fornos Siderugicos com base em redes neurais artificias, Tese de doutorado, Faculdade de Engenharia Química, UNICAMP, 2006

35 KUNDRAT DAVID M., Development of an Analytical Equation for Calculation of the Blast Furnace Fuel Rate, Manuscript submitted February 6, 1986.

36 FERNANDEZ A.N.F., PIZZO M. S., MORAES Jr. D., Termodinâmica Química, 1 Edição 2006 .

37 BABICH A., SENK D., GUDENAU W., MAVROMMATIS K., Ironmaking Textbook, Aachen University Departament of Ferrous Metallurgy-RWTH, Aachen 2008.

38 SESHADRI SEETHARAMAN, Fundamentals of Metallurgy, Woodhead Publishing in Materials, Cambridge, England, 2005.

39 ADILSON DE CASTRO JOSE, DE SOUZA B. ANDERSON, Estudo Numérico da Reciclagem de $\mathrm{CO}_{2}$ na zona de combustao do Alto-Forno, Tecnol. Metal. Mater. Miner., São Paulo, v. 6, n. 1, p.13-18, jul.-set. 2009.

40 GRIEVESON P., High Temperature Chemistry-its Role in Metal Prodution, Pure \& Appl. Chem., Vol. 54, N 7, pp. 1313-1324, England, 1982.

41 CORNELL R.M., SCHWERTMANN U., The Iron Oxides Structure, Properties, Reactions, Occurences and Uses, Second completely revised and Extended edition, Germany 2003.

42 VIVALDINO M. FERNANDEZ, Efeito do Tipo de Carvão Injetado nas Ventaneiras do Alto-Forno no consumo de Combustíveis (Fuel-Rate), Dissertação de Mestrado, Faculdade de Engenharia Metalúrgica e de Minas, Universidade Federal de Minas Gerais, Belo Horizonte-MG, 2007.

43 WORLD STEEL ASSOCIATION-STEELUNIVERSITY, Guia del Usuario de Altos Hornos, Versión 1.10,

44 ANDERSON W. de SOUZA BALTAZAR et all, Modelagem e simulação computacional da injeção de carvão pulverizado no canal adutor da raceway de Altos-Fornos, Estudios Tecnológicos-Vol 2, N 2:65-67, Jul/Dez. 2006. 
45 RODRIGUES. L. H.; Developing an approach to help companies synchronise manufacturing. Tese de doutorado Departament of Management Sciences, University of Lancaster. 1994.

46 JORGE MADIAS, Procesos alternativos en la producción de arrabio, Acero Latinoamericano, Junio 2009. 


\section{Anexo A}

Função Cp e valores para as constantes, Kubaschevski.

Tabela 1, correspondente ao livro de Kubaschevski para dados dos valores das constantes a, b, c, na função Cp para vários compostos.

$$
C p=a+b t+c t^{-2}
$$

\begin{tabular}{|c|c|c|c|c|}
\hline & Temperatura & $\mathrm{a}$ & $\mathrm{b}$ & $\mathrm{c}$ \\
\hline $\mathrm{O}_{2}$ & $25-2727$ & 7,16 & 1,0 & $-0,4$ \\
\hline $\mathrm{N}_{2}$ & $25-2220$ & 6,66 & 1,02 & - \\
\hline $\mathrm{H}_{2} \mathrm{O}$ & $25-2220$ & 7,17 & 2,56 & 0,8 \\
\hline $\mathrm{FeO}$ & $1378-1527$ & 16,30 & - & - \\
\hline $\mathrm{CaO}$ & $25-879$ & 11,86 & 1,08 & $-1,66$ \\
\hline $\mathrm{Al}_{2} \mathrm{O}_{3}$ & $25-1577$ & 25,84 & 4,25 & $-6,82$ \\
\hline $\mathrm{MgO}$ & $0-923$ & 10,74 & 2,345 & $-2,26$ \\
\hline $\mathrm{MnO}$ & $25-1527$ & 11,11 & 1,94 & $-0,88$ \\
\hline $\mathrm{SiO}_{2}$ & $575-1727$ & 14,41 & 1,94 & - \\
\hline $\mathrm{CaS}$ & $0-723$ & 10,2 & 3,8 & - \\
\hline
\end{tabular}




\section{Apêndice I}

Equação para o traçado do diagrama de predominância

Seja a equação (1) como a representação da reação de redução de um óxido metálico sólido com o redutor gasoso $\mathrm{CO}$.

$$
\mathrm{MO}_{2}+\mathrm{CO}=\mathrm{MO}+\mathrm{CO}_{2}
$$

A equação de Van't Hoff que representa a reação química da redução da equação (1) diz:

$$
\Delta G=\Delta G^{\circ}+R T \ln \mathrm{J}
$$

No estado de equilíbrio:

$$
\Delta G=0 \quad \text { e } \quad \mathrm{j}=K
$$

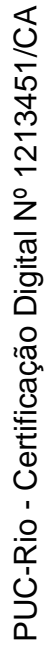

Logo a equação (2) fica:

$$
\Delta G^{\circ}=-R T \ln \mathrm{K}
$$

Lembrando que a constante de equilíbrio para a reação (1) pode ser definida como:

$$
K=\frac{a_{M O}}{a_{M O_{2}}} \times \frac{p_{\mathrm{CO}_{2}}}{p_{C O}}
$$

$$
\begin{aligned}
& \operatorname{Logo}(4) \mathrm{em}(3) \\
& \Delta G^{\circ}=-R T \ln \left(\frac{a_{\mathrm{MO}}}{a_{\mathrm{MO}_{2}}} \times \frac{p_{C O_{2}}}{p_{C O}}\right) \\
& -\frac{\Delta G^{\circ}}{R T}=\ln \left(\frac{a_{M O}}{a_{M O_{2}}} \times \frac{p_{\mathrm{CO}_{2}}}{p_{C O}}\right)
\end{aligned}
$$

Extraindo antilogaritmo na equação (5)

$$
e^{-\frac{\Delta G^{\circ}}{R T}}=\frac{a_{M O}}{a_{M O_{2}}} \times \frac{p_{\mathrm{CO}_{2}}}{p_{C O}}
$$

Isolando: $\frac{p_{\mathrm{CO}_{2}}}{p_{\mathrm{CO}}}$ em a equação (6) 
E lembrando por definição de frações parciais que:

$$
\begin{aligned}
& p_{\mathrm{CO}_{2}}=N_{\mathrm{CO}_{2}} \times P_{T} \\
& p_{C O}=N_{C O} \times P_{T}
\end{aligned}
$$

Logo a equação (6) fica:

$$
\begin{aligned}
\frac{N_{C O_{2}} \times P_{T}}{N_{C O} \times P_{T}} & =\frac{a_{M O_{2}}}{a_{M O}} \times e^{-\frac{\Delta G^{\circ}}{R T}} \\
\frac{N_{C O_{2}}}{N_{C O}} & =\frac{a_{M O_{2}}}{a_{M O}} \times e^{-\frac{\Delta G^{\circ}}{R T}}
\end{aligned}
$$

Também:

$$
\begin{aligned}
& N_{\mathrm{CO}_{2}}+N_{C O}=1 \\
& \text { Logo: } \quad N_{\mathrm{CO}_{2}}=1-N_{C O}
\end{aligned}
$$

(8) em (7)

$$
\frac{1-N_{C O}}{N_{C O}}=\frac{a_{M O_{2}}}{a_{M O}} \times e^{-\frac{\Delta G^{\circ}}{R T}}
$$

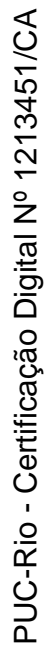

$$
\begin{gathered}
\frac{1}{N_{C O}}=\frac{a_{M O_{2}}}{a_{M O}} \times e^{-\frac{\Delta G^{\circ}}{R T}}+1 \\
N_{C O}=\left[\frac{a_{M O_{2}}}{a_{M O}} \times e^{-\frac{\Delta G^{\circ}}{R T}}+1\right]^{-1}
\end{gathered}
$$




\section{Apêndice II}

Fechamento do Balanço de Energia.

Do balanço de energia temos segundo a equação

$$
\begin{aligned}
& C_{B T}=\frac{C_{N Z C}}{C_{G Z C}} \\
& C_{B T}=\frac{C_{N Z C}}{C_{G Z C}}=\frac{C_{P T}+C_{G U S A}+C_{E S C}-C_{R Q Z E}}{C_{A R}+C_{R Q Z C}} \\
& C_{B T}=\frac{C_{P T}+C_{G U S A}+C_{E S C}-\left(\Delta \mathrm{H}_{S i}+\Delta \mathrm{H}_{M n}+\Delta \mathrm{H}_{P}+\Delta \mathrm{H}_{S}+\Delta \mathrm{H}_{2}+\Delta \mathrm{H}_{R D}+\Delta \mathrm{H}_{R I}\right)}{C_{G Z C}} \\
& C_{B T}=\frac{C_{P T}+C_{G U S A}+C_{E S C}-\left(\Delta \mathrm{H}_{S i}+\Delta \mathrm{H}_{M n}+\Delta \mathrm{H}_{P}+\Delta \mathrm{H}_{S}+\Delta \mathrm{H}_{2}\right)}{C_{G Z C}}-\frac{\Delta \mathrm{H}_{R D}+\Delta \mathrm{H}_{R I}}{C_{G Z C}}
\end{aligned}
$$

Fazendo $C_{P T}+C_{G U S A}+C_{E S C}-\left(\Delta \mathrm{H}_{S i}+\Delta \mathrm{H}_{M n}+\Delta \mathrm{H}_{P}+\Delta \mathrm{H}_{S}+\Delta \mathrm{H}_{2}\right)=\gamma$

$C_{B T}=\frac{\gamma}{C_{G Z C}}-\frac{\Delta \mathrm{H}_{R D}+\Delta \mathrm{H}_{R I}}{C_{G Z C}}$

$C_{B T} \times C_{G Z C}-\gamma=-\left(\Delta \mathrm{H}_{R D}+\Delta \mathrm{H}_{R I}\right)$

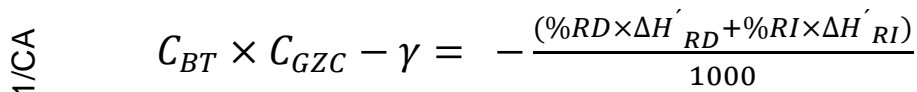

Lembrando que:

$\% R D=\frac{X-G}{1.05+\omega} \quad$ e que $\quad \% R I=\frac{1.05+\omega+G-X-\frac{K_{H} Z}{K_{H}+1}}{1.05+\omega}$ e que $\quad R D=\frac{X}{1.05+\omega+G}$

$C_{B T} \times C_{G Z C}-\gamma=-\frac{\left(\frac{X-G}{1.05+\omega} \times \Delta H^{\prime}{ }_{R D} \quad+\frac{1.05+\omega+G-X-\frac{K_{H} Z}{K_{H}+1}}{1.05+\omega} \times \Delta H^{\prime}{ }_{R I}\right)}{1000}$

$\left(C_{B T} \times C_{G Z C}-\gamma\right)[1000(1.05+\omega)]=-\left[(X-G) \times \Delta H_{R D}^{\prime}+(1.05+\omega+G-X-\right.$ $\left.\left.\frac{K_{H} Z}{K_{H}+1}\right) \times \Delta H_{R I}^{\prime}\right]$

Fazendo $A=1.05+\omega+G \quad$ logo: $X=R D(A)$

$\left(C_{B T} \times C_{G Z C}-\gamma\right)[1000(1.05+\omega)]=-\left\{[R D(A)-G] \times \Delta H_{R D}^{\prime}+[A(1-R D)-\right.$ $\left.\left.\frac{K_{H} Z}{K_{H}+1}\right] \times \Delta H_{R I}^{\prime}\right\}$ 